
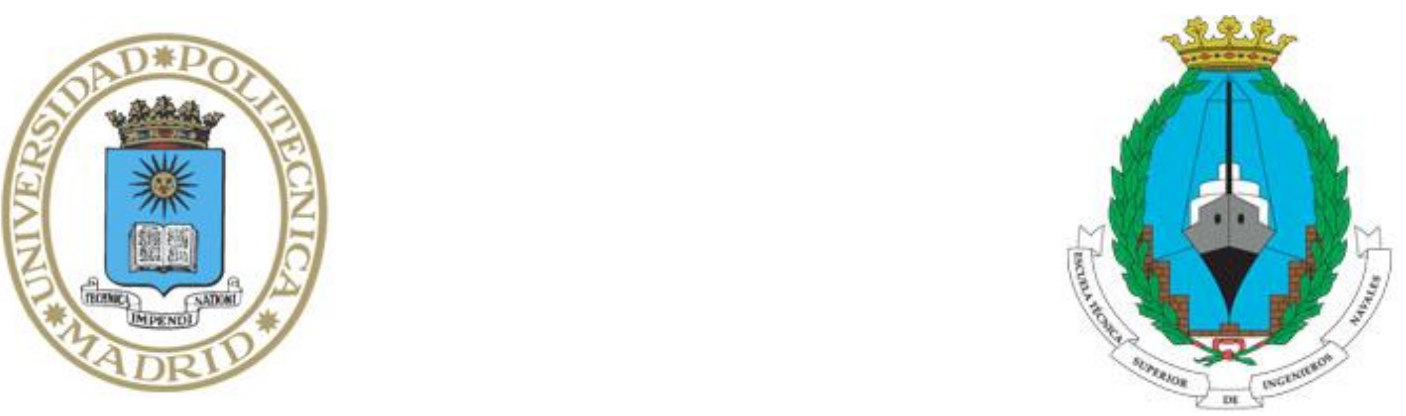

DEPARTAMENTO DE ARQUITECTURA, CONSTRUCCIÓN Y SISTEMAS OCEÁNICOS Y NAVALES (DACSON)

ESCUELA TÉCNICA SUPERIOR DE INGENIEROS NAVALES

UNIVERSIDAD POLITÉCNICA DE MADRID

\title{
ESTUDIO DEL POTENCIAL DE APROVECHAMIENTO ENERGÉTICO DEL OCÉANO EN LA COSTA ANDALUZA
}

Texto para la obtención del grado de Doctor en Ingeniería Naval

Autora:

Ma Pilar Blanco Fernández

Ingeniera Naval y Oceánica por la Universidad Politécnica de Madrid

Director

Francisco Pérez Arribas

Doctor Ingeniero Naval por la Universidad Politécnica de Madrid

junio de 2017 
ESTUDIO DEL POTENCIAL DE APROVECHAMIENTO ENERGÉTICO DEL OCÉANO EN LA COSTA ANDALUZA.

Autora: Ma Pilar Blanco Fernández

(Página intencionadamente en blanco) 


\section{AGRADECIMIENTOS.}

Quiero expresar mi agradecimiento a todas las personas que me han ayudado a sacar adelante este proyecto de "El Doctorado", desde mis profesores a mis amistades, desde las primeras épocas hasta las más recientes. Y en particular a mi director de Tesis por su paciencia en esta última etapa.

A mis padres y hermanos que me han enseñado el valor del esfuerzo y me han facilitado un punto de referencia para ver las cosas con perspectiva.

A mi marido y mis hijos por su apoyo incondicional. 


\section{ESTADO DEL ARTE Y APORTACIONES DE LA TESIS.}

Cada vez hay más escritos y mayor investigación sobre la energía oceánica, tanto la energía mecánica, de las olas, corrientes y mareas, como de la térmica o química. Sin embargo la gran mayoría de lo escrito se refiere a alguno de los dispositivos de aprovechamiento de la energía en particular o a algún aspecto de dichos dispositivos.

Son menos los trabajos dedicados a situar geográficamente estos dispositivos y muy pocos los que se limitan al marco de Andalucía, principalmente patrocinados por la Junta de Andalucía u otros organismos oficiales.

De esta manera, tomando como punto de partida el Estudio sobre el Potencial Bruto de Energías Marinas en el Litoral Andaluz, tanto Fase I como Fase II, me pareció interesante desarrollarlo más en profundidad, estudiando para cada una de las zonas referidas en este Estudio los mejores dispositivos de aprovechamiento de la energía undimotriz, de las corrientes y las mareas que se podrían instalar y los condicionantes a los que se verían sometidos.

Con este criterio he ampliado el campo de estudio a la combinación de tecnologías de manera que se pueda obtener la energía eléctrica necesaria para la actividad principal mediante energías marinas aportando una visión diferente al aprovechamiento de la energía oceánica en la Comunidad Andaluza. 


\section{RESUMEN}

El objetivo del documento es estudiar la posibilidad de utilizar distintos dispositivos de aprovechamiento de la energía del mar en la costa de Andalucía con distintos fines.

En todos los casos estos dispositivos se han diseñado para la obtención de energía eléctrica, sin embargo, podemos decidir verter directamente esa energía a la red eléctrica o utilizarla in-situ en otras instalaciones.

En este documento desarrollaré los principales métodos de aprovechamiento del potencial energético del océano en las costas Andaluzas. Para ello describiré las principales características de la Costa Andaluza y su potencial energético. Seguidamente detallaré los artefactos que existen en la actualidad para convertir la energía del océano en energía eléctrica. Y por último estableceré la relación más adecuada de artefactos para cada tipo de energía y lugar geográfico así como su posibilidad de utilización combinada con otras tecnologías orientadas a la consecución directa de fines específicos y distintos de la obtención de energía eléctrica.

\section{ABSTRACT}

The aim of this paper is the study of the possibility of using several devices harnessing the sea energy in the Coast of Andalucía

Although all of these devices are designed in order to obtain electric power we can decide injecting this energy to the electrical network throughout a TSO or using it in-situ providing power to different facilities.

In this document the main methods of harnessing the energetic potential of the ocean in the Andalucía Coast are developed. For this reason the Andalucía Coast will be described not only geographically but energetically. Then, the devices to transform the sea energy in electricity will be detailed and, in the end, the optimum relationship between devices and places will be established as well as the synergy of the use of these devices combined themselves or with facilities with different purposes. 


\section{TABLA DE CONTENIDOS}

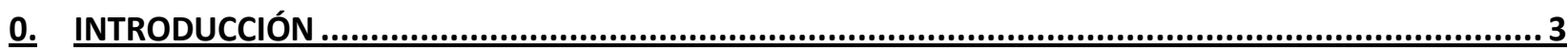

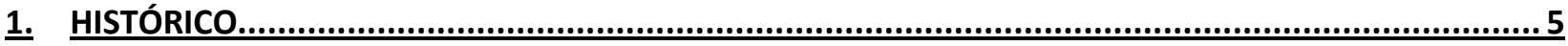

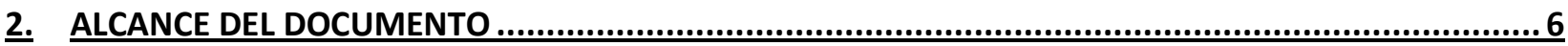

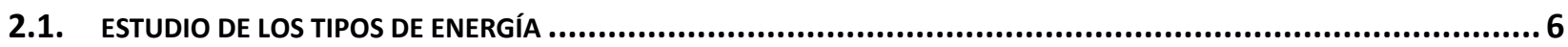

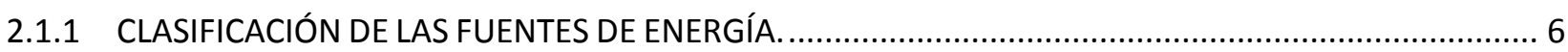

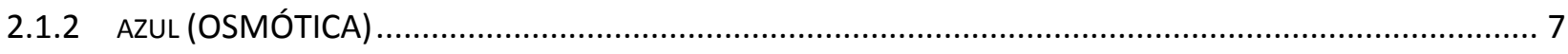

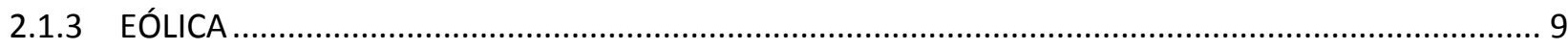

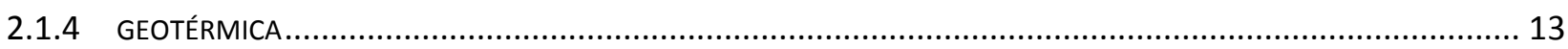

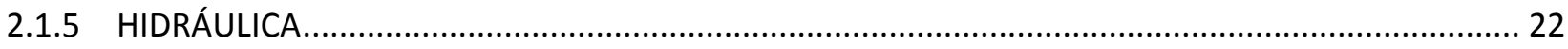

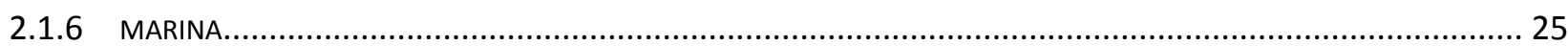

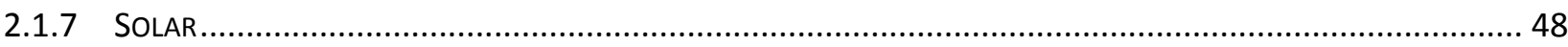

2.2. ESTUDIO DE LOS DISPOSITIVOS DE CAPTACIÓN DE LA ENERGÍA DE LAS OLAS. .......................................52

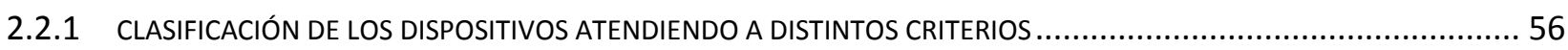

2.3. ESTUDIO DE LOS DISPOSITIVOS DE CAPTACIÓN DE LA ENERGÍA DE LAS CORRIENTES Y LAS MAREAS. ................... 75

2.3.1 CLASIFICACIÓN DE LOS DISPOSITIVOS ATENDIENDO A DISTINTOS CRITERIOS.............................................. 75

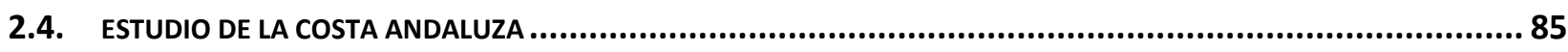

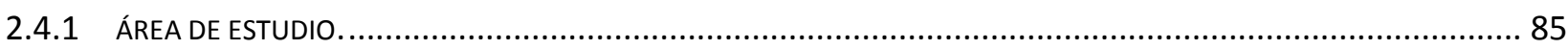

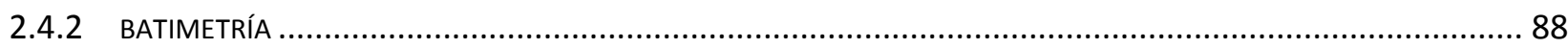

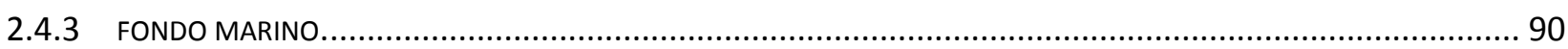

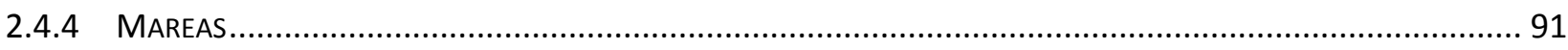

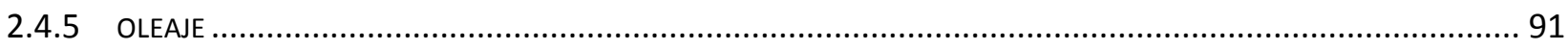

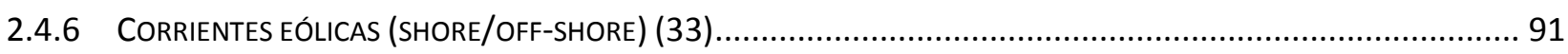

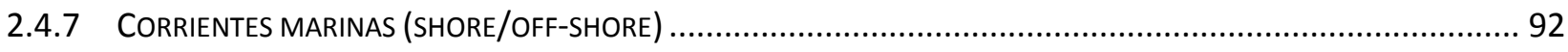

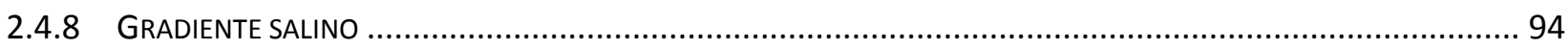

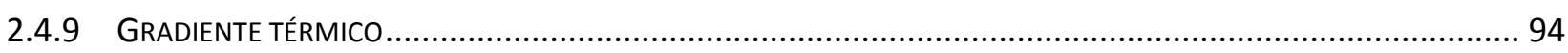

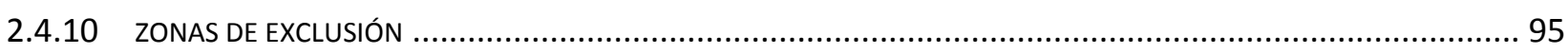

2.5. ADECUACIÓN DE DISPOSITIVOS A LAS CARACTERÍSTICAS DE LA COSTA ANDALUZA.................................... 100

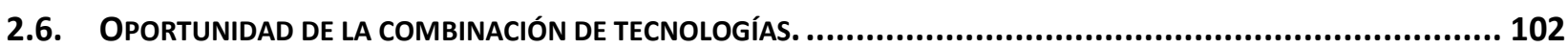

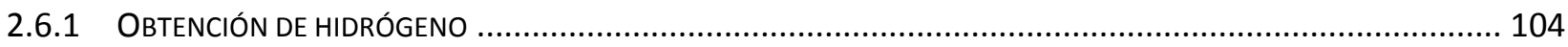

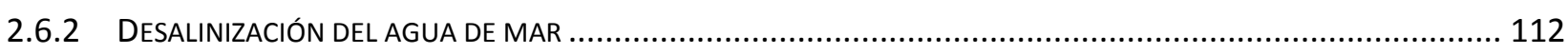

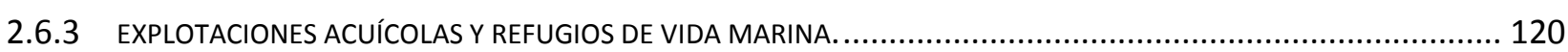

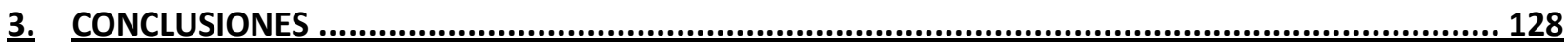

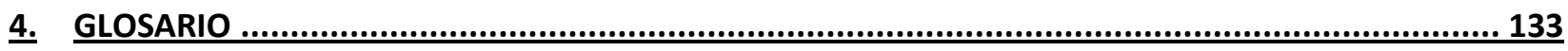


ESTUDIO DEL POTENCIAL DE APROVECHAMIENTO ENERGÉTICO DEL OCÉANO EN LA COSTA ANDALUZA.

Autora: Mạ Pilar Blanco Fernández

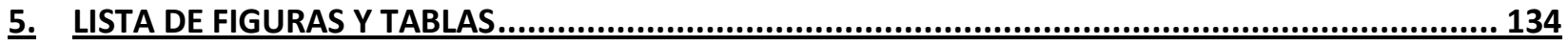

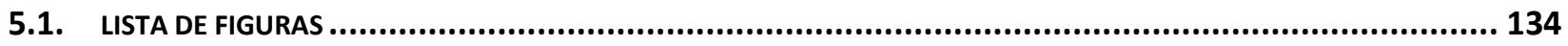

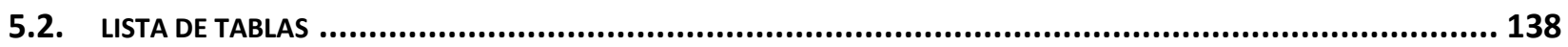

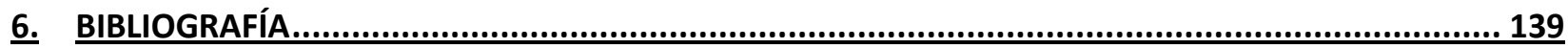

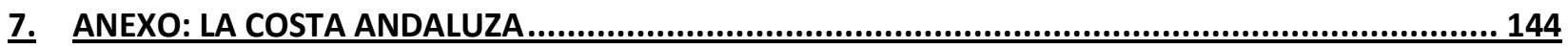

8. ANEXO: MAPA EÓLICO DE LA COSTA ANDALUZA. ...

9. ANEXO: MAPA DE CORRIENTES MARINAS EN LA COSTA ANDALUZA. ............................. 156 


\section{INTRODUCCIÓN}

Durante la crisis económica mundial de los años 70, el precio del petróleo experimentó un fuerte incremento, poniendo de relieve la necesidad de los países desarrollados de reducir la dependencia de los combustibles fósiles. A partir de entonces se empezaron a investigar fuentes alternativas renovables para la obtención de energía eléctrica.

Posteriormente y debido al efecto del Calentamiento Global los países han llegado a acuerdos internacionales, cumbre de Río en 1992, Kioto en 1997, etc., para reducir la emisión de gases de efecto invernadero provenientes principalmente de quemar combustibles fósiles para la generación de energía eléctrica.

En nuestros días, con la actual crisis mundial, se hace especialmente importante el desarrollo de las energías renovables que permitirán la generación local de energía, ahorro de los costes de transporte, la independencia respecto de otros países y de la volatilidad de los precios de los combustibles fósiles. Esto toma más relevancia en el caso de España cuya dependencia energética es superior al 80\%. Solo en el carbón la dependencia es más del $75 \%$

Históricamente España ha vivido de cara a la costa, obteniendo de ella una parte importante de sus recursos económicos tanto de la pesca y la acuicultura como del comercio.

Con sus casi $8.000 \mathrm{Km}$ de costa, se abre a tres mares. El Mar Cantábrico, el Océano Atlántico y el Mar Mediterráneo.

Por las características de su costa y su situación geográfica tiene un gran potencial de aprovechamiento de las energías provenientes del mar. Esto supondría un vector más de explotación del mar y desarrollo tecnológico de las zonas costeras, lo que la UE ha potenciado como "Economía Azul”, manteniendo la estabilidad ecológica de los océanos. Andalucía es la comunidad autónoma que tiene un mayor frente marítimo abriéndose a dos mares, el Mar Mediterráneo y el Océano Atlántico. También es la que dispone de las mayores instalaciones de producción naval. Estos hechos favorecen el desarrollo e implantación tanto de instalaciones de aprovechamiento energético del océano como de instalaciones que fabriquen los dispositivos necesarios para dicho aprovechamiento. En este trabajo nos centraremos en el aprovechamiento energético del océano en la costa andaluza, proponiendo los dispositivos más adecuados para cada objetivo y la posibilidad 
ESTUDIO DEL POTENCIAL DE APROVECHAMIENTO ENERGÉTICO DEL OCÉANO EN LA COSTA ANDALUZA.

Autora: Ma Pilar Blanco Fernández

de combinar tecnologías para un uso distinto de la producción de electricidad para verter en la red, dando respuesta a las necesidades de las comunidades costeras. 


\section{HISTÓRICO}

Desde la Antigüedad los hombres han aprovechado la energía del viento, de las corrientes fluviales y de las mareas para transformarlas en un trabajo útil para ellos.

Desde las velas de los barcos hasta los molinos de viento y norias los artefactos de aprovechamiento de lo que ahora llamamos energías renovables se han venido utilizando y desarrollando a través de tiempos inmemoriales.

Hay documentación que data los primeros molinos de marea en el siglo VII mientras que las primeras patentes para aprovechamiento de la energía undimotriz aparecieron durante la Revolución Francesa en Paris. Sin embargo el verdadero desarrollo de las tecnologías de aprovechamiento de la energía del océano no ha comenzado hasta el último cuarto del siglo XX.

Actualmente el desarrollo de estos dispositivos está en estado de prototipo o investigación en la mayoría de los casos aunque ya hay centrales de energía mareomotriz y undimotriz que alimentan núcleos urbanos. 


\section{ALCANCE DEL DOCUMENTO}

\subsection{ESTUDIO DE LOS TIPOS DE ENERGÍA}

\subsubsection{CLASIFICACIÓN DE LAS FUENTES DE ENERGÍA.}

Una fuente de energía alternativa es aquella que puede suplir a las actuales por su menor efecto contaminante o por su posibilidad de renovación.

Las energías alternativas pueden ser permanentes o renovables y temporales o no renovables.

La energía renovable se define como la energía que se presenta en la naturaleza de modo continuo y se obtiene de fuentes virtualmente inagotables, ya sea por la inmensa cantidad de energía que contienen o porque son capaces de regenerarse por medios naturales en escalas temporales humanas.

Es importante tener en cuenta que las energías alternativas, incluso las renovables, también son finitas por lo que tendrán un límite máximo de explotación. Por tanto, aunque se pueda realizar una transición a estas nuevas energías de forma suave y gradual, no van a permitir continuar con el modelo económico actual basado en el crecimiento perpetuo. De ahí surge el concepto de Desarrollo Sostenible que se basa en:

- Uso de fuentes de energía renovable.

- Uso de fuentes limpias.

- Explotación extensiva de las fuentes de energía, aumentando el autoconsumo, que evite en la medida de lo posible la construcción de grandes estructuras de generación y distribución de energía eléctrica.

- Disminución de la demanda energética aumentando el rendimiento de los dispositivos, $\mathrm{y}$

- Reducción o eliminación el consumo energético innecesario.

Las energías renovables se pueden clasificar a su vez en contaminantes, aquellas cuyo modo de obtención o uso emite subproductos que puedan incidir negativamente en el medio ambiente, y en no contaminantes o limpias. Las energías renovables contaminantes son:

- Biomasa (la fuente de energía primaria procede de los residuos de origen biológico de las actividades humanas, agrícolas, ganaderas, forestales, etc.). 
- Biocombustibles (la fuente de energía primaria procede de aceites, grasas y alcoholes de origen biológico).

Las energías renovables limpias son:

- Azul (la fuente de energía primaria procede del Gradiente Salino en la desembocadura de los Ríos)

- Eólica (la fuente de energía primaria procede del Viento)

- Geotérmica (la fuente de energía primaria procede del Calor de la Corteza Terrestre)

- Hidroeléctrica (la fuente de energía primaria procede del gradiente de nivel del Cauce de los Ríos)

- Marina (la fuente de energía primaria procede del Mar)

- Solar (la fuente de energía primaria procede del Sol)

En este apartado explicaré con detalle en qué consiste cada una de éstas.

\subsubsection{AZUL (OSMÓTICA)}

La potencia osmótica o energía azul es la energía obtenida por la diferencia en la concentración de sal entre el agua de mar y el agua dulce de los ríos mediante los procesos de ósmosis
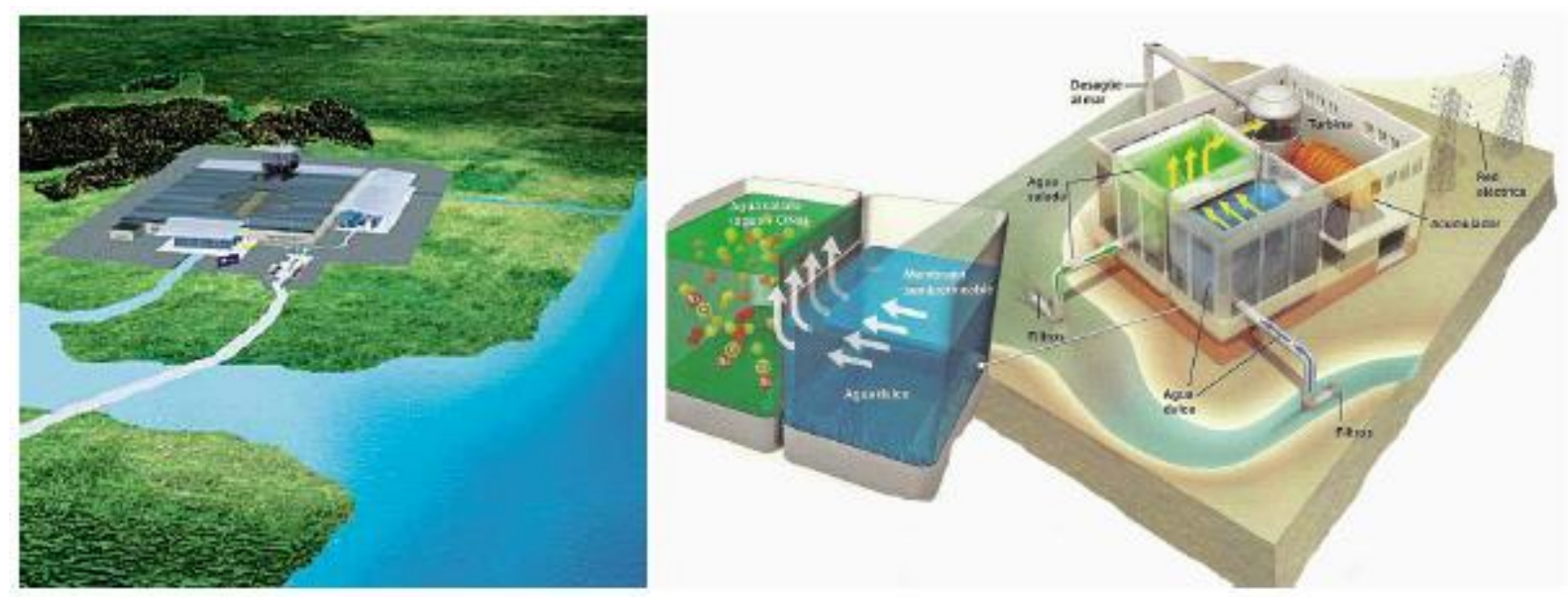

Figura 1: Esquema de funcionamiento de una planta de potencia osmótica (Starkraft)

Una planta osmótica se alimenta de agua dulce y salada en cámaras separadas por una membrana artificial. El agua dulce fluye hacia el lado de agua salada produciendo un incremento de presión que se corresponde con una columna de agua de unos $120 \mathrm{~m}$, que puede ser utilizada en una turbina hidráulica y generar electricidad. 
Las instalaciones de energía Azul se localizan en las desembocaduras de los ríos. VENTAJAS:

El residuo es únicamente agua salobre.

La energía generada es predecible y estable.

En las proximidades de las desembocaduras de muchos ríos hay ciudades o comunidades industriales por lo que se ahorrarían instalaciones de transporte de energía.

Las instalaciones pueden ser construidas parcial o completamente bajo tierra con lo que el impacto visual se reduciría sustancialmente.

La gestión del agua asociada al funcionamiento de la planta puede ser diseñada de forma que los biotipos del río, estuario y océano sean mantenidos en un estado saludable.

\section{INCONVENIENTES.}

Los estuarios pueden ser rutas de navegación o ecosistemas protegidos.

Las membranas son de costosa producción.

Están en fase de estudio o plantas piloto.

TECNOLOGÍA.

Para la energía azul se han desarrollado dos tecnologías complementarias basadas en membranas específicas:

Presión Retardada por Ósmosis (PRO, Pressure Retarded Osmosis, por sus siglas en inglés) Utiliza tecnologías basadas en poner en contacto dos fluidos con diferente concentración de sales (mar y río) a través de una membrana específica que permite pasar el agua pero no las sales. Esto genera una diferencia de presión que se puede aprovechar en una turbina En la planta generadora el agua de mar es bombeada, filtrada e introducida en los módulos de membranas, donde se diluye con el agua dulce que entra a través de las membranas. La presión se controla del lado del agua salada.

El agua dulce es introducida en los módulos de membranas desde el cauce del río. Es transferida por ósmosis dentro del agua de mar incrementando la presión que circula por una turbina de la central generando electricidad.

En la Figura 2 se ve un esquema de funcionamiento de una Planta Osmótica (1). 

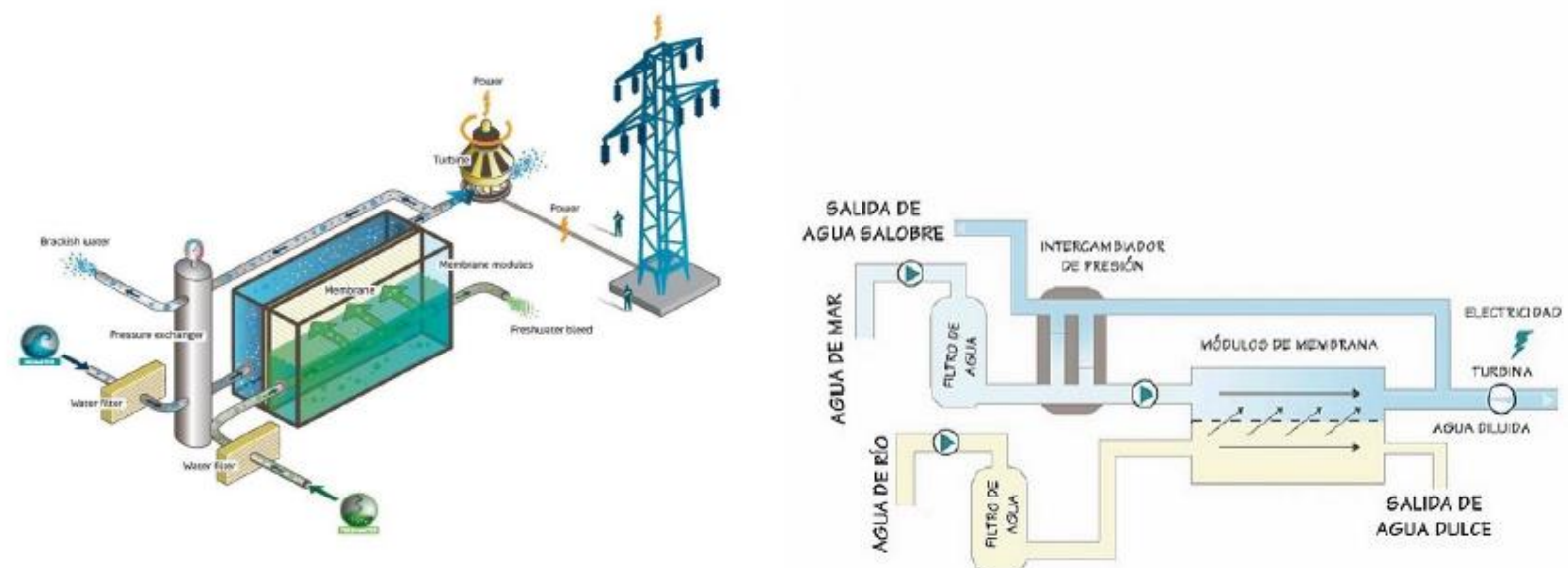

Figura 2: Esquema de funcionamiento tecnología PRO

Electrodiálisis Inversa (RED, Reverse ElectroDialysis, por sus siglas en inglés) utiliza una membrana selectiva basada en polímeros eléctricamente modificados de polietileno. La planta emplea el fenómeno inverso a la desalación de agua. El agua salada y el agua dulce se ponen en contacto, por un lado, con una membrana de intercambio de aniones o iones negativos (siglas en inglés AEM) y una membrana de intercambio de cationes o iones positivos (siglas en inglés CEM) por el otro. Los aniones Cl- de la sal sólo pueden pasar a través de la membrana de intercambio de aniones, mientras que los cationes $\mathrm{Na}+$ sólo a través de la membrana de intercambio de cationes. Como resultado, surge un voltaje por la diferencia de las cargas positivas y negativas de forma similar a lo que ocurre en una pila.

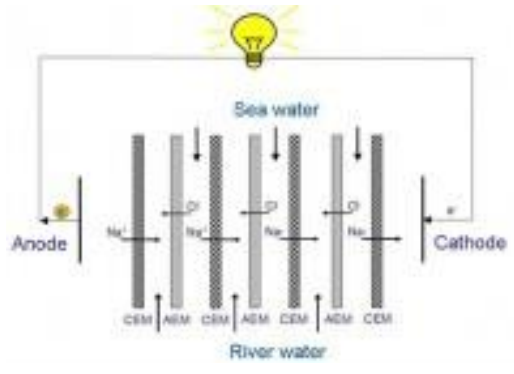

Figura 3: Esquema de funcionamiento de tecnología RED

\subsubsection{EÓLICA}

La Energía Eólica es la energía cinética del viento.

El viento es una consecuencia de la radiación solar. Debido, fundamentalmente, a la redondez de la Tierra se originan diferencias de insolación entre los distintos puntos del 
planeta. En los polos, los rayos solares inciden oblicuamente por lo que calientan menos la superficie de la Tierra. En el ecuador inciden perpendicularmente y la calientan más. Estas diferencias de insolación dan lugar a diferentes zonas térmicas que provocan diferencias de densidad en las masas de aire lo que produce su movimiento.

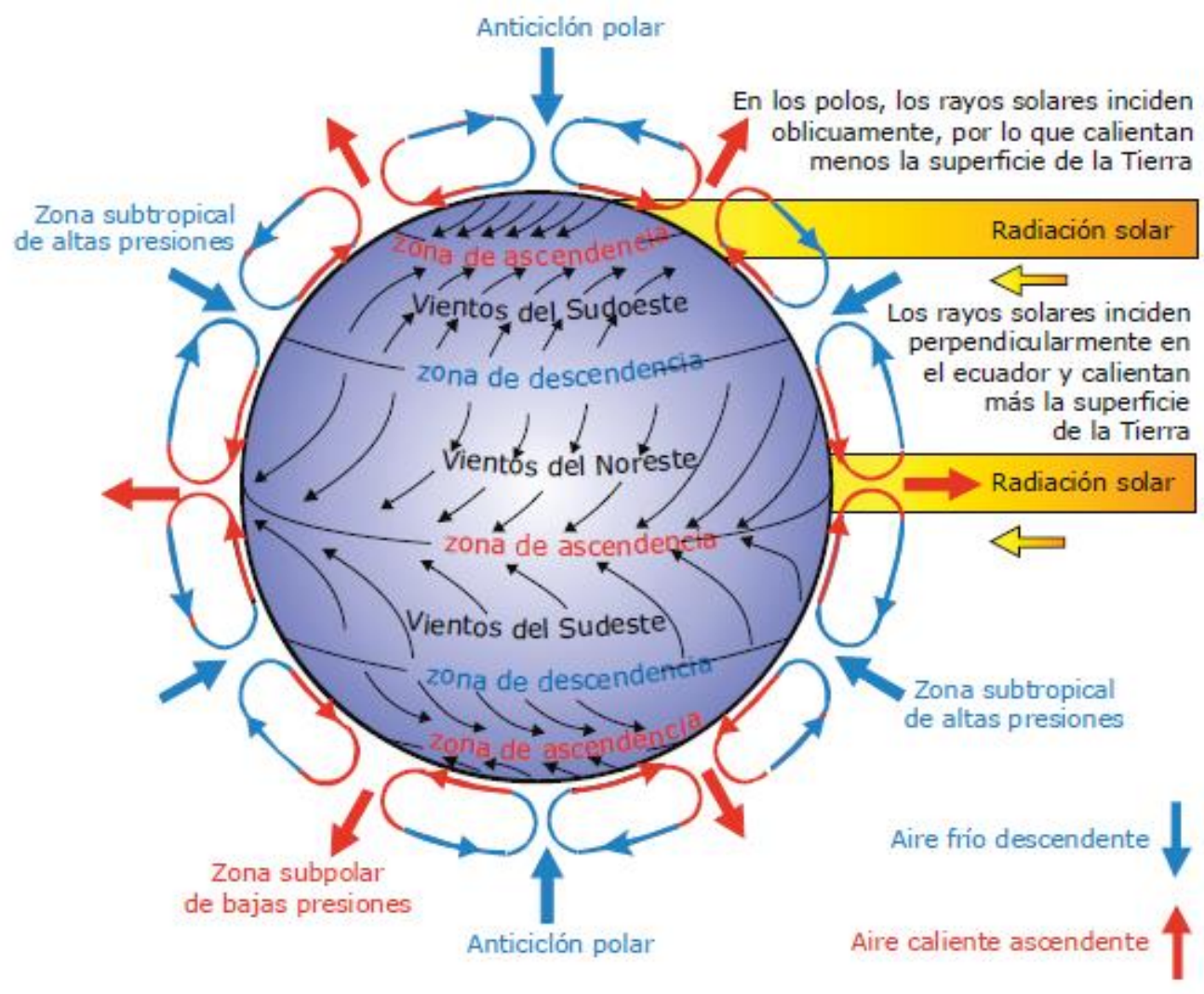

Figura 4: Circulación atmosférica general teniendo en cuenta el efecto de la fuerza de Coriolis (2)

Hay que tener en cuenta que en la circulación global del aire influye la rotación de la Tierra sobre su eje (efecto de la fuerza de Coriolis), el movimiento de traslación de la Tierra en torno del Sol (produciendo las estaciones), la composición de la Tierra en océanos y continentes y la orografía de los Continentes.

Los vientos generales que circundan el globo terrestre se llaman macro climáticos. Estos, debido a la orografía del terreno y las diferencias de presión, varían sus características originando los vientos micro-climáticos o locales. Estos últimos pueden ser clasificados en vientos inducidos térmicamente (brisas marinas y corrientes valle-montaña), vientos inducidos por la orografía (se produce efecto Bernoulli en la distribución del flujo) y vientos generales influenciados por los efectos climáticos locales. 


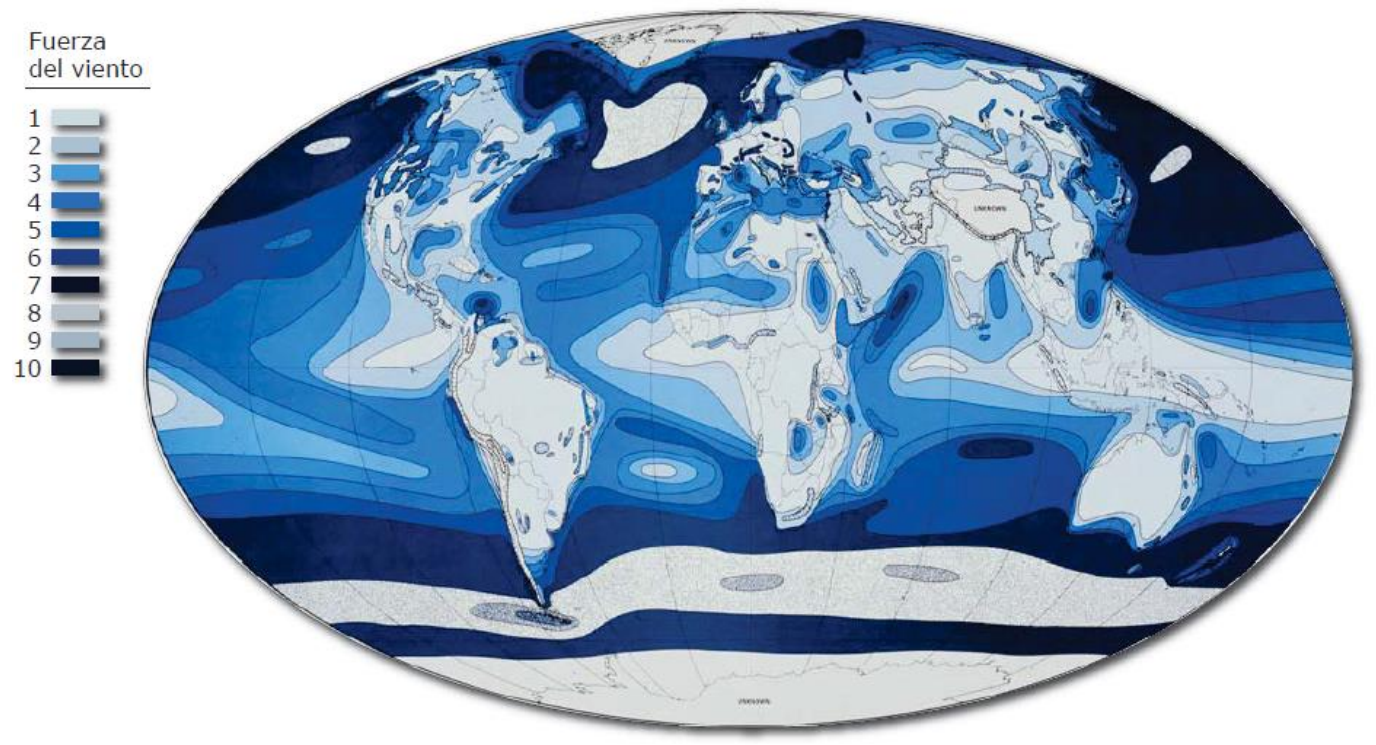

Figura 5: Distribución estimada del potencial eólico en el mundo (2)

La máxima potencia mecánica que, idealmente, puede extraerse de una vena de aire es del $60 \%$ de la que transporta la vena sobre el dispositivo captador de energía.

\section{VENTAJAS}

Es un recurso inagotable.

Es compatible con otras actividades agrícolas y ganaderas.

Permite la independencia de otras energías y la energía producida compensa los consumos propios de las instalaciones.

La tecnología está muy desarrollada.

\section{DESVENTAJAS}

La densidad energética del viento es muy baja.

Los sitios más adecuados para la generación eólica suelen estar remotos y de difícil acceso. Impacto sobre las aves. De la experiencia Española se deduce que dicho impacto ha sido nulo

Impacto visual.

El origen del ruido en los aerogeneradores se debe a factores mecánicos y aerodinámicos. La influencia de dicho impacto depende de la distancia.

Los impactos por erosión son generados principalmente por el movimiento de tierras para el trazado de los accesos y por las excavaciones realizadas para la construcción de 
cimentaciones. Pueden minimizarse realizando adecuados trazados de los caminos y reponiendo la vegetación en esas zonas.

TECNOLOGÍA.

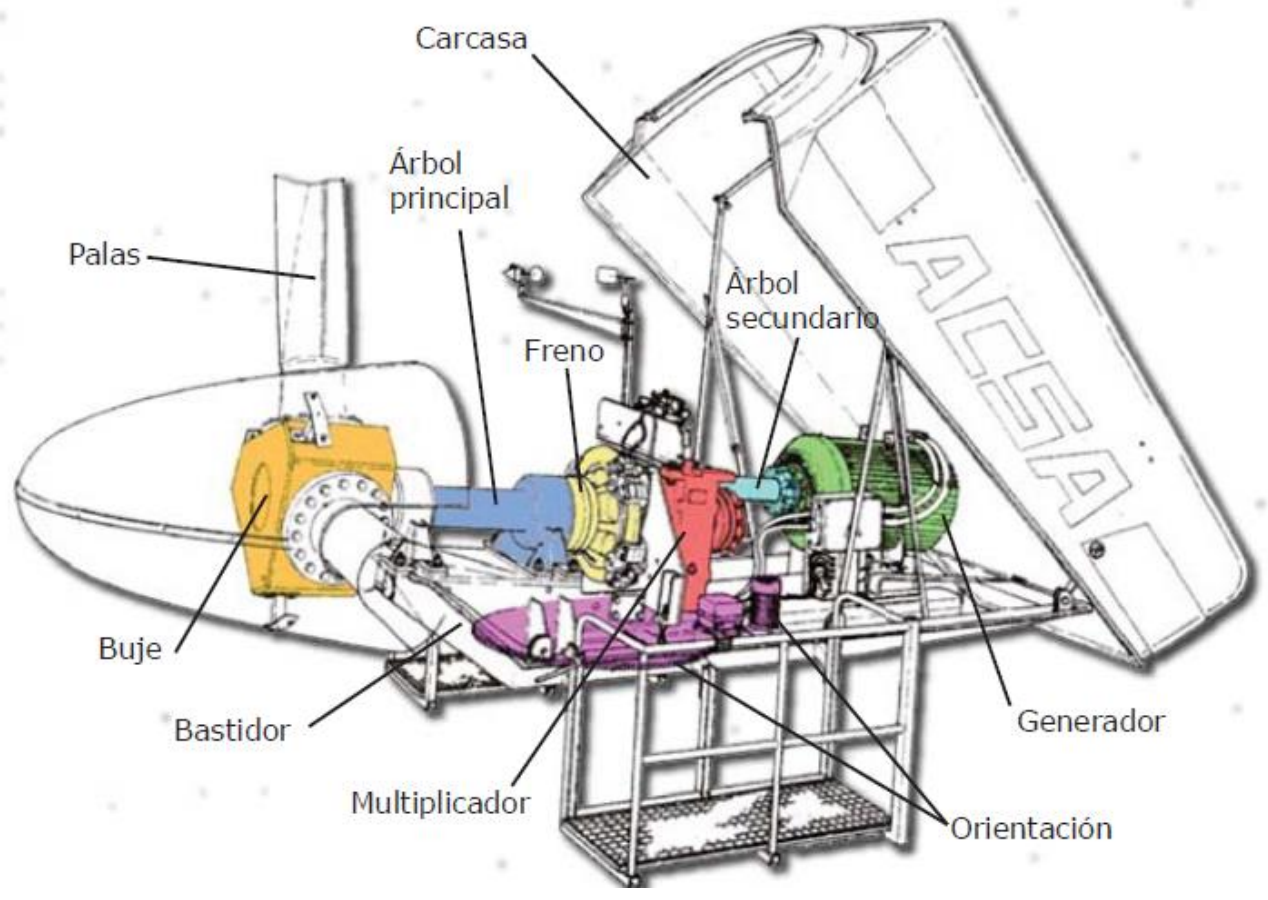

Figura 6: Componentes de un aerogenerador de eje horizontal (2)

De forma general pueden señalarse los siguientes subsistemas componentes:

Subsistema de captación. Encargado de transformar la energía cinética del viento en energía mecánica de rotación; integrado por las palas y el buje que conforman el rotor. Se pueden clasificar en:

- Según la posición del eje de giro del rotor en máquinas de eje horizontal o de eje vertical (éstas últimas apenas se utilizan debido al bajo rendimiento)

- Según el número de palas de los rotores en multipala o lentos (entre 6 y 24 palas) o en rotores tipo hélice o rápidos (1, 2 ó 3 palas)

- Según la disposición del rotor frente a la velocidad del viento en rotores de barlovento (son los más frecuentes) o de sotavento o auto orientables

- Según si el buje es rígido o basculante.

- Según si las palas son de paso controlable o fijo.

Subsistema de transmisión mecánica. La velocidad de giro del subsistema de captación es, en general, menor que la velocidad a la que debe girar el generador eléctrico. Por ello es 
necesario incluir una caja multiplicadora de la velocidad y un árbol de transmisión secundario.

Subsistema de generación eléctrica. Puede ser de corriente continua, dinamo, o de corriente alterna (son los únicos que se utilizan actualmente y, en la mayoría de los casos, máquinas asíncronas), alternador.

Subsistema de orientación, encargado de detectar la dirección del viento y situar el plano del rotor perpendicular a esa dirección. Sólo es necesario en las máquinas con rotores a barlovento y pueden ser desde veletas o colas de orientación hasta servomotores. Subsistema de control y regulación. Su misión es incrementar la captación de energía cinética del viento y mejorar la potencia eléctrica generada, así como garantizar un funcionamiento seguro.

Subsistema soporte. Está formado por la góndola, en la que se montan los distintos subsistemas de la máquina eólica, y la torre.

Los aerogeneradores pueden utilizarse tanto aislados, no conectados a la red eléctrica, como conectados. Cuando están conectados a la red eléctrica pueden ser instalaciones de un único generador o de varios, formando un parque eólico.

\subsubsection{GEOTÉRMICA}

La energía geotérmica proviene de la gran cantidad de calor que tiene la Tierra almacenado en su interior. Esta energía procede del calor acumulado en el núcleo durante el proceso de formación del planeta y de las radiaciones emitidas por la desintegración atómica de isótopos radioactivos.

El calor almacenado en el interior de la Tierra no está uniformemente distribuido, es más elevado en el núcleo (aproximadamente $7000^{\circ} \mathrm{C}$ ) y menor en la corteza. Este gradiente térmico origina un flujo de calor hacia la corteza fundamentalmente por conducción.

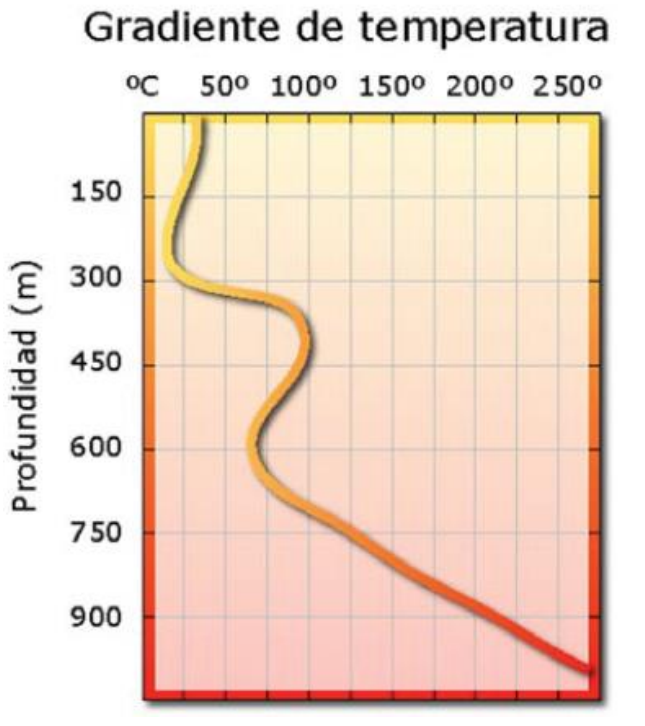

Figura 7: Gradiente de temperatura en la corteza terrestre (2) 
ESTUDIO DEL POTENCIAL DE APROVECHAMIENTO ENERGÉTICO DEL OCÉANO EN LA COSTA ANDALUZA. Autora: Ma Pilar Blanco Fernández

A nivel global del planeta, a medida que se profundiza en la corteza terrestre, la temperatura aumenta aproximadamente $3^{\circ} \mathrm{C}$ por cada $100 \mathrm{~m}$. Sin embargo existen zonas de la superficie terrestre que presentan anomalías geotérmicas, originadas por la ascensión de parte del material fundido del manto que queda atrapado en espacios próximos a la superficie. Así, en determinados lugares de la corteza pueden existir gradientes de temperatura de $100^{\circ} \mathrm{C}$ y $200^{\circ} \mathrm{C}$ por $\mathrm{Km}$. En estas zonas se dice que existen yacimientos geotérmicos.

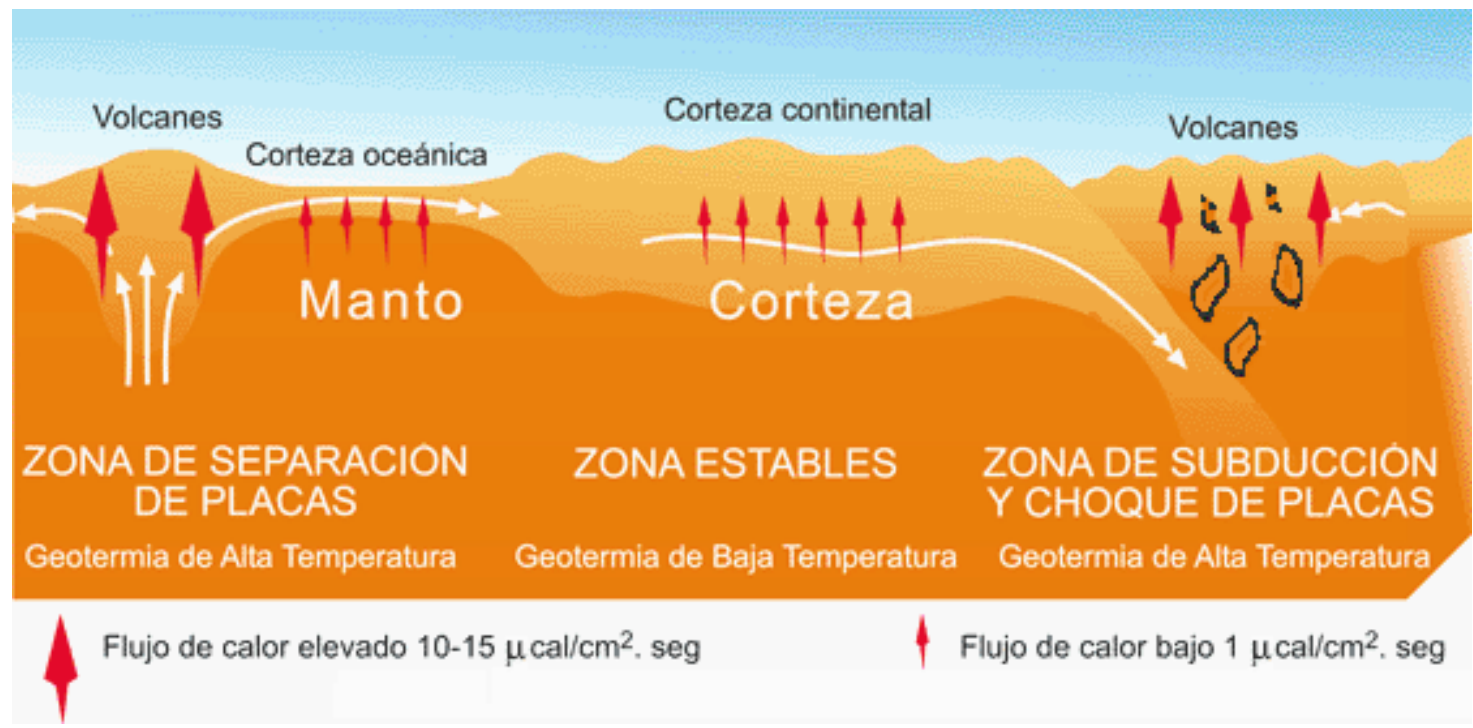

Figura 8: Estructura interna de la Tierra y repartición de flujos caloríficos según la estabilidad geológica de la zona (3)

Cuando el calor de estos yacimientos se encuentra a profundidades razonables para poder extraerlo con la tecnología existente, es posible aprovecharlo energéticamente. 
ESTUDIO DEL POTENCIAL DE APROVECHAMIENTO ENERGÉTICO DEL OCÉANO EN LA COSTA ANDALUZA.

Autora: Mạ Pilar Blanco Fernández

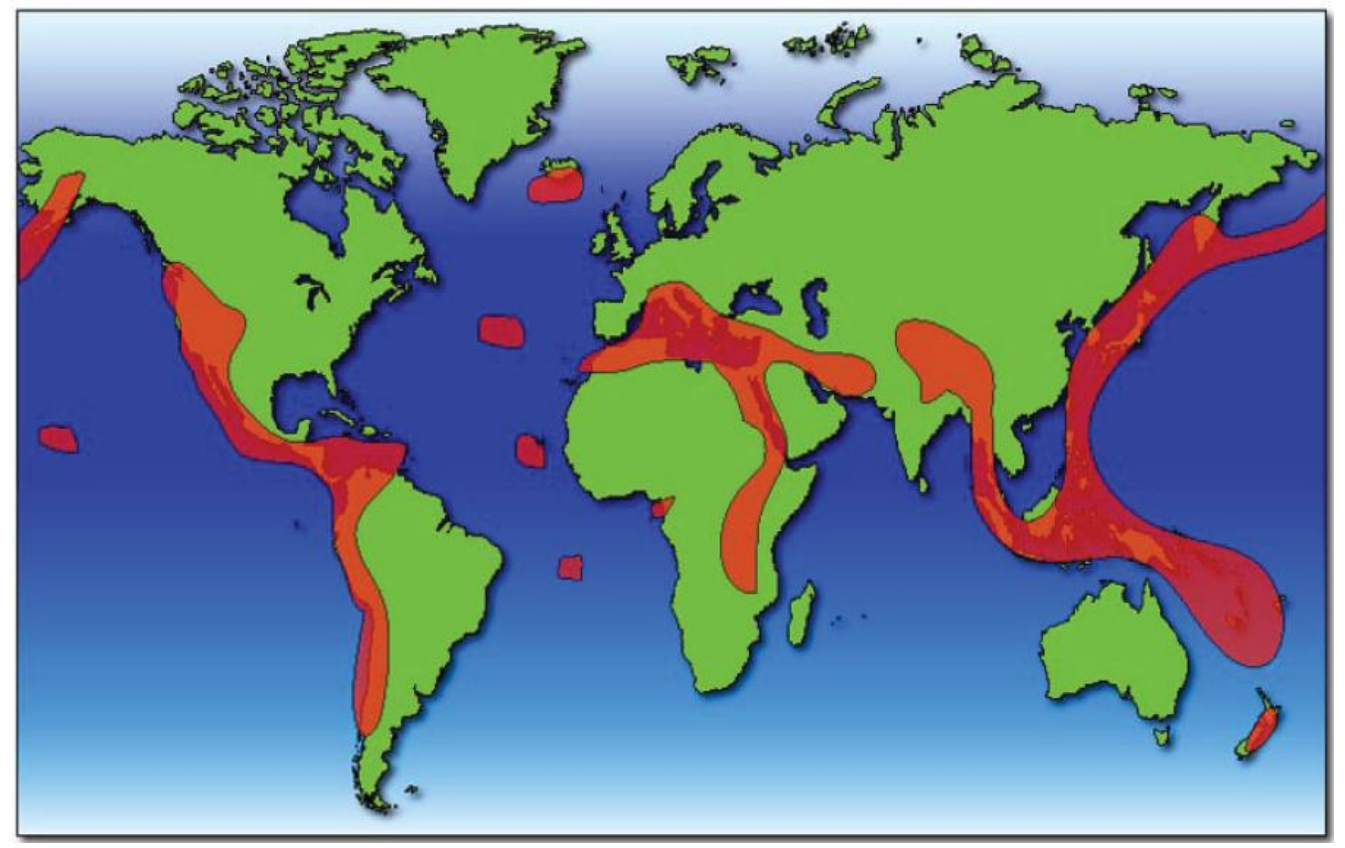

Figura 9: Zonas de mayor potencial geotérmico (2)

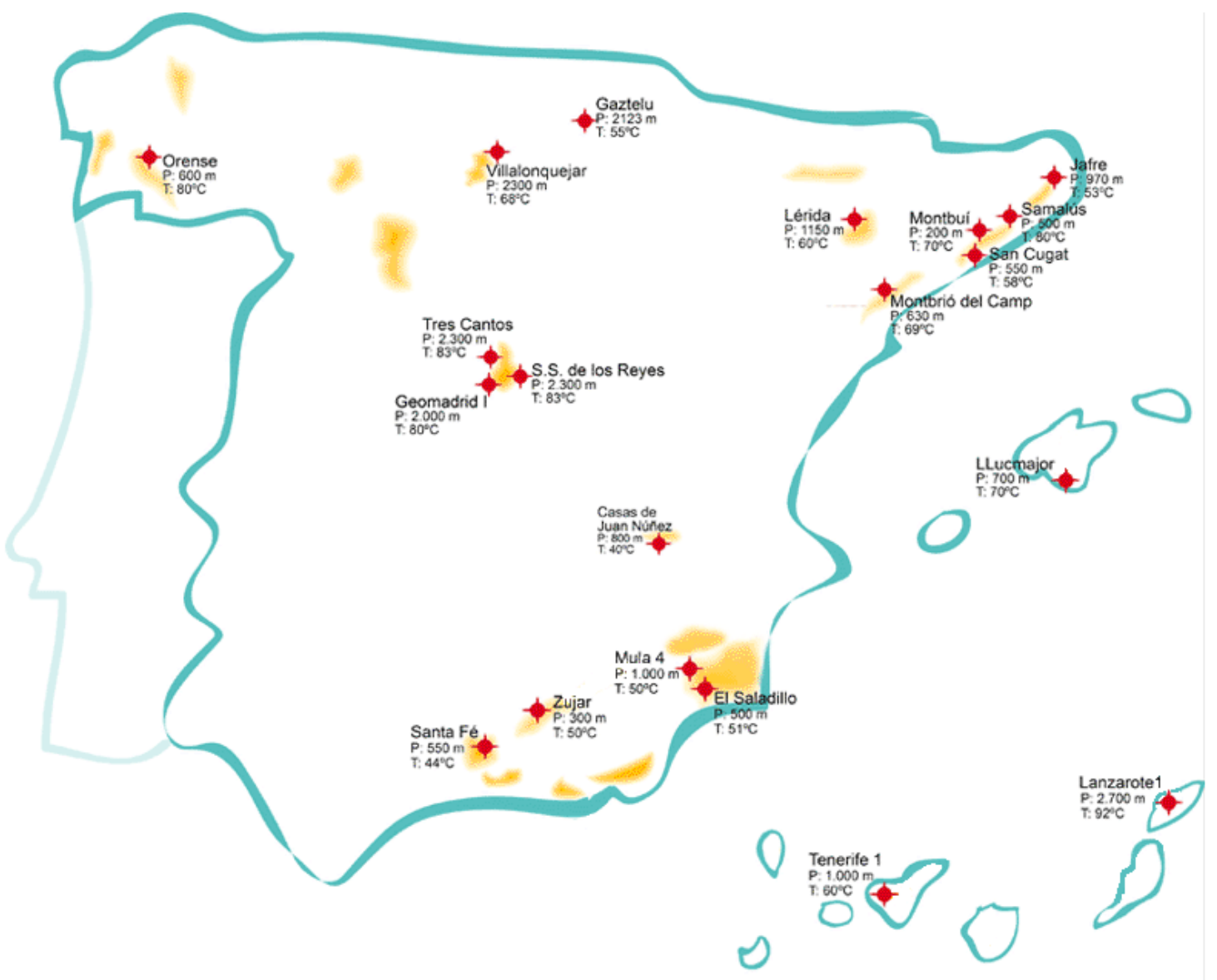

Figura 10: Distribución del potencial geotérmico en España (4) 
Se conoce como geotermia tanto el conjunto de técnicas utilizadas para la exploración, evaluación y explotación de la energía geotérmica como a la ciencia que estudia los fenómenos térmicos internos del planeta.

Desde el punto de vista práctico se puede restringir la definición de energía geotérmica a la energía calorífica contenida en las rocas del subsuelo y que puede ser extraída por el hombre en términos económicos. Así, podemos definir los yacimientos geotérmicos como las áreas geográficas que cumplen las condiciones necesarias para que se pueda explotar económicamente la energía geotérmica existente en el subsuelo. Estas condiciones no son las mismas si se trata de un yacimiento de alta temperatura que si se trata de uno de baja temperatura.

Para que exista un yacimiento geotérmico de alta temperatura se requieren las siguientes circunstancias:

Presencia de una fuente de calor activo. Generalmente se trata de un cuerpo de magma situado a una profundidad razonable.

Presencia de agua. El yacimiento debe ser susceptible de ser recorrido por una corriente de agua ya sea existente en la naturaleza o inyectada artificialmente desde la superficie.

Presencia de un depósito formado por rocas permeables situadas a profundidad accesible mediante perforaciones.

Existencia de una cubierta impermeable, para impedir que los fluidos se escapen hacia el exterior del yacimiento. Generalmente esta cubierta no es perfecta por lo que existe un escape de fluido a la superficie, dando lugar a geiser, fumarola, solfatara o fuente termal. 


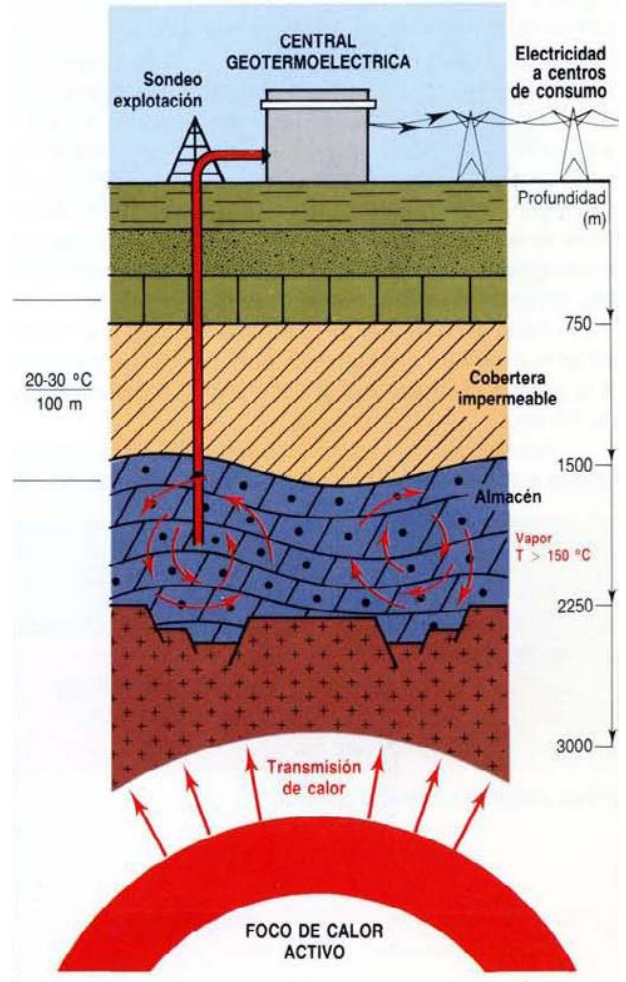

Figura 11: Yacimiento geotérmico de alta temperatura

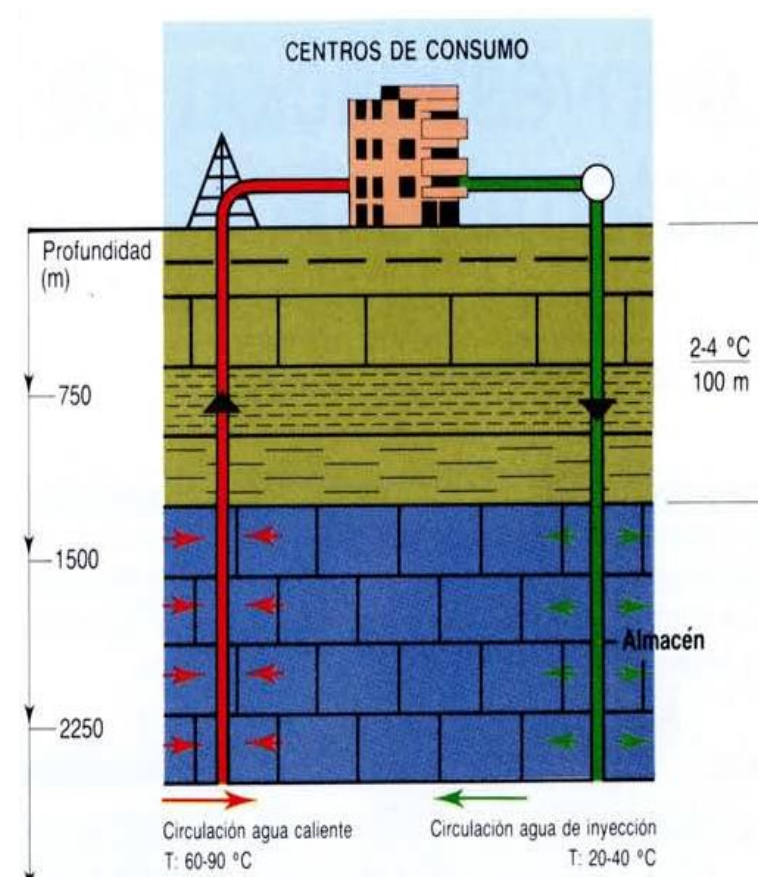

Figura 12: Yacimiento geotérmico de baja temperatura

Los yacimientos geotérmicos de baja temperatura (60-100ํㅡ) cumplen las siguientes condiciones:

Rocas permeables a profundidad de $1.500-2.500 \mathrm{~m}$

Suficiente demanda energética en la misma zona.

Los yacimientos de muy baja temperatura están siendo aprovechables al mejorar la tecnología de utilización y aprovechamiento del calor, principalmente con las bombas de calor, pudiendo aprovecharse desde los $15^{\circ} \mathrm{C}$

Una opción de futuro serían los yacimientos de roca caliente seca en los que no existe un fluido geotérmico y no existe un almacén térmico, están situados a profundidades no muy elevadas y en condiciones de alta temperatura debido a su proximidad a cámaras magmáticas en áreas volcánicas. Las técnicas de explotación se basan en la creación de una red de fracturas que permitan la formación de una zona de intercambio térmico por la que se hace circular un fluido inyectado desde la superficie, que retorna a ésta tras haber incrementado notablemente su temperatura. Cuando se domine la técnica de fracturación artificial y los procedimientos de perforación e inyección de fluidos a grandes profundidades se podrán considerar económicamente viables. 


\section{VENTAJAS}

Disminuye la dependencia energética de los combustibles fósiles

No genera ruidos exteriores ni impacto visual

No está sujeta a la fluctuación de los mercados.

El área de terreno requerido por megavatio es menor que para otro tipo de energía Muy baja emisión de $\mathrm{CO}_{2}$ y $\mathrm{SO}_{2}$.

Rendimiento energético muy alto.

\section{DESVENTAJAS}

No se puede transportar como energía primaria.

Está disponible en lugares muy localizados (excepto si se utiliza para climatización)

El fluido (agua con gases y minerales disueltos) puede aumentar los costes de

mantenimiento por corrosión, depósitos de minerales, partículas sólidas en suspensión y la necesidad de desgasificación si va a haber pérdidas de presión en la red.

Las zonas más energéticas son inestables geológicamente.

TECNOLOGÍA.

El calor contenido en rocas y suelos es demasiado difuso para ser extraído directamente de forma económica, siendo necesario disponer de un fluido, generalmente agua, para transportar el calor hacia la superficie de forma concentrada (mediante sondeos, sondas geotérmicas, colectores horizontales o mediante intercambiadores de calor tierra-aire enterrados a poca profundidad en el subsuelo)

Una vez en superficie, el fluido se destinará a la producción de energía eléctrica o se aprovechará su calor directamente en intercambiadores de calor o bombas térmicas si su contenido en calor no permite el primer uso.

En Tabla 1 se muestran las aplicaciones más importantes de la energía geotérmica con los rangos de temperatura de utilización y, en su parte inferior, se establece una agrupación de la energía geotérmica en cuatro grandes tipos: muy baja, baja, media y alta temperatura Diferentes autores establecen diferentes límites de temperatura para estos intervalos, en la Tabla 1 se han recogido los que establece el “Código Minero” en Francia 
Tabla 1: Principales usos de la energía geotérmica en función de la temperatura

\begin{tabular}{|c|c|c|c|c|c|}
\hline & & 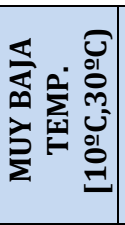 & 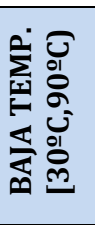 & 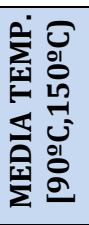 & 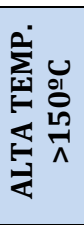 \\
\hline \multirow{7}{*}{ 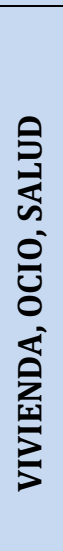 } & Calefacción con bombas de calor-climatización & $\mathrm{X}$ & $\mathrm{X}$ & & \\
\hline & Calefacción por suelo radiante & & $\mathrm{X}$ & & \\
\hline & Centros de ocio-piscinas & & $\mathrm{X}$ & & \\
\hline & Balneoterapia-Termalismo & & $\mathrm{X}$ & & \\
\hline & Precalentamiento (agua-aire) & & $\mathrm{X}$ & & \\
\hline & Agua caliente sanitaria & & $\mathrm{X}$ & & \\
\hline & Calefacción urbana & & $\mathrm{X}$ & $\mathrm{X}$ & \\
\hline \multirow{7}{*}{ 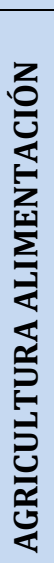 } & Piscicultura-Acuicultura & & $\mathrm{X}$ & & \\
\hline & Cultivo de setas & & $\mathrm{X}$ & & \\
\hline & Calefacción de invernaderos por el suelo & & $\mathrm{X}$ & & \\
\hline & Calefacción de invernaderos por el aire & & $\mathrm{X}$ & $\mathrm{X}$ & \\
\hline & Precalentamiento (agua-aire) & & $\mathrm{X}$ & & \\
\hline & Secados de productos agrícolas, maderas, pescados & & $\mathrm{X}$ & $\mathrm{X}$ & \\
\hline & Fábricas de conservas & & & $\mathrm{X}$ & \\
\hline \multirow{10}{*}{ 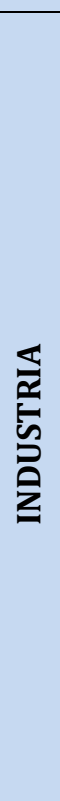 } & Precalentamiento (agua-aire) & & $\mathrm{X}$ & & \\
\hline & Deshielo & & $\mathrm{X}$ & & \\
\hline & Lavado de lana-Tintes & & & $\mathrm{X}$ & \\
\hline & Secado de productos industriales & & $\mathrm{X}$ & $\mathrm{X}$ & \\
\hline & Producción de E. Eléctrica en plantas de ciclo binario & & $\mathrm{X}$ & $\mathrm{X}$ & \\
\hline & Refrigeración por absorción & & & $\mathrm{X}$ & \\
\hline & Extracción de sustancias químicas & & & $\mathrm{X}$ & \\
\hline & Destilación agua dulce & & & $\mathrm{X}$ & \\
\hline & Recuperación de metales & & & $\mathrm{X}$ & \\
\hline & Producción de E. Eléctrica & & & $\mathrm{X}$ & $\mathrm{X}$ \\
\hline
\end{tabular}




\begin{tabular}{|c|c|c|c|c|}
\hline Evaporación de soluciones concentradas & & & $\mathrm{X}$ & \\
\hline Fabricación pasta papel & & & $\mathrm{X}$ & \\
\hline Refrig. Por absorción con amoniaco & & & $\mathrm{X}$ & $\mathrm{X}$ \\
\hline & 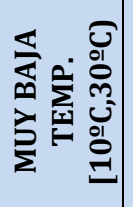 & 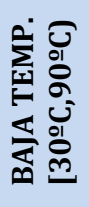 & 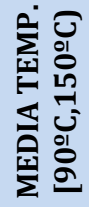 & 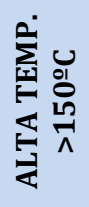 \\
\hline
\end{tabular}

Las centrales de vapor seco utilizan los recursos en forma de vapor en estado de saturación o ligeramente recalentado (vapor seco) para su inyección directa en la turbina. Se trata de la primera tecnología empleada por una central geotérmica pero son de uso obligado cuando el contenido en gases no condensables supera el $50 \%$ o cuando el contenido total de gases excede del 10\%, debido al alto costo que supondría su separación en los condensadores. (5)

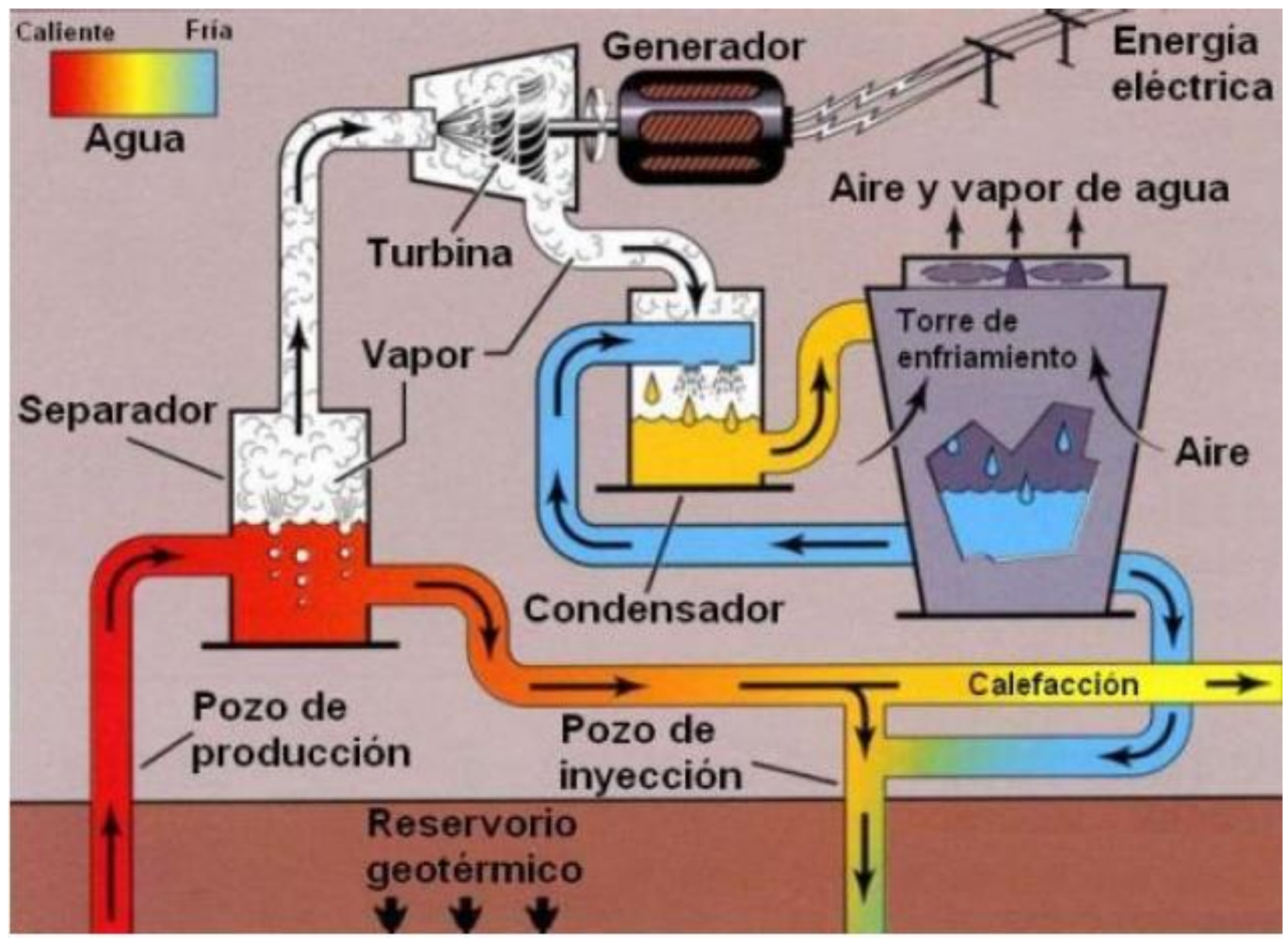

Figura 13: Esquema de funcionamiento de una planta de vapor seco (6) 
ESTUDIO DEL POTENCIAL DE APROVECHAMIENTO ENERGÉTICO DEL OCÉANO EN LA COSTA ANDALUZA.

Las centrales de tipo flash son las más extendidas para recursos de alta temperatura.

Durante el ascenso del fluido se produce una disminución de presión que propicia la ebullición, liberando el vapor. La presencia de dos fases hace necesaria su separación, en la que se obtiene el vapor que será enviado a la turbina, así como una fracción líquida que se rechaza o se utiliza para aprovechamientos secundarios (agricultura, procesos industriales, ...)

El ciclo flash puede constar de una o varias etapas, tantas como permita la entalpía del agua separada.

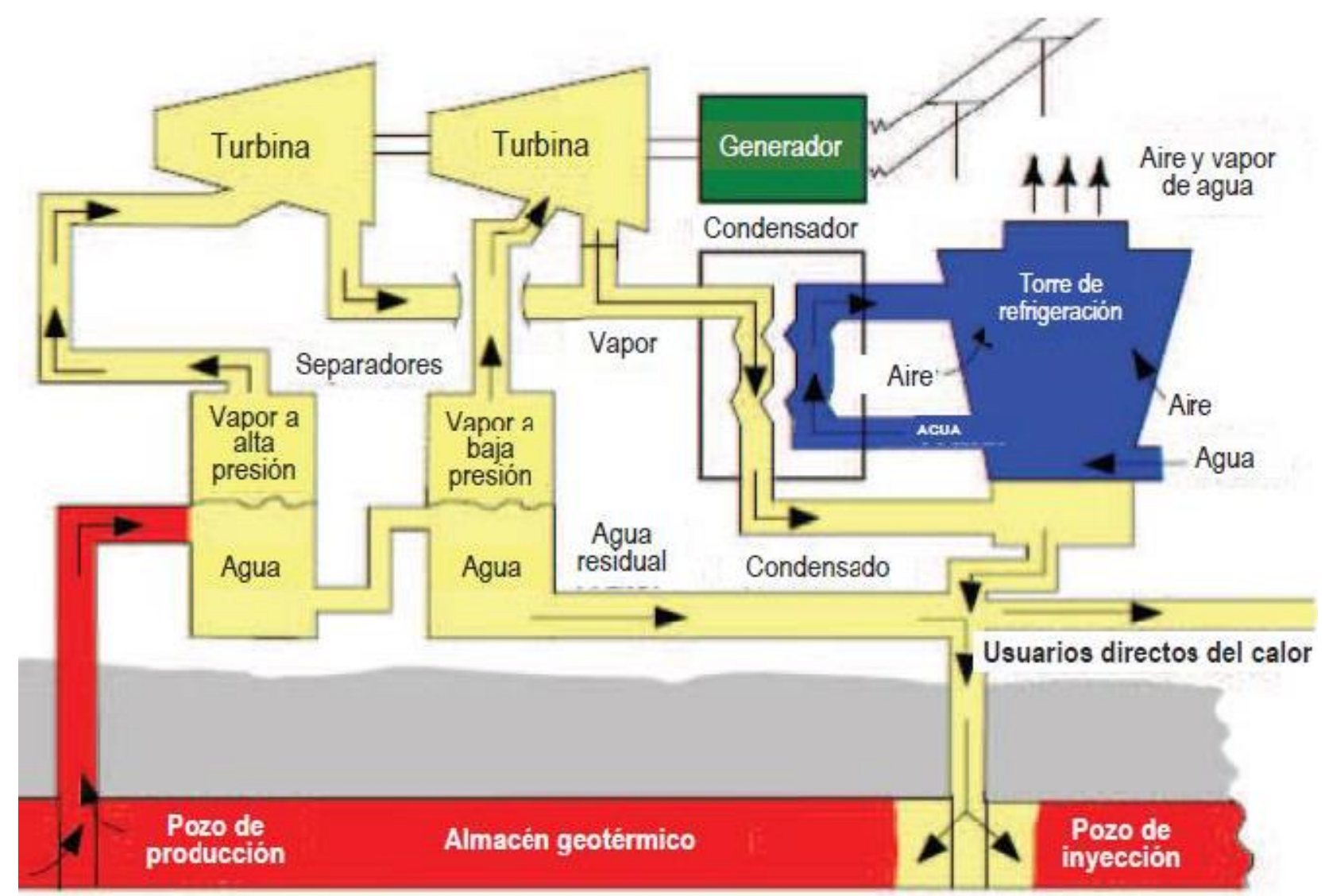

Figura 14: Esquema de funcionamiento de planta tipo flash doble (6)

Las centrales de tipo binario se emplean en la explotación de yacimientos de media temperatura y elevada salinidad. Utiliza la temperatura del agua geotérmica para calentar otro fluido con bajo punto de ebullición y alta presión de vapor a temperatura alta. 


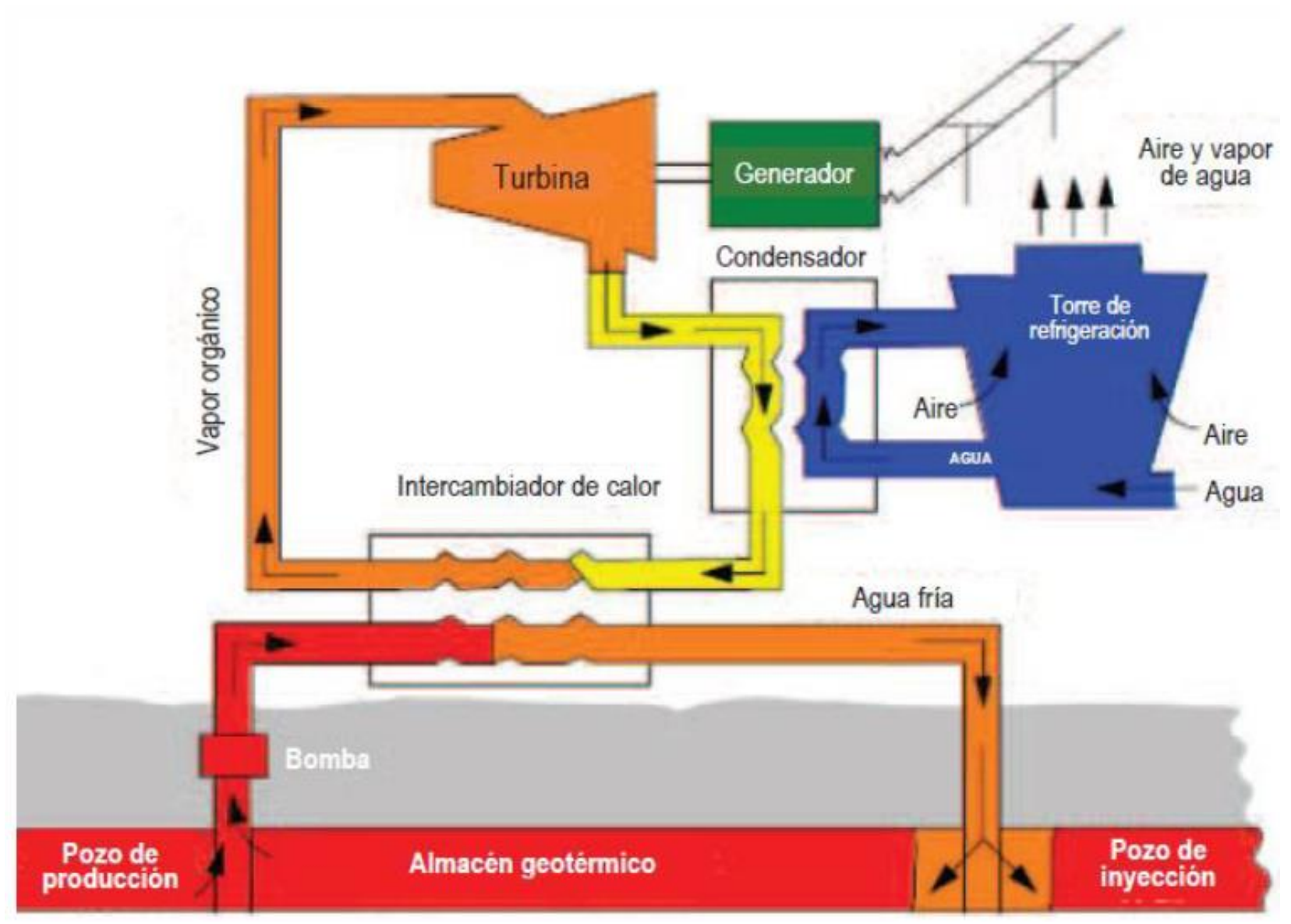

Figura 15: Esquema de funcionamiento de una planta de ciclo binario (6)

Las centrales de ciclo combinado flash-binario aprovechan los beneficios de estas dos tecnologías mediante una combinación de ambas. En estas centrales, el vapor separado mediante un proceso flash se aprovecha en una turbina para generar electricidad, mientras que el vapor que sale de dicha turbina a baja presión se condensa en un sistema binario. De este modo se hace un uso eficaz de las torres de refrigeración por aire en aplicaciones flash y se aprovechan las ventajas del proceso binario.

La energía geotérmica es un recurso aún sin explotar por lo que se están desarrollando nuevas tecnologías emergentes y nuevas aplicaciones que contribuirán a ampliar el potencial geotérmico disponible. Las más importantes son los sistemas geotérmicos híbridos en los que se combina la energía geotérmica y otra fuente convencional, los sistemas geotérmicos estimulados y la coproducción con petróleo y gas.

\subsubsection{HIDRÁULICA}

La energía hidráulica comprende la energía cinética del movimiento de masas de agua y la energía potencial del agua disponible a una cierta altura. 


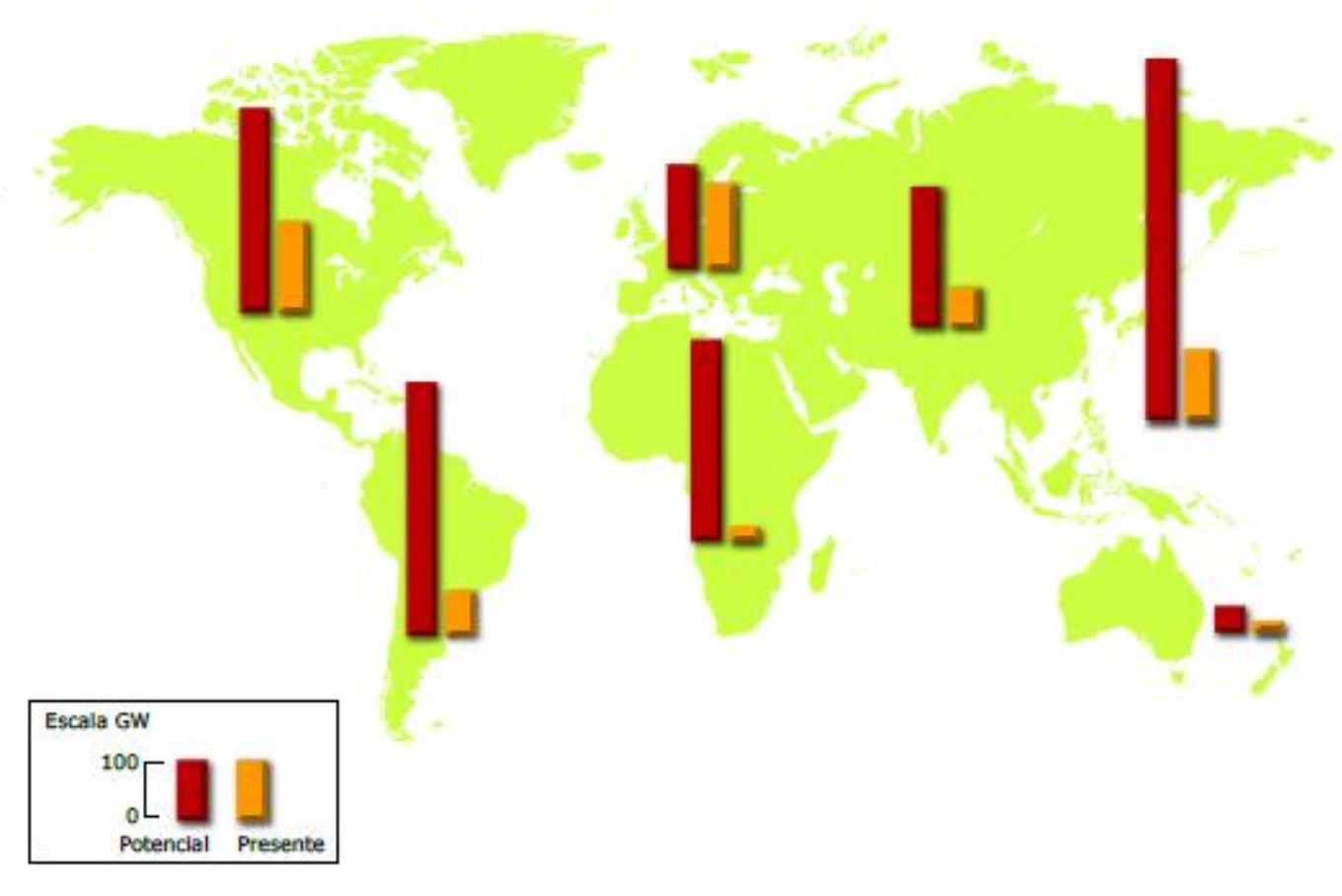

Figura 16: Potencia instalada frente a potencia instalable, en las seis grandes áreas del mundo (2)

El agua, en su caída entre dos niveles del cauce o conducida por tubería cerrada en un arroyo con gran desnivel, se hace pasar por una turbina hidráulica que transmite la energía a un alternador donde se convierte en electricidad.

\section{VENTAJAS.}

Debido al ciclo del agua su disponibilidad es inagotable.

Tiene un alto rendimiento energético

No produce residuos.

Los embalses que se construyen permiten utilizar el agua almacenada para regadío o actividades recreativas.

Los embalses regulan el caudal del río evitando riesgos de inundación.

No utiliza combustibles evitando además la volatilidad de los precios de los mismos.

Con un mantenimiento adecuado, su explotación es más prolongada que las plantas que utilizan combustibles.

Es una tecnología muy madura.

\section{INCONVENIENTES.}

La construcción de grandes embalses inunda importantes extensiones de terreno en función de la topografía, lo que se traduce en pérdida de suelo agrícola, ganadero, forestal o núcleos rurales. 
Alteraciones bioclimáticas locales.

Reducción de la diversidad biológica.

Cambia los ecosistemas en el río aguas abajo ya que el agua que sale de las turbinas apenas lleva sedimento lo que puede erosionar los márgenes de los ríos.

Cuando las turbinas se abren y cierran repetidas veces, el caudal del río se puede modificar drásticamente causando una dramática alteración en los ecosistemas.

TECNOLOGÍA.

La tipología de las centrales hidroeléctricas es muy variada. Estas dependen de:

- La altura útil del salto.

- La capacidad de generación.

- El tipo de tecnología.

- La localización y tipo de presa, embalse, etc.

Según el tipo de central las instalaciones hidráulicas pueden clasificarse fundamentalmente en:

- Centrales de agua fluyente, aprovechan desniveles naturales del cauce de un río y mediante una presa o azud desvían parte del caudal por un canal de derivación hasta la turbina.

- Centrales con embalse, el almacenamiento del agua se lleva a cabo mediante la construcción de un embalse o aprovechando uno construido para otros usos.

De forma general pueden señalarse los siguientes subsistemas componentes en una central hidroeléctrica:

- Obra civil:

- Elementos de retención (azudes y presas) destinados a retener el cauce de un río y elementos de seguridad para la evacuación de caudales (aliviaderos y compuertas)

- Canales de derivación para conducir el caudal de agua hasta una cámara de descarga. Pueden ser a cielo abierto, enterrados o una conducción a presión.

○ Cámara de carga consistente en un depósito ubicado en el otro extremo del canal.

- Tuberías forzadas, encargadas de conducir el agua desde la cámara de carga o desde el embalse hasta las turbina. 
○ Edificio central, en cuyo interior están las turbinas, los generadores eléctricos y demás aparatos de regulación y control.

- Turbinas hidráulicas y transmisiones mecánicas.

○ Turbinas de acción.

○ Turbinas de reacción.

- Generadores eléctricos.

- Pueden ser de corriente continua, dinamo, o

- De corriente alterna, alternador (estos son los únicos que se utilizan actualmente)

- Subsistema de regulación y control.

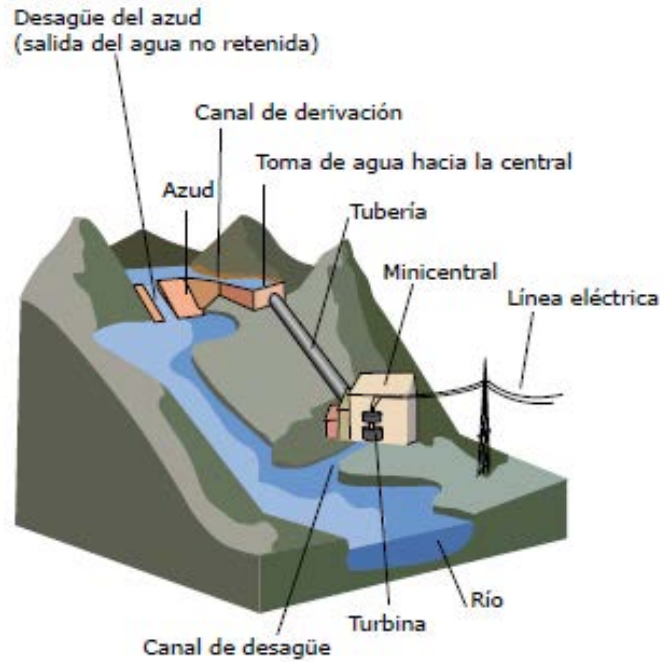

Figura 17: Central hidroeléctrica de agua fluyente (2)

\subsubsection{MARINA}

Los mares y los océanos son inmensos colectores solares de los cuales se puede extraer energía de orígenes diversos.

- La radiación solar incidente sobre los océanos, en determinadas condiciones atmosféricas, da lugar a los gradientes térmicos oceánicos a bajas latitudes y profundidades menores de $1000 \mathrm{~m}$.

- La alteración de los vientos y las aguas son responsables del oleaje y de las corrientes marinas.

- La influencia gravitacional de los cuerpos celestes sobre las masas oceánicas provoca mareas.

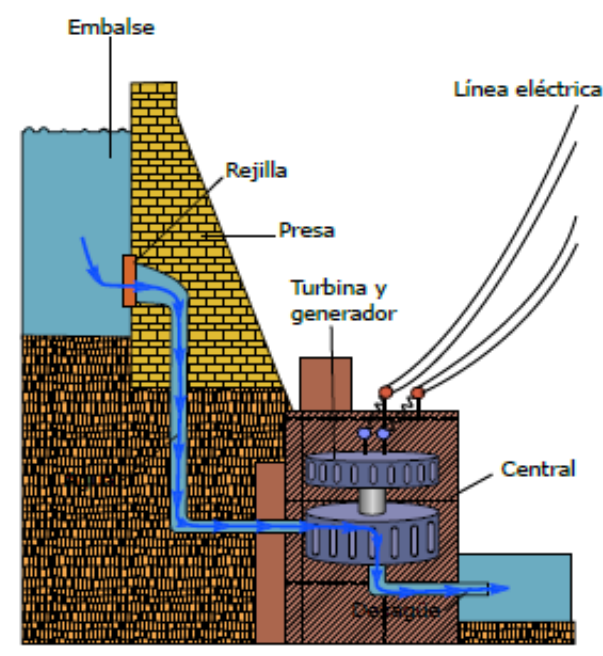

Figura 18: Central hidroeléctrica con embalse (2) 
ESTUDIO DEL POTENCIAL DE APROVECHAMIENTO ENERGÉTICO DEL OCÉANO EN LA COSTA ANDALUZA.

La evolución de la generación de electricidad a partir de las energías marinas aparece en las siguientes tablas (7)

Tabla 2: Capacidad máxima de generación neta de centrales de energía marina para producir electricidad

\begin{tabular}{|l|l|l|l|l|l|l|l|l|l|l|}
\hline CAP (MW) & $\mathbf{2 0 0 6}$ & $\mathbf{2 0 0 7}$ & $\mathbf{2 0 0 8}$ & $\mathbf{2 0 0 9}$ & $\mathbf{2 0 1 0}$ & $\mathbf{2 0 1 1}$ & $\mathbf{2 0 1 2}$ & $\mathbf{2 0 1 3}$ & $\mathbf{2 0 1 4}$ & $\mathbf{2 0 1 5}$ \\
\hline Mundo & 265 & 267 & 267 & 269 & 271 & 525 & 528 & 527 & 527 & 533 \\
\hline Europa & 241 & 241 & 241 & 241 & 243 & 243 & 246 & 244 & 245 & 248 \\
\hline España & & & & & & 0 & 0 & 0 & 0 & 0 \\
\hline
\end{tabular}

Tabla 3: Capacidad máxima conectada de generación neta de centrales de energía marina para producir electricidad

\begin{tabular}{|l|l|l|l|l|l|l|l|l|l|}
\hline PROD (GWh) & $\mathbf{2 0 0 6}$ & $\mathbf{2 0 0 7}$ & $\mathbf{2 0 0 8}$ & $\mathbf{2 0 0 9}$ & $\mathbf{2 0 1 0}$ & $\mathbf{2 0 1 1}$ & $\mathbf{2 0 1 2}$ & $\mathbf{2 0 1 3}$ & $\mathbf{2 0 1 4}$ \\
\hline Mundo & 490 & 496 & 488 & 489 & 516 & 959 & 944 & 890 & 954 \\
\hline Europa & 464 & 465 & 465 & 449 & 478 & 478 & 462 & 420 & 484 \\
\hline España & & & & & & 0 & 0 & 0 & 0 \\
\hline
\end{tabular}

\subsubsection{DE LAS OLAS O UNDIMOTRIZ}

La energía de las olas se puede considerar como una forma concentrada de energía solar. El viento se genera debido al calentamiento diferencial de la superficie de la tierra y éste a su vez transmite parte de su energía a la superficie del agua generando oleaje. La cantidad de energía que se transmite al agua depende de la velocidad del viento, el periodo de tiempo durante el cual esté actuando y la extensión o "fetch" sobre la que actúe.

Las olas se pueden clasificar atendiendo a diversos criterios:

Clasificación General:

- Ondas estacionarias: aquellas que tienen puntos nodales en los que el desplazamiento es nulo y otros ventrales donde el desplazamiento es máximo o mínimo

- Ondas transitorias o progresivas: aquellas que varían su periodo y longitud en el tiempo y en el espacio.

Clasificación según las Fuerzas Perturbadoras:

- Ondas generadas por el Viento u otros agentes atmosféricos: los fenómenos meteorológicos perturban la superficie del mar produciendo olas. 
- Ondas generadas por la Atracción de los Astros: la fuerza gravitatoria de la Luna y el Sol provocan ondas largas más conocidas como mareas, con periodos de 12 a 24 horas.

- Ondas generadas por Terremotos: son ondas de periodo largo y progresivas muy energéticas, se propagan desde un epicentro.

Clasificación según las Fuerzas Restauradoras:

- Fuerza de Coriolis: solo es significativa para las ondas de periodos mayores a 5 min (mareas)

- Fuerza de la Gravedad: es significativa para las ondas de periodos del orden de segundos a minutos.

- Tensión Superficial: predomina en las ondas de longitud y periodos cortos.

Clasificación según el Periodo de Duración:

- Olas de Periodo Largo: (5 min a 24h). Entran en esta clasificación las mareas, tsunamis y demás olas provocadas por terremotos y tormentas.

- Olas de Gravedad: (1seg a $30 \mathrm{seg}$ ). Corresponden las olas cuya fuerza restauradora principal es la gravedad.

- Olas Capilares: (menos de $0.1 \mathrm{seg}$ ). Tienen un papel importante en la transferencia de energía del aire al agua para formar las corrientes superficiales.

En la siguiente Figura 19 se representan los tipos de olas según la fuerza perturbadora, restauradora y su periodo, incluyendo la curva de energía asociada en cada caso particular. (8) 
ESTUDIO DEL POTENCIAL DE APROVECHAMIENTO ENERGÉTICO DEL OCÉANO EN LA COSTA ANDALUZA.

Periodo

$\begin{array}{cc}24 \mathrm{~h} & 12 \mathrm{~h} \\ \text { Olas de periodo largo } \\ 5 \mathrm{~m}\end{array}$

Terremotos, tormentas

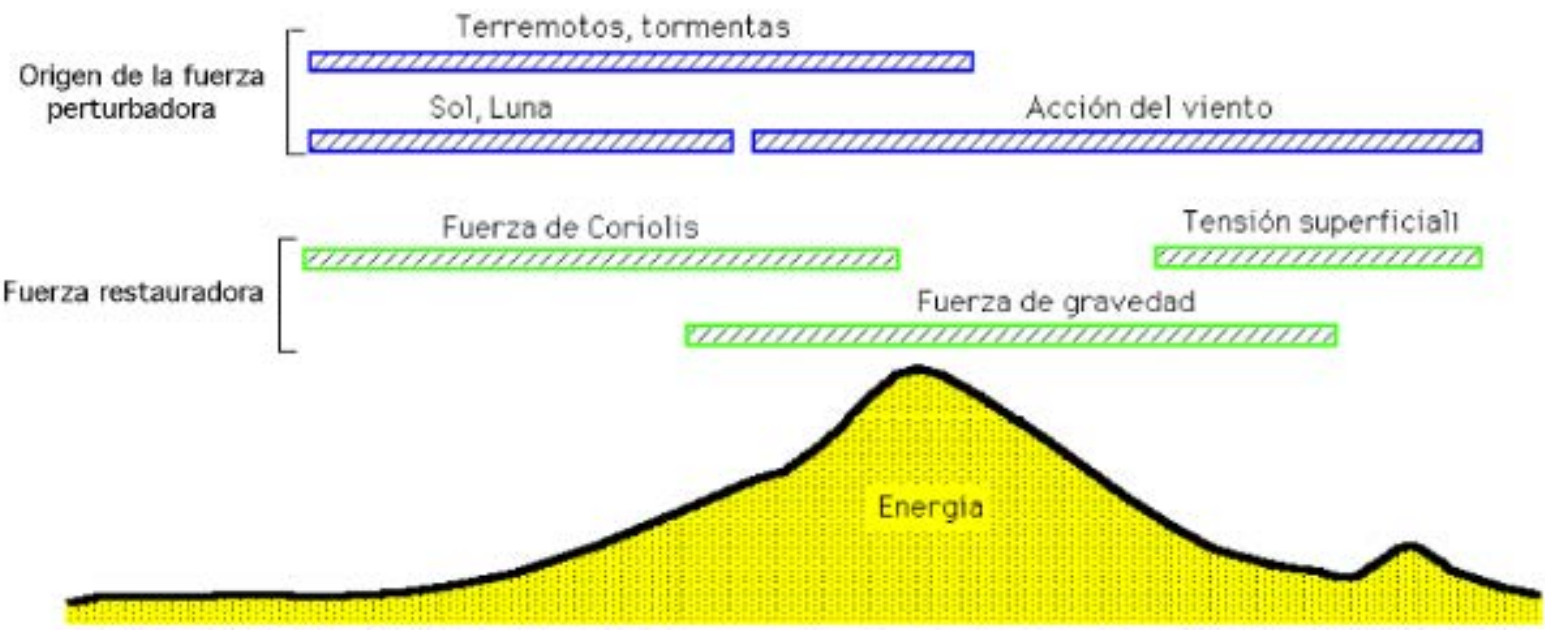

Figura 19: Representación esquemática de los tipos de olas que existen en la superficie del océano y de la energía en ellas contenida

Dado que tres cuartas partes de la superficie terrestre están recubiertas por mar este recurso supone una fuente importante en el ámbito de las energías renovables.

Los niveles de energía deseables para la explotación de este recurso se encuentran en las zonas de latitud $30^{\circ}$ a $60^{\circ}$ en ambos hemisferios inducidos por los vientos alisios predominantes en estas regiones, con un potencial disponible de entre 20 y $70 \mathrm{KW} / \mathrm{m}$. Mientras que los climas con un nivel más bajo de energías corresponden a latitudes de entre $\pm 30^{\circ}$ 


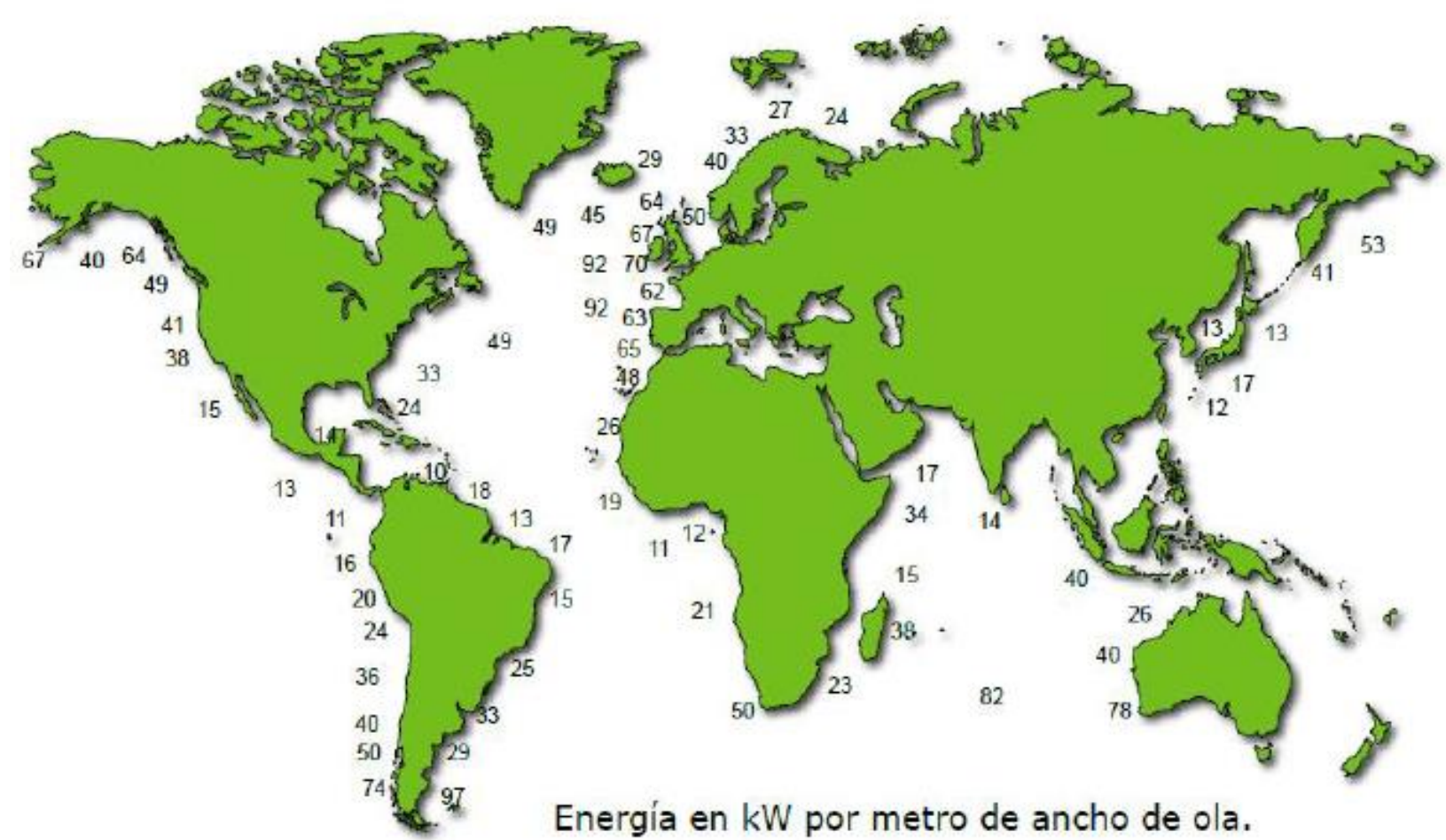

Figura 20: Distribución de energía del oleaje en aguas profundas en kW/m (2)

A nivel europeo se ha desarrollado un proyecto para establecer un atlas de energía del oleaje en aguas profundas correspondiente a la costa atlántica y mediterránea europea, WERATLAS. 


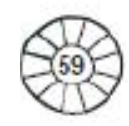

ISLAS AZORES
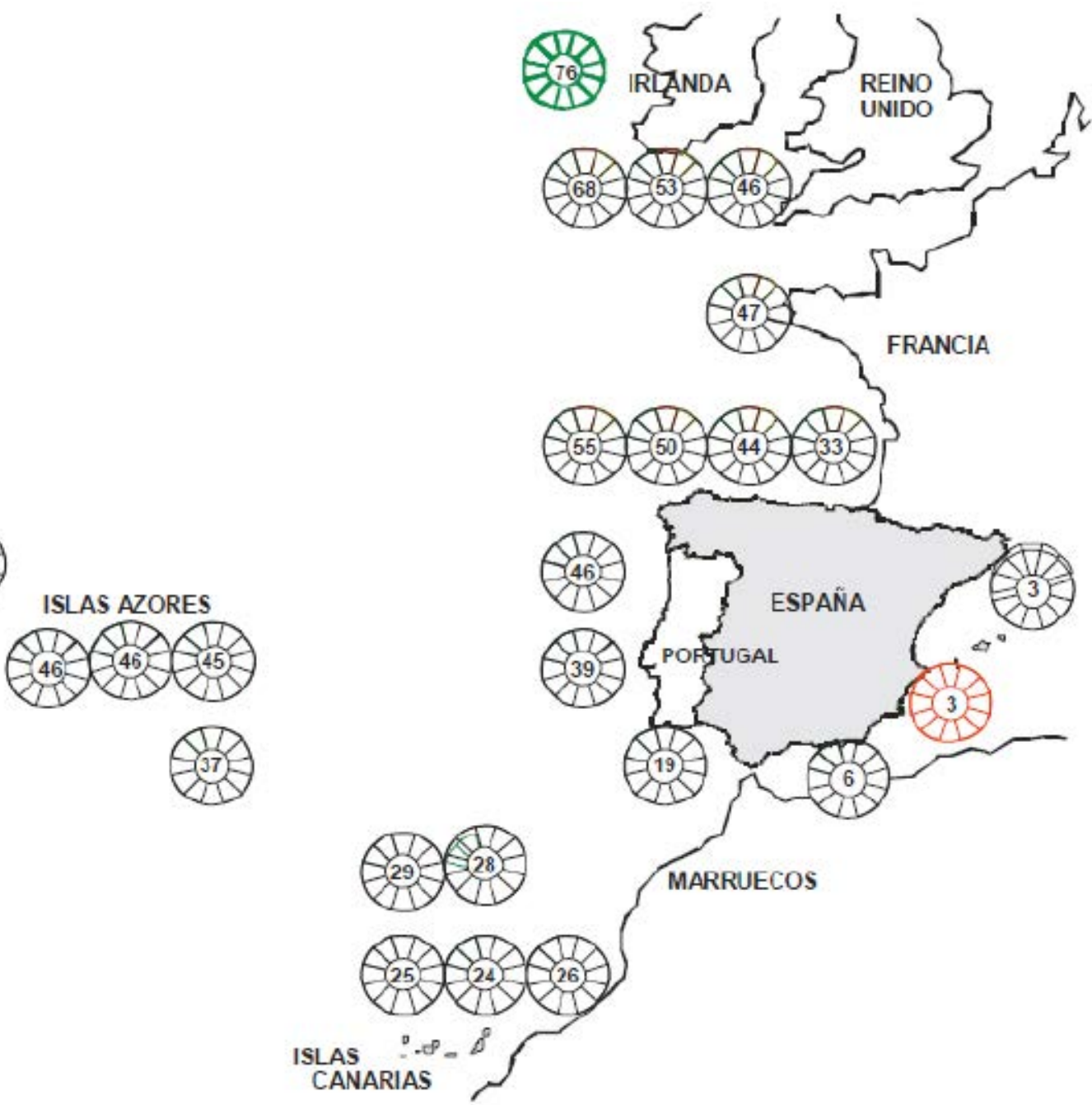

Figura 21: Distribución de energía del oleaje en aguas profundas en $\mathrm{kW} / \mathrm{m}$ a nivel Europeo (9)

\section{VENTAJAS.}

Las principales ventajas que tienen estos métodos de obtención de energías son:

$\mathrm{Al}$ absorber la energía de las olas, estos aparatos crean aguas en calma a su abrigo produciendo áreas válidas para actividades marinas, comerciales o recreativas.

Es un recurso abundante con una energía muy concentrada.

Es relativamente predecible y al poder hacer un aprovechamiento modular de los dispositivos puede extraer energía en la mayoría de las condiciones ambientales.

Es más consistente que la mayoría de las fuentes renovables.

\section{INCONVENIENTES.}

Entre otros, los principales inconvenientes de los sistemas de aprovechamiento de la energía de las olas pueden ser los siguientes: 
Irregularidad en la amplitud, fase y dirección de las olas; ello dificulta la obtención de la máxima eficiencia del aparato en todo el rango de frecuencias de excitación.

La carga estructural en el caso de condiciones climáticas extremas, tales como huracanes, pueden superar a la carga media en más de 100 veces poniendo en peligro la integridad del dispositivo.

Es necesario acoplar el lento e irregular movimiento de una ola con la mayor frecuencia de excitación (aprox. 500 veces mayor) que normalmente precisan los generadores eléctricos. Molestias y destrucción de la vida marina. Estos dispositivos pueden tener una variedad de efectos en el comportamiento del oleaje, lo que puede influir en los ecosistemas próximos, tanto en el proceso de instalación de los mismos, en este caso con el tiempo se recuperaría, como durante su explotación, por ejemplo el ruido que, aunque no influiría en las actividades humanas, puede viajar largas distancias debajo del agua y puede afectar a los mamíferos marinos.

Estos dispositivos pueden originar un incremento de la erosión de la costa o un incremento del depósito de sedimentos debido a la reducción de la acción del oleaje.

Conflictos con la navegación e interferencias con la pesca, comercial y deportiva, y con otras actividades recreativas.

TECNOLOGÍA.

Existen miles de patentes que proponen diferentes dispositivos para extraer la energía de las olas. Así mismo, existen criterios para clasificar a los distintos dispositivos que se han diseñado:

- Por la posición relativa de los dispositivos respecto de la costa: ubicados en la costa, cercanos a la costa y en alta mar.

- Por su capacidad de extraer energía: pequeña, mediana y gran capacidad.

- Por su geometría y posición relativa respecto del oleaje: los totalizadores o terminadores son dispositivos largos, que tienen su eje principal paralelo al frente de olas, es decir, perpendicular a la dirección en que las olas se mueven, y que extraen la energía de las mismas de una sola vez; los atenuadores son dispositivos largos, cuyo eje principal es paralelo a la dirección del movimiento de las olas, es decir, perpendicular al frente de olas, y que extraen la energía de forma progresiva; y los 
ESTUDIO DEL POTENCIAL DE APROVECHAMIENTO ENERGÉTICO DEL OCÉANO EN LA COSTA ANDALUZA.

Autora: Ma Pilar Blanco Fernández

captadores puntuales, que son dispositivos aislados de dimensiones reducidas que aprovecha la concentración y convergencia del oleaje.

Por su movimiento relativo respecto de las olas: Aparatos de estructura fija o inmóvil, que disponen de una estructura que se fija a la costa o al fondo del mar y aparatos flotantes o semisumergidos.

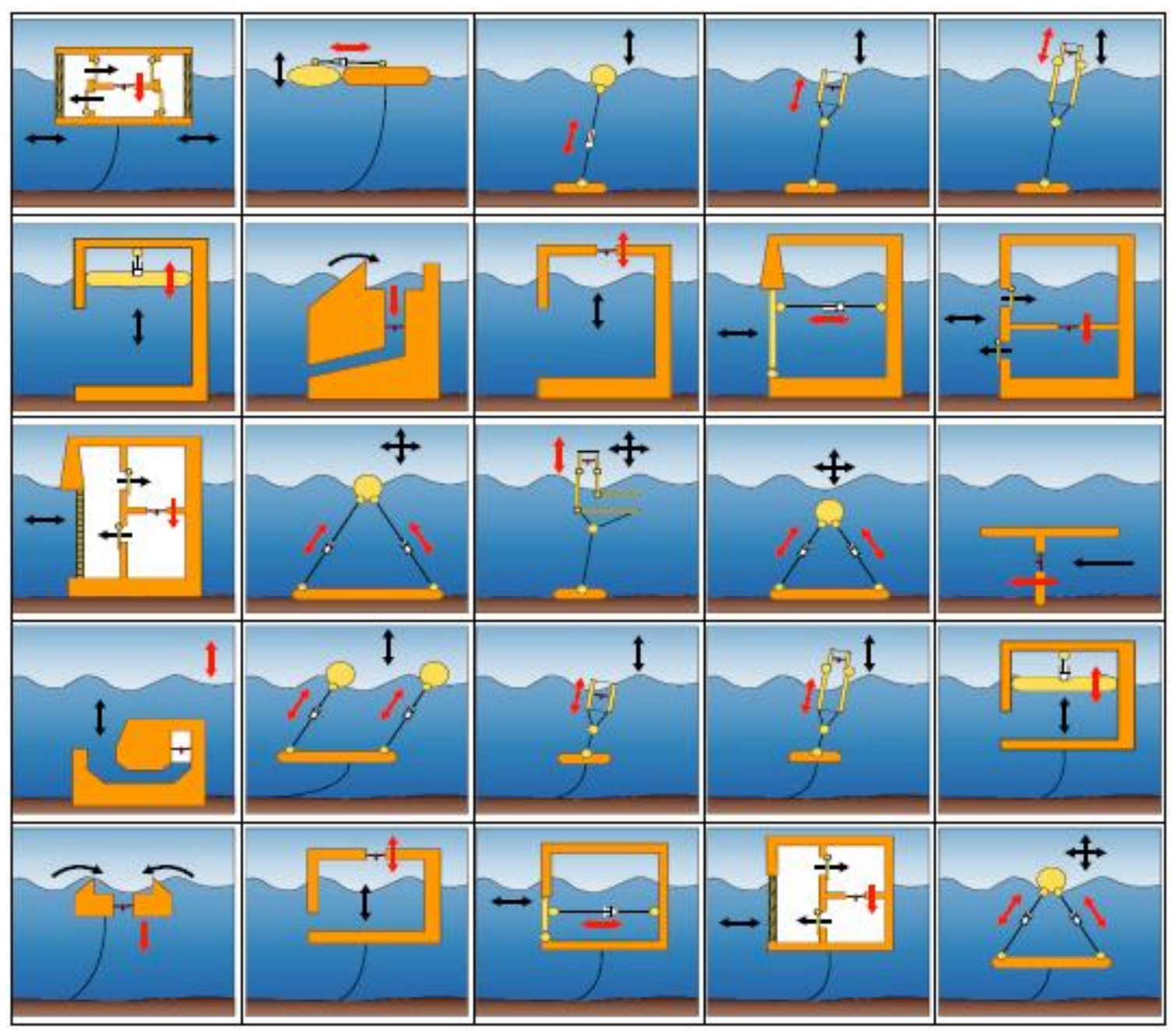

Figura 22: Diferentes tipos de dispositivos para extraer la energía de las olas (2) 


\subsubsection{DE LAS CORRIENTES}

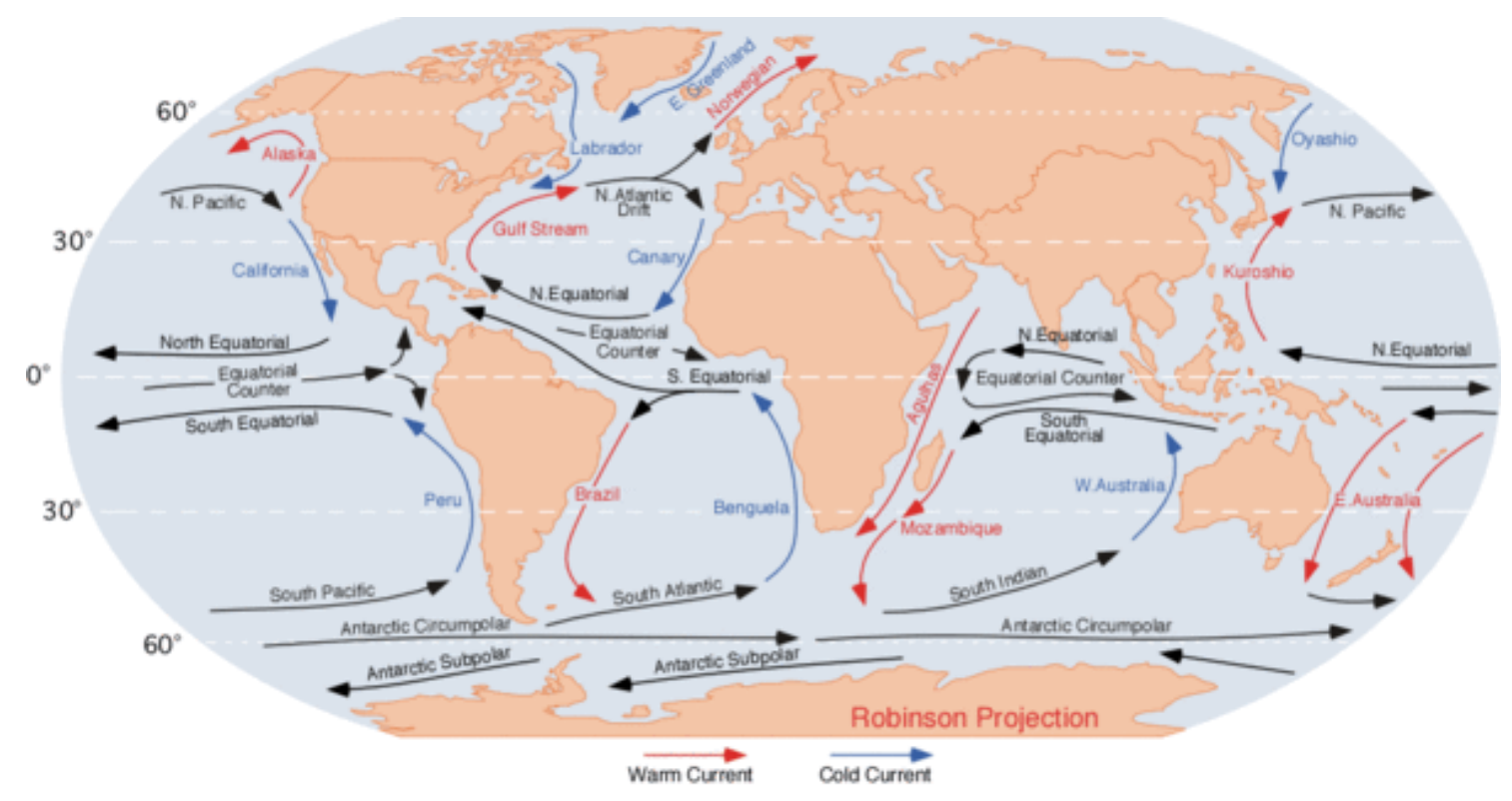

Figura 23: Principales corrientes marinas (10)

Las corrientes marinas u oceánicas son un movimiento superficial de las aguas de los océanos y de los mares más extensos. En general cuando hablamos de las corrientes marinas nos referimos a las que se producen en la superficie, mientras que las sub-marinas son movimientos de compensación de las corrientes superficiales.

Las corrientes marinas se componen de un movimiento horizontal en la superficie, generado por el viento y la inercia de la masa líquida a la rotación terrestre, y de un movimiento vertical debido a la fuerza centrífuga de la rotación de la Tierra, este movimiento se ve influenciado por la configuración del relieve submarino y de las costas, y la diferencia de temperatura de las aguas superficiales y las profundas. Otros aspectos que influyen sobre la distribución de las corrientes marinas es el efecto estacional debido al movimiento de traslación de la Tierra, las mareas y la desviación de las corrientes debido al efecto Coriolis.

Las corrientes se pueden clasificar atendiendo a varios criterios, los más utilizados son:

- Según su temperatura,

○ Cálida, flujo de aguas superficiales tiene su origen en la Zona Intertropical y se dirige, a partir de las costas orientales de los continentes, hacia latitudes medias y altas en dirección contraria a la rotación terrestre. 
- Fría, flujo de aguas frías, se mueven como consecuencia del movimiento de rotación terrestre a partir de las costas occidentales de los continentes por el ascenso de aguas frías de grandes profundidades a la superficie en la zona intertropical y subtropical.

- Según el fenómeno que la genera,

- Oceánicas, son producidas por la inercia al movimiento de rotación terrestre por lo que presentan un movimiento constante, en general, en sentido E-O en la zona intertropical o en sentido inverso en las latitudes medias o altas.

○ de Marea, son corrientes superficiales y periódicas con ciclo diario producidas por la atracción lunar y solar, ésta en menor grado.

○ de Oleaje, son producidas por los vientos, en especial, por tempestades y huracanes que se asocian al movimiento de las masas de aire tanto de origen continental como marino.

○ de Deriva Litoral, constituyen la resultante de la acción de las corrientes oceánicas al llegar a las costas cuyo trazado presenta alguna inclinación o desviación con respecto a la dirección original de las mismas.

- de Densidad, es debida a la disminución de la temperatura (y aumento de la densidad) de la masa de agua a medida que hay más profundidad. Su efecto es más pronunciado en los estrechos.

- Según la profundidad,

- De Impulsión, son movimientos verticales generados debajo de los $1000 \mathrm{~m}$ de profundidad que se mueven hacia la superficie para compensar a las corrientes superficiales.

○ De gradiente o descarga, son movimientos horizontales superficiales generados por la rotación de la Tierra y están afectadas por los vientos predominantes. Son corrientes circulares o espirales con giro hacia la derecha en latitudes próximas al Trópico de Cáncer y hacia la izquierda en el Trópico de Capricornio.

\section{VENTAJAS}

Posibilidad de predecir su disponibilidad

Factores de capacidad del 40 al 60\%. 
Impacto medioambiental mínimo, no producen contaminación visual, polución o ruido y no afectan a la vida marina ya que sus rotores son lo suficientemente lentos.

Al situarse por debajo de la superficie del mar los daños producidos por las tormentas son bajos.

Se puede predecir con exactitud las cargas máximas que deben soportar, que serán siempre del orden de las de diseño, y no necesitan de ninguna torre que soporte su peso ya que se pueden dejar flotando amarradas al fondo, de forma que se orienten por la propia corriente. INCONVENIENTES

Impacto para la navegación, ya que las mejores corrientes se encuentran en zonas ubicadas principalmente en estrechos o desembocaduras de ríos con gran tránsito marino.

Si se colocan cerca de la superficie del agua pueden tener problemas por crecimiento de algas y microorganismos en la superficie del dispositivo.

Uno de los condicionantes principales a la hora de introducir equipos de extracción de la energía de las corrientes marinas es la presencia de un fondo irregular o inclinado. TECNOLOGÍA

El proceso de captación se basa en convertidores de energía cinética similares a los aerogeneradores.

El rotor de la turbina va montado en una estructura apoyada en el fondo o suspendida de un flotador. Es conveniente que la posición del rotor esté próxima a la superficie para aprovechar la zona donde las velocidades del agua son más altas.

La energía extraíble es función del diámetro del rotor de la turbina y de la velocidad de las corrientes. En los equipos actuales, necesitan de una velocidad máxima de la corriente superior a $3 \mathrm{Kn}$ para poder ser utilizable, siendo necesarios en muchos casos valores medios de 2 a $4 \mathrm{~m} / \mathrm{s}$ para obtener valores de rentabilidad proyectada suficientes.

Una opción es montarlas en el interior de conductos que, a la vez de protegerlas, dirigen y aumentan/disminuyen la velocidad del flujo y su presión aguas abajo del dispositivo. Los rotores pueden ser axiales (tipo hélice de eje horizontal) o de flujo cruzado (tipo Giromill de eje vertical) Las turbinas se pueden colocar sobre el lecho marino, previamente acondicionado (20-30 m. de profundidad) o sobre un sistema flotante con los convenientes amarres (50 m. de profundidad) 

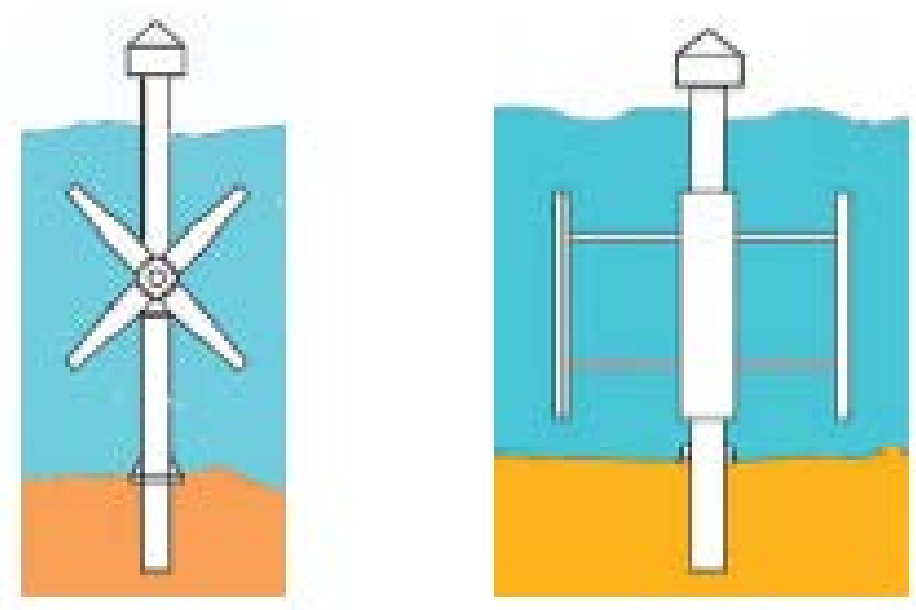

Figura 24: Rotor axial y de flujo cruzado (8)

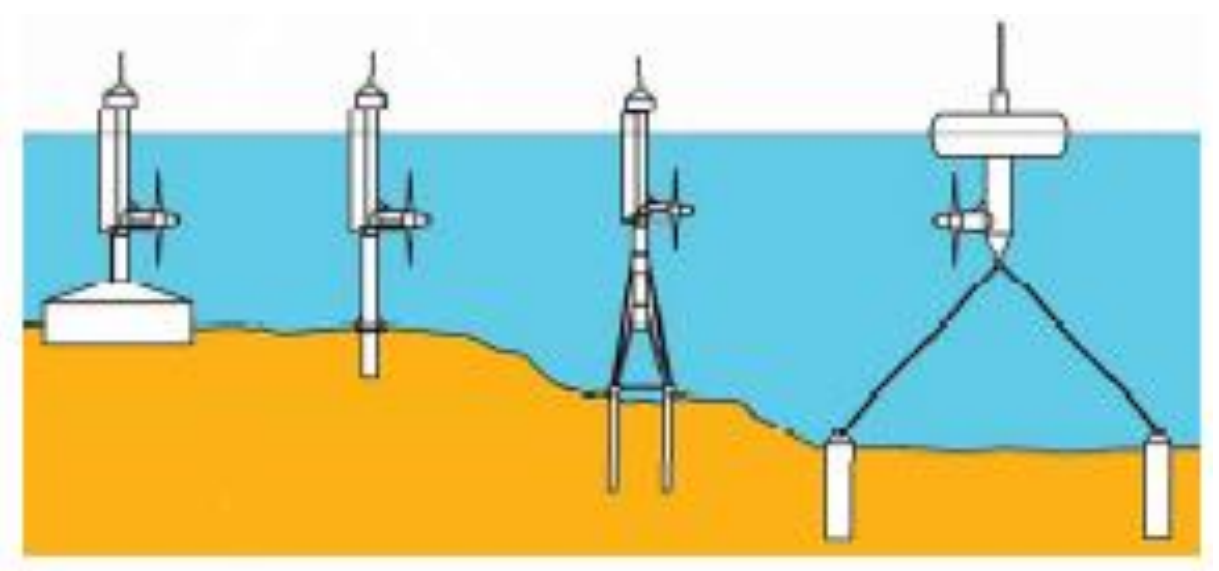

Figura 25: Esquemas de estructuras soporte (8)

Otro tipo de tecnología que se ha desarrollado para el aprovechamiento de las corrientes marinas consiste en hidrodeslizadores. Se trata de un hidrodeslizador acoplado a un brazo oscilante cuyo movimiento está provocado por el empuje de elevación de la corriente sobre una superficie parecida a un ala. Este movimiento bombea un fluido hidráulico a una turbina para generar electricidad.

\subsubsection{DE LAS MAREAS O MAREOMOTRIZ.}

La energía mareomotriz es la que se obtiene gracias al movimiento generado por las mareas.

Las mareas son movimientos oscilatorios del nivel del mar con origen en la fuerza de atracción gravitatoria que ejercen sobre las partículas líquidas de los océanos el Sol y la Luna, ésta en mayor medida por estar más cerca. 
ESTUDIO DEL POTENCIAL DE APROVECHAMIENTO ENERGÉTICO DEL OCÉANO EN LA COSTA ANDALUZA.

Autora: Mạ Pilar Blanco Fernández

El comportamiento de las mareas y su desnivel depende de la posición relativa de la Tierra, el Sol y la Luna y de la proporción mares-tierra, de su distribución geográfica, de la topografía local, de la profundidad de las cuencas oceánicas, de los fenómenos meteorológicos y otros factores.

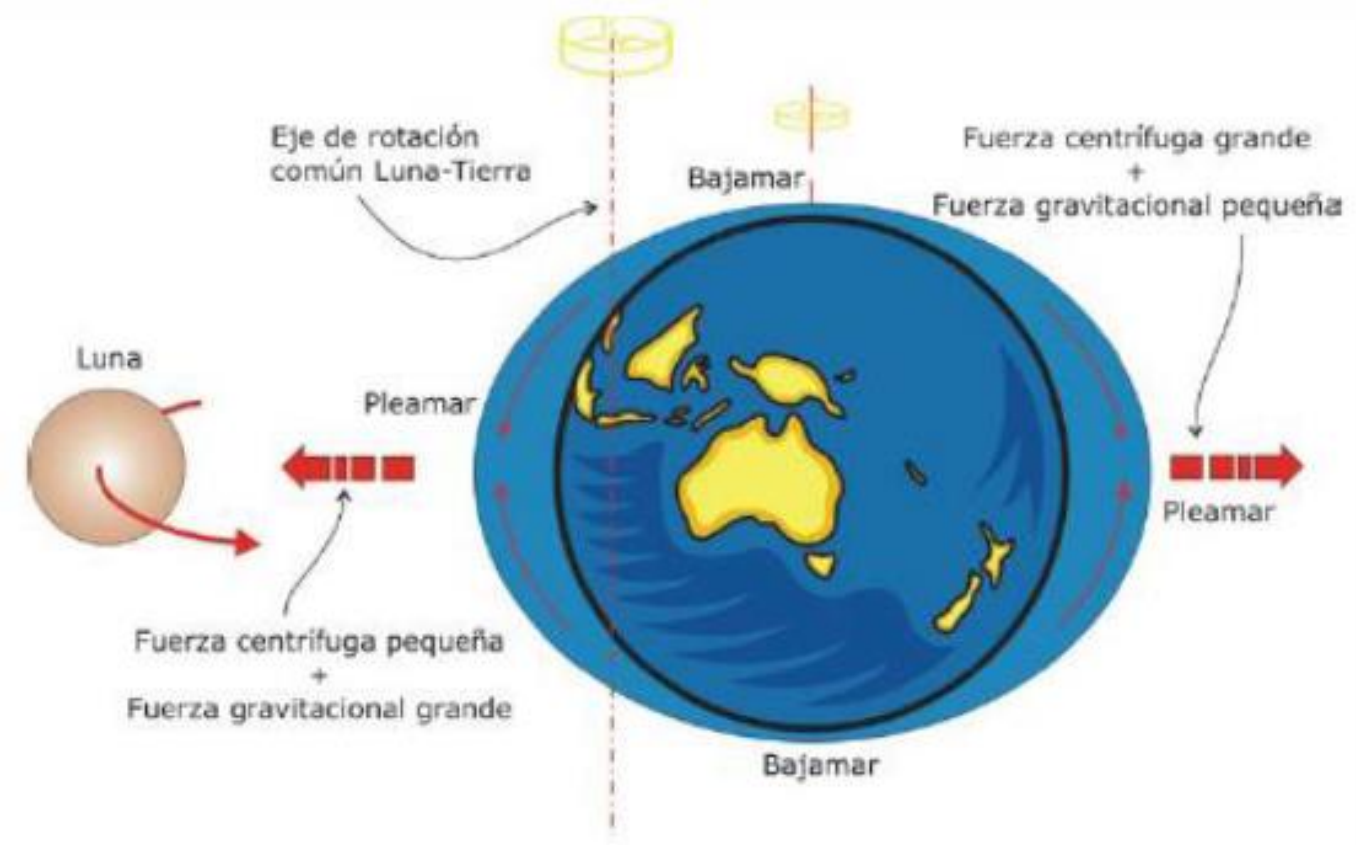

Figura 26: Origen de las mareas (2)

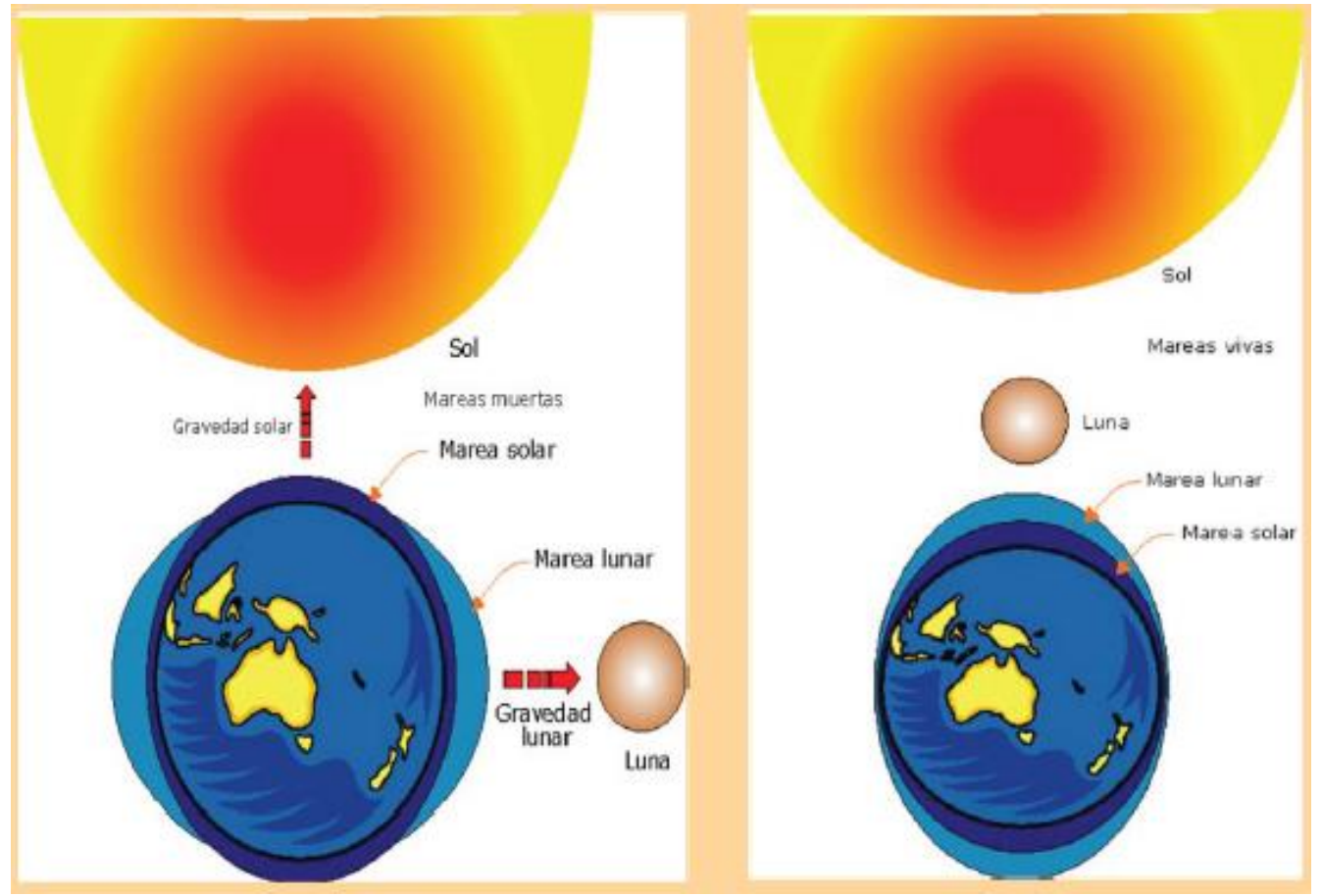

Figura 27: Mareas vivas y mareas muertas (2) 
Las pleamares y bajamares se producen dos veces al día.

Durante las fases de Luna nueva y llena, cuando el Sol, la Luna y la Tierra están alineados, las ondas producidas por la atracción del Sol y la de la Luna coinciden creando las mareas vivas con pleamares más altas y bajamares más bajas que las mareas promedio.

Sin embargo cuando la Luna está en el primer o tercer cuadrante las ondas están sometidas a fuerzas opuestas con lo cual la amplitud de la marea es menor que el promedio. Es el fenómeno conocido como marea muerta, donde las mareas altas son más bajas y las bajas más altas que lo habitual.

Tanto las mareas vivas como las muertas se producen 60 horas después de las fases correspondientes de la Luna, dando lugar a la edad de la marea o de la fase de desigualdad. La amplitud de las mareas, diferencia entre el nivel más alto y más bajo, suele ser pequeña en medio del océano pero puede alcanzar hasta $20 \mathrm{~m}$ en determinadas zonas costeras. La amplitud de las mareas da lugar a que el agua de los mares contenga energía cinética, denominada mareomotriz.

Para el aprovechamiento eficaz de la energía mareomotriz es necesario que la amplitud de las mareas sea al menos de cinco metro y que exista una bahía apropiada para la recogida y almacenamiento del agua de las pleamares.

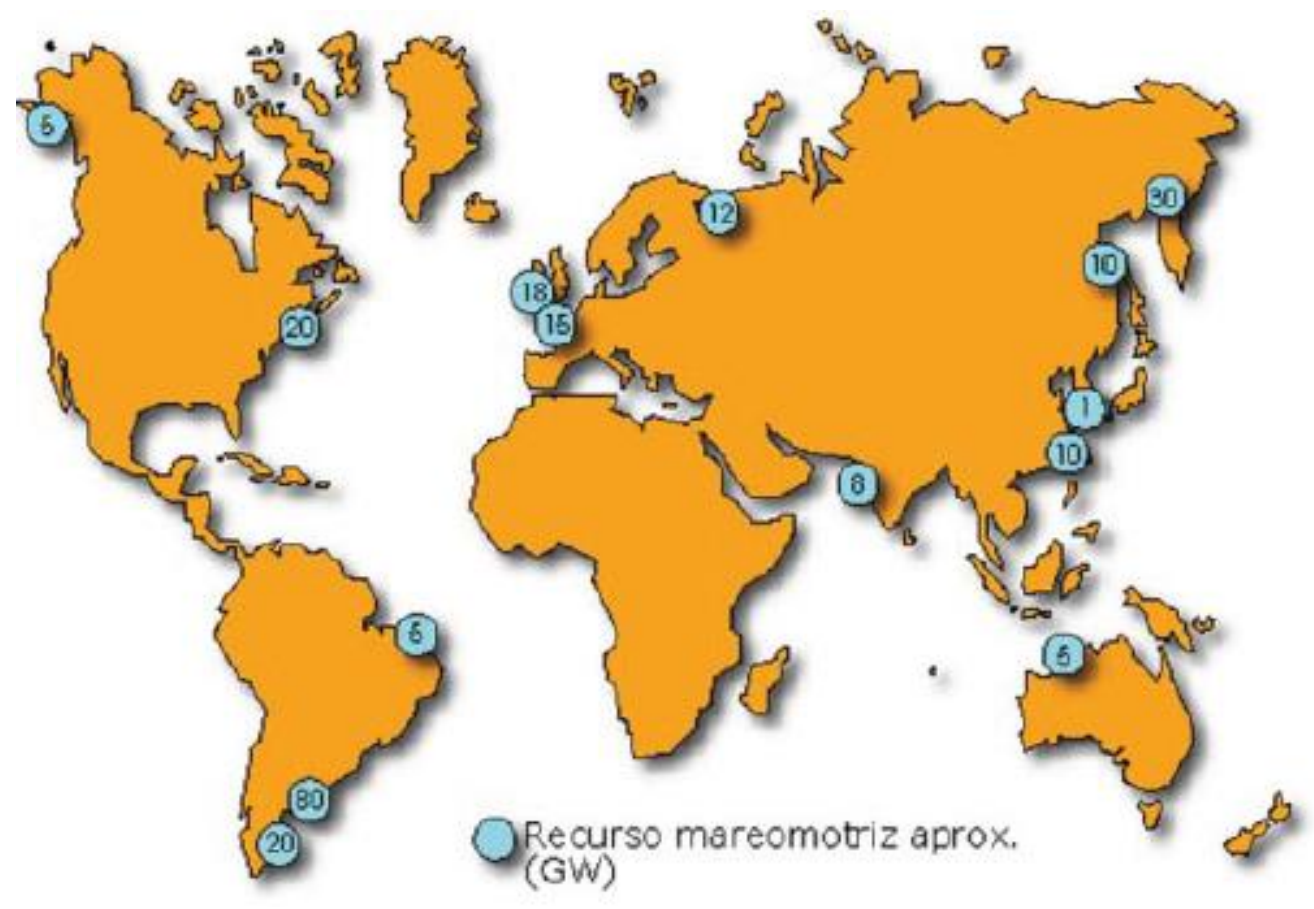

Figura 28: Lugares del mundo con recursos mareomotrices (2) 


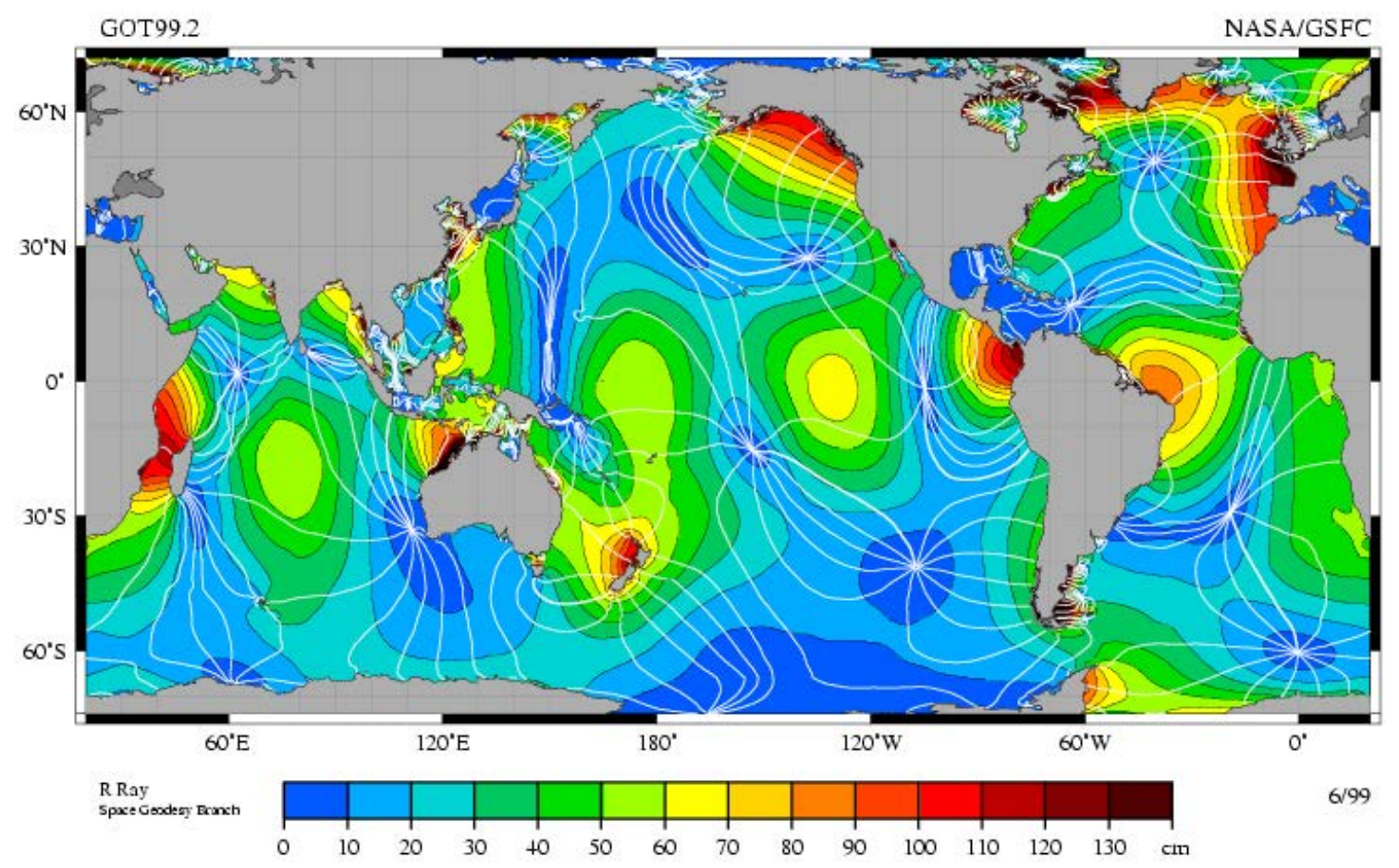

Figura 29: Mapa mundial de amplitud de mareas (11)

\section{VENTAJAS:}

Las mareas son predecibles y su suministro es seguro con un potencial que no varía de forma trascendental anualmente, solo se limita a los ciclos de mareas y corrientes.

La vida de estas instalaciones puede superar los 75 años.

Los costes de operación (combustibles) son nulos.

\section{INCONVENIENTES:}

El periodo durante el cual se puede generar energía es menor que el de un sistema convencional. Por tanto se necesita invertir en equipos de gran capacidad que solo se usan intermitentemente para reemplazar una cantidad limitada de la energía generada por una planta convencional lo que hace que tengan un costo alto en comparación con la mayoría de los otros tipos de plantas eléctricas.

Requieren mucho tiempo para recuperar el valor de la inversión.

Tienen un impacto ambiental negativo en los ecosistemas de los estuarios y las marismas ya que modifica el paisaje de la costa.

TECNOLOGÍA: 
La amplitud de la marea se puede aprovechar mediante la construcción de diques que cierran bahías para almacenar el agua durante la pleamar. Se retiene hasta la bajamar y se libera en las horas intermareales para aprovechar la energía potencial originada por el desnivel mar-dique haciendo pasar el agua a través de turbinas que, acopladas a un generador eléctrico, producen electricidad.

Cuando la instalación se diseña para aprovechar la energía únicamente en la etapa de vaciado de un estuario (durante la bajamar) se dice que opera en un ciclo elemental de simple efecto. Sólo se aprovecha el flujo de agua en un sentido así que solo se aprovechan dos periodos diarios para generación eléctrica. 
ESTUDIO DEL POTENCIAL DE APROVECHAMIENTO ENERGÉTICO DEL OCÉANO EN LA COSTA ANDALUZA.

Autora: Ma Pilar Blanco Fernández
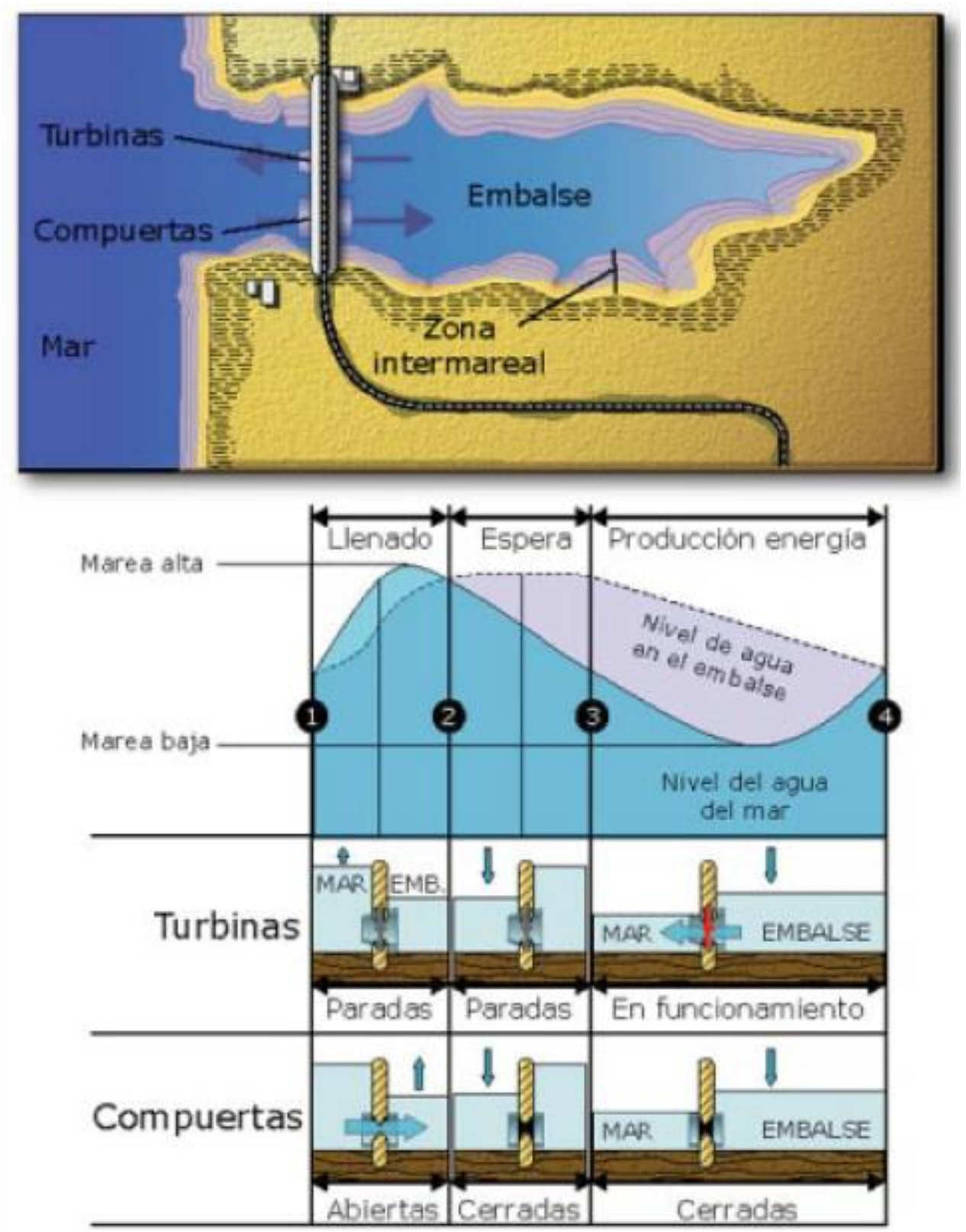

1 Paro de las turbinas y apertura de las compuertas
Cierre de las compuertas
3. Puesta en marcha de las turbinas
4 Paro de las turbinas y apertura de las compuertas

Figura 30: Esquema de una central mareomotriz de ciclo elemental de efecto simple (2)

Para aprovechar la energía del agua en los dos sentidos se diseñan instalaciones que operan según un ciclo elemental de doble efecto. Estas instalaciones pueden disponer de turbinas de doble sentido. 
ESTUDIO DEL POTENCIAL DE APROVECHAMIENTO ENERGÉTICO DEL OCÉANO EN LA COSTA ANDALUZA.

Autora: Mạ Pilar Blanco Fernández
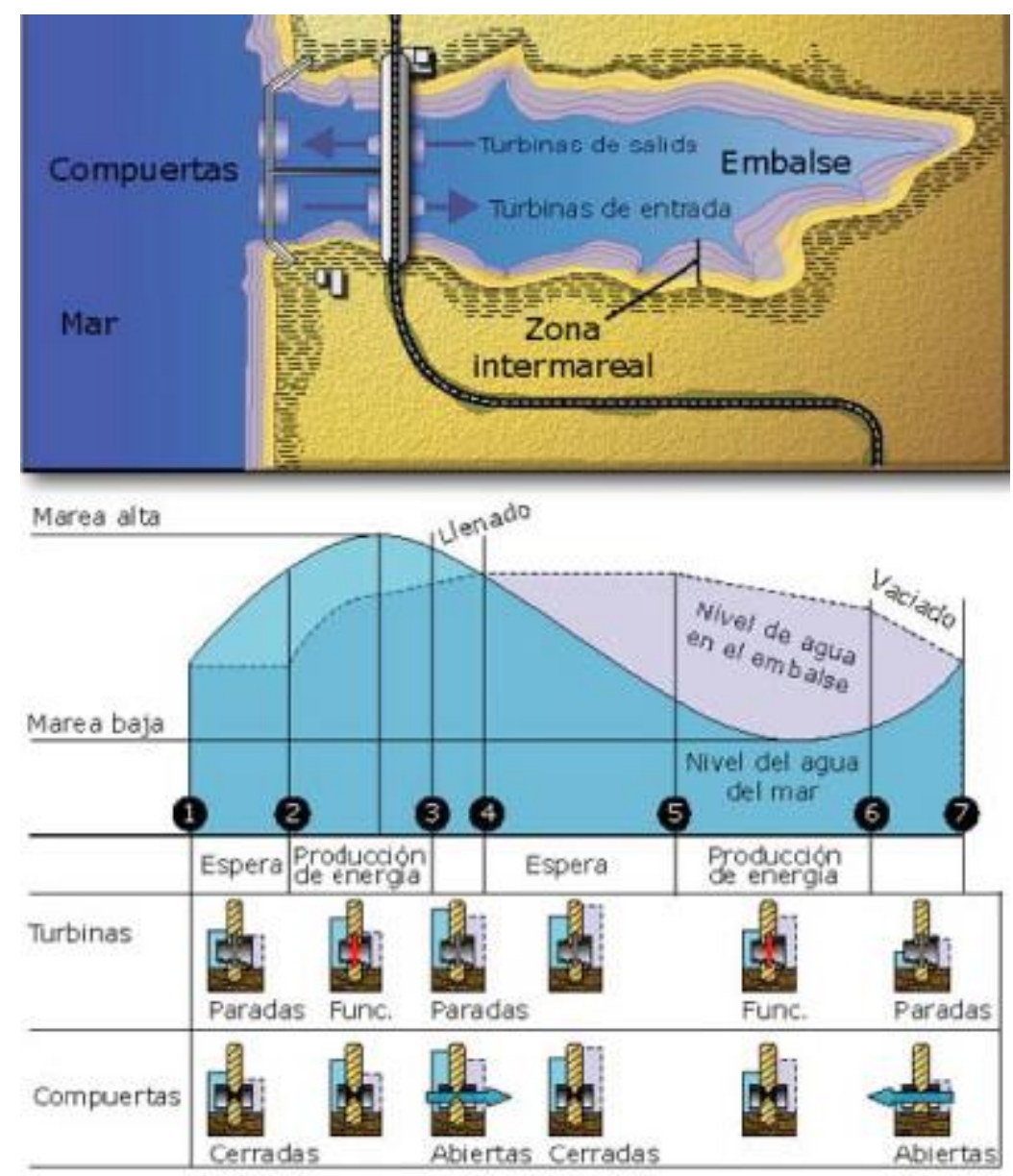

(1) Cierre de las compuertas

2 Puesta en marcha de las turbinas

(3) Paro turbinas, apertura de compuertas

4 Cierre de compuertas

(5) Puesta en marcha turbinas

6 Paro turbinas, apertura de compuertas

$(7$ Clerre de compuertas

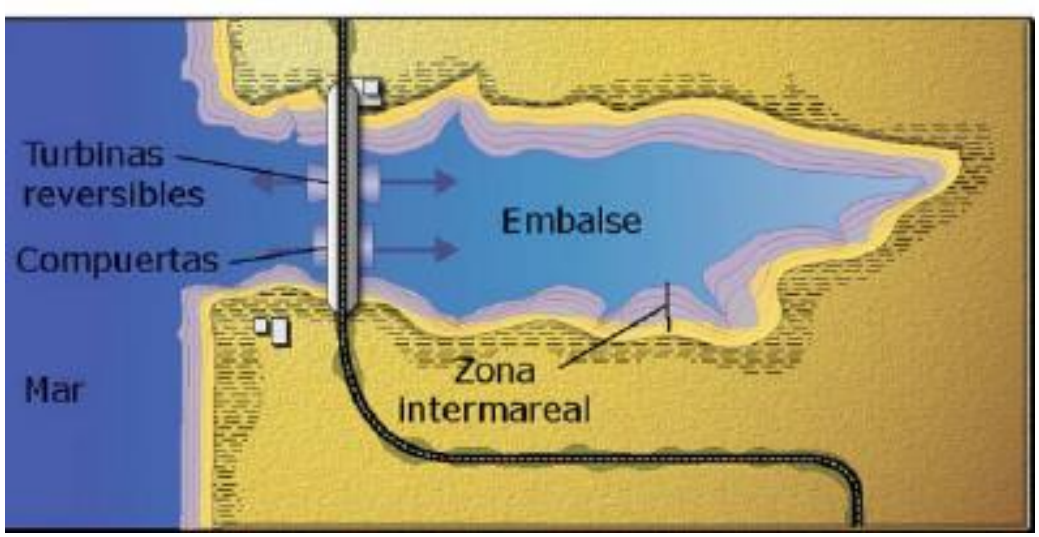

Figura 31: Esquema de central mareomotriz de doble efecto (2) 
Por último, se han diseñado instalaciones de ciclo múltiple. Utilizan varios embalses para minimizar los valles de producción energética que se producen en las instalaciones de ciclo elemental.

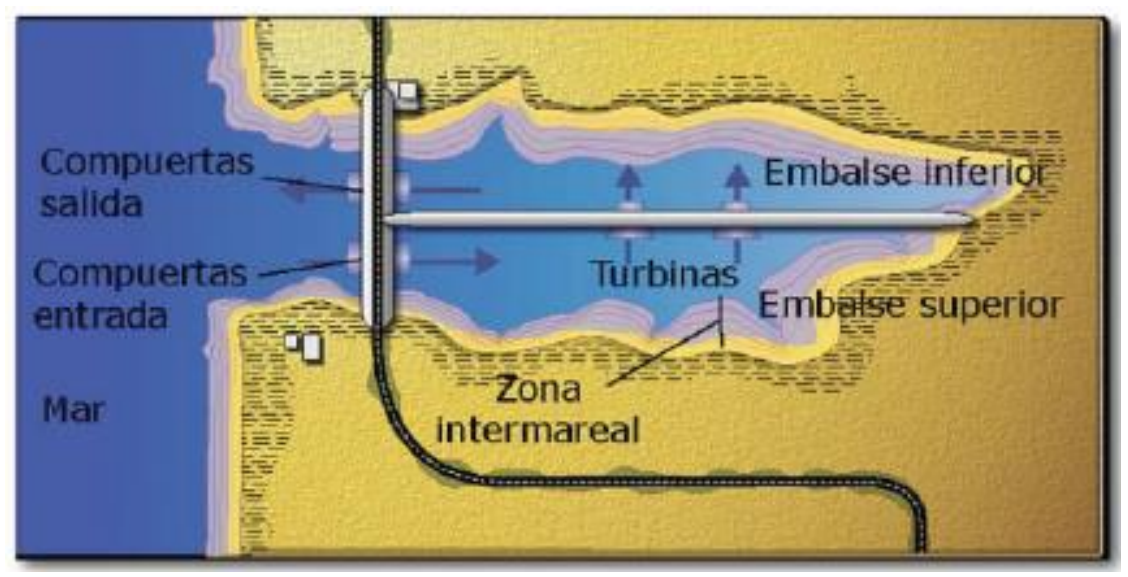

Figura 32: Esquema de central mareomotriz de ciclo múltiple (2)

En cualquiera de las configuraciones los componentes básicos son los mismos: turbinas (reversibles o no), diques, compuertas, generadores eléctricos, subsistema de control e infraestructura de transporte de la energía eléctrica generada.

Como en las centrales mareomotrices los saltos de agua son relativamente pequeños las turbinas más adecuadas son las de hélice de flujo axial y de alta velocidad. Los tipos más utilizados son la turbina de bulbo axial, la turbina Kaplan tubular y la turbina de rotor anular, en éste caso el generador eléctrico está integrado en la turbina alrededor del rodete de los álabes.

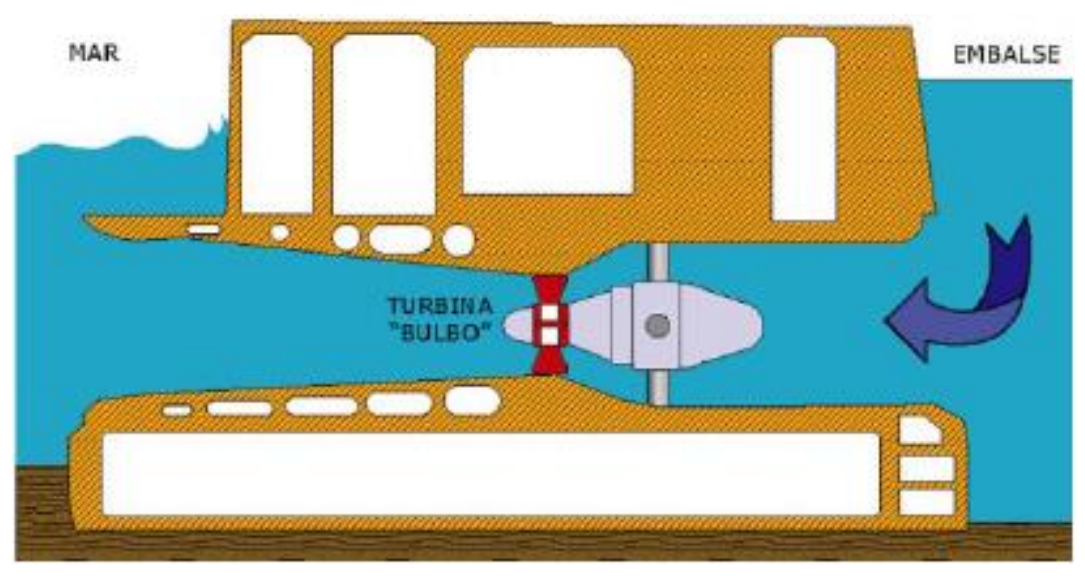

Figura 33: Turbina de bulbo axial (2) 


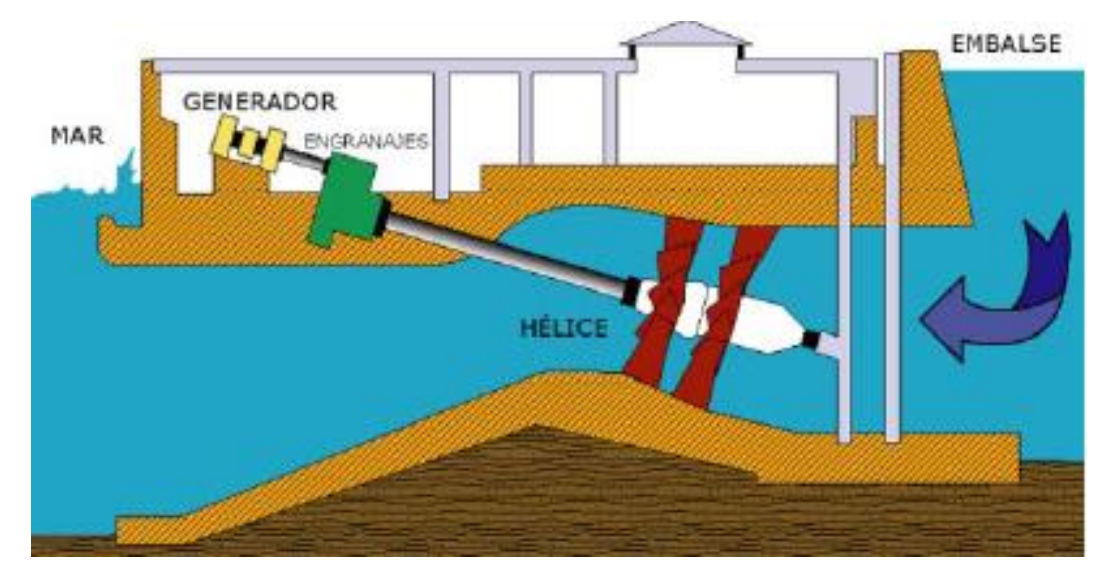

Figura 34: Turbina Kaplan tubular (2)

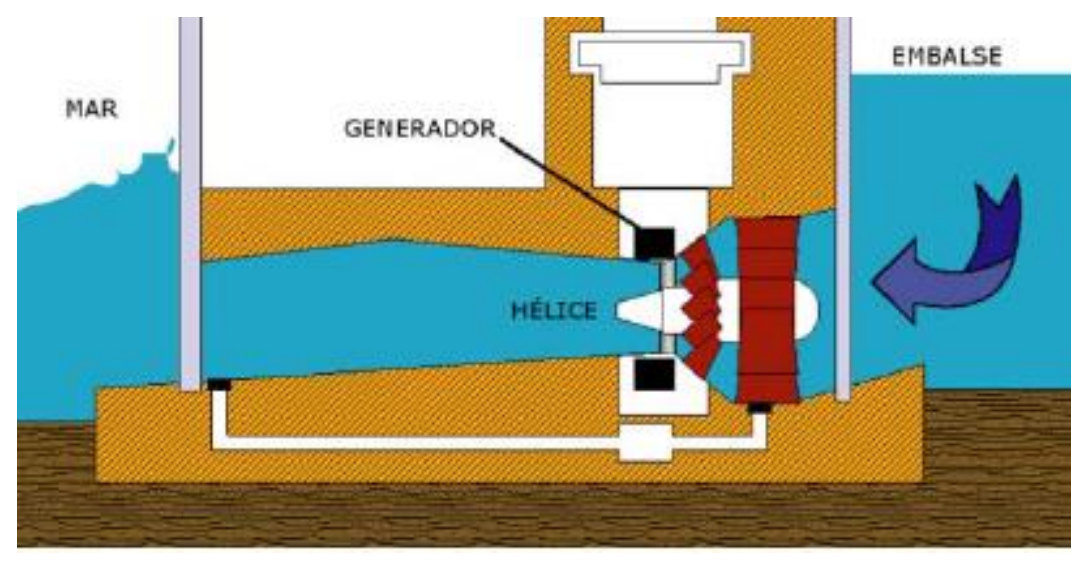

Figura 35: Turbina de rotor anular (2)

\subsubsection{DEL GRADIENTE TÉRMICO}

Las radiaciones que llegan a la superficie terrestre desde el Sol están formadas por ondas de pequeña longitud de onda. Parte de esta radiación es absorbida por el ozono de la estratosfera y otra parte es reflejada por las nubes, aproximadamente un 34\%. El 66\% restante es absorbida por la superficie terrestre.

Existe un equilibrio anual entre la energía absorbida por la Tierra y la que ésta emite de nuevo al espacio. Si no fuera así la Tierra sufriría un incremento continuo de temperatura, aproximadamente $1^{\prime} 5^{\circ} \mathrm{C}$ diarios.

Como dos terceras partes de la superficie terrestre están cubiertas de agua y el 97'7\% se encuentra en el mar, la mayor parte de la radiación solar absorbida por la Tierra se hace por el mar.

Debido a que el calor específico del mar es más alto que el de la tierra, aquél se enfría y calienta más lentamente. Sin embargo, en la tierra la radiación solar se queda casi toda en la 
superficie mientras que en el agua del mar la radiación solar penetra hasta los mil metros (de promedio $100 \mathrm{~m}$ ).

Todo esto hace que el mar sea el colector solar y el sistema de almacenamiento de energía más grande del mundo. Además, la gran inercia térmica de los océanos permite que la temperatura sea más estable en ellos y menos marcados sus cambios, tanto en el transcurso del día y la noche como de las estaciones.

Conforme se profundiza en el mar la intensidad de la radiación decrece y la temperatura disminuye. Simplificando se puede decir que la distribución vertical de temperaturas del océano abierto consiste en dos capas.

Una capa superior de agua relativamente caliente con una temperatura uniforme (desde los 20 a los 200m dependiendo de las condiciones locales). Debajo de esta capa hay una zona de transición llamada Termoclina, en algunos lugares se presenta como un descenso brusco de la temperatura aunque generalmente la transición es gradual.

Esta franja (entre los 200 y 400m) separa las aguas superficiales, menos densas y menos salinas, de las profundidades, más frías, densas y salinas. La temperatura de la capa inferior decrece progresivamente hasta alcanzar $4^{\circ} \mathrm{C}$ a $1 \mathrm{Km}$. En profundidades de $1500 \mathrm{~m}$ o mayores, en cualquier parte del mundo, la temperatura del agua es inferior a $4^{\circ} \mathrm{C}$ independientemente de la temperatura superficial.

En las profundidades de los abismos (a $11 \mathrm{Km}$ de la superficie), la temperatura es menor a

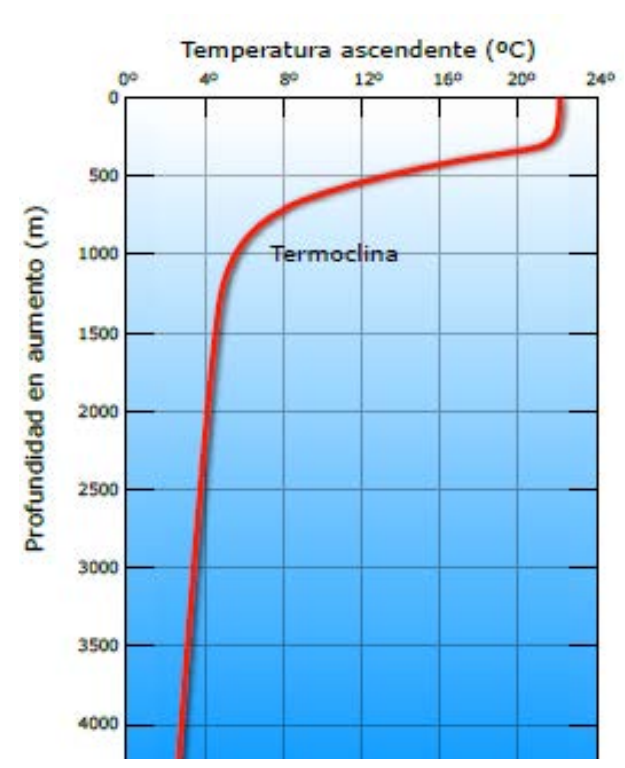
$2^{\circ} \mathrm{C}$.

La diferencia de temperaturas entre la capa superior y la inferior varía entre $10^{\circ} \mathrm{C}$ y $25^{\circ} \mathrm{C}$ dependiendo de la zona del planeta, hallándose los valores más elevados en las aguas ecuatoriales. Esto da lugar a que se almacene una importante cantidad de energía calorífica denominada energía Maremotérmica. Para el aprovechamiento de esta energía se requiere que el gradiente térmico sea al menos de $20^{\circ} \mathrm{C}$.

Figura 36: Distribución genérica de la temperatura en mar abierto (2) 


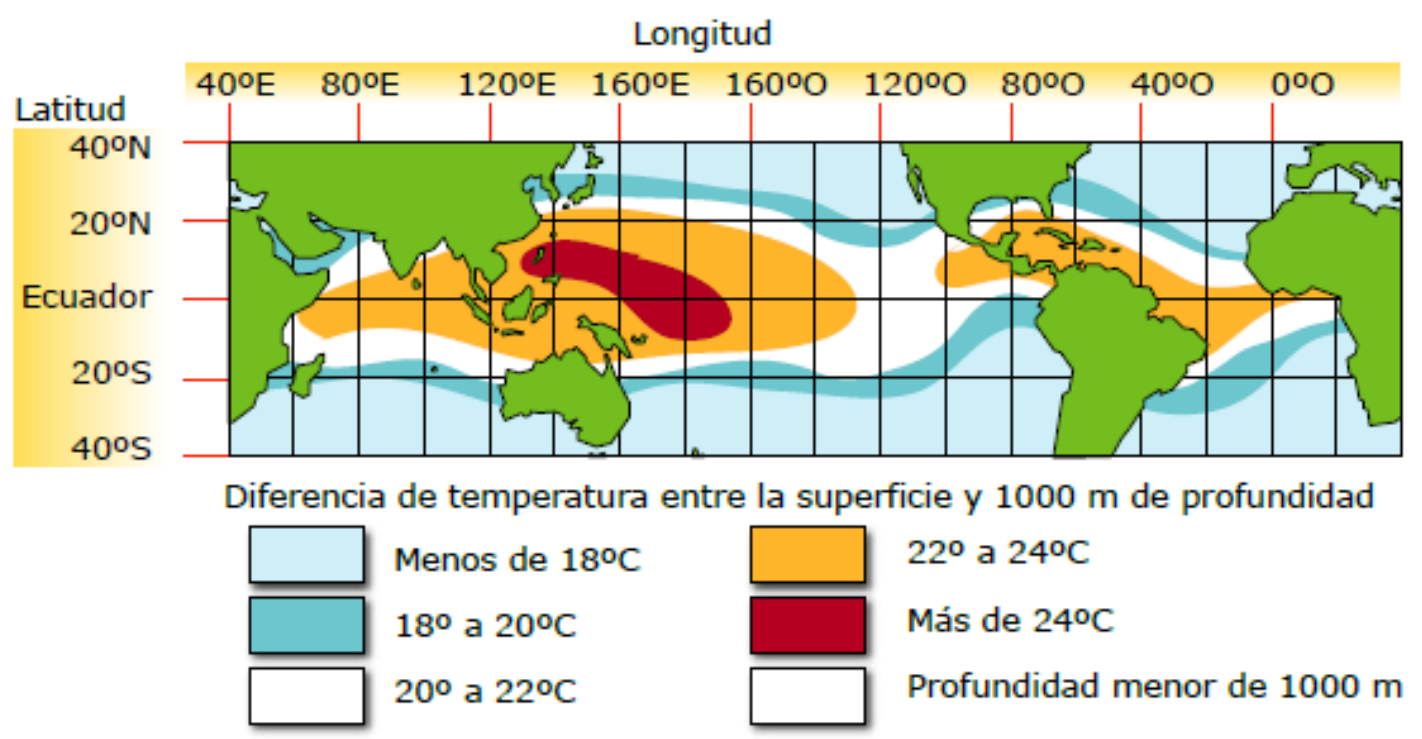

Figura 37: Distribución de los gradientes de temperatura (2)

TECNOLOGÍA:

En las plantas CETO (Conversión de Energía Térmica del Océano) se transforma la energía térmica en energía eléctrica utilizando el ciclo de Rankin. En este ciclo se emplea calor para evaporar un fluido de trabajo cuya presión de vapor sea bastante grande a las temperaturas de la superficie del océano que posteriormente se utiliza para el accionamiento de una turbina, la cual se acopla a un generador eléctrico.

Además de las condiciones impuestas en la presión de vapor del fluido, una planta CETO requiere unas enormes dimensiones de los sistemas de circulación de las corrientes templada y fría; hay que hacer notar que el agua fría se bombea desde profundidades de 600 a $900 \mathrm{~m}$.

Existen básicamente tres tipos de sistemas para el aprovechamiento de esta fuente de energía:

- Sistemas de ciclo abierto.

- Sistemas de ciclo cerrado.

- Sistemas de ciclo híbrido. 

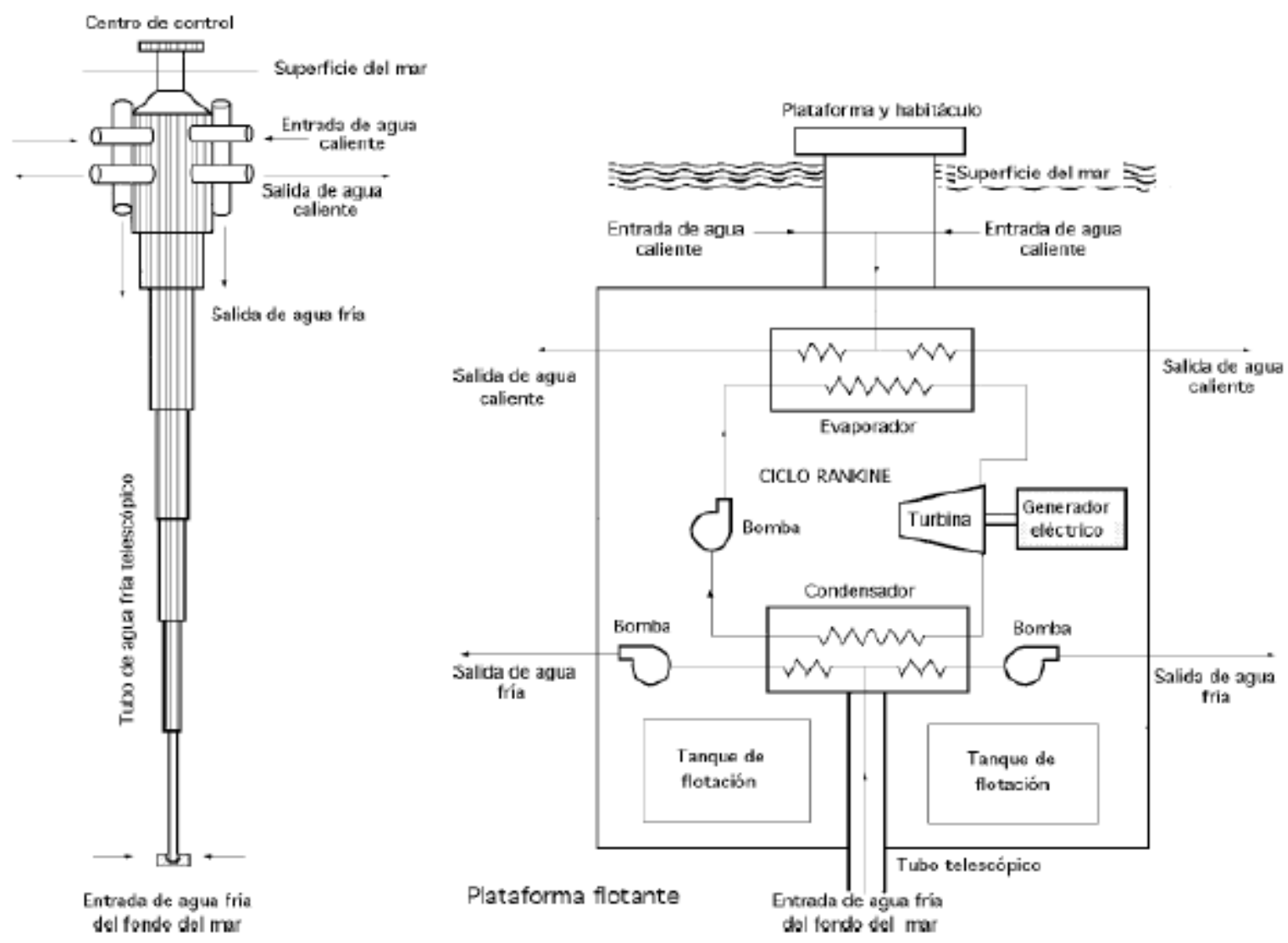

Figura 38: Disposición esquemática de una central C.E.T.0. de 100MW (8)

\section{VENTAJAS.}

La fuente de energía es prácticamente inagotable

Las plantas CETO podrían obtener determinados productos como el aluminio, el metanol o el amoniaco para la industria de fertilizantes.

El hidrógeno líquido también se podría producir y llevarse a la costa para utilizarlo en celdas de combustible.

\section{INCONVENIENTES.}

Obstrucción de las superficies intercambiadoras de calor por organismos marinos.

El rendimiento de una máquina térmica está limitado por el Principio de Carnot por lo que una máquina del tipo CETO tendría un rendimiento máximo del 8.6\%. 


\subsubsection{SOLAR}

El Sol es el origen de la energía solar y de las otras fuentes renovables de energía. Debido a los procesos de fusión nuclear que se producen en la estrella emite al espacio energía en forma de radiación electromagnética constantemente.

Una parte de dicha radiación llega a la atmósfera terrestre, aproximadamente $1367 \mathrm{~kW} / \mathrm{m}^{2}$. De ésta el 16\% es absorbida por la estratosfera y la troposfera y el 22,5\% por el suelo; el 4\% es reflejada directamente al espacio desde el suelo.

La atmósfera difunde el 17,5\% de la radiación, del cual el 10,5\% es absorbido por el suelo y el $7 \%$ regresa al espacio exterior.

Las nubes reflejan al espacio exterior un 24\%, absorbiendo un 1,5\% y enviando al suelo, como radiación difusa, el 14,5\% que es absorbido por él.

En resumen, sólo llega al suelo el 47,5\% (aproximadamente 900W/m²) de la radiación solar que llega a la Tierra. Esta energía alcanza la superficie de la Tierra de tres maneras:

- Radiación directa, incide sobre los objetos iluminados por el Sol sin haber interaccionado con nada y sin cambiar de dirección (días soleados)

- Radiación difusa, incide indirectamente, como reflejo de la radiación solar que es absorbida por las partículas en suspensión de la atmósfera (días nublados)

- Radiación reflejada o albedo, procede de la reflexión de la radiación directa en los elementos del entorno (reflejo en el agua o en la nieve)

La distribución de la energía solar que llega a la superficie terrestre no es uniforme, depende de factores como el grado de nubosidad, la turbidez atmosférica, vientos predominantes, época del año, latitud del lugar, orientación de la superficie,... En la Figura 39 se representa un mapa estimativo de la radiación solar en el Mundo, en $\mathrm{W} / \mathrm{m}^{2}$. Puede observarse que la radiación es superior en las zonas ecuatoriales y tropicales e inferior en las zonas polares. 


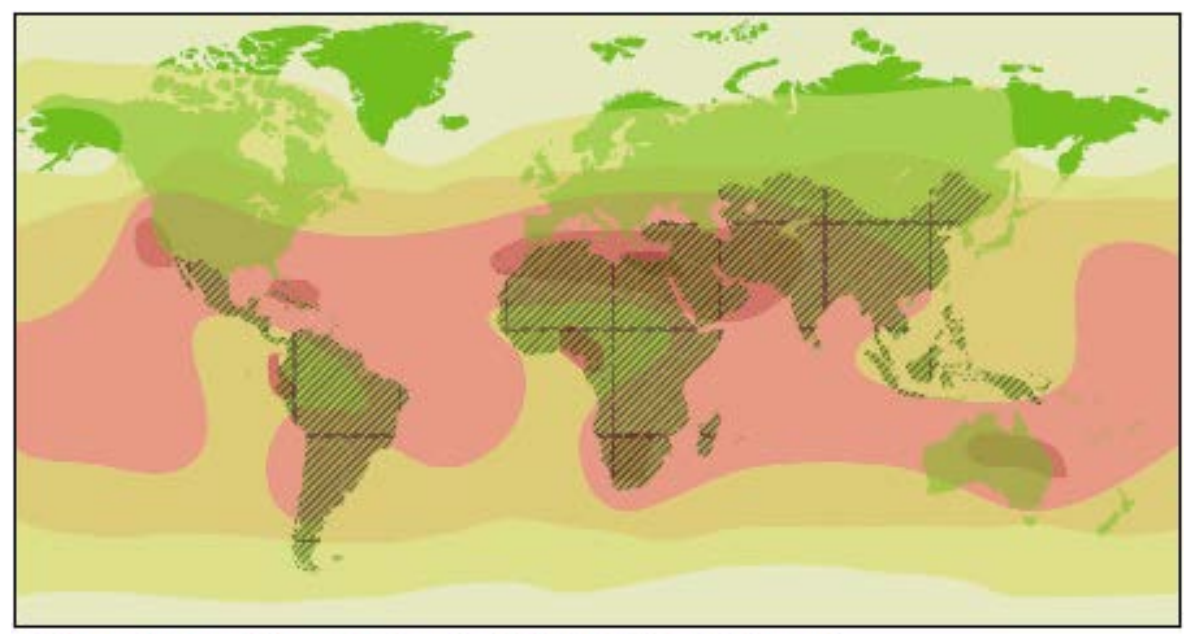

Promedio anual de radiación solar (Watios $/ \mathrm{m}^{2}$ en 24 horas)

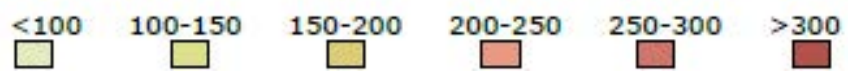

Figura 39: Mapa estimativo de la radiación solar en el mundo (2)

En cualquier caso hay que tener en cuenta que no toda la radicación puede ser transformada por los dispositivos tecnológicos existentes para su utilización en forma de potencia calorífica o eléctrica ya que hay que tener en cuenta los rendimientos de los equipos de transformación energética.

VENTAJAS.

Reducción de la emisión de contaminantes a la atmósfera.

La rentabilidad de las instalaciones solares térmicas es mayor cuanto más elevado sea el número de usuarios.

No produce contaminación por posibles derrames de fluidos de trabajo.

Evita el uso de combustibles fósiles.

\section{INCONVENIENTES.}

Impacto visual de las instalaciones, en caso de ser térmicas de baja temperatura se pueden integrar dentro de las edificaciones minimizando el impacto.

Sus costes de explotación son aún muy altos.

Hay que hacer frente a la variabilidad de la radiación solar y a las incertidumbres meteorológicas.

TECNOLOGÍA.

En la actualidad, la tecnología que se utiliza para captar la energía solar directa y convertirla en una forma útil de energía se ha desarrollado en dos direcciones: 
Tecnología de conversión térmica, que absorbe la energía solar y la transforma en calor. Si utilizamos una máquina termodinámica podríamos transformar esta energía térmica en electricidad.

Tecnología de conversión eléctrica, que permite la transformación directa de la energía solar en energía eléctrica, tecnología solar fotovoltaica.

La energía térmica captada puede utilizarse de forma pasiva o activa. La pasiva se aprovecha mediante el acondicionamiento pasivo de los edificios, diseñándolos de manera que aprovechen óptimamente las condiciones ambientales del entorno.

La energía térmica activa se puede clasificar en función del margen de temperatura que se requiera:

- Baja temperatura $\left(\mathrm{T}<90^{\circ} \mathrm{C}\right)$, se suele utilizar para calentamiento de agua para su uso como agua caliente sanitaria. Utilizan colectores o paneles solares térmicos planos sin concentración, utilizan la energía solar con la misma intensidad con la que incide.

- Media temperatura $\left(90^{\circ} \mathrm{C}<\mathrm{T}<400^{\circ} \mathrm{C}\right)$, se utiliza para la producción de calor en procesos industriales o para generar electricidad al calentar un fluido y someterlo a un ciclo térmico. Utilizan colectores de concentración, el más extendido es el cilindro-parabólico.

- Alta temperatura $\left(\mathrm{T}>400^{\circ} \mathrm{C}\right)$, se utiliza para generar energía eléctrica. Utilizan concentradores de foco puntual, en general discos parabólicos o centrales de torre.

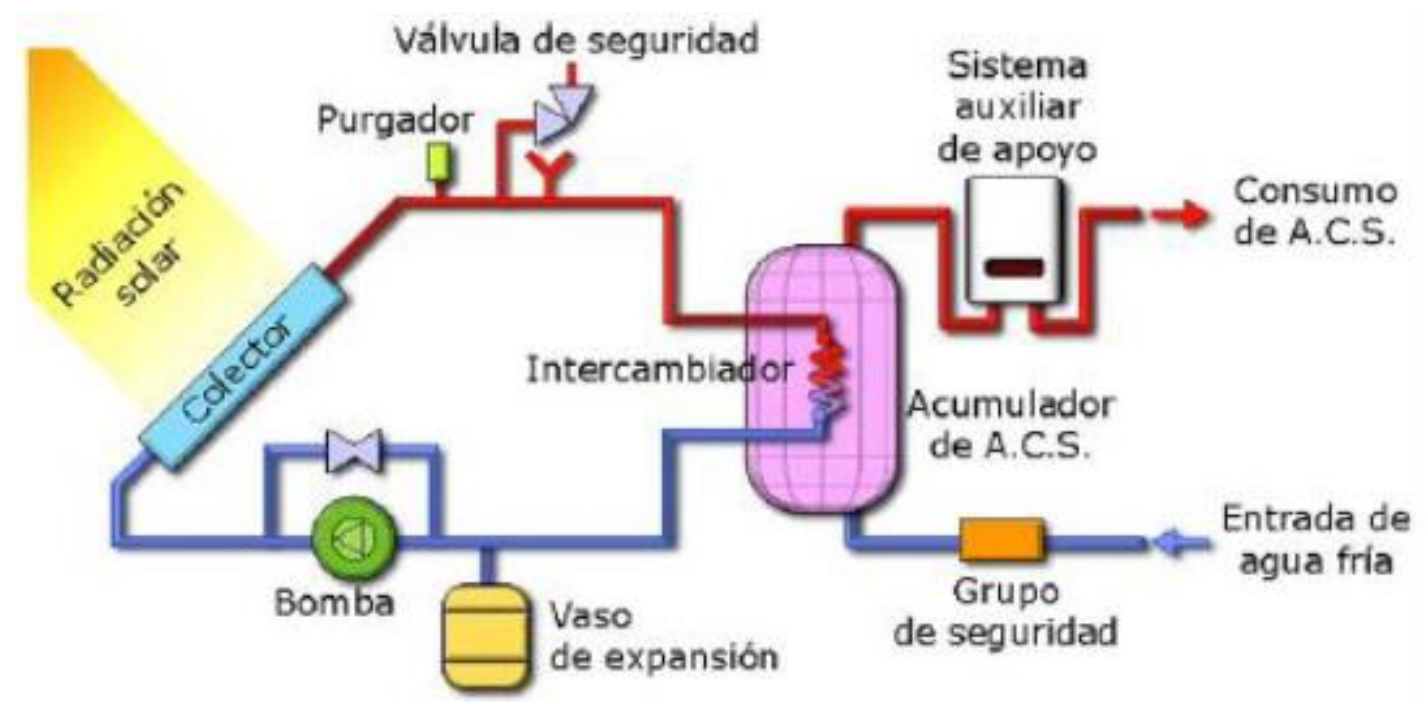

Figura 40: Esquema conceptual de un sistema captador solar térmico de baja temperatura (2) 


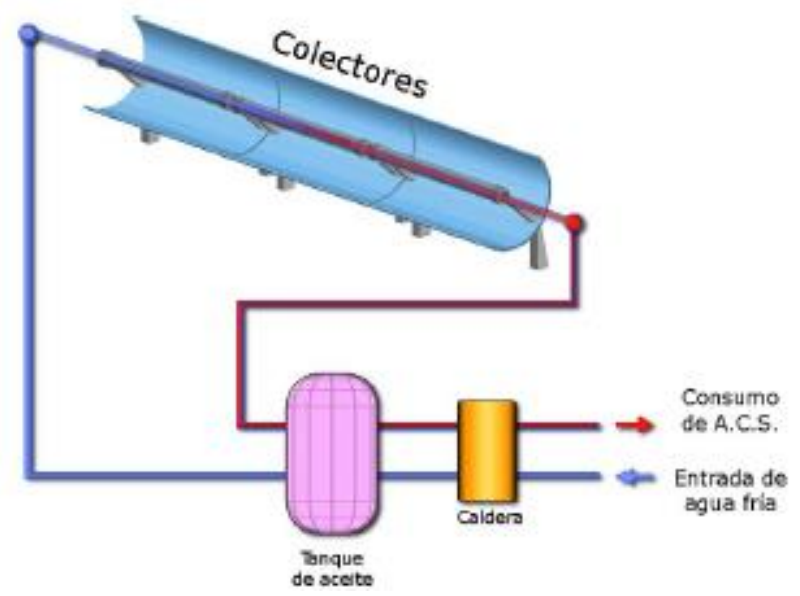

Figura 41: Esquema conceptual de un sistema captador solar térmico de media temperatura (2)

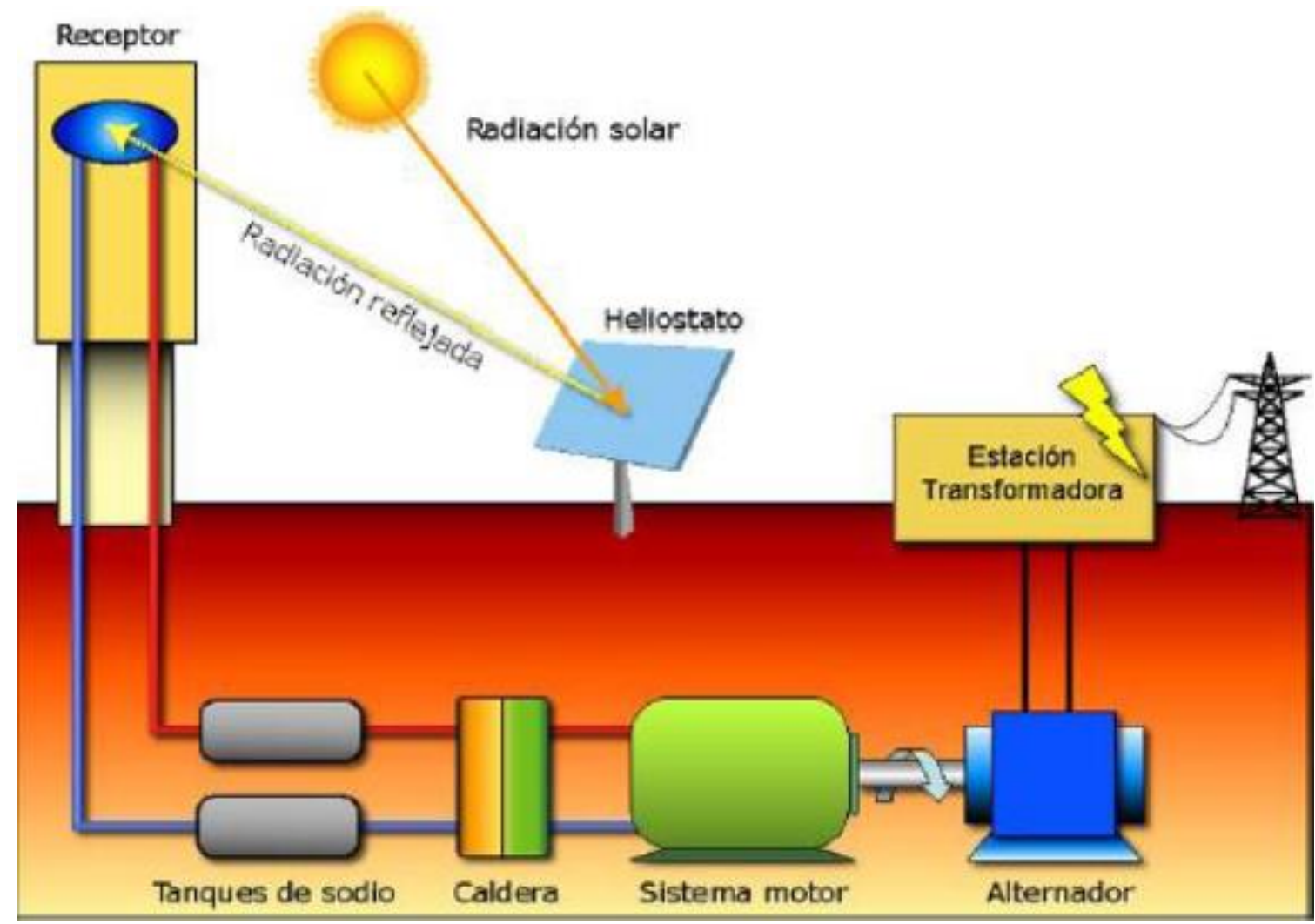

Figura 42: Esquema conceptual de un sistema captador solar térmico de alta temperatura (2)

La energía solar fotovoltaica se basa en la utilización de células solares o fotovoltaicas, fabricadas con materiales semiconductores cristalinos que generan corriente eléctrica cuando incide la radiación solar sobre ellos. El silicio es la base de la mayoría de los materiales utilizados para la construcción de las células solares. 


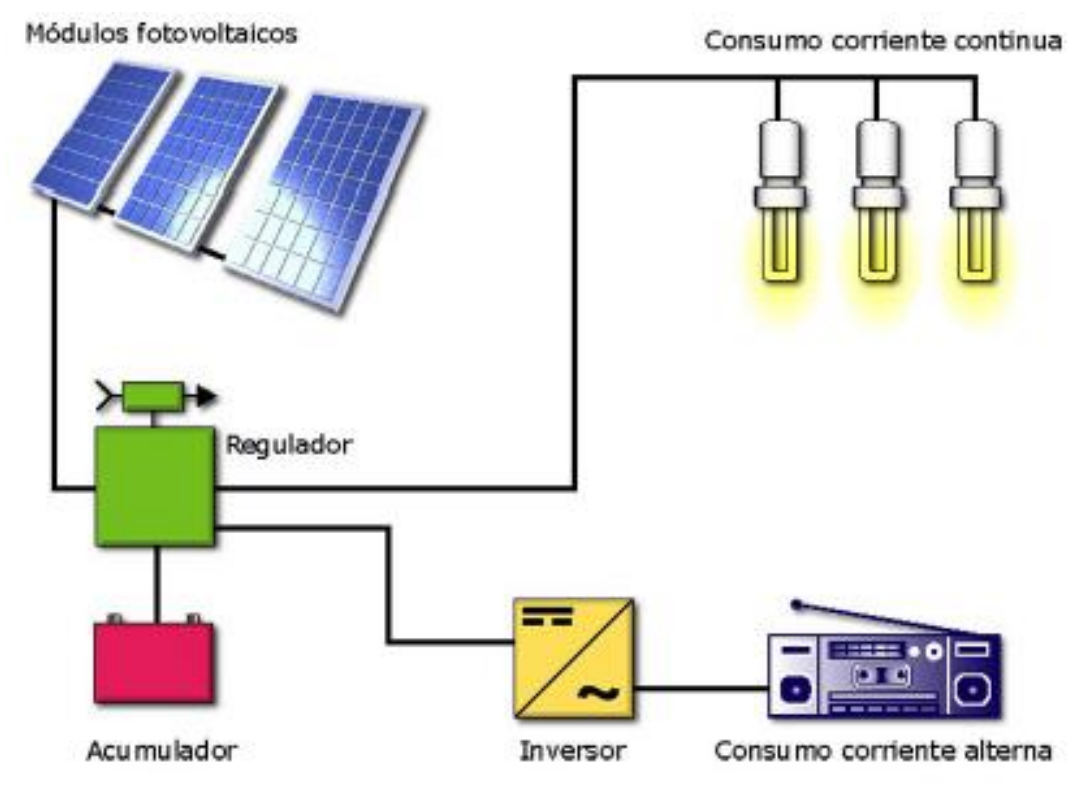

Figura 43: Esquema conceptual de una instalación solar fotovoltaica (2)

El captador está formado por un panel fotovoltaico de superficie entre 0,5 y 0,8m² integrado por un conjunto de células fotovoltaicas que se conectan en serie y paralelo con el objetivo de conseguir determinados niveles de tensión e intensidad eléctrica para una radiación dada.

\subsection{ESTUDIO DE LOS DISPOSITIVOS DE CAPTACIÓN DE LA ENERGÍA DE LAS OLAS.}

A día de hoy, los vectores de energías oceánicas más desarrollados son los dispositivos eólicos marinos, que ya están produciendo energía, y los dispositivos de aprovechamiento de las olas y las corrientes y mareas.

Las olas tienen la densidad energética mayor de todas las fuentes de energía renovable procedentes del mar. A cambio es muy variable pero se pueden predecir las olas que habrá en un punto con varios días de antelación, por lo que puede ser la fuente de energía renovable más barata. (12)

La energía de las olas se mide en Flujo de transporte de energía en kW/m mediante la fórmula $E_{F}=\left[\left(g^{2} \rho / 64 \pi\right) H_{S}^{2} T_{M}\right] \approx 0,491\left(H_{S}^{2} T_{M}\right)$

Donde g representa la gravedad $\left(9,8086 \mathrm{~m} / \mathrm{s}^{2}\right)$ y $\rho$ la densidad del agua de mar $(1,025$ $\mathrm{kg} / \mathrm{m}^{3}$ ) 
De esta manera, periodos entre 7 y 10 segundos y amplitudes de $3 \mathrm{~m}$ producen flujos de energía entre 40 y $50 \mathrm{~kW} / \mathrm{m}(2)(8)$

La Tabla 4 muestra diferentes ecuaciones utilizadas para estimar la energía de las olas.

Tabla 4: Energía de las olas dependiendo del modelo seleccionado (9)

\begin{tabular}{|l|c|l|}
\hline Model & Distribution & Flux (kW/m) \\
\hline Pierson-Moskowitz & $s(\omega)=\frac{8,1 \cdot 10^{-3} g^{2}}{(2 \pi)^{4} \cdot \omega^{5}} \cdot e^{-0,74\left(\frac{g}{2 \pi \omega U_{19,5}}\right)^{4}}$ & $E_{F}=0,549 \cdot H_{S}^{2} \cdot T_{Z}$ \\
\hline Bretshneider-Mitsuyasu & $s(f)=0,257 \cdot H_{S}^{2} \cdot \frac{T_{S}}{\left(T_{S} \omega\right)^{5}} \cdot e^{-1,03\left(T_{S} \omega\right)^{-4}}$ & $E_{F}=0,441 \cdot H_{S}^{2} \cdot T_{S}$ \\
\hline Jonswap & $s(f)=\frac{a H_{S}^{2} \omega_{p}^{4}}{\omega^{5}} \cdot e^{-1,25\left(\frac{\omega_{p}}{\omega}\right)^{4}} \cdot \gamma \cdot e^{-\frac{\left(\omega-\omega_{p}\right)^{2}}{2 \sigma^{2} \omega_{p}^{2}}}$ & $E_{F}=0,458 \cdot H_{S}^{2} \cdot T_{S}$ \\
\hline ISSC & $s(f)=\frac{0,313 H_{S}^{2} \omega_{p}^{4}}{\omega^{5}} \cdot e^{-1,25\left({ }^{\omega_{p}} / \omega\right)^{4}}$ & $E_{F}=0,5949 \cdot H_{S}^{2} \cdot T_{Z}$ \\
\hline
\end{tabular}

Otras ventajas que tienen los dispositivos de aprovechamiento de la energía de las olas (WEC en sus siglas en inglés) son: su escaso impacto ambiental, que la variación de energía debida a las estaciones se acompasa a la demanda eléctrica en climas templados y que admite la introducción de generadores síncronos para un control reactivo de la potencia. La insignificante demanda de medios terrestres es un aspecto importante.

El establecimiento de estos dispositivos en instalaciones marinas, fijas o móviles, colaboraría en el desarrollo de otras industrias, como Astilleros y empresas de equipos y logística, y promovería la creación de empleo en pequeñas y medianas empresas. Así como el desarrollo tecnológico.

Se estima que el potencial de la energía de las olas mundial supone una contribución en el mercado de la electricidad del orden de 2000 TWh/año (13), aproximadamente el 10\% del consumo mundial de electricidad (estudios recientes asignan al área del Noreste del Atlántico, incluido el Mar del Norte, olas capaces de generar cerca de 290 GW) con un coste en inversión de 820M millones de €.

Si tuviéramos que hacer un estudio de viabilidad para un parque de dispositivos WEC, habría que atender a los siguientes puntos:

1. Interrupción de la energía de las olas. Las plantas de potencia de las olas no presentan una barrera impermeable a las olas que viajan a la costa. Los espacios entre dispositivos y una eficiencia de absorción menor del 100\% permiten que una cantidad considerable de la energía atraviese la planta. 
2. Interacciones con la vida marina y las aves marinas. Los dispositivos de poco francobordo proveen un espacio para las focas y leones marinos en sus migraciones, mientras que los de mucho francobordo proveen de espacios a colonias de aves marinas. Cuando éstas se adapten a este espacio artificial se debe tener cuidado para mitigar los impactos de estas comunidades. Se espera que haya un cierto nivel de perturbación del fondo marino y de los animales que viven en él durante la instalación y el mantenimiento, pero este impacto aún no se ha definido.

3. Emisiones a la atmósfera y al océano. Para artefactos que usen circuitos hidráulicos cerrados hay que tener en cuenta posibles pérdidas o derrames. Para aquellos equipos o superficies del casco sumergidas hay que estudiar los ruidos submarinos. Para los que tienen turbinas de aire, el ruido atmosférico. Todos estos efectos pueden ser reducidos durante las etapas de diseño, pero todas las emisiones deben ser controladas.

4. Impacto ambiental. Desde la costa estos artefactos no afectan al paisaje, ya que apenas se ven. A causa de que las aguas resguardadas están muy explotadas por los pescadores, la planta debe estar correctamente señalizada para evitar riesgos en la navegación, durante el día y la noche, pero se prevé que apenas tendrán impacto visual desde la costa.

5. Conflictos con otros usos del espacio marino. Principalmente con áreas protegidas, áreas de navegación, de pesca, de investigación científica, de uso militar, rutas de cables de comunicaciones y sitios de acumulación de residuos.

6. Instalación y desmantelamiento. La instalación del cable de potencia debe realizarse durante los meses de calma. El desmantelamiento incluye las estructuras fijas al fondo marino y la retirada gradual de los artefactos flotantes (ya que pueden estar siendo utilizados por focas y leones marinos en sus migraciones o por colonias de aves marinas)

7. Beneficios ambientales. Reducción de gases contaminantes a la atmósfera. Se eliminan los gastos de transporte de fuel a la planta de generación de electricidad, disminuyendo los riesgos ambientales de dicho transporte. Como la energía eléctrica generada se va a utilizar in situ en la planta de generación de hidrógeno se eliminan 
largos cables de potencia, tanto submarinos como aéreos, reduciendo el impacto visual de los mismos.

La poca experiencia que hay con la energía de las olas hace que se tenga una visión parcial de los posibles efectos nocivos para el medioambiente producidos por los dispositivos WEC ni su eficiencia. Sin embargo, éstos aparecen en las Tabla 5 y Tabla 6:

Tabla 5: Efectos en el medio ambiente de dispositivos WEC

\begin{tabular}{|l|l|l|l|}
\hline Efecto en el medioambiente & En la costa & Cerca de la costa & Offshore \\
\hline Desertización terrestre & Débil & & \\
\hline Construcción/Mantenimiento & Débil & & \\
\hline Esparcimiento & Débil & Débil & \\
\hline Erosión de la costa & Débil & Débil/Medio & Débil/Medio \\
\hline Estructura del flujo de sedimentos & & Débil & Débil \\
\hline Peligros para la navegación & & Débil & Débil \\
\hline Peces y organismos marinos & Débil & Débil & Débil \\
\hline Contaminación acústica & Débil & Débil/Medio & Débil/Medio \\
\hline Pérdidas de los fluidos de trabajo & & Débil & \\
\hline Especies en peligro & Débil & Débil & \\
\hline Daños por anclaje del artefacto & & & \\
\hline
\end{tabular}

Tabla 6: Principales características de los dispositivos WEC

\begin{tabular}{|c|c|c|c|c|c|c|c|}
\hline Name & Type & $\begin{array}{c}\text { Power } \\
(\mathrm{kW})\end{array}$ & $\begin{array}{c}\text { Used } \\
\text { surface } \\
\left(\mathbf{m}^{2}\right)\end{array}$ & $\begin{array}{c}\text { Ratio approx. } \\
\text { Power/Surface } \\
\left(\mathbf{x 1 0}^{3}\right)\end{array}$ & Efficiency & Fluid & Place \\
\hline Alda & OWC & 1.000 & - & - & & Air & On-Shore \\
\hline Aquabuoy & $\mathrm{FP}$ & 500 & 157 & 3.183 & $40 \%$ & sea water & Off-Shore \\
\hline AWS & $\mathrm{FP}$ & 1.200 & 90 & 13.296 & & Air & Near Shore \\
\hline Cockerell & WAB & 2.000 & 5.000 & 400 & & $\begin{array}{c}\text { pressure } \\
\text { oil }\end{array}$ & Off-Shore \\
\hline BBDB & OWC & 200 & 36 & 5.556 & $35 \%$ & Air & Near Shore \\
\hline Breakwave & OWC & 750 & 525 & 1.427 & & Air & On-Shore \\
\hline
\end{tabular}




\begin{tabular}{|c|c|c|c|c|c|c|c|}
\hline Name & Type & $\begin{array}{l}\text { Power } \\
\text { (kW) }\end{array}$ & $\begin{array}{c}\text { Used } \\
\text { surface } \\
\left(\mathrm{m}^{2}\right)\end{array}$ & $\begin{array}{c}\text { Ratio approx. } \\
\text { Power/Surface } \\
\left(\mathbf{x 1 0}^{3}\right)\end{array}$ & Efficiency & Fluid & Place \\
\hline Ship Kaimei & WAB & 2.000 & 960 & 2.083 & $<10 \%$ & Air & Off-Shore \\
\hline $\begin{array}{c}\text { Cylinder of } \\
\text { Bristol }\end{array}$ & WAB & 2.000 .000 & 1.656 .000 & 1.208 & & sea water & Off-Shore \\
\hline Clam & OWC & 2.500 & 2.827 & 884 & & Air & Off-Shore \\
\hline $\begin{array}{c}\text { Converter of } \\
\text { Belfast }\end{array}$ & oWC & 75 & 51 & 1.471 & & Air & On-Shore \\
\hline Unión Fenosa & OWC & 27 & 48 & 559 & & sea water & On-Shore \\
\hline El Pato Salter & WAB & 2.310 & 4.050 & 570 & $90 \%$ & $\begin{array}{c}\text { pressure } \\
\text { oil }\end{array}$ & Off-Shore \\
\hline in China & oWC & 30 & 40 & 750 & $10-35 \%$ & Air & On-Shore \\
\hline in Kujukuri & owC & 30 & 31 & 955 & & Air & On-Shore \\
\hline in Pico & OWC & 500 & 96 & 4.167 & $54 \%$ & Air & On-Shore \\
\hline Energetech & OWC & 500 & 875 & 571 & & Air & On-Shore \\
\hline Kvaerner & OWC & 600 & 79 & 6.366 & & Air & On-Shore \\
\hline Limpet & OWC & 500 & 84 & 5.952 & & Air & On-Shore \\
\hline Migthy Wale & OWC & 110 & 1.200 & 92 & $54 \%$ & Air & Near Shore \\
\hline $\begin{array}{c}\text { Multiwave } \\
\text { Plane }\end{array}$ & OTD & 30 & 22 & 1.374 & & sea water & Near Shore \\
\hline NEL & owC & 2.000 .000 & 1.552 .000 & 1.289 & $46 \%$ & Air & Off-Shore \\
\hline Nereida & OWC & 250 & 700 & 537 & & Air & On-Shore \\
\hline Oyster & WAB & 500 & 216 & 2.315 & & sea water & Near Shore \\
\hline Pelamis & WAB & 750 & 490 & 118 & $72 \%$ & $\begin{array}{c}\text { pressure } \\
\text { oil }\end{array}$ & Off-Shore \\
\hline PowerBuoy & $\mathrm{FP}$ & 20 & 20 & 1.531 & & $\begin{array}{c}\text { pressure } \\
\text { oil }\end{array}$ & Off-Shore \\
\hline Sakata & OWC & 60 & 360 & 167 & $18 \%$ & Air & On-Shore \\
\hline Searev & FP & 500 & 375 & 1.333 & & $\begin{array}{c}\text { pressure } \\
\text { oil }\end{array}$ & Off-Shore \\
\hline SSG & OTD & 12.000 & 75.000 & 1.944 & $50 \%$ & sea water & Everywhere \\
\hline Tapchan & OTD & 400 & 7.000 & 57 & $33 \%$ & sea water & On-Shore \\
\hline Wavebob & $\mathrm{FP}$ & 1.500 & 225 & 6.667 & & $\begin{array}{c}\text { pressure } \\
\text { oil }\end{array}$ & Off-Shore \\
\hline Wavedragon & OTD & 6.000 & 51.000 & 160 & $81 \%$ & sea water & Off-Shore \\
\hline Waveroller & WAB & 13 & 16 & 825 & & $\begin{array}{c}\text { pressure } \\
\text { oil }\end{array}$ & Near Shore \\
\hline Wavestar & $\begin{array}{l}\text { Multy } \\
\text { FP }\end{array}$ & 6.000 & 1.440 & 4.167 & & $\begin{array}{c}\text { pressure } \\
\text { oil }\end{array}$ & Near Shore \\
\hline
\end{tabular}

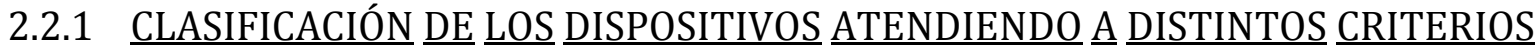

La energía procedente de las olas se convierte en electricidad en dos pasos. Primero se convierte en una combinación de energía cinética y potencial mediante alguna de las más de 
mil patentes de dispositivos WEC, que absorben la energía de las olas por un proceso mecánico. En el siguiente paso, la energía absorbida por el dispositivo se convierte en electricidad mediante turbinas de aire o agua, sistemas de aceite hidráulico y generadores directos.

Las turbinas de aire necesitan que la energía de la ola se convierta en presión y flujo de aire antes de convertirlo en electricidad. Las turbinas de agua pueden operar directamente con el agua del mar. Estos son los sistemas más desarrollados y con mejores rendimientos por el momento.

Los dispositivos se pueden clasificar atendiendo a varios criterios,

Según la posición relativa respecto a la costa:

- En la costa (onshore)

- Cerca de la costa (nearshore), 20-40m de profundidad, y

- Mar adentro (offshore), $>40 \mathrm{~m}$ de profundidad.

Según el principio de funcionamiento y de captación de la energía:

- Sistemas pasivos o estáticos, la estructura está inmóvil durante todo el proceso de conversión, de manera que la energía se genera sólo con el propio movimiento de las partículas de agua

- Sistemas activos u oscilantes, aprovechan el movimiento relativo entre las partes fijas y las móviles del dispositivo. Existen dos tipos:

$\checkmark \quad$ El oleaje actúa directamente sobre el cuerpo móvil, la conversión primaria se basa en el movimiento relativo entre dos cuerpos.

El oleaje actúa sobre una interfaz agua-aire de modo que la ola desplaza el aire, que desplaza a su vez al cuerpo móvil.

Según su geometría y posición relativa respecto al oleaje se pueden clasificar en:

- Totalizadores o terminadores, son dispositivos largos con su eje principal paralelo al frente de olas y extrae la energía de las mismas de una sola vez (WAB)

- Atenuadores, son dispositivos largos cuyo eje principal es paralelo a la dirección del movimiento de las olas y extraen la energía de forma progresiva (WAB)

- Captadores puntuales, son dispositivos aislados de dimensiones reducidas que aprovechan la concentración y convergencia del oleaje (FP) 
- Columna de agua oscilante, las olas actúan como un pistón sobre el aire contenido dentro del dispositivo (OWC)

- De rebose, el agua de las olas se acumula en una estructura y después se hace pasar a través de turbinas para volver al mar (OTD)

\subsubsection{SEGÚN SU POSICIÓN RESPECTO A LA COSTA:}

\section{DISPOSITIVOS EN LA COSTA.}

Están fijos o arraigados a la costa y pueden estar aislados o formando parte de diques, puertos u otras infraestructuras costeras.

Presentan la ventaja de tener un coste de instalación y mantenimiento menor que el de otro tipo de dispositivos, puesto que son de fácil acceso, se encuentran cimentadas sobre roca y el transporte de la energía a la red presenta menos impedimentos. Sin embargo disponen de un potencial energético menor que el explotable mar adentro, aunque se pueda ver compensado por efectos de concentración de energía por refracción o difracción.

No necesitan los anclajes de aguas más profundas ni largos cables eléctricos submarinos pero se ven limitados por la geografía de la costa.

DISPOSITIVOS CERCA DE LA COSTA.

Son aquellos dispositivos situados a una distancia máxima de $500 \mathrm{~m}$ de la costa y a una profundidad de entre 20 y $30 \mathrm{~m}$. Pueden estar o apoyados en el fondo o flotantes.

Presentan a ventaja de tener un coste de instalación y mantenimiento menor que en aguas profundas y el transporte de la energía a la red es sencillo.

Disponen de un potencial energético menor que el explotable mar adentro, aunque algo mayor que el de tipo onshore.

El mayor inconveniente es, además del impacto visual, que su instalación implica la modificación de la dinámica costera.

DISPOSITIVOS MAR ADENTRO.

La principal ventaja que representan es que aprovechan un potencial energético mayor pero su coste y la complejidad de la instalación son elevados y el sistema de amarre, igual que la estructura, debe resistir grandes esfuerzos.

Hay que tener en cuenta que en los lugares más energéticos, la accesibilidad al dispositivo para mantenimiento y reparación es difícil y que puede suponer interferencias con el tráfico marino. 
Estos dispositivos pueden ser flotantes o estar sumergidos.

\subsubsection{DISTINTOS DISPOSITIVOS SEGÚN SU GEOMETRÍA Y POSICIÓN RELATIVA RESPECTO A LAS OLAS}

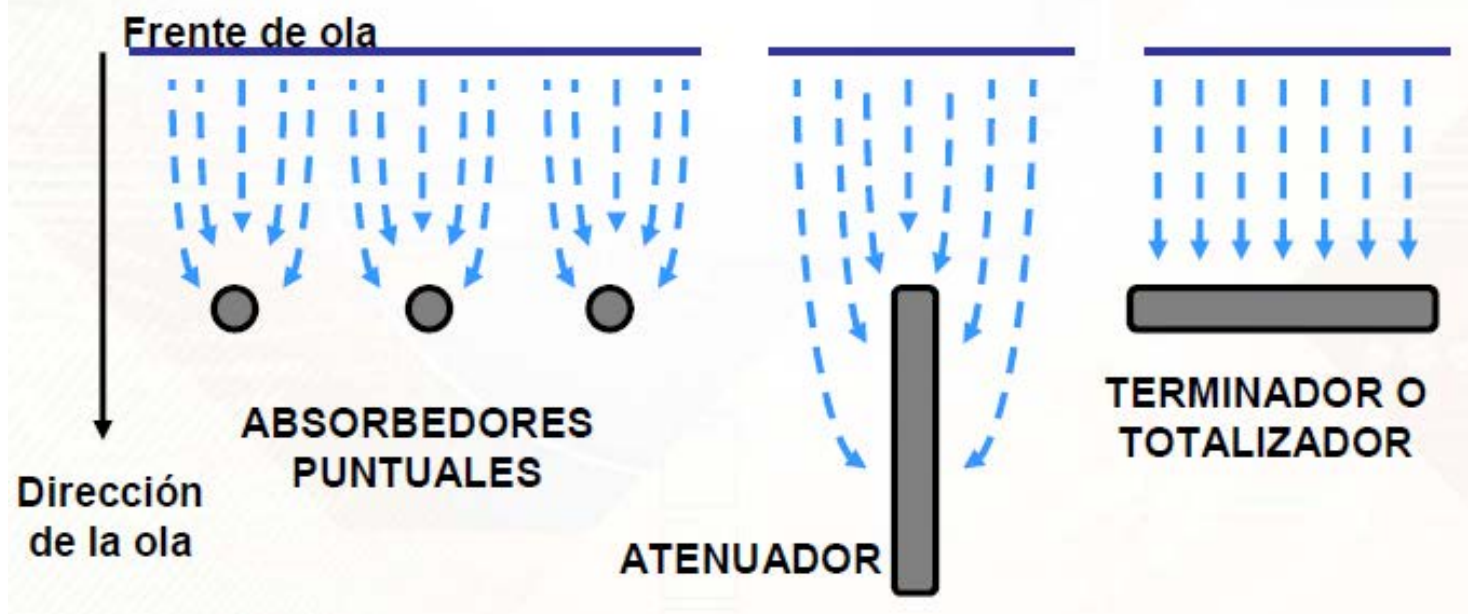

Figura 44: Actuación de las olas sobre un WEC (14)

\section{TOTALIZADORES O TERMINADORES (WAB)}

CILINDRO DE BRISTOL: Este dispositivo fue desarrollado por la Universidad de Bristol y consiste en un cilindro de $100 \mathrm{~m}$ de longitud y 16m de diámetro flotante, sumergido 6m por debajo de la superficie del agua, que recoge el movimiento de las olas. El cilindro está mecánicamente conectado a una unidad de energía mediante un sistema mecánico formado por palancas y uniones flexibles. Las uniones se mueven lentamente siguiendo el movimiento circular del cilindro, permitiendo así la transferencia de energía a una turbina hidráulica que genera energía eléctrica. La turbina se encuentra ubicada sobre el lecho marino sobre la misma estructura que sirve de anclaje.

Al estar completamente sumergido todo el dispositivo no está sometido a fuerzas excesivas durante los temporales. 


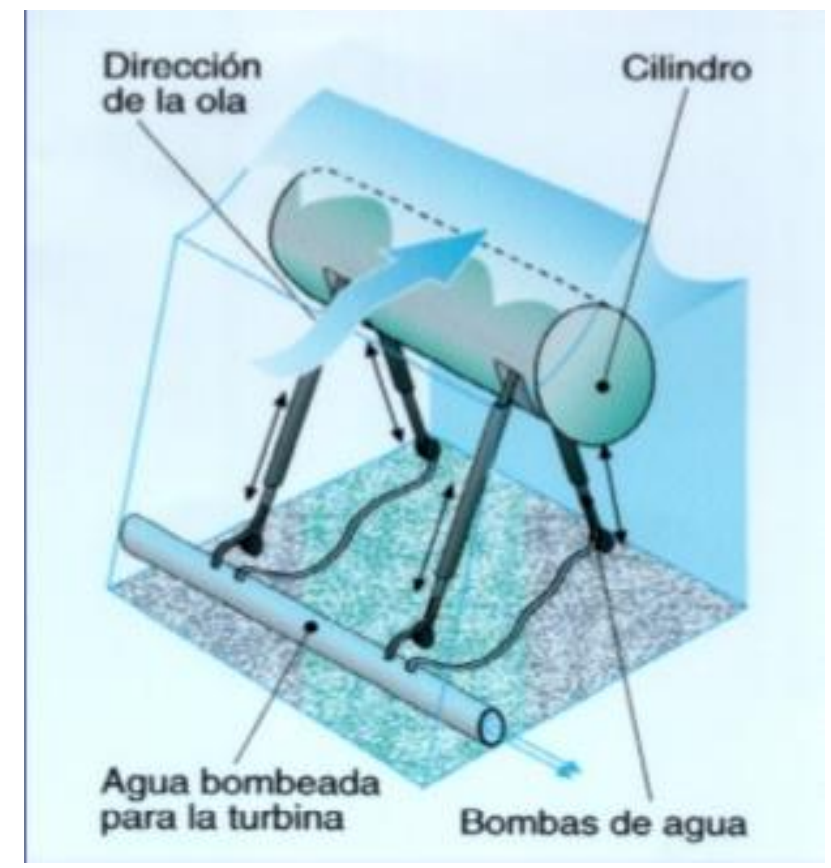

Figura 45: Esquema Cilindro de Bristol

OYSTER: (15)Consiste en un flotador tipo aleta que se une mediante una bisagra al fondo marino, a unos 10-15m de profundidad y alrededor de 500m de la costa.

Esta aleta está completamente sumergida y oscila hacia delante y detrás acompañando al movimiento de las olas. Este movimiento de la aleta dirige dos pistones hidráulicos que llevan agua a presión hasta la costa por una tubería submarina hasta una turbina hidráulica convencional que genera energía eléctrica.
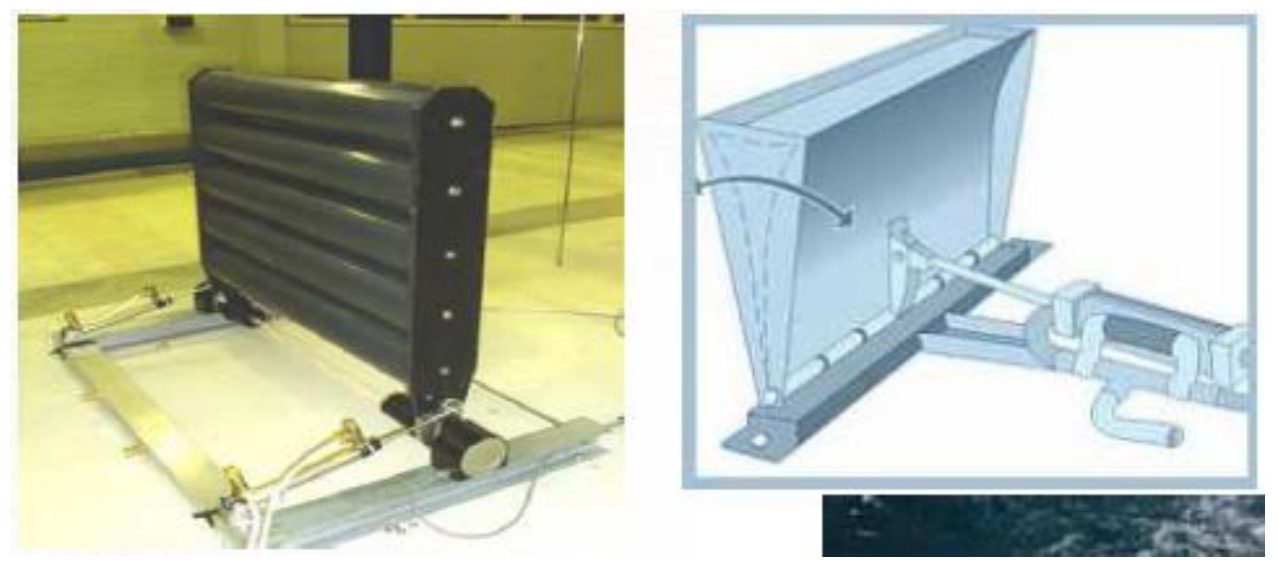

Figura 46: Esquema Oyster

PATO DE SALTER: Se trata de un dispositivo flotante que consta de unos patos unidos por una espina fija, aquellos se mueven conforme avanza el tren de olas y se mantiene estable 
mediante un giróscopo que hay en su interior que impulsa un fluido hacia una turbina hidráulica que es la que genera la electricidad.

El perfil del pato le permite mantenerse orientado perpendicular al frente de olas.

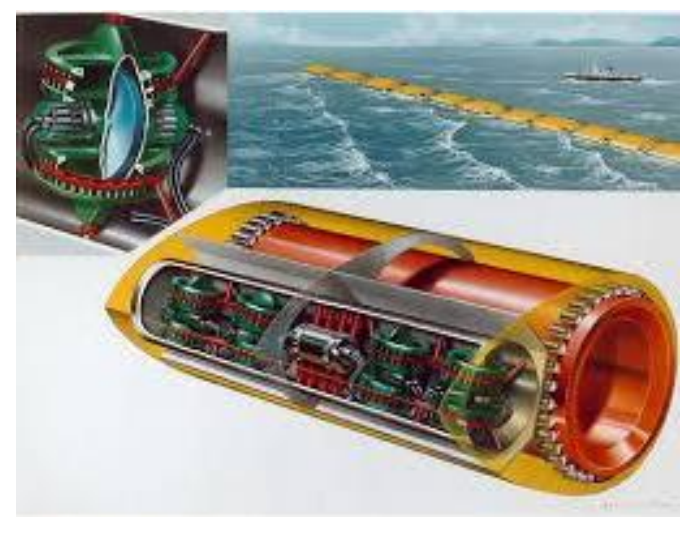

Figura 47: Esquema Pato de Salter

\section{ATENUADORES (WAB)}

PELAMIS ${ }^{1}$ : (16) Consiste en una estructura cilíndrica articulada semisumergida que dispone en sus nodos de unión de un sistema hidráulico que actúa sobre un generador eléctrico. El movimiento relativo (vertical-horizontal) de una articulación respecto a su nodo actúa sobre 4 pistones hidráulicos que alimentan un depósito a presión.

Este dispositivo está más orientado a la resistencia a las condiciones marinas que a la eficiencia en la conversión de energía. Por tanto, en vez de intentar absorber toda la energía disponible en cada ola, convierte solo una porción. De esta manera el sistema puede sobrevivir casi sin mantenimiento en condiciones meteorológicas marinas muy adversas, que podrían dañar a un sistema optimizado solamente para la eficiencia de conversión energética.

\footnotetext{
${ }^{1}$ La empresa fabricante del dispositivo PELAMIS ya no existe aunque la patente sigue existiendo.
} 


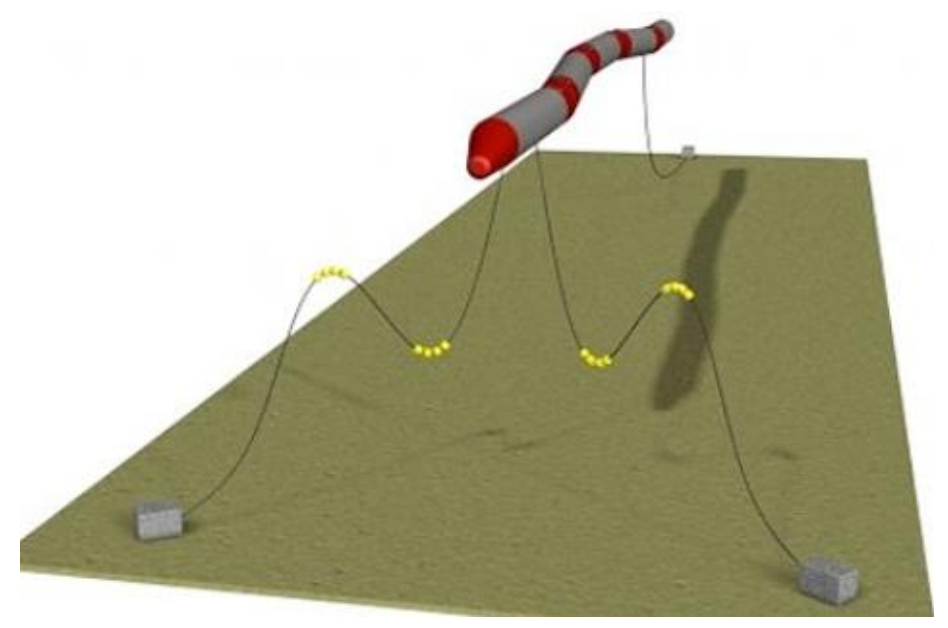

Figura 48: Esquema dispositivo Pelamis

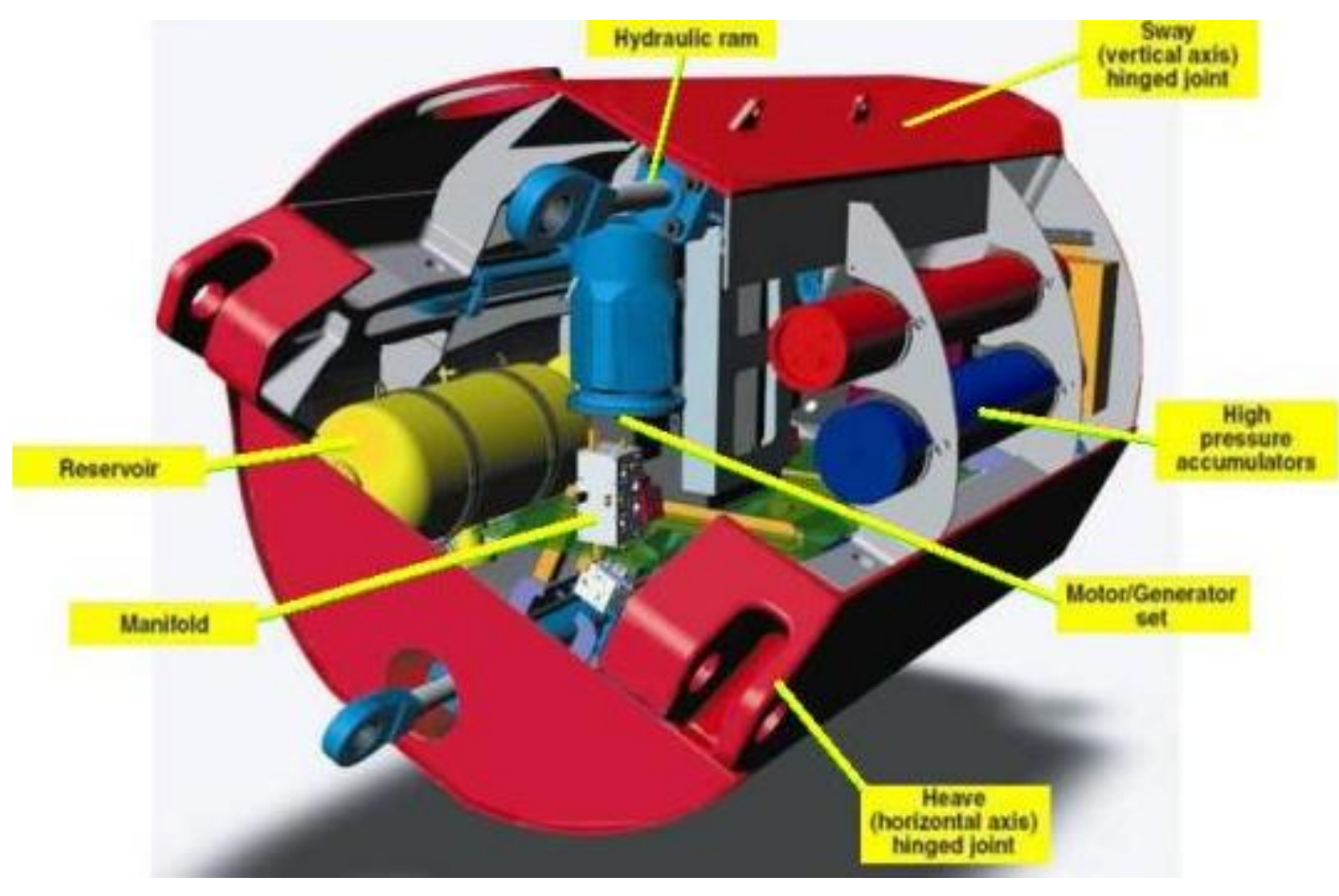

Figura 49: Interior dispositivo Pelamis

BALSA DE COCKERRELL: Consiste en tres flotadores entre los cuales se instalan dos bombas de pistón que son las que extraen la energía de las olas. Las balsas suben y bajan impulsando un líquido a un motor que mueve un generador mediante un sistema hidráulico instalado en cada articulación. 


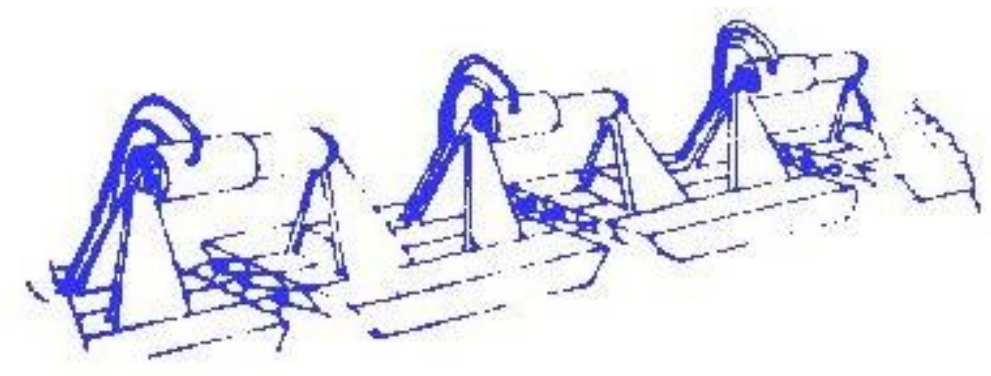

Figura 50: Esquema de dispositivo balsa de Cockerell

\section{CAPTADORES PUNTUALES (FP)}

AQUABUOY: Se trata de una boya hueca de $6 \mathrm{~m}$ de diámetro y $30 \mathrm{~m}$ de puntal que genera hasta $250 \mathrm{KW}$ dependiendo del estado de la mar fondeada en aguas de más de $50 \mathrm{~m}$ de profundidad.

En la cabeza de la boya hay un pistón que se mueve por el efecto de la presión del aire interior al ser comprimido y descomprimido en el movimiento de la ola. El agua a presión alimenta un acumulador hidráulico que suaviza el efecto de los picos de ola y se descarga en una turbina acoplada a un generador eléctrico. (17)

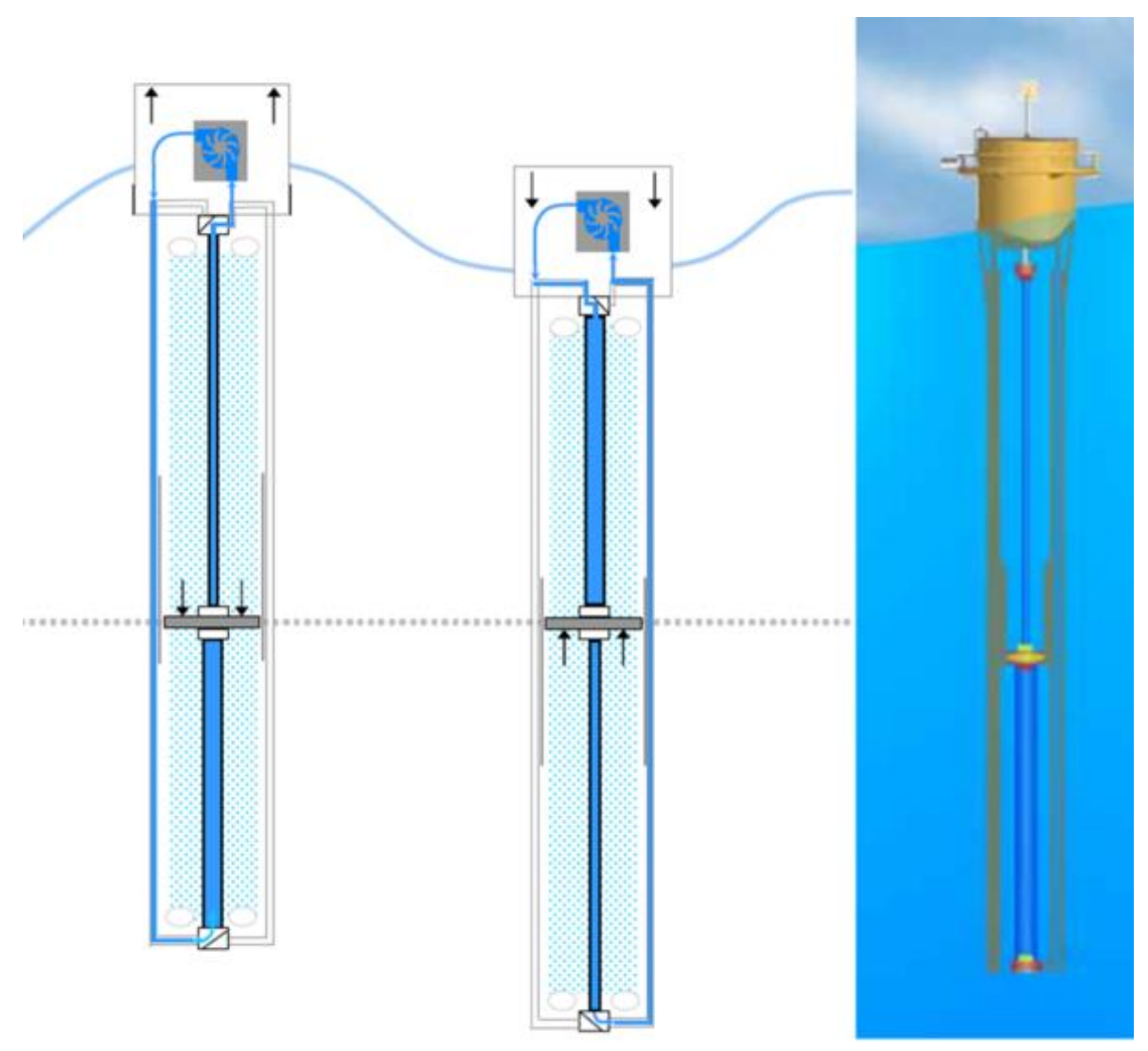

Figura 51: Esquema de dispositivo AquaBuoY 
ESTUDIO DEL POTENCIAL DE APROVECHAMIENTO ENERGÉTICO DEL OCÉANO EN LA COSTA ANDALUZA.

Autora: Ma Pilar Blanco Fernández

POWERBUOY: Es el mismo sistema que el anterior pero fijo al fondo marino (18).

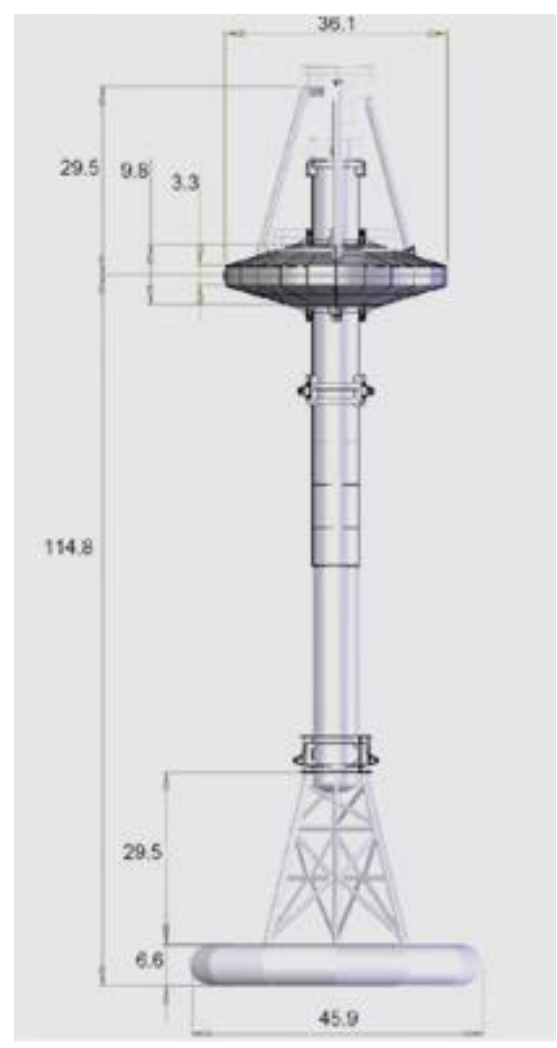

Figura 52: Powerbuoy

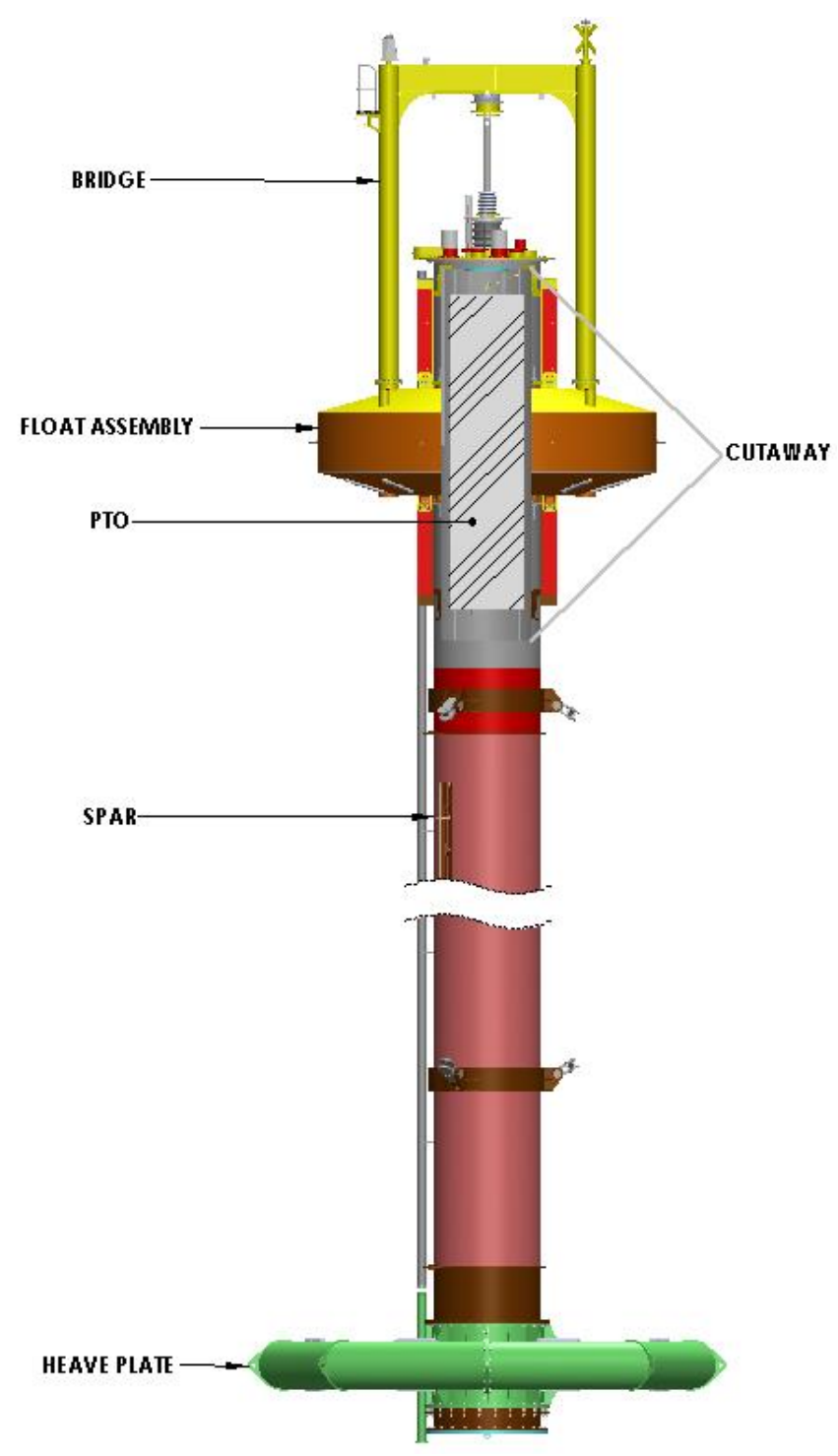

Figura 53: Esquema de dispositivo Powerbuoy 
WAVEBOB: Se trata de una boya flotante en la que la energía se produce por el movimiento axial relativo de dos cuerpos flotantes. Este movimiento hace que un aceite hidráulico atraviese todo un circuito hasta el PTO. (19)

En la Figura 54 se observan las distintas partes que forman esta boya. El cuerpo 1 flota conforme el perfil de la ola mientras que el cuerpo 2 tiene un lastre que aumenta su inercia y oscila a frecuencia distinta.

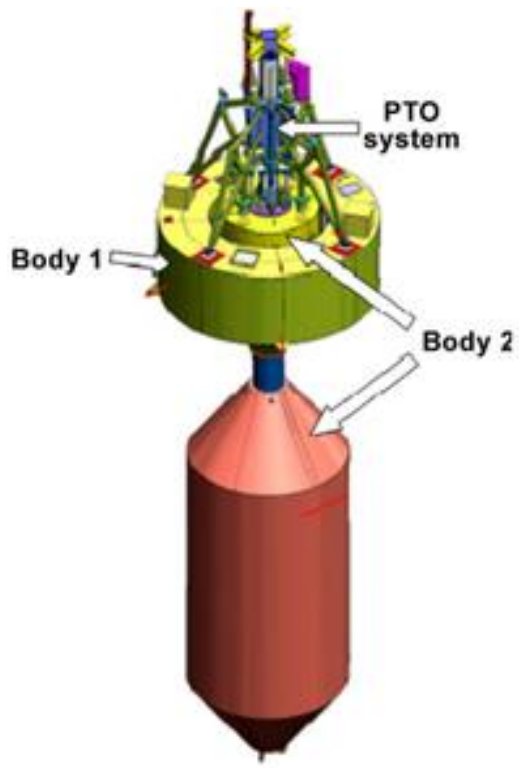

Figura 54: Esquema dispositivo WaveBob

ARCHIMEDES WAVE SWING (AWS): Dispositivo sumergido y apoyado en el fondo del mar a una profundidad de entre 40 y $100 \mathrm{~m}$ lo que le permite estar próximo a la costa.

Se trata de una estructura presurizada en la que la parte superior cilíndrica es móvil y hace la función de un pistón. Toda la estructura está llena de aire, por lo que el movimiento de las olas hace que la parte móvil suba y baje por el principio de Arquímedes comprimiendo y descomprimiendo generando electricidad mediante un PTO. 


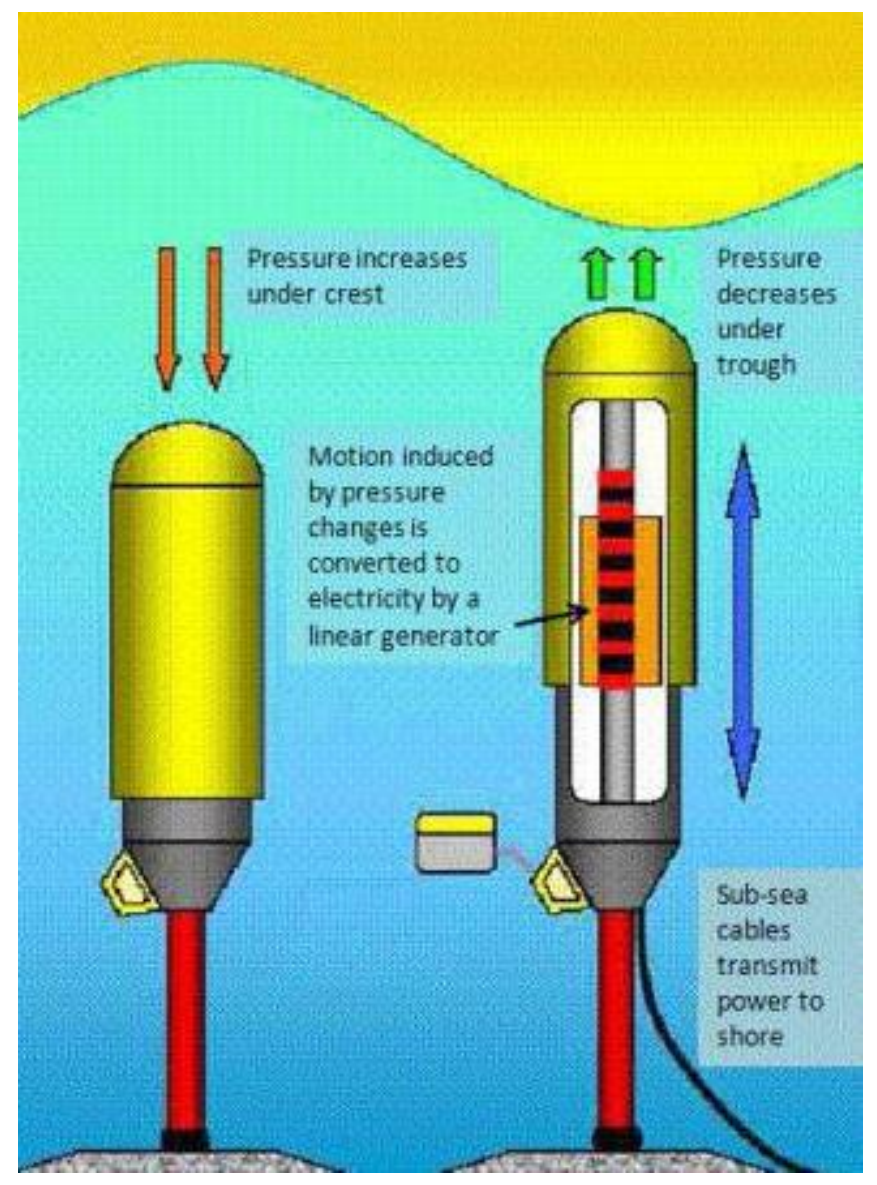

Figura 55: Esquema de funcionamiento dispositivo AWS

Para adaptar la instalación a las diferentes estaciones del año se actúa sobre el aire contenido en el cilindro y, por estar sumergido, las condiciones climatológicas no representan un riesgo para el dispositivo.

Este dispositivo trabaja mejor con olas procedentes de mar de fondo. WAVESTAR2: (se trata de un dispositivo que agrupa a varios absorvedores puntuales) Se trata de 20 flotadores unidos mediante brazos articulados a una plataforma que está fija al fondo marino. El movimiento de los flotadores se transmite mediante un fluido hidráulico al rotor de un generador produciendo electricidad. (20)

2 Este mismo principio se puede utilizar asociado a un rompeolas o acantilado para aprovechar la energía de las grandes olas. 


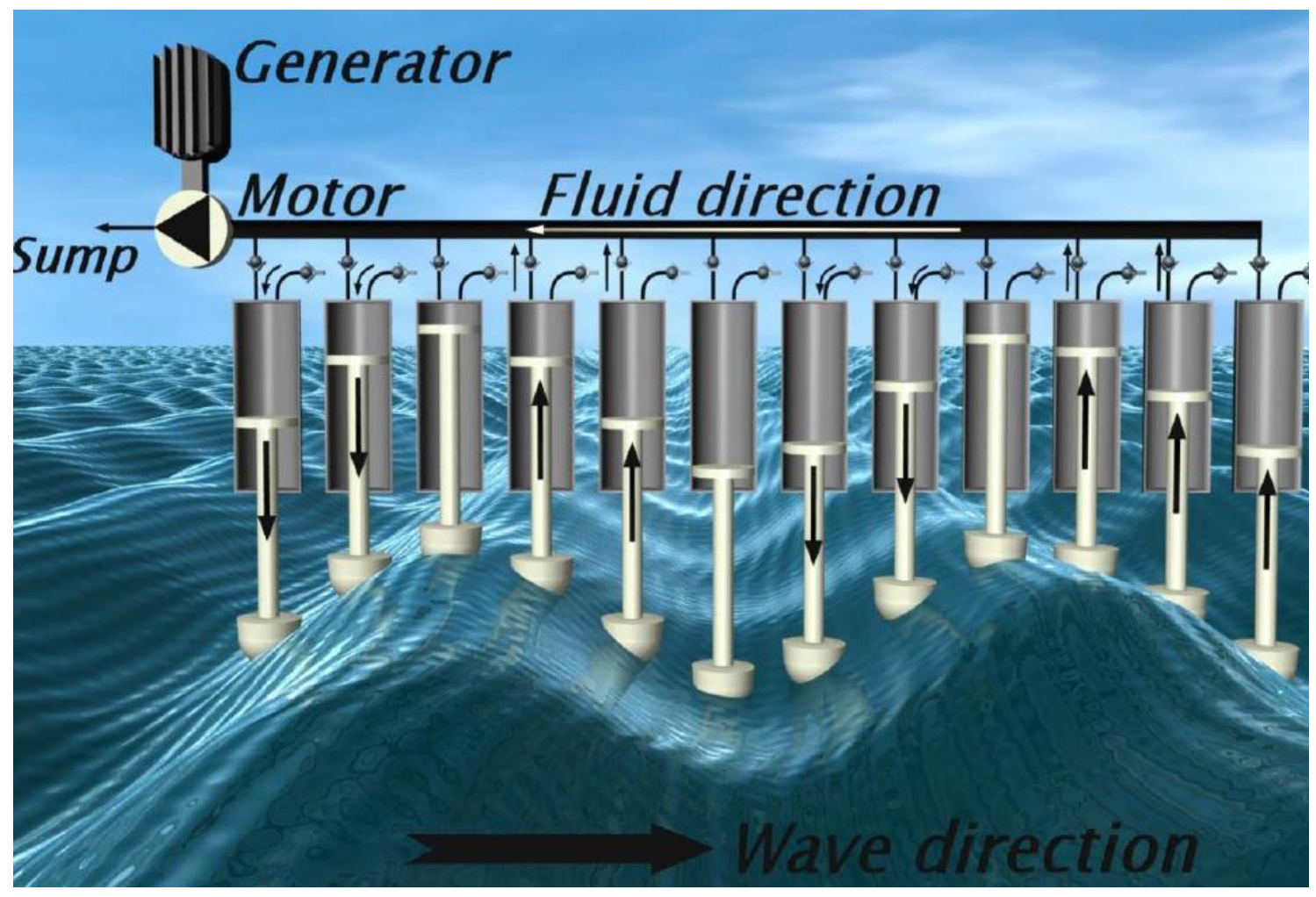

Figura 56: Principio de funcionamiento dispositivo Wavestar

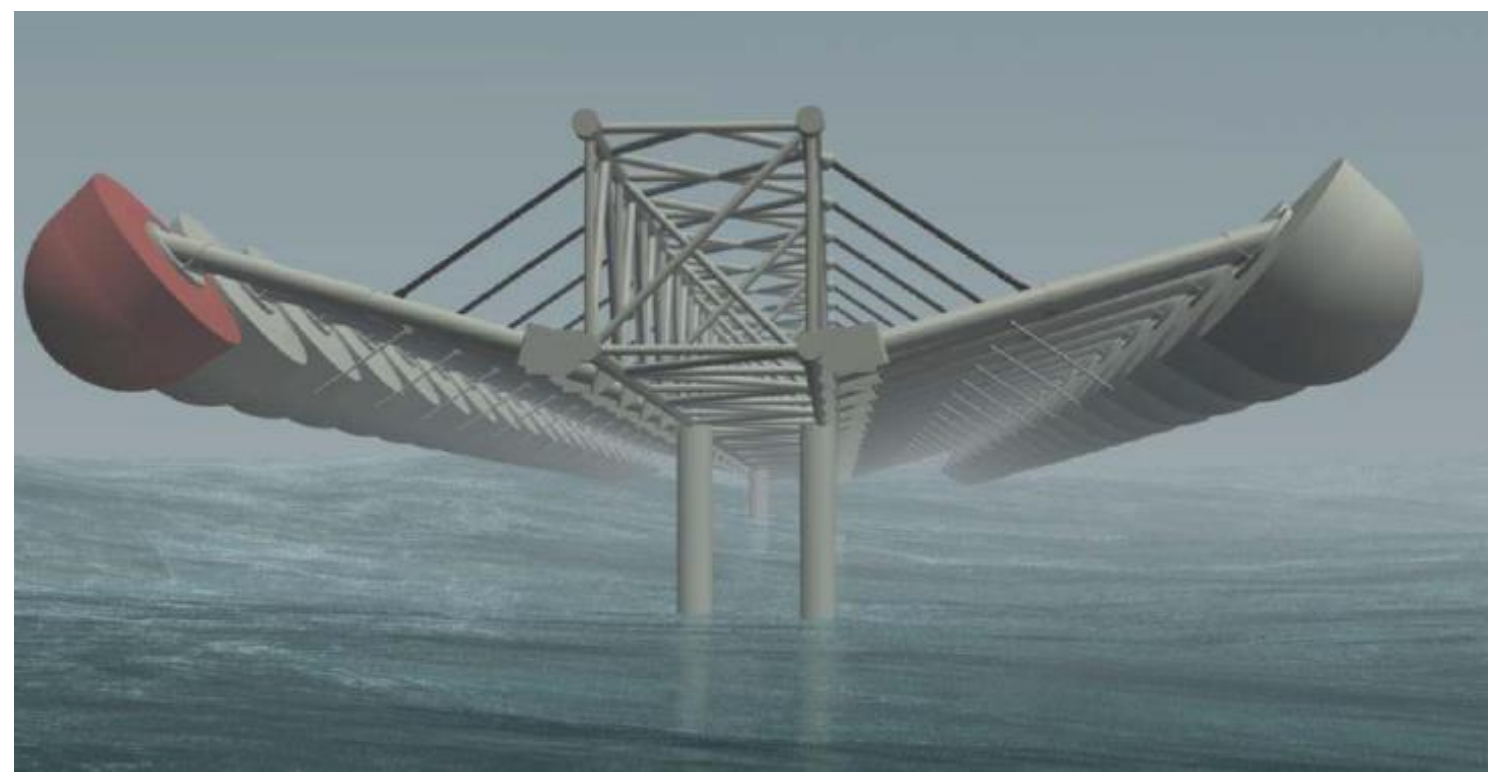

Figura 57: Infografía Wavestar en posición de protección frente a tormentas

\section{COLUMNA DE AGUA OSCILANTE (OWC)}

BACKWARD BENT DUCT BUOY (BBDB): Consiste en un dispositivo flotante con un conducto en forma de $\mathrm{L}$ abierto al mar por la parte horizontal y al aire por la vertical donde hay una 
turbina. La ola al incidir en el dispositivo hace que el aire salga o entre a través de la turbina, generando electricidad.

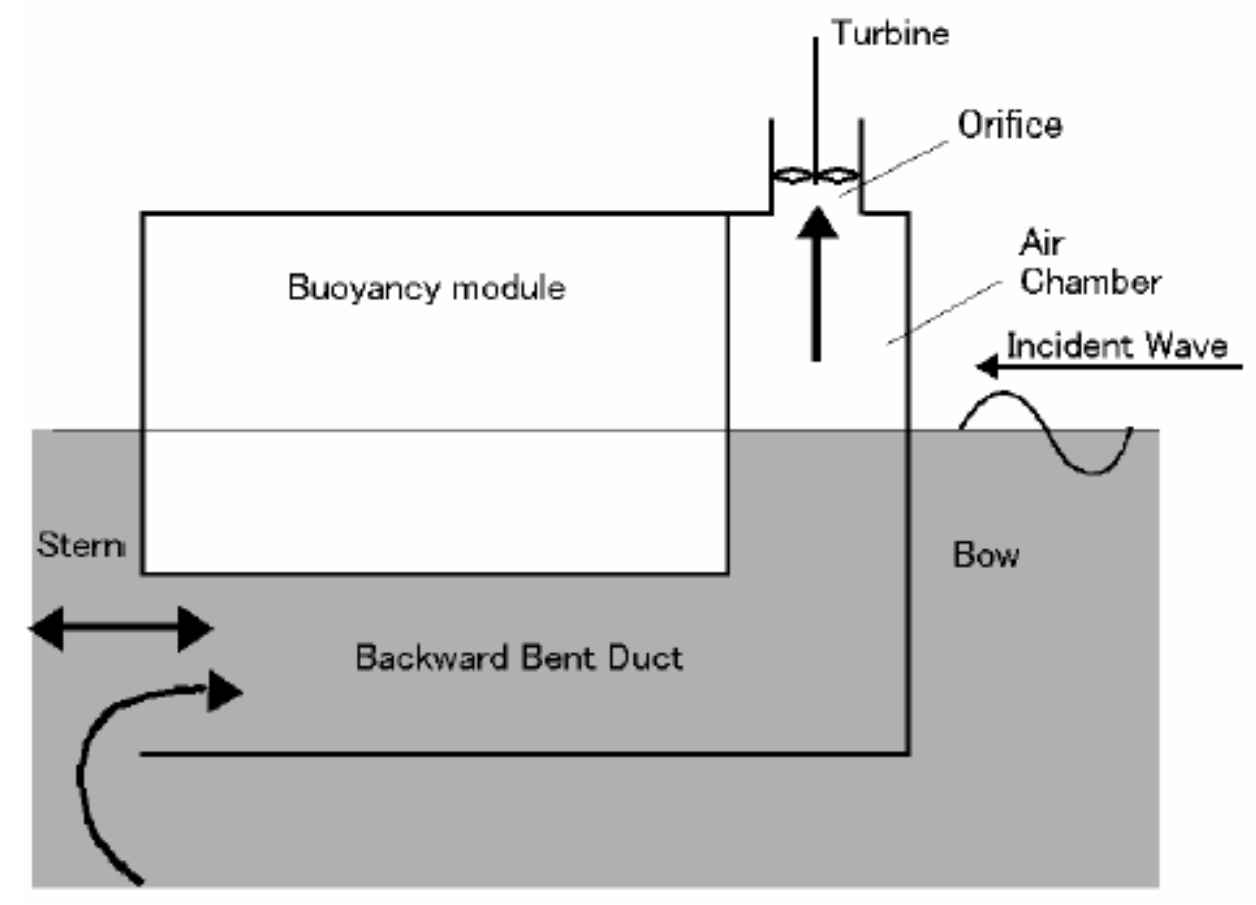

Figura 58: Concepto dispositivo BBDB

BREAKWAVE: Se trata de una cámara situada en un rompeolas abierta al mar. En la parte más alta de la cámara hay situadas tres turbinas $(2+1)$ que al pasar el aire por ellas generan electricidad.

INSTALACIÓN EN PICO: (Figura 59 y Figura 60) La instalación consiste en una estructura cilíndrica de hormigón armado con una cámara neumática sobre la superficie libre del agua que se comunica con las olas por un orificio sumergido en la parte frontal y con la atmósfera a través de un conducto de fibra que contiene turbinas de aire $(2+4)$

La instalación está dentro de un acantilado en la Isla de Pico en las Azores (Portugal). 


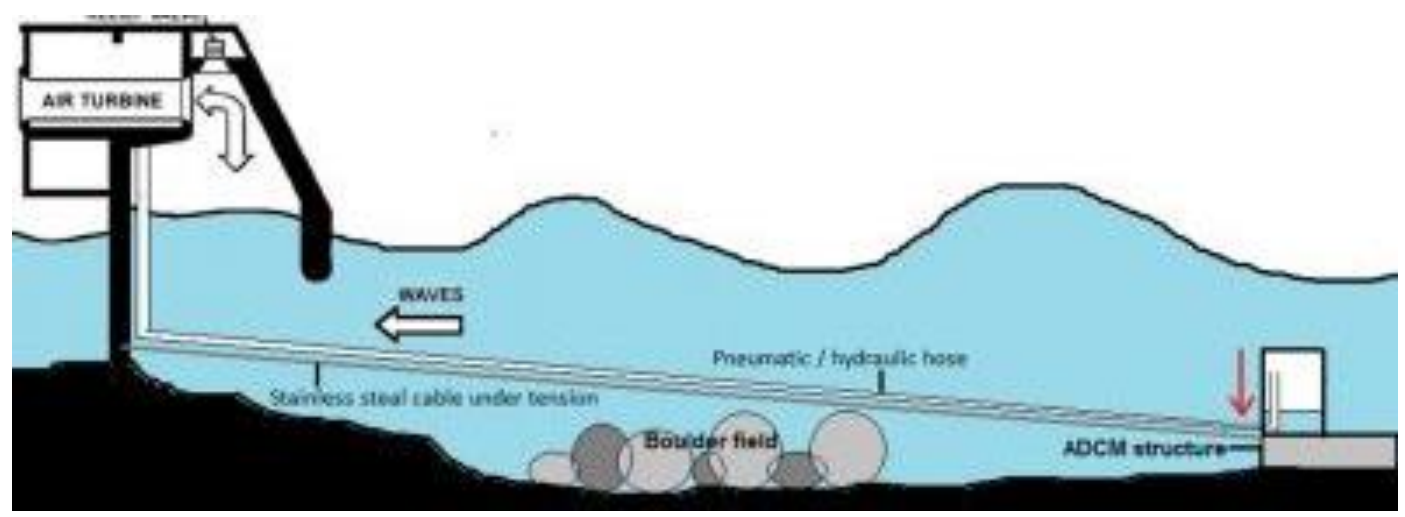

Figura 59: Esquema de instalación

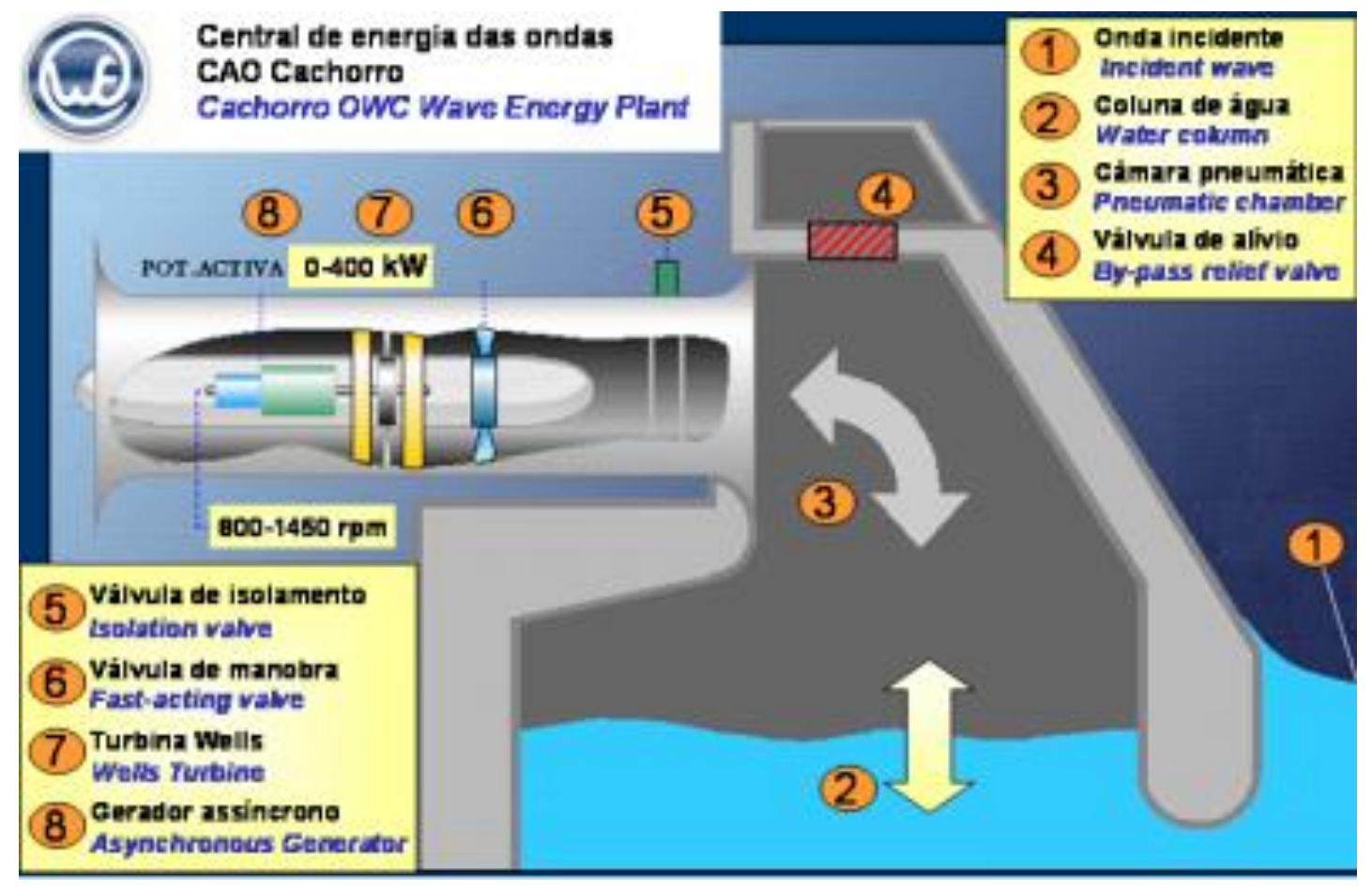

Figura 60: Esquema de operación de la planta

ENERGETECH: Se trata de un dispositivo construido en la costa. Representa una evolución en el diseño de un OWC en dos áreas principalmente:

- La pérdida de energía de las olas al acercarse a la costa se ve compensada por la utilización de un reflector parabólico que las dirige hacia la cámara del OWC situada en el foco de la parábola (esto aumenta en un 30\% los costes de instalación y en un $300 \%$ la eficiencia del dispositivo)

- Han diseñado una nueva turbina de paso controlable que puede cambiar según la dirección del flujo del aire. 
ESTUDIO DEL POTENCIAL DE APROVECHAMIENTO ENERGÉTICO DEL OCÉANO EN LA COSTA ANDALUZA.

Autora: Ma Pilar Blanco Fernández

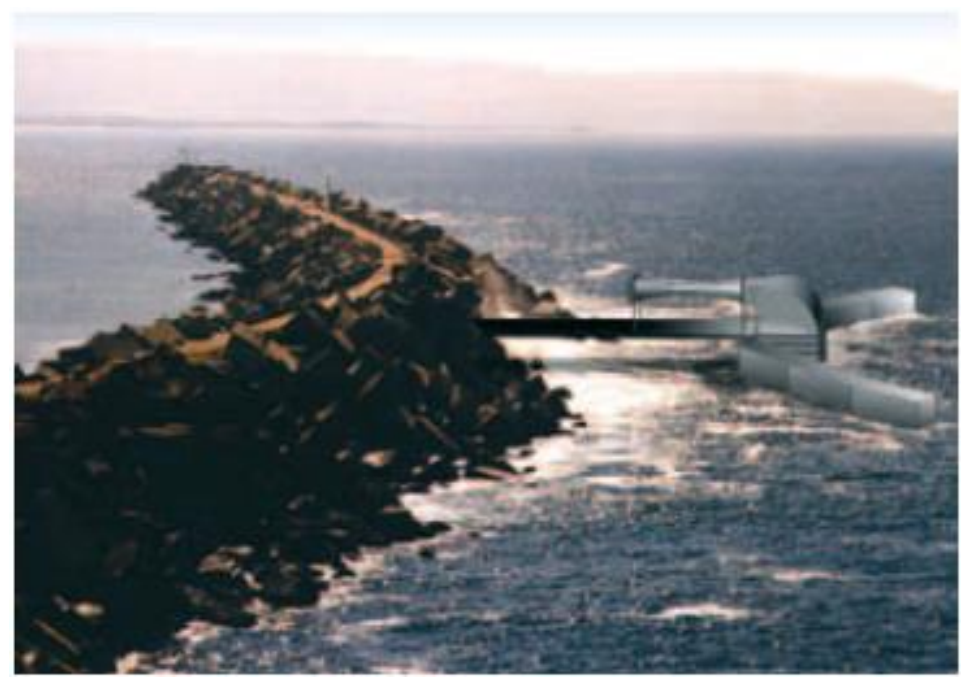

Figura 61: Infografía del captador de Energetech

MIGHTYWALE: Es el dispositivo OWC flotante más grande que hay actualmente. Ha sido desarrollado por Japón.

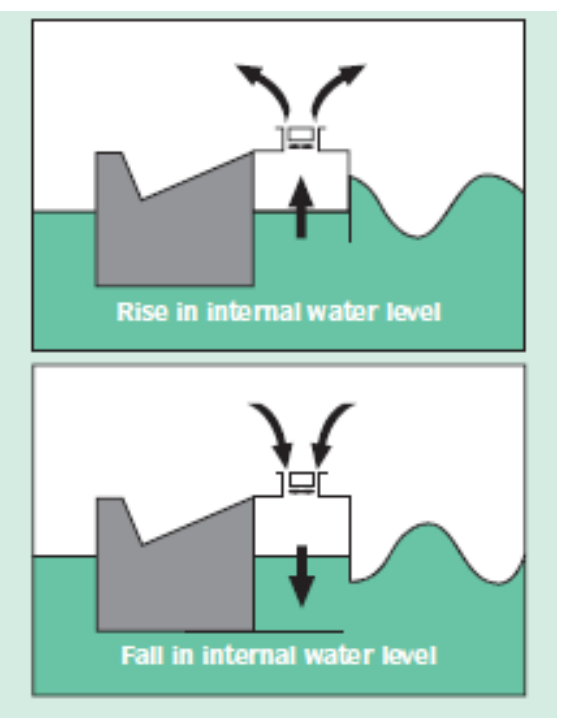

Figura 62: Esquema de operación dispositivo Mighty Whale 


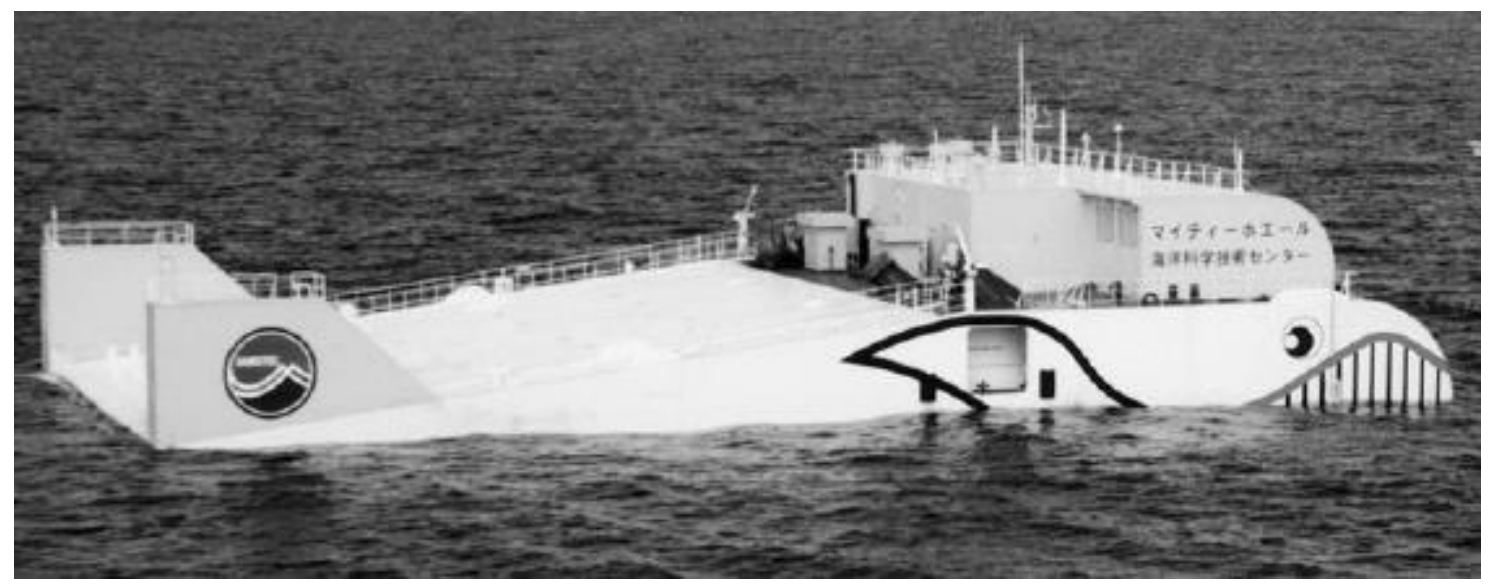

Figura 63: Dispositivo Mighty Whale

NEREIDA: Utiliza turbinas Wells en un rompeolas construido en Mutriku (Guipúzcoa, España, Figura 64 y Figura 65). Consiste en 16 cilindros correspondientes a respectivos captadores OWC disponiéndose en 100m del rompeolas. Cada turbina aporta 15KW

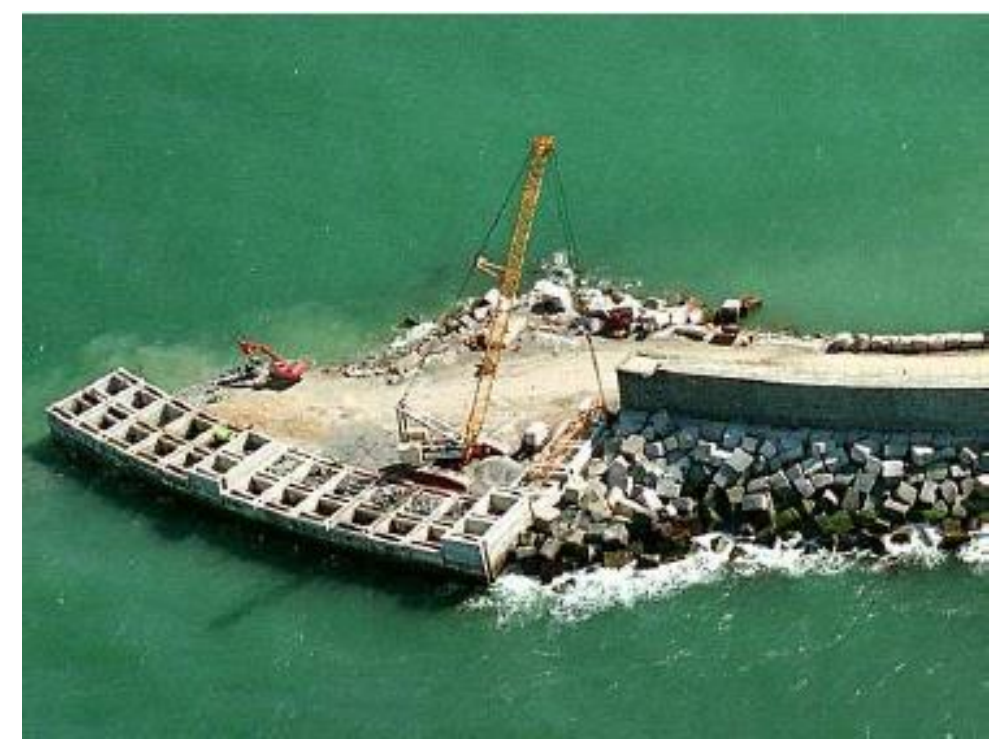

Figura 64: Instalación de la central Mutriku 


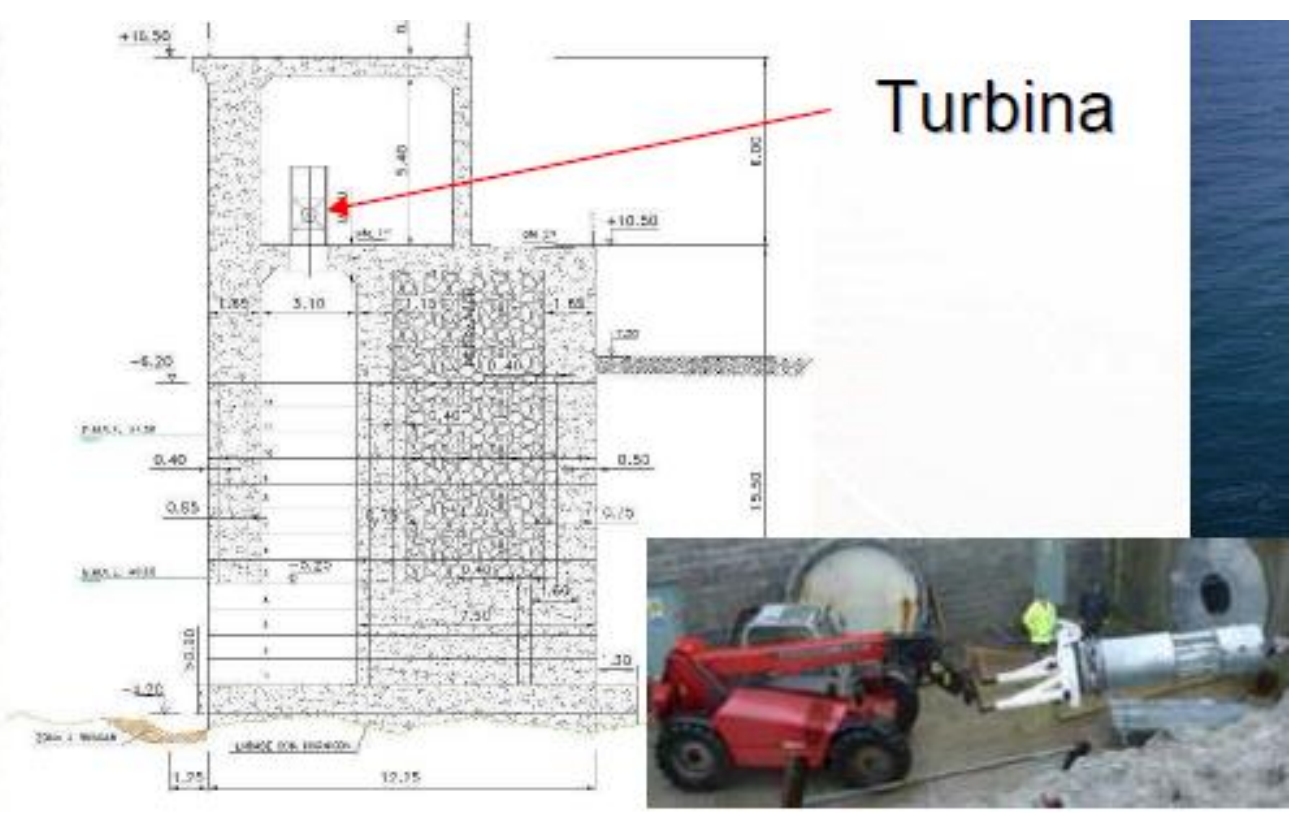

Figura 65: Esquema de la cámara de cada OWC Nereida

CLAM: Es un captador flotante consistente en 12 cámaras de aire dispuestas en forma de circunferencia e interconectadas de manera que su cara exterior está formada por una membrana flexible que al incidir las olas en ella comprime el aire interior y pasa a través de una turbina.

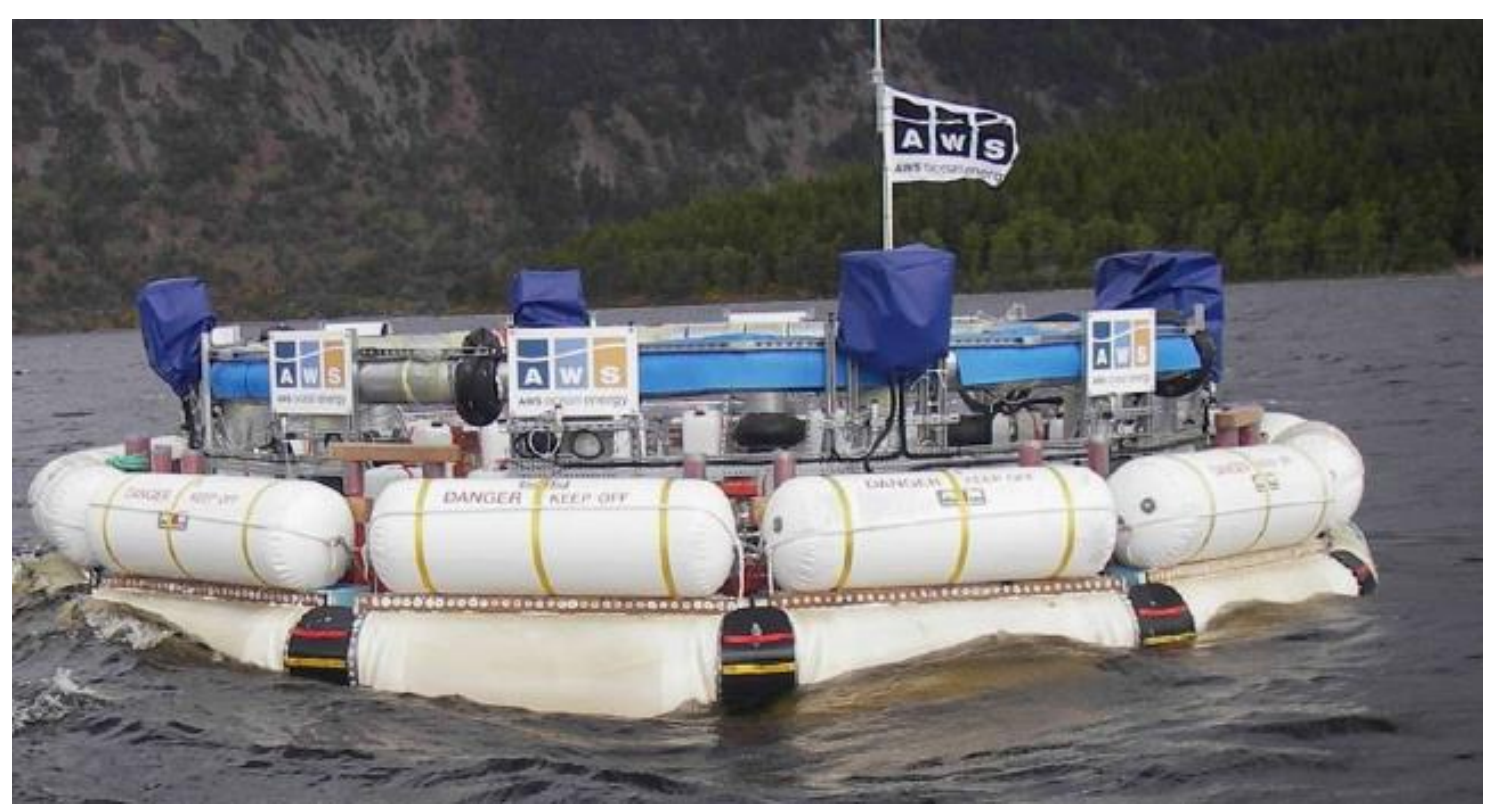

Figura 66: Dispositivo CLAM 


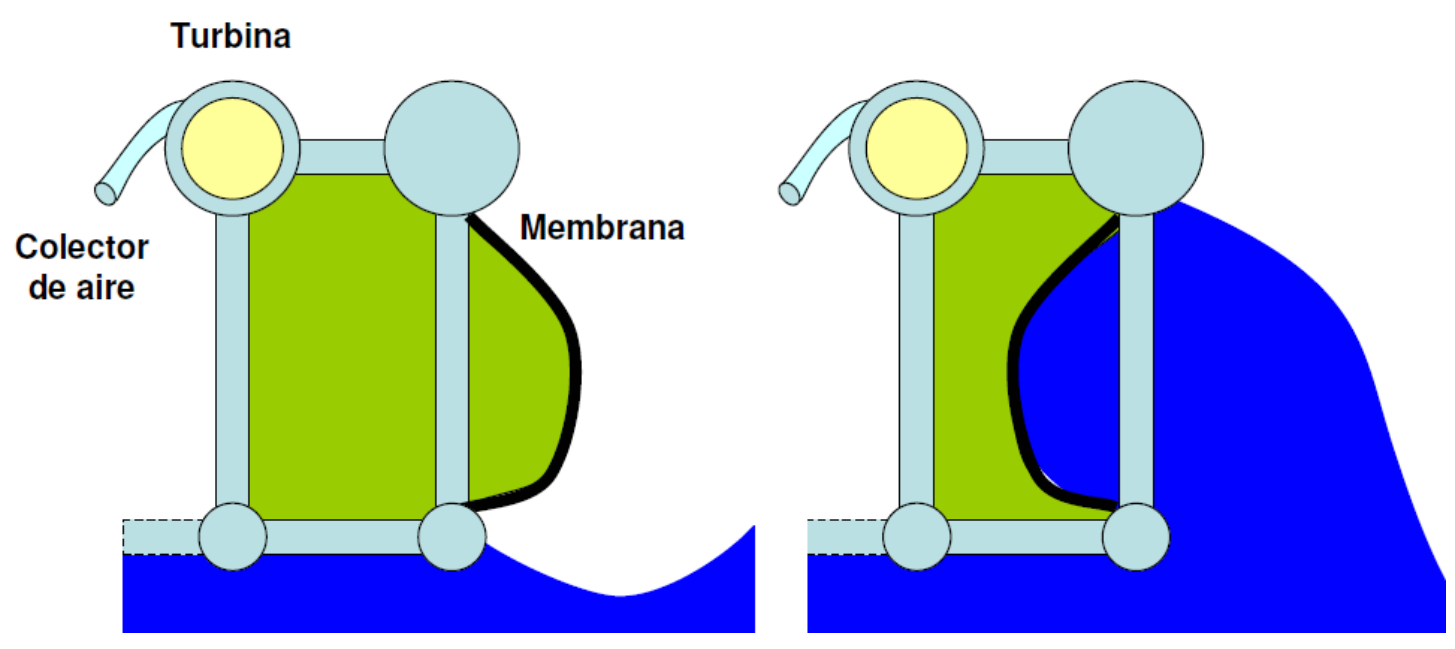

Figura 67: Esquema de funcionamiento dispositivo CLAM

REBOSE (OTD)

$S S G$ : Se trata de un dispositivo situado en la costa que utiliza varios depósitos de agua uno encima del otro en los que se introduce el agua por la altura de la ola. Este agua pasa por unas turbinas hasta el depósito inferior, generando electricidad.

Las ventajas de esta disposición, aparte de que se pueden utilizar instalaciones costeras y se reduce el coste de cables submarinos, es que puede aprovechar un amplio espectro de olas aumentando la eficiencia total.

Si se utiliza en instalaciones portuarias, se puede reutilizar el agua en las propias instalaciones del puerto. 


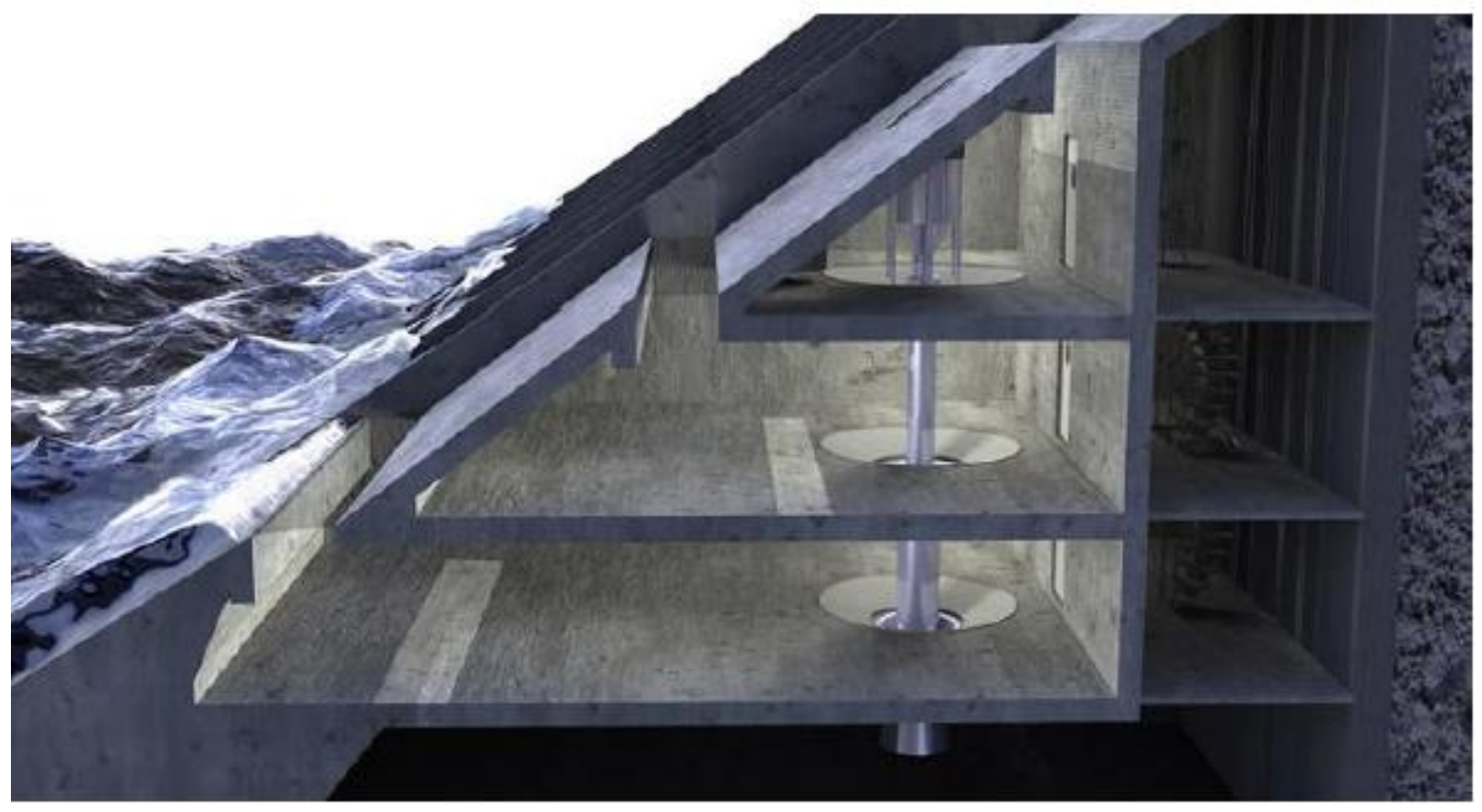

Figura 68: Representación del captador SSG con turbina multi-etapa (21)

TAPCHAN: Es un dispositivo muy simple, similar en muchos aspectos a una central hidráulica. Donde la orografía lo permite, o las instalaciones cercanas, se construye un depósito que se llena por el efecto de las olas o las mareas, después el agua almacenada se hace pasar por unas turbinas utilizando la presión de la columna de agua.

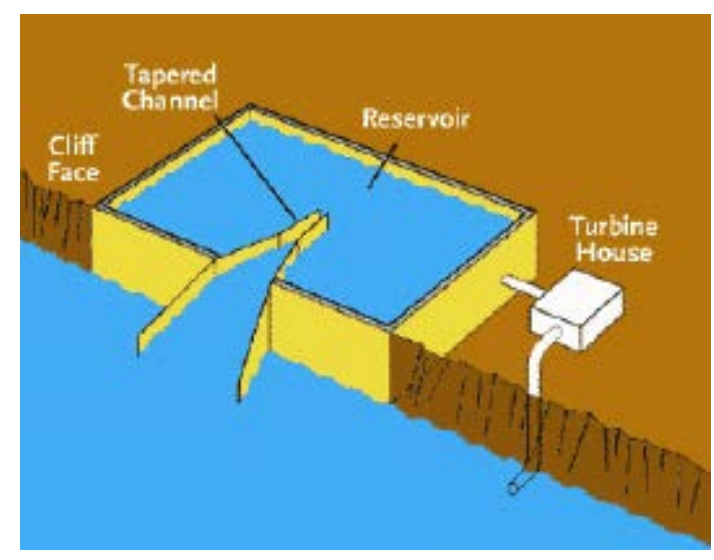

Figura 69: Esquema de dispositivo TAPCHAN (Boyle, 1996)

WAVEDRAGON: Es un dispositivo flotante que eleva las olas oceánicas hasta un depósito por encima del nivel del mar dirigiéndolas mediante unos brazos de doble curvatura y hace pasar ese agua almacenada a través de turbinas, generando electricidad como en una central hidráulica. 


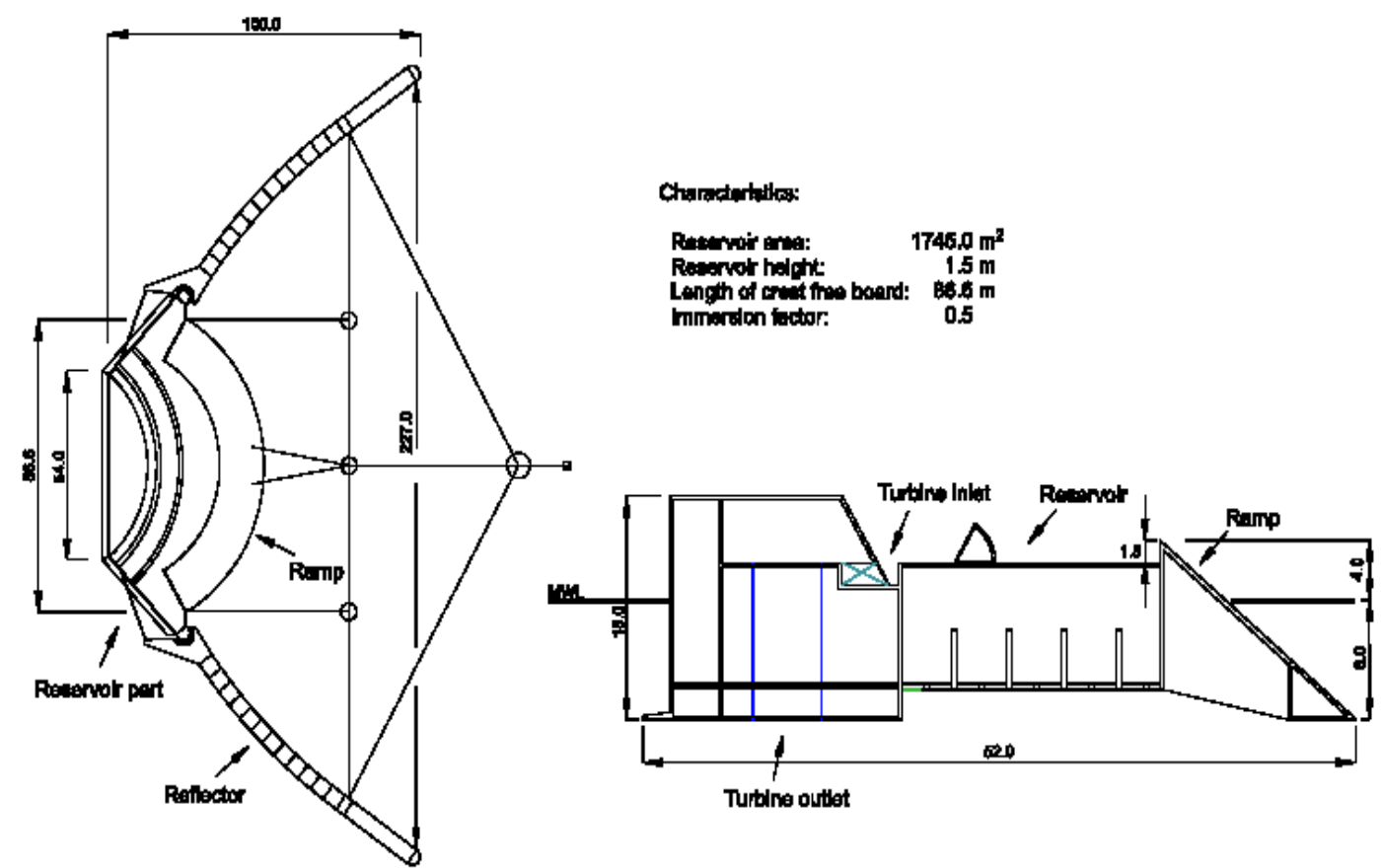

Figura 70: Planta y sección de un dispositivo WD, modelo de 1998 con rampa de curvatura simple de 40으 (22)

\subsection{ESTUDIO DE LOS DISPOSITIVOS DE CAPTACIÓN DE LA ENERGÍA DE LAS CORRIENTES Y LAS MAREAS.}

Estas tecnologías son factibles de implementar sólo en aquellas zonas de la costa en que la diferencia de la marea alta con la baja es de varios metros, en general mayor a unos cinco metros de altura. En estas condiciones es viable instalar una central mareomotriz.

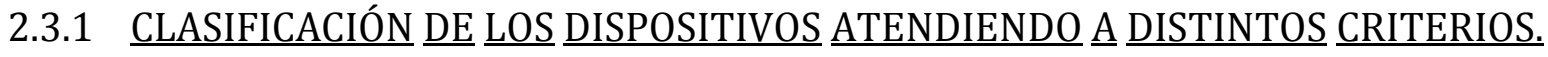

La energía procedente de las mareas se convierte en electricidad en dos pasos. Primero se convierte la energía de las corrientes en energía cinética y la energía de las mareas en potencial mediante alguno de los distintos dispositivos que absorben la energía por un proceso mecánico. En el siguiente paso, la energía absorbida por el dispositivo se convierte en electricidad mediante la combinación de turbinas y PTOs.

Los dispositivos TEC se clasifican en:

- Energía mareomotriz central barrera (Presa de marea). Es la más desarrollada en los sistemas mareomotrices, la forma más eficiente es la que tiene turbinas que aprovechan tanto la entrada del mar al embalse como la salida. 
- Generador de corriente de marea (TSG por sus iniciales en inglés) hacen uso de la energía cinética del agua en movimiento en turbinas de manera similar a la eólica.

- Turbinas de eje horizontal. Aprovechan la energía cinética contenida en las corrientes marinas.

○ Turbinas de eje vertical.

- Energía mareomotriz dinámica (DTP por sus iniciales en inglés) es una tecnología de generación en fase teórica, explota la interacción entre las energías cinética y potencial en las corrientes de marea. Se basa en la construcción de largos malecones que al entrar mar adentro generan diferencias de fase de mareas produciendo un diferencial de nivel de agua importante (al menos $2.3 \mathrm{~m}$ ) en aguas marinas ribereñas poco profundas con corrientes de mareas que oscilan paralelas a la costa. Esta tecnología se podría utilizar en la mayoría de las costas del mundo ya que no necesita de condiciones tan estrictas como las presas de marea.

\subsubsection{DISTINTOS DISPOSITIVOS.}

ENERGÍA MAREOMOTRIZ CENTRAL BARRERA.

PLANTA DE LA RANCE (Francia). Consta de 24 turbinas que generan 240MW/día y proporciona el 4\% de la energía requerida por la región de Bretaña a un costo de 0,12 $€ /$ kWh. 


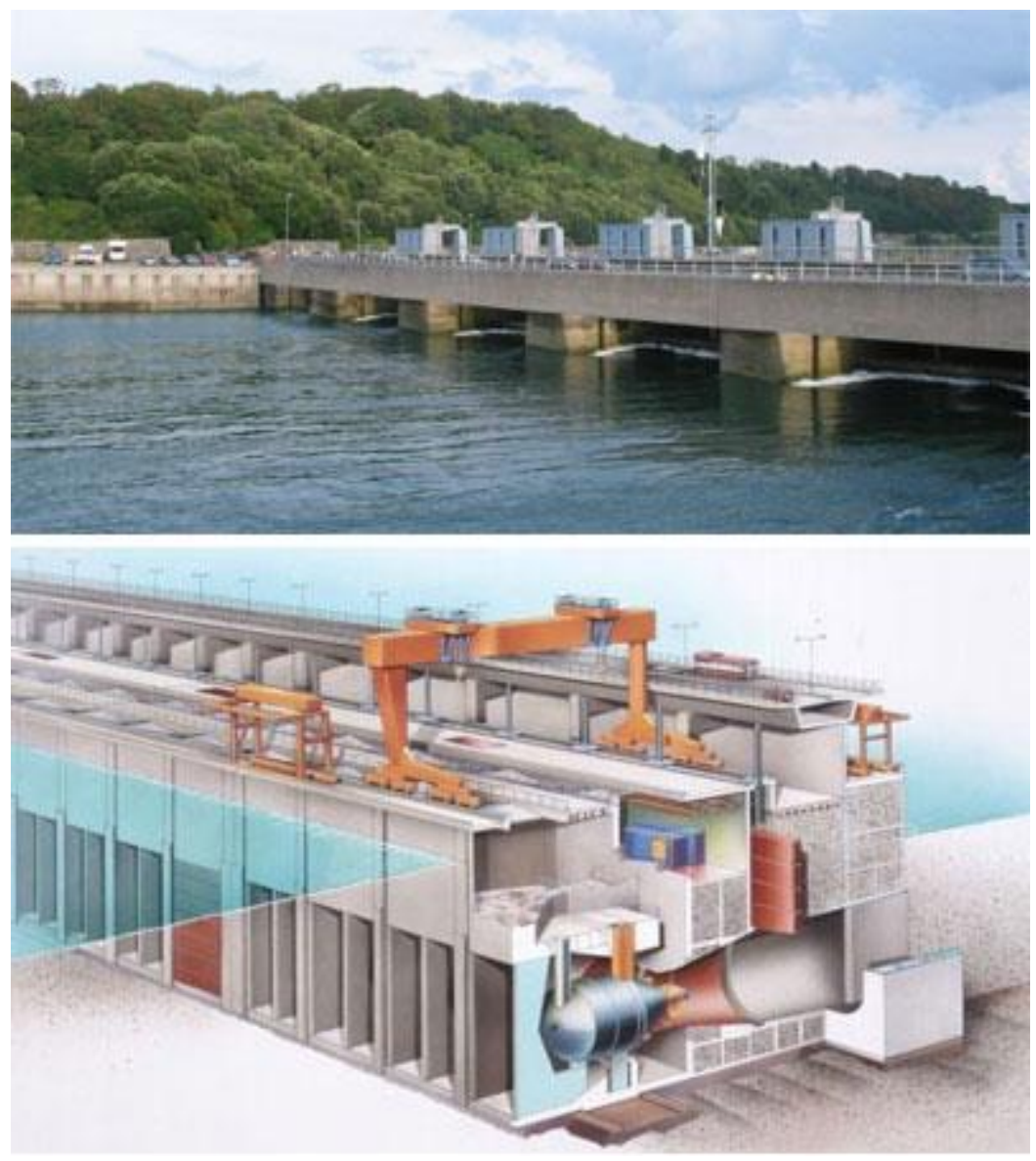

Figura 71: Foto y dibujo de la presa de marea de La Rance

PLANTA DE SHIHWA LAKE (Corea del Sur). Consta de 10 turbinas que generan 254 MW/día. LAGO DE MAREA. Consiste en una construcción similar a una presa de marea pero sin la necesidad de un estuario. Se construye un lago artificial en una línea de costa con una diferencia mareal importante.

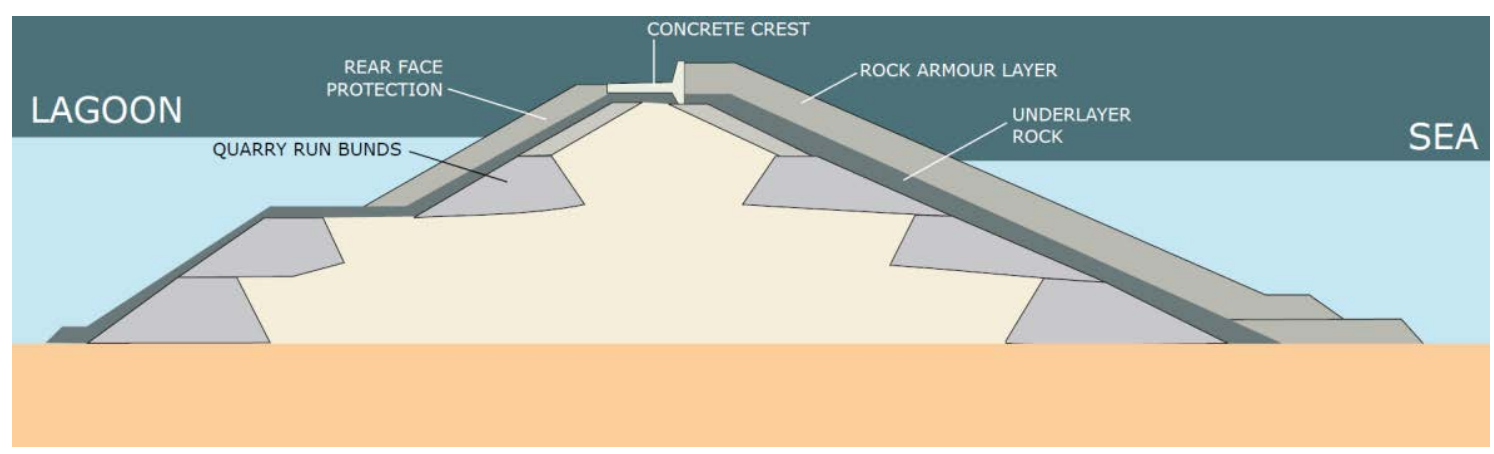

Figura 72: Perfil de la estructura de contención de un lago de marea

El diseño de la estructura civil debe tener en cuenta los efectos medioambientales que puede tener toda la estructura en las zonas cercanas por la modificación de las corrientes 
ESTUDIO DEL POTENCIAL DE APROVECHAMIENTO ENERGÉTICO DEL OCÉANO EN LA COSTA ANDALUZA.

Autora: Ma Pilar Blanco Fernández

que se producen sin embargo favorece otros usos del lago como la acuicultura, el turismo, etc.

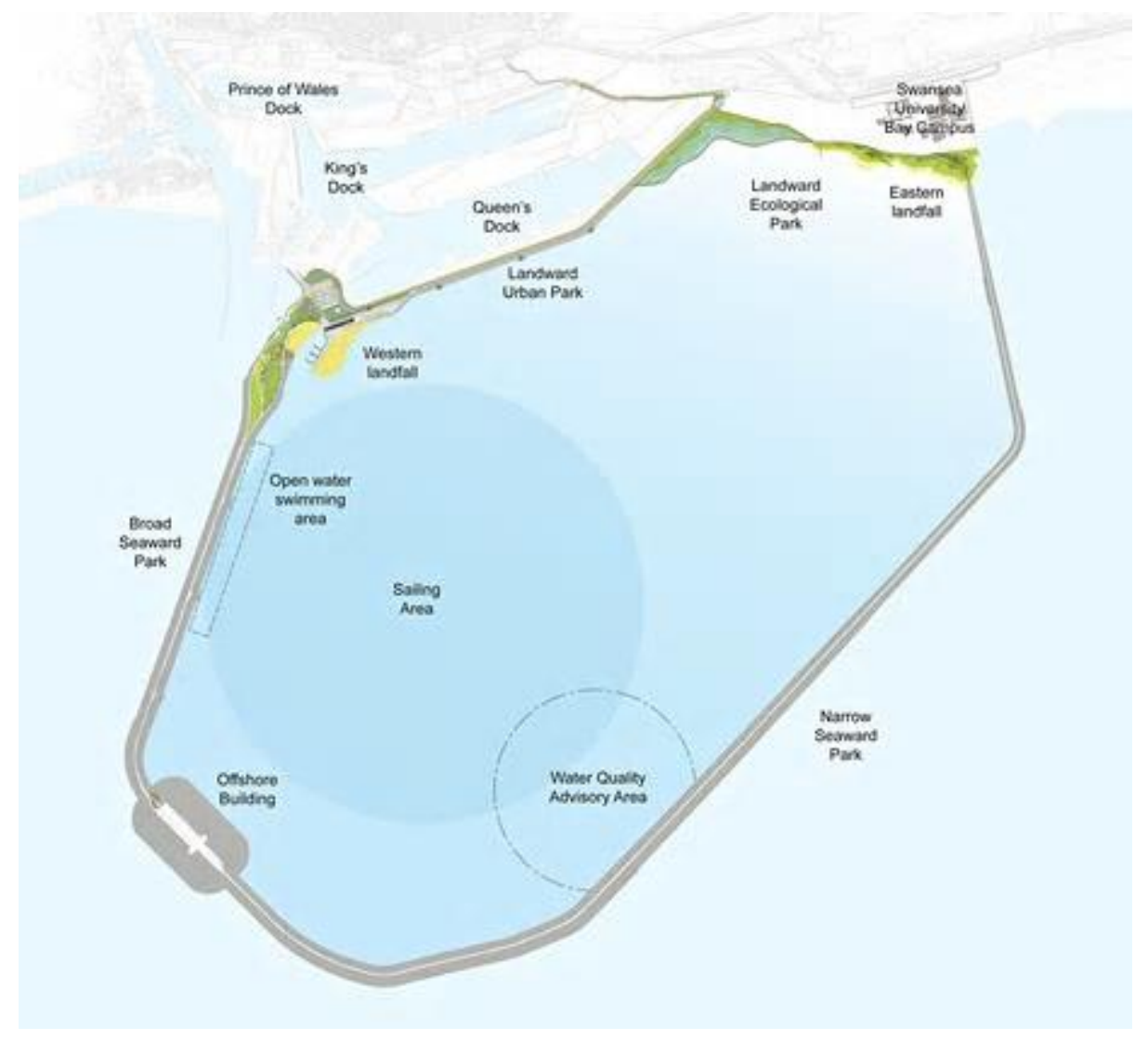

Figura 73: Plano del futuro lago de marea de Swansea Bay (Gales)

Utiliza turbinas Kaplan bidireccionales de 7m de diámetro. El número de turbinas depende de las características físicas y energéticas del lugar donde se vaya a construir. 


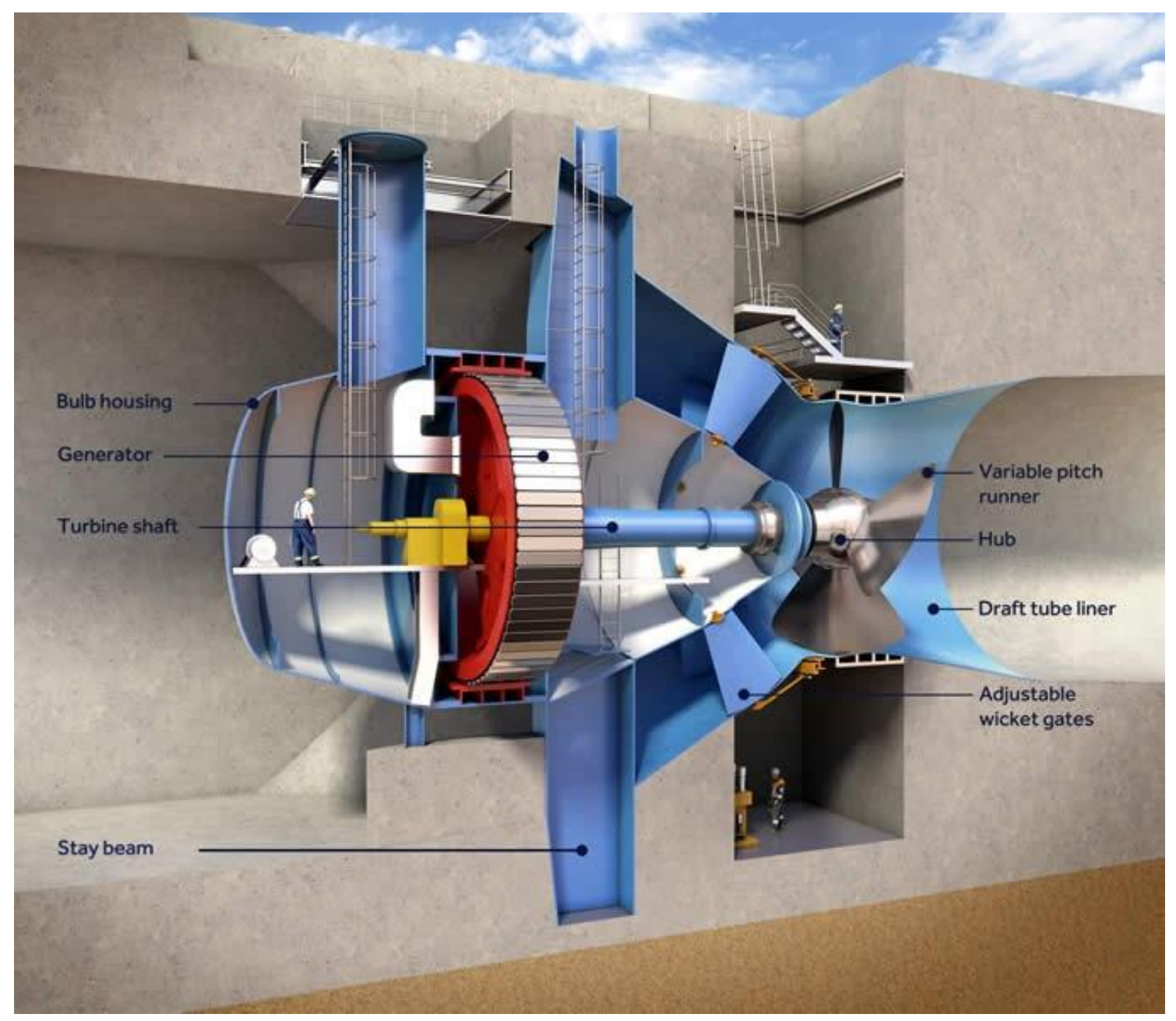

Figura 74: Elementos principales de una turbina convencional bidireccional

\section{GENERADOR DE CORRIENTE DE MAREA.}

DELTA STREAM. Dispositivo apoyado en el fondo marino sin necesidad de un sistema de anclaje o pilotaje. Genera electricidad a través de tres turbinas de eje horizontal montadas sobre una estructura común triangular 


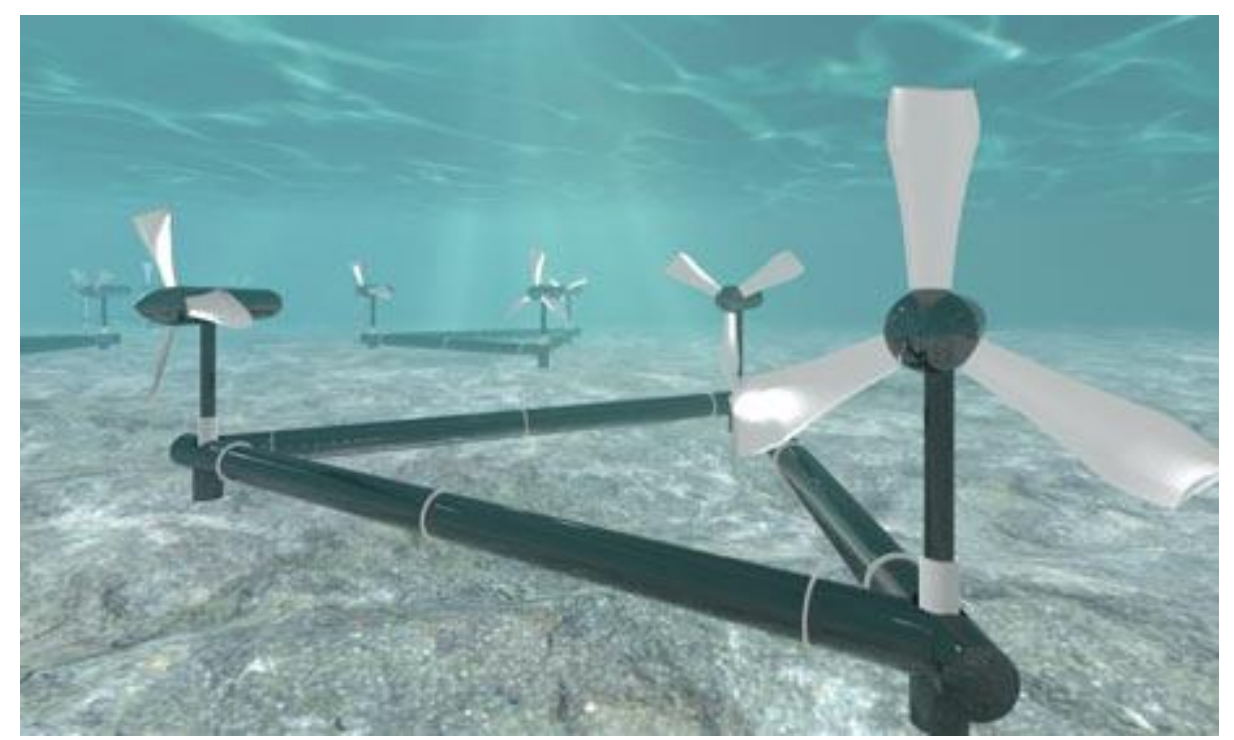

Figura 75: Infografía del dispositivo TidalStream (23)

Cada turbina tiene su propio sistema hidráulico de auto-orientación.

TURBINA BEC (24) Se trata de una turbina flotante de eje vertical basado en el diseño del ingeniero francés Darrieus que permite generar electricidad a partir de corrientes de $1 \mathrm{~m} / \mathrm{s}$ que son direccionadas mediante toberas convergentes-divergentes hacia el rotor.

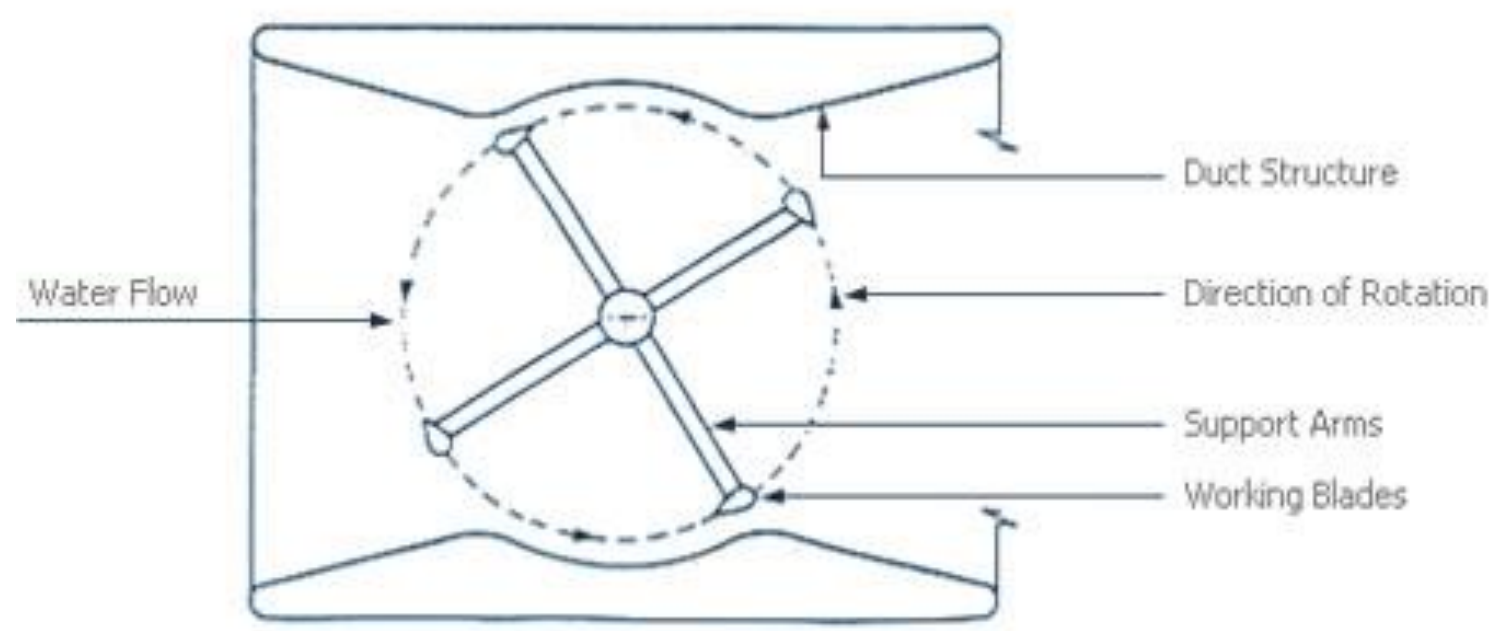

Figura 76: Corte horizontal dispositivo turbina BEC 


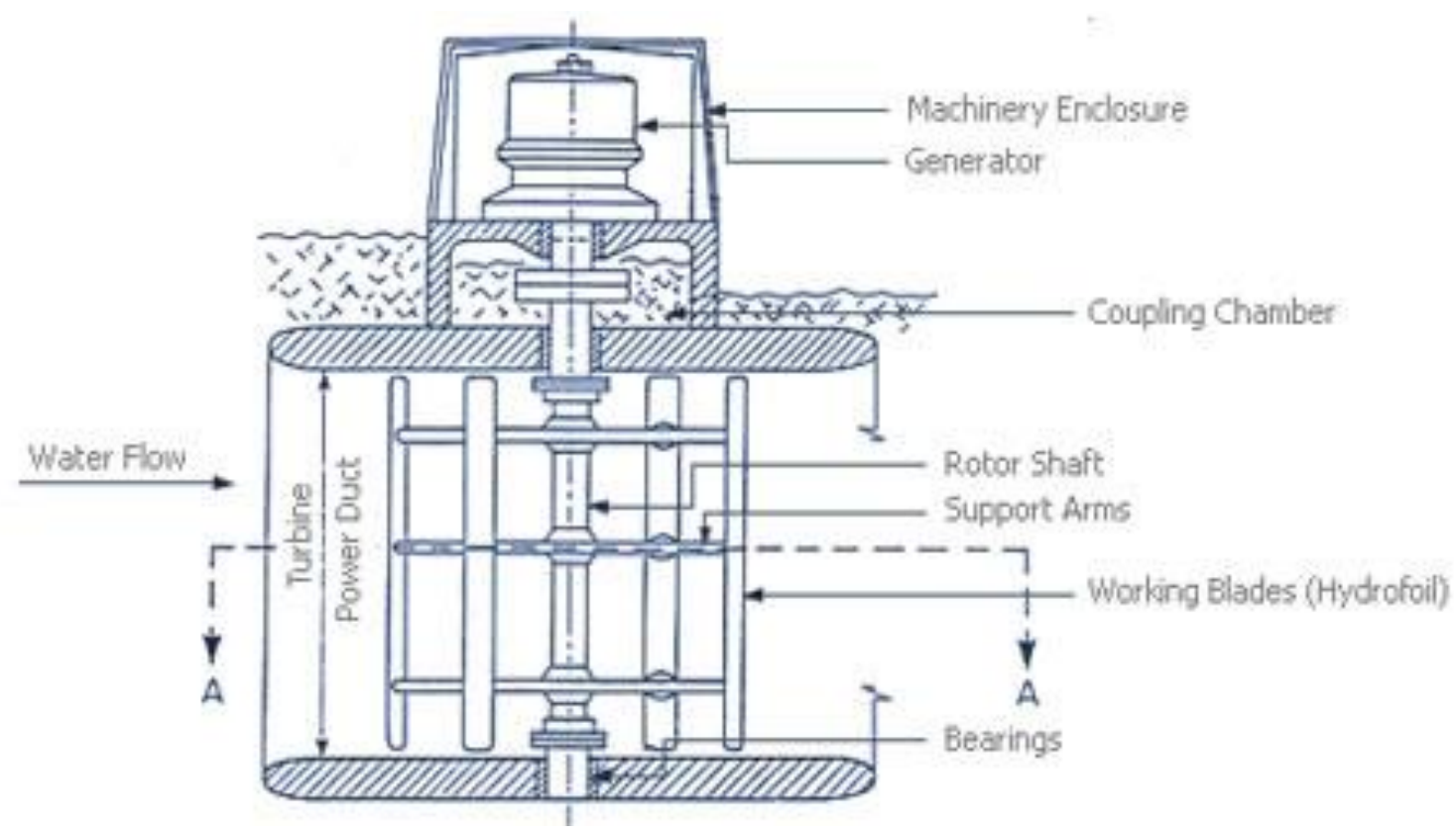

Figura 77: Corte vertical dispositivo turbina BEC

Estos dispositivos son flotantes, manteniendo la maquinaria eléctrica fuera del agua, lo que facilita su mantenimiento.

Se pueden poner en la desembocadura de los ríos y disponer varios juntos formando una barrera de marea paralela a la costa en configuración DTP

TURBINA KOBOLD: se trata de una turbina de eje vertical de 3 palas de $6 \mathrm{~m}$ de diámetro patentada por SEAPOWER scrl (25). 


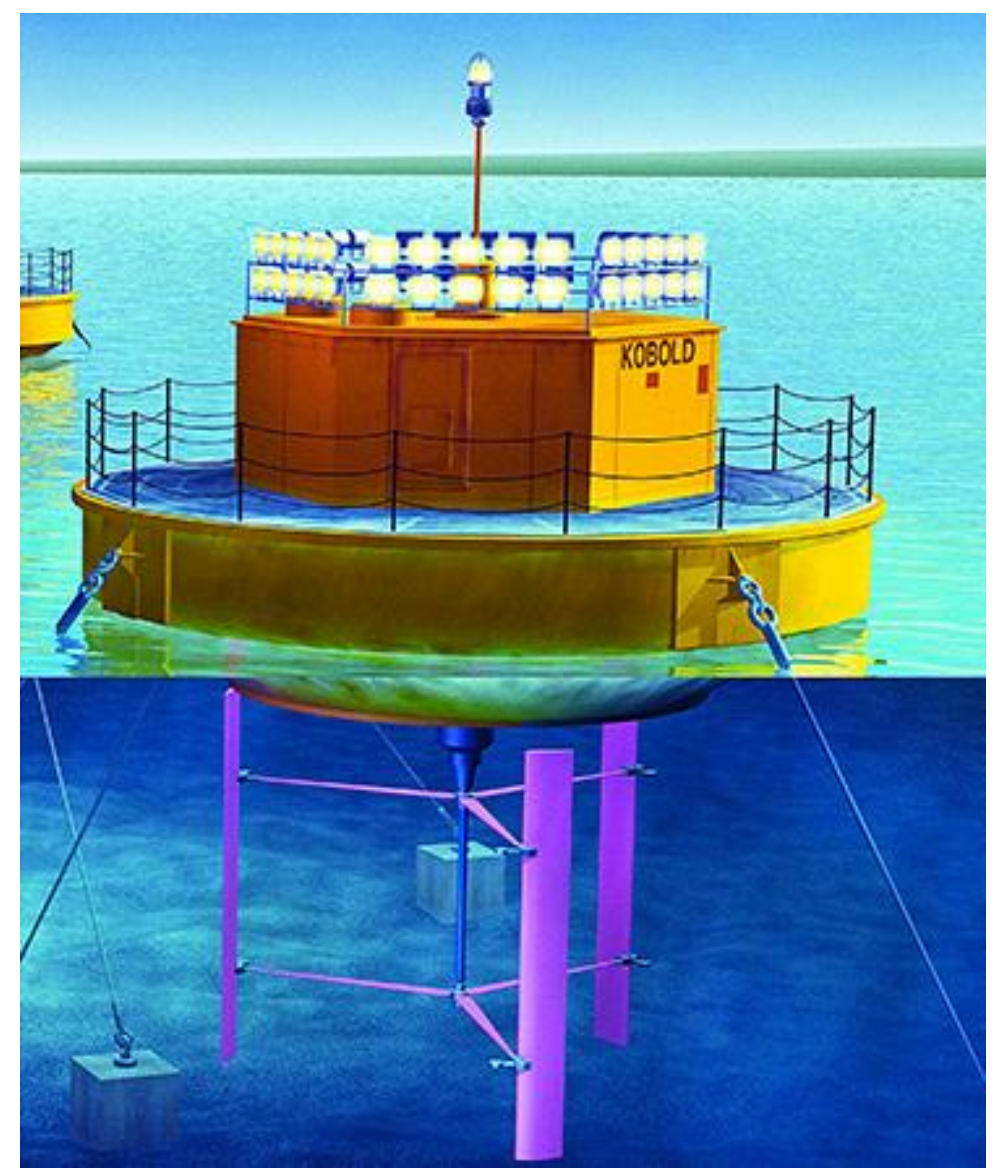

Figura 78: Dibujo de turbina Kobold (26)

Un prototipo está trabajando en el Estrecho de Messina desde el 2001 con una potencia de diseño de $100 \mathrm{~kW}$ y un rendimiento del $23 \%$

TURBINA GEM: se trata de una turbina de eje horizontal diseñada para corrientes lentas patentada por SEAPOWER scrl.
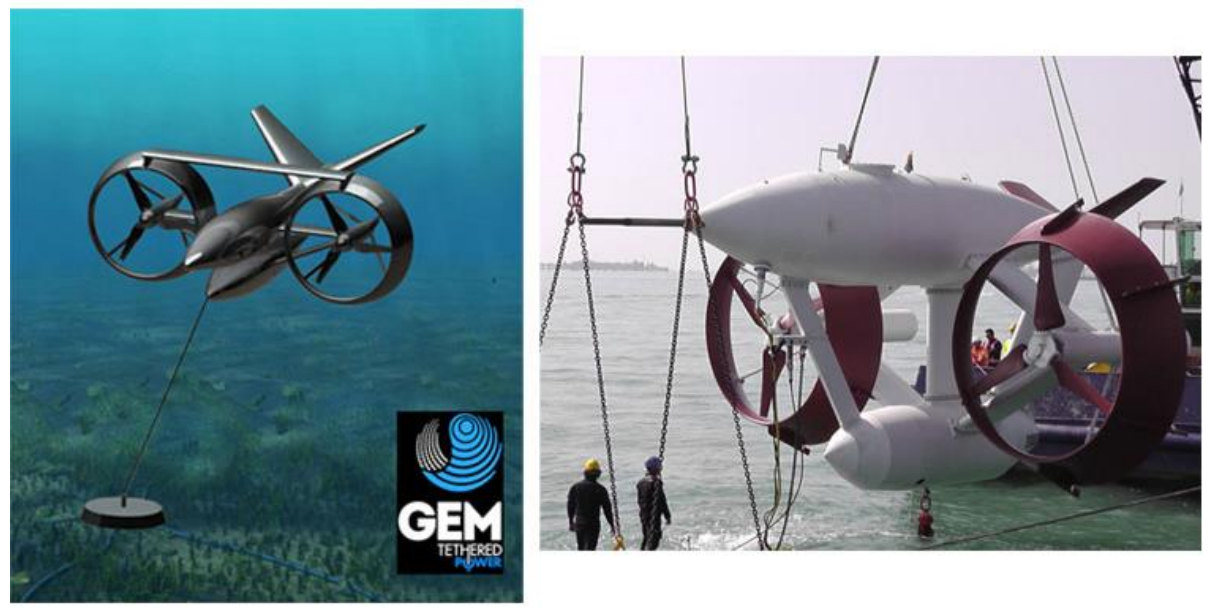

Figura 79: Turbina GEM (26) 
ESTUDIO DEL POTENCIAL DE APROVECHAMIENTO ENERGÉTICO DEL OCÉANO EN LA COSTA ANDALUZA.

Autora: Ma Pilar Blanco Fernández

El dispositivo tiene una manga de $10.4 \mathrm{~m}$, eslora total de $9.2 \mathrm{~m}$ y puntal de $5.2 \mathrm{~m}$ pudiendo sumergirse por medios propios hasta la profundidad deseada en la que se fondeará. Se auto-orienta a la corriente pero en caso de necesidad se puede orientar en remoto. MOLINO SUMERGIDO: La concepción de este tipo de dispositivos TEC proviene del diseño de aerogeneradores en tierra y consta de un molino sumergido a una cierta profundidad y fijado a un pilar central el cual está fondeado al suelo marino. Los modelos dependen del número de hélices, tipo de fondeo, etc.

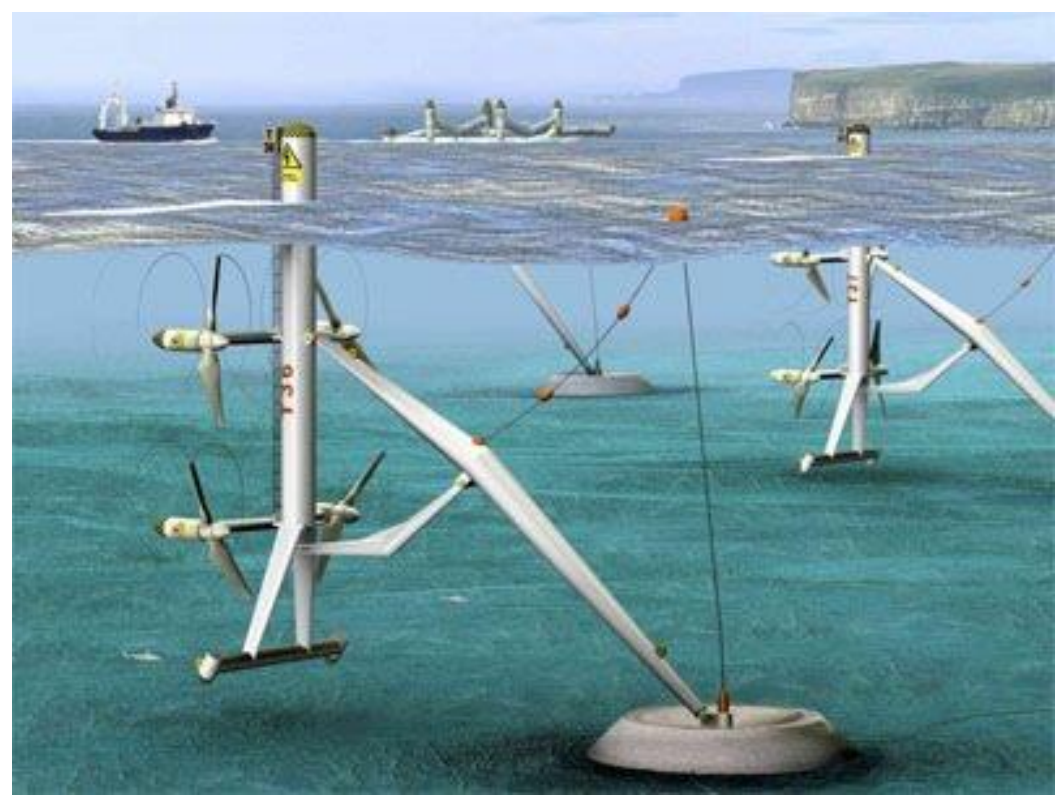

Figura 80: Dibujo de dispositivo TEC de cuatro rotores de Tidal Stream Partners (27)

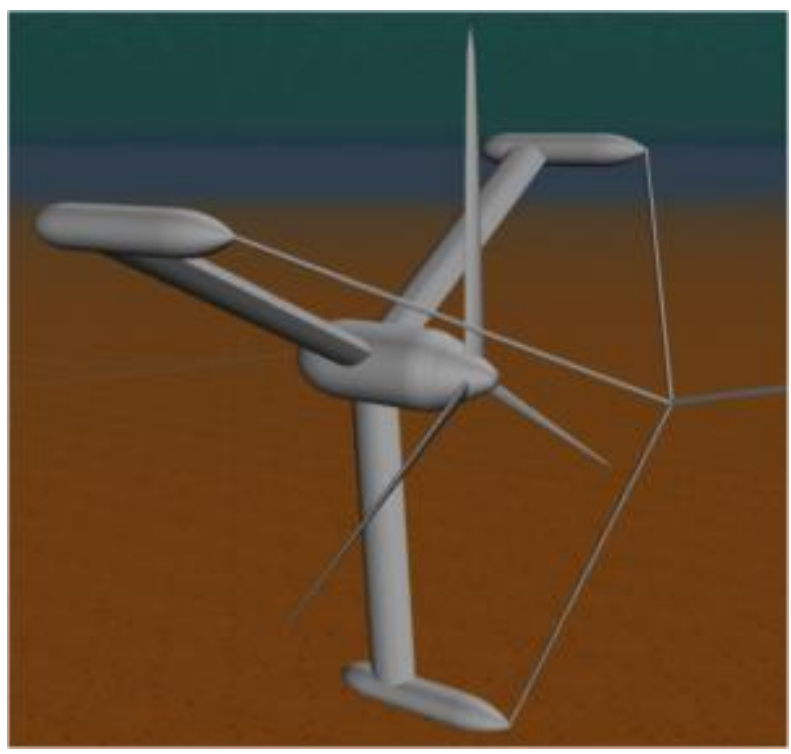

Figura 81: Infografía dispositivo TEC GESMEY (28) 
ESTUDIO DEL POTENCIAL DE APROVECHAMIENTO ENERGÉTICO DEL OCÉANO EN LA COSTA ANDALUZA.

Autora: Mạ Pilar Blanco Fernández

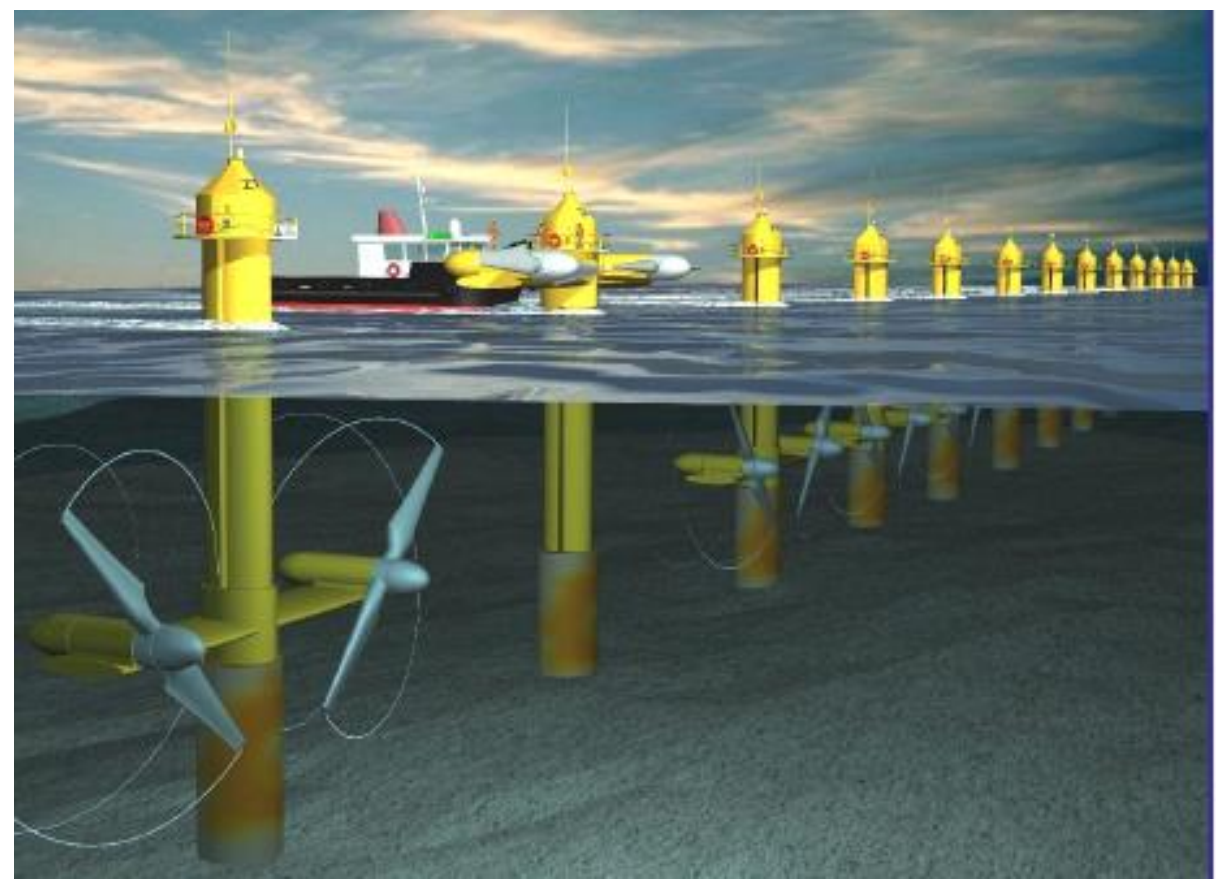

Figura 82: Dibujo de un futuro campo de generadores TEC de dos rotores (29)

LTT, TURBINA ROTECH: Se trata de una tobera convergente-divergente que tiene en el interior la turbina. Se instala en los lechos marinos por gravedad y permite modificar el tamaño para aprovechar el efecto de escala dependiendo de la velocidad de la corriente del lugar donde se vaya a instalar. (30)

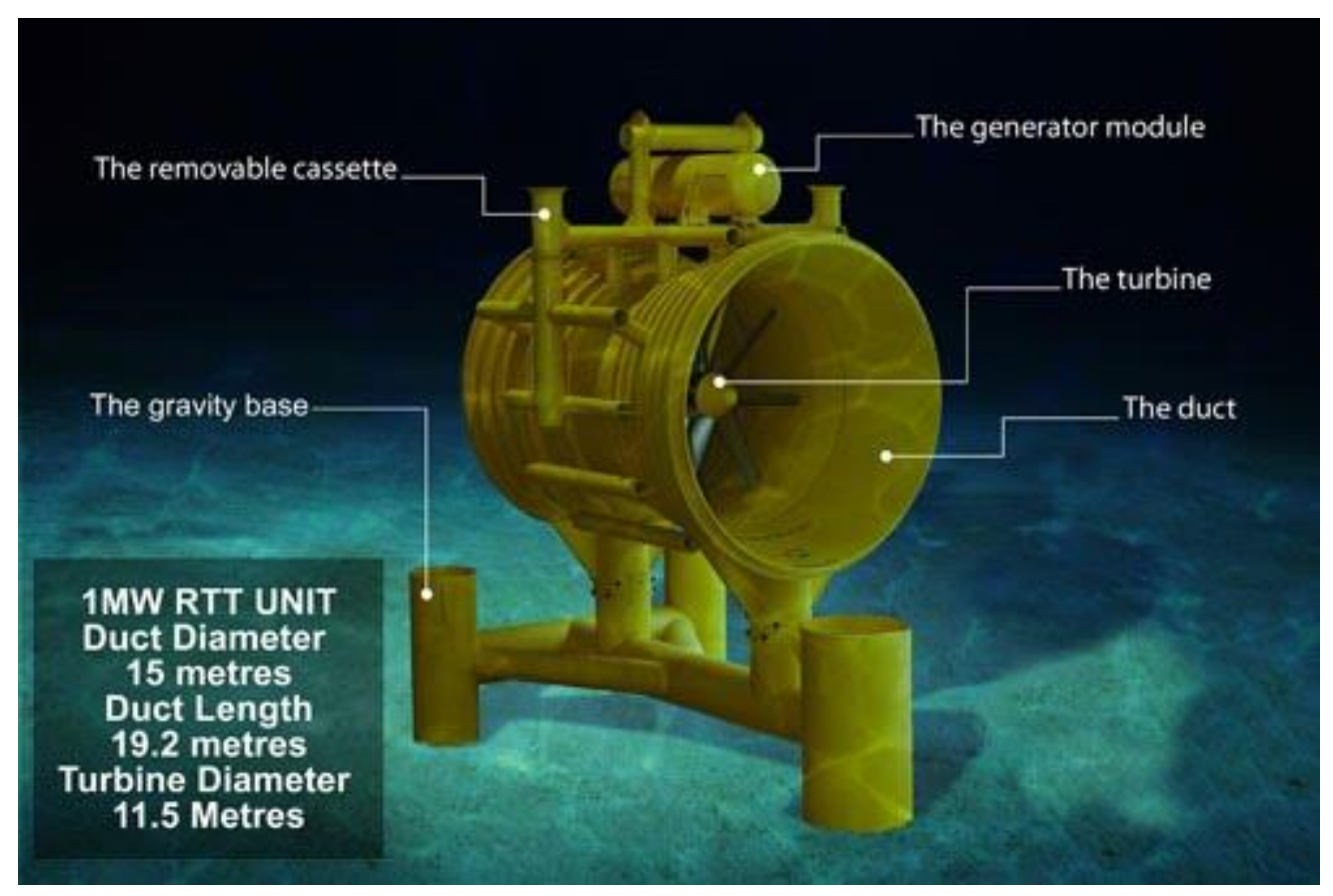

Figura 83: Dibujo de dispositivo Rotech 
Para el mantenimiento del dispositivo basta con extraer la parte central del mismo, que contiene la turbina, y llevársela a un lugar adecuado para realizarlo.

STINGRAY: Consiste en un plano horizontal de perfil hidrodinámico unido a un brazo articulado. Cuando las corrientes inciden en el perfil hace que este ascienda o descienda hasta un tope en el que el perfil cambia el ángulo de ataque produciendo que las corrientes lo muevan en sentido contrario al inicial.

El movimiento oscilatorio produce sobrepresión en aceite hidráulico que mueve los cilindros y estos en un generador. La electricidad se traslada a la costa mediante cables submarinos.

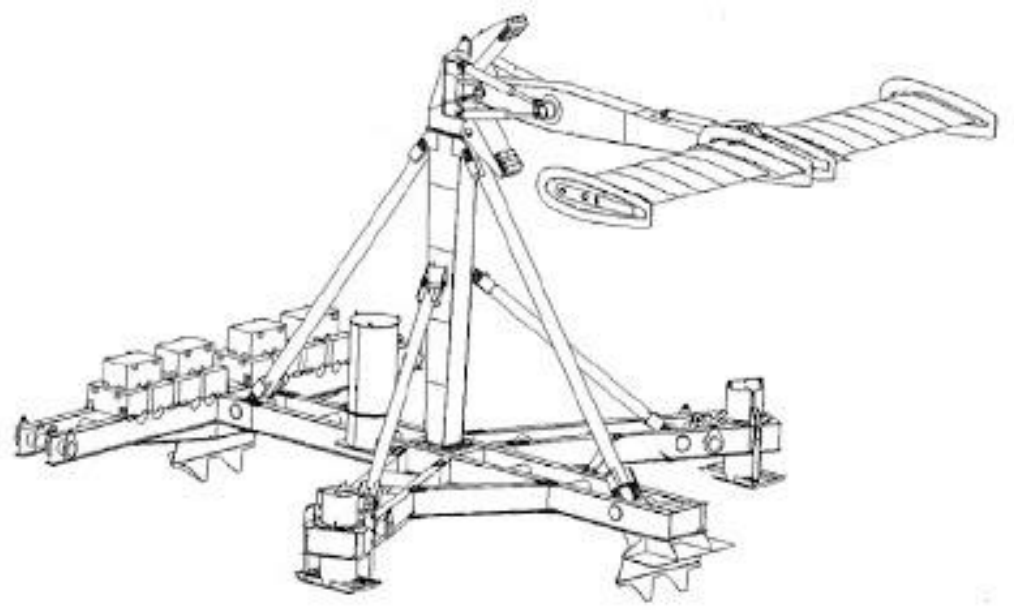

Figura 84: Diseño de dispositivo Stingray

El generador se sitúa en el fondo marino mediante una base metálica suficientemente estable. (27)

\subsection{ESTUDIO DE LA COSTA ANDALUZA}

\subsection{1 ÁREA DE ESTUDIO.}

Las distintas características que presenta la costa andaluza recomienda la presentación de los resultados del estudio divididos en distintas zonas de aplicación, aunque para la simulación hidrodinámica se estudien las influencias de áreas de mayor dimensión donde se requiera.

Inicialmente se consideran siete zonas de características uniformes en mayor o menor medida:

- Costa de Huelva, 
ESTUDIO DEL POTENCIAL DE APROVECHAMIENTO ENERGÉTICO DEL OCÉANO EN LA COSTA ANDALUZA.

Autora: Ma Pilar Blanco Fernández

- Costa Atlántica de Cádiz,

- Estrecho de Gibraltar,

- Costa Occidental de Málaga,

- Costa Oriental de Málaga, Granada y Occidental de Almería,

- Costa Sur de Almería y

- Costa Oriental de Almería.

En la Tabla 7 aparecen los valores energéticos totales en Andalucía mientras que en las Figura 85 y Figura 86 se observa la distribución de la energía de las olas y de las corrientes marinas. (31) (32)

Tabla 7: Resumen Potenciales Brutos Marinos en Andalucía

\begin{tabular}{|l|l|}
\hline TIPO DE POTENCIAL & POTENCIAL BRUTO (MW) \\
\hline Gradiente Térmico & 350 \\
\hline Gradiente Salino & Aprox. 1.000 \\
\hline Mareas & 50 \\
\hline Olas & 2.000 \\
\hline Corrientes Marinas & 7.000 \\
\hline TOTAL & 10.400 \\
\hline
\end{tabular}

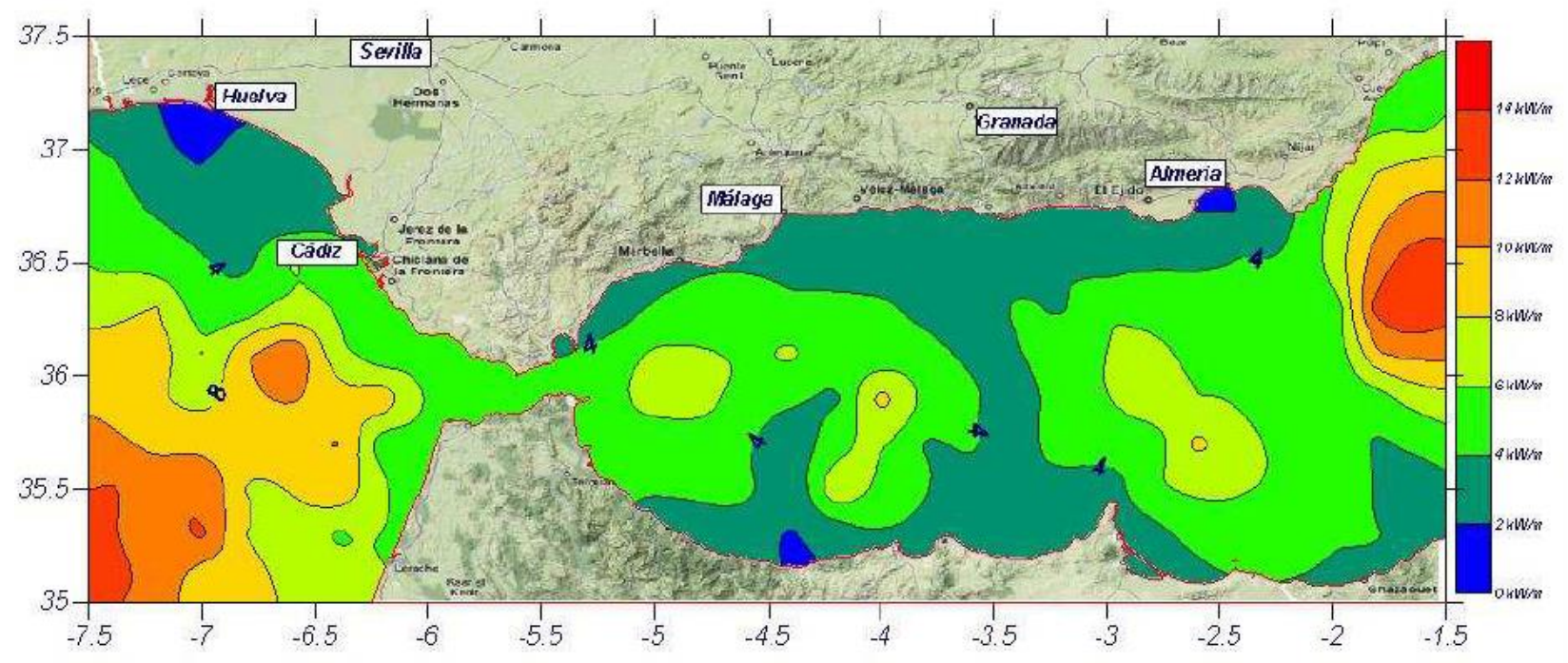

Figura 85: Flujo de energía asociado al oleaje en Andalucía 


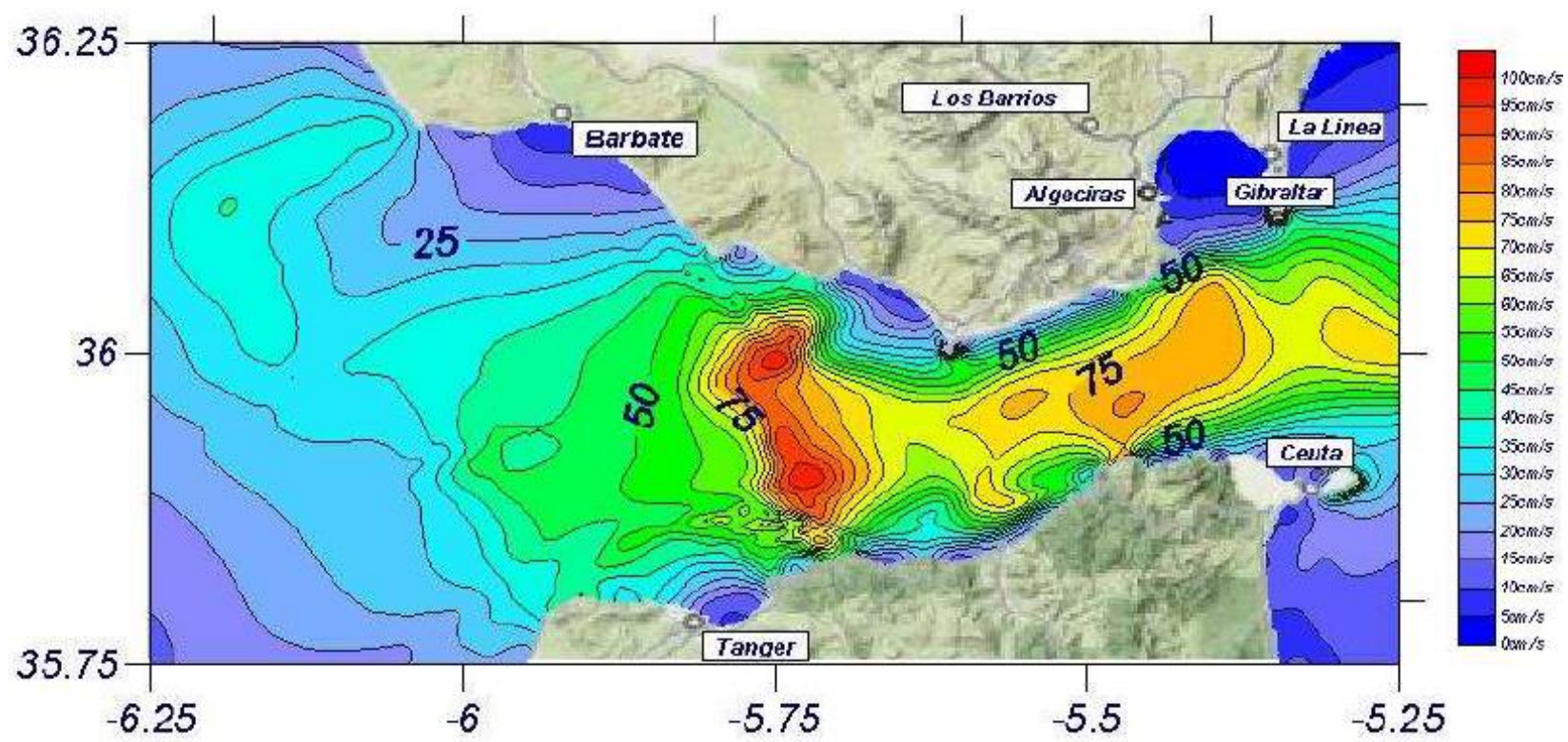

Figura 86: Potencial de corrientes marinas en Andalucía

Considerando la necesidad de enfocarse en las zonas con mayor potencial he reducido el estudio a tres zonas.

- Estrecho de Gibraltar,

- Costa Atlántica (incluye la costa de Huelva y la costa atlántica de Cádiz) y

- Costa Oriental de Almería.

La zona del Estrecho de Gibraltar es una de las zonas oceanográficas más singulares del mundo, presenta características únicas y una disposición de embudo, de este a oeste, que amplifica las enormes diferencias de todo tipo que existen entre un Océano abierto con importantes corrientes y un Mar cerrado prácticamente sin mareas, debido a la importante restricción que supone que sólo hay $13 \mathrm{Km}$ de separación entre Europa y África. Cubre las áreas descritas en la carta náutica del “Instituto Hidrográfico de la Marina” número 445. La Costa de Huelva y Costa Atlántica de Cádiz comprende el tramo entre la desembocadura del río Guadiana, frontera con Portugal, y Punta Camarinal, cerca de Bolonia.

La costa en esta zona presenta una primera subzona con forma de arco cóncavo abierto principalmente hacia el S-SO y cubre áreas descritas en las cartas náuticas del "Instituto Hidrográfico de la Marina" números 441 y 442 y una segunda subzona entre el río Guadalquivir y punta Camarinal que presenta una forma compleja, principalmente convexa, con orientación media hacia el oleaje y los vientos provenientes del 0-SO, cubre las áreas descritas en las cartas números 443 y 444 
La Costa Oriental de Almería comprende el tramo entre el Cabo de Gata y el límite con la región de Murcia.

En esta zona la costa presenta una forma recta, con orientación media hacia el oleaje y vientos provenientes del E y E-SE. Cubre las áreas descritas en las cartas náuticas del “Instituto Hidrográfico de la Marina” números 461, 359 y 360.

\subsubsection{BATIMETRÍA}

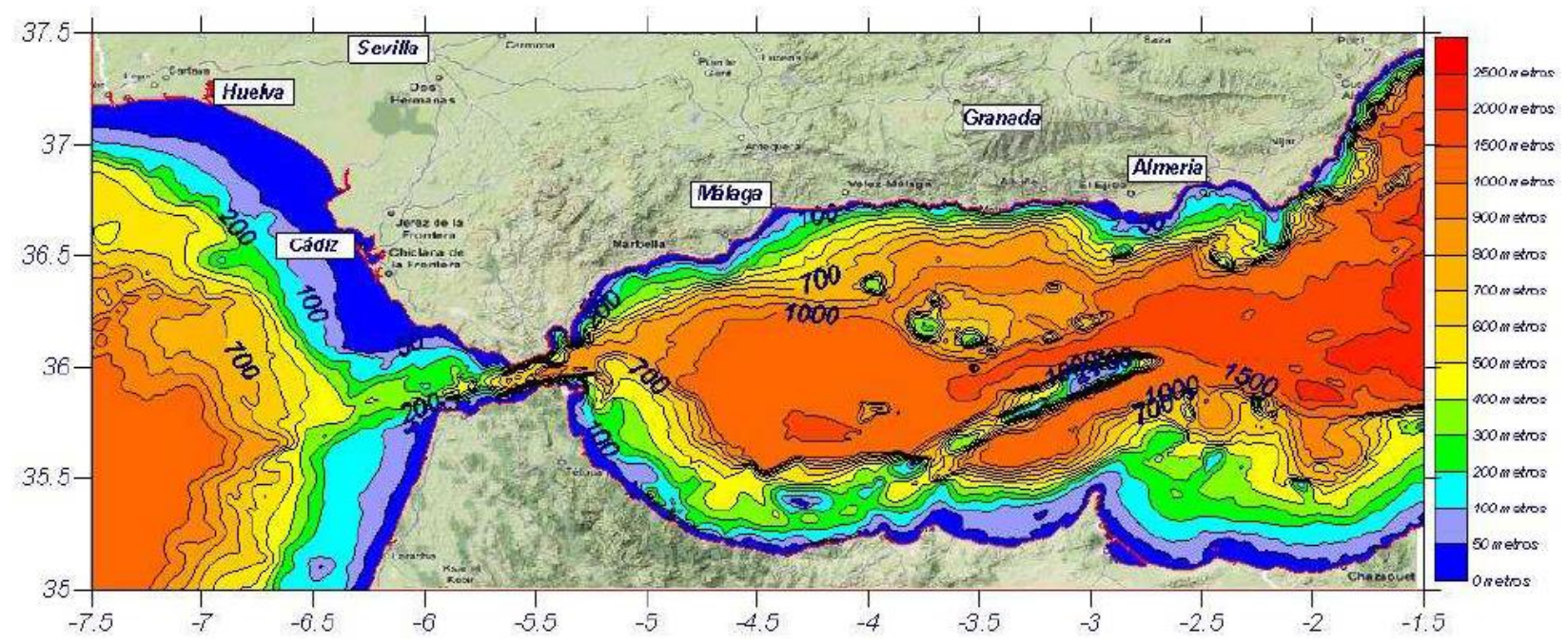

Figura 87: Batimetría (datos de IHM y de NGDC)

La batimetría del Estrecho de Gibraltar de forma general presenta un cañón de 600 metros de profundidad que conecta las zonas relativamente someras del Golfo de Cádiz con las aguas profundas del Mar de Alborán.

En más detalle, se observa que la zona occidental en su parte más profunda presenta isobatas desde $355 \mathrm{~m}$ hasta $630 \mathrm{~m}$ al noreste de Tánger. La zona oriental tiene una profundidad media superior a los $700 \mathrm{~m}$. alcanzando valores máximos de más de $1000 \mathrm{~m}$. en la depresión localizada al sur de la punta del Acebuche. 


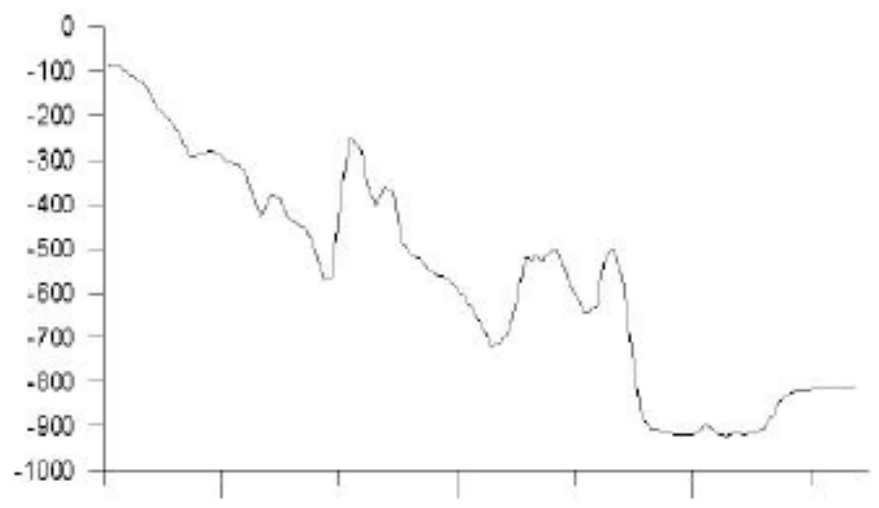

Figura 88: Perfil del Estrecho

La batimetría de la zona Atlántica es especialmente suave y uniforme, siendo la zona de mayor superficie la plataforma continental y menor profundidad media.

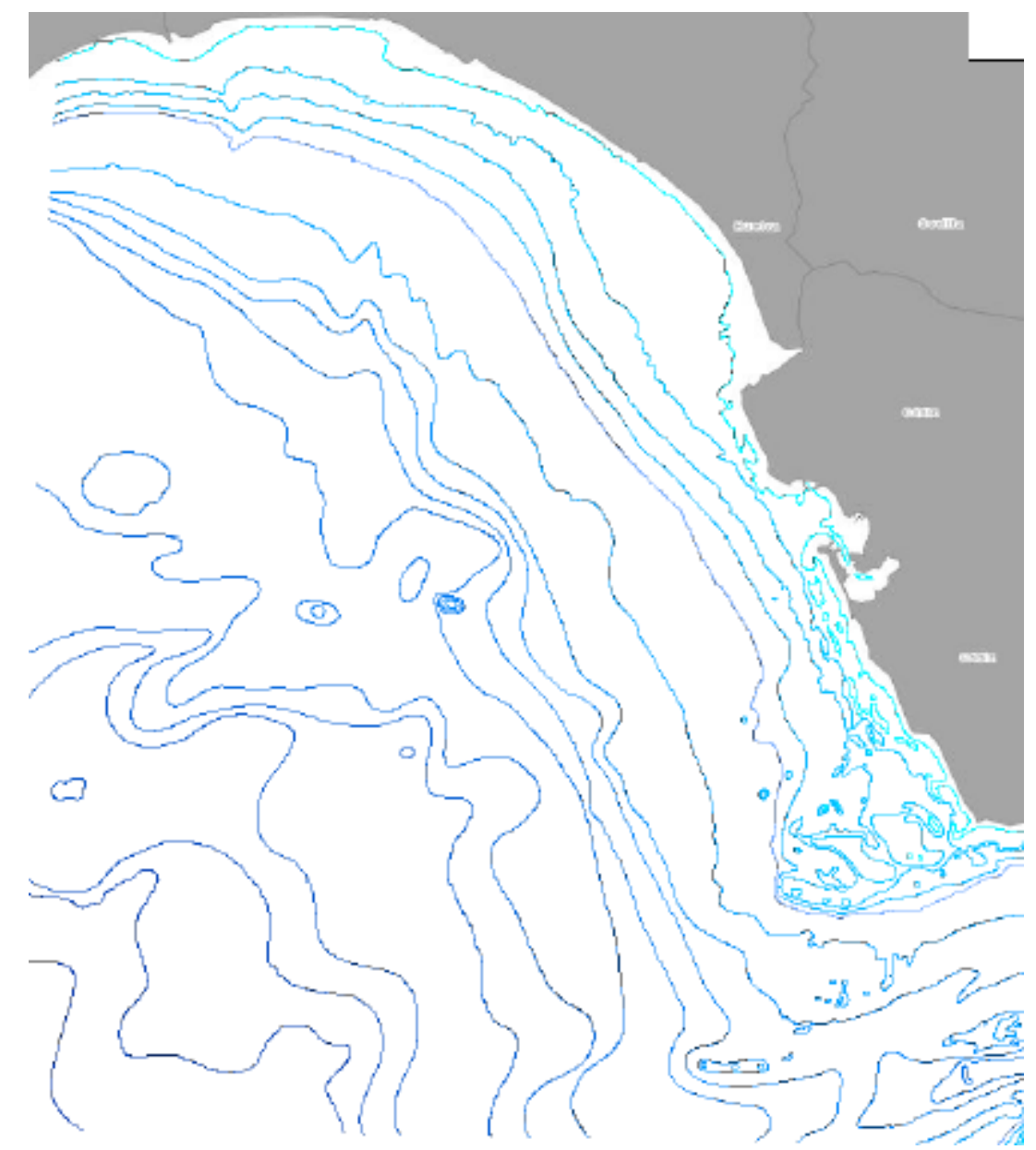

Figura 89: Batimetría de la zona Atlántica

La batimetría de la zona Oriental es la más abrupta de toda la costa Andaluza y muy compleja, presenta una escasa plataforma continental, característica común a toda la costa 
mediterránea andaluza, pero en ésta, en apenas cinco kilómetros de distancia a la costa, se superan los $1000 \mathrm{~m}$ de profundidad.

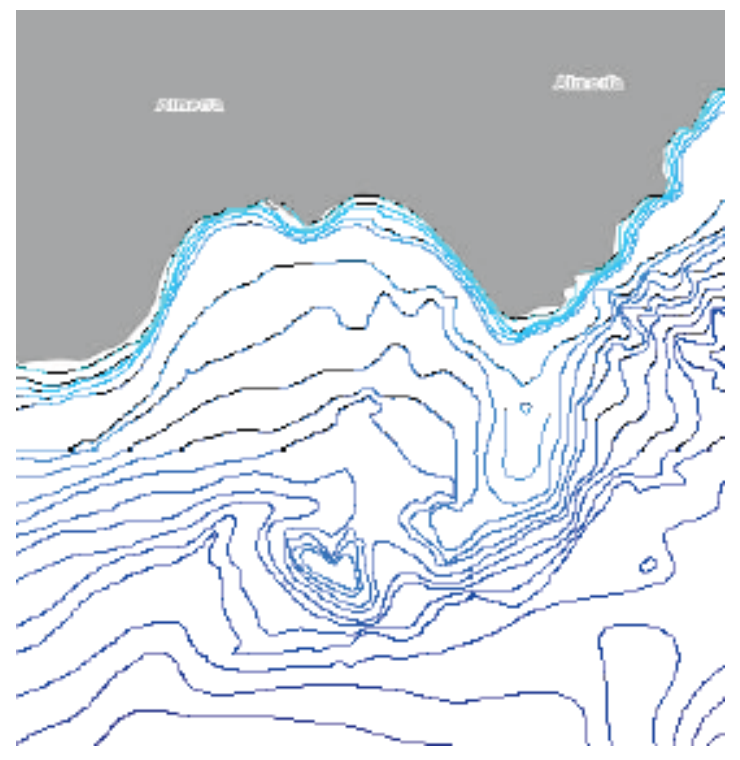

Figura 90: Batimetría de la zona oriental

\subsubsection{FONDO MARINO.}

Uno de los retos que debe superar la instalación de cualquier dispositivo de energías marinas es su fijación al fondo marino (salvo aquellos situados en la orilla) Los tipos de fondo marino para las tres zonas de interés han sido extraídos de la base de datos del "Atlas de Andalucía", datos que provienen a su vez de los metadatos proporcionados por el Instituto Hidrográfico de la Marina al Instituto Cartográfico de Andalucía.

Los mapas del fondo marino de las zonas en estudio se encuentran en el Anexo (pag. 144) Aquí se representa el tipo de fondo por cuatro tonos de azul que corresponden, de más claro a más oscuro, a suelos arenosos, fango, grava y roca respectivamente. Los fondos de roca son apropiados para la utilización de pilotes y anclajes (tensos o sueltos). Las zonas de grava son apropiadas para taladrar si son de poco espesor o para anclaje de gravedad si la profundidad es adecuada. En las zonas de fango y de arena se pueden utilizar anclajes de succión o de gravedad.

En la zona del Estrecho se observa que a pesar de la complejidad del fondo marino existen zonas muy compatibles con la instalación de equipos de generación de energías renovables marinas al separarnos de la costa. 


\subsubsection{MAREAS}

En la zona del Estrecho de Gibraltar se observa una fuerte transición del rango máximo de mareas desde los 3,70m de Cádiz hasta los tan sólo 1,60 m de Tarifa o 1,30m de Algeciras (datos de diferencia entre la pleamar y la bajamar durante las máximas mareas vivas), lo que supone una gran dificultad para estudiar el potencial de las importantes corrientes presentes en todo el área.

Partiendo de los datos de los mareógrafos de Huelva y Cádiz se puede establecer en la zona Atlántica un rango de mareas de entre 3 y 4 metros entre la pleamar y la bajamar durante las mareas vivas.

En la zona Oriental la diferencia entre la pleamar y bajamar de la marea viva equinoccial está en torno a los $0,5 \mathrm{~m}$.

\subsubsection{OLEAJE}

La zona Atlántica se plantea muy abierta a la influencia de los vientos y olas provenientes del Atlántico, pero la suave pendiente de la plataforma continental supone importantes fenómenos de asomeramiento y disipación que modifican sus características.

La zona Oriental está abierta a los vientos y oleajes provenientes desde el E, SE y S, con una amplia zona de desarrollo del oleaje o "fetch", por lo que recibe prácticamente sin modificar el mar de fondo generado por tormentas en el centro del Mediterráneo.

\subsubsection{CORRIENTES EÓLICAS (SHORE/OFF-SHORE) (33)}

El viento en Andalucía presenta una marcada estacionalidad, vientos del tercer cuadrante en primavera y verano, que viran al primero en otoño e invierno en la Andalucía Atlántica, con la excepción de Tarifa que presenta el mayor número de días de viento contabilizado a lo largo del año en toda España; mientras que en la Andalucía Mediterránea se produce una mayor diversidad de direcciones durante la primavera y el verano, para simplificarse durante el otoño y el invierno, presentando Granada la singularidad de estar más de la mitad del año bajo un régimen de calmas y permaneciendo el resto bajo los flujos del tercer cuadrante. Da lugar a un efecto monzónico en cuanto a la dirección de los vientos. En Almería la dirección N prevalece de noviembre a febrero, alcanzando su cota más elevada en diciembre (32.3\%). En cambio los meses de verano cambian los vientos a E 
(21.4\%) y SO mientras que en primavera hay cierta igualdad entre el 0 y el OSO e incluso SO.

En Huelva los vientos del tercer cuadrante son hegemónicos desde abril hasta octubre, sobresaliendo sobre el resto el SO y el SSO, alcanzando sus máximos en Julio (22.2\%) para el SO y en Junio (14.6\%) para el SSO. Para los meses de noviembre a febrero e inclusive en marzo predominan las direcciones del primer cuadrante y en concreto el NE y el N, teniendo su techo en $11.3 \%$ durante diciembre y $9.5 \%$ en marzo respectivamente. Huelva se ubica en uno de los ámbitos geográficos andaluces que menor número de Calmas registra, pues sólo presenta un $15.9 \%$ a lo largo de todo el año, y por tanto es uno de los enclaves españoles que registra mayor número de días de viento anualmente Tarifa tiene dos direcciones de viento predominantes. Los flujos direccionales de levante a lo largo de la totalidad de los meses del año, alcanzando sus cotas máximas en septiembre y octubre con el 58.7\% y el 53\% respectivamente, mientras que en abril (36.1), mayo (40.5) y junio (42.8) predominan los vientos del oeste. Se puede decir que en Tarifa la rosa de los vientos queda reducida a dos rumbos, el $\mathrm{E}$ y el $\mathrm{O}$, apuntando de noviembre a abril e incluso mayo el SO y el NO, pero como testimoniales ante el enorme empuje de las dos direcciones antes citadas.

Tarifa es el enclave andaluz y de España que menos número de días de calma registra, tiene una media anual en porcentaje de frecuencias de $2.7 \%$, siendo el verano el periodo estacional que menor índice de Calmas presenta a lo largo del año, con un 2\%, seguido del otoño, primavera e invierno. Esto es debido, en parte, al efecto orográfico de pasillo que acelera o intensifica localmente los intercambios aéreos mediterráneos-atlánticos y viceversa.

La representación de las direcciones predominantes y las potencias medias se encuentra en el Anexo (pag. 148)

\subsubsection{CORRIENTES MARINAS (SHORE/OFF-SHORE)}

El Anexo (pag. 156) representa el esquema de circulación de las masas de agua atlántica y mediterránea. La corriente de agua atlántica que se dirige hacia el sureste en el Golfo de Cádiz, se divide en dos ramas a la altura del Estrecho: una que gira hacia el suroeste para formar un gran remolino anticiclónico que cubre gran parte del Golfo y otra que gira hacia el Este para penetrar en el Mediterráneo. Esta masa de agua superficial atlántica entra en el 
Mar de Alborán a través del Estrecho de Gibraltar, constituyendo el "chorro atlántico" que es deflectado hacia el NE, formando un giro anticiclónico. La vena atlántica que circunda el giro anticiclónico, pasa al sur de la isla de Alborán tomando dirección NE, alimenta un segundo remolino anticiclónico en la zona oriental de Alborán. En algunos casos continúa hacia el E para luego desviarse hacia el N. El agua atlántica que llega al Cabo de Gata se encuentra con la mediterránea que llega en dirección SO y se produce una convergencia, viéndose empujada la atlántica hacia el SE y parte es retenida por el remolino anticiclónico oriental, continuando la otra hacia el Este. Así mismo se detecta un tipo de circulación ciclónica, entre el chorro atlántico y las costas de Estepona, por encontrarse este lugar a la izquierda de la corriente atlántica, generándose un afloramiento de aguas profundas ricas en sales nutritivas, con altos valores de salinidad y bajos de temperatura. Este hecho también se ha encontrado en aguas frente a Málaga. El agua mediterránea intermedia circula hacia el Estrecho de Gibraltar, y tras su bifurcación a la altura de la Isla de Alborán discurre por la base del talud continental hasta el Estrecho donde se une con el agua mediterránea profunda. El paso del flujo mediterráneo tiene lugar a unos $200 \mathrm{~m}$ de profundidad y se hunde por debajo de la masa atlántica. Gran parte del flujo mediterráneo sufre una inflexión hacia el norte al entrar en el Golfo de Cádiz y sigue el contorno del talud hasta que en la zona profunda del mismo se divide encauzándose en dos cañones submarinos que allí existen.

En la zona del Estrecho la máxima intensidad de corriente en superficie es de $2 \mathrm{Kn}$ hacia el Oeste y de 4 a $7 \mathrm{Kn}$ hacia Levante. Estas velocidades se registran cerca de la costa, a ambas orillas, y sobre todo en los puntos prominentes, disminuyendo en las bahías.

En la parte más angosta del Estrecho, hacia el Este, entre los meridianos de Tarifa y punta Europa la intensidad de la corriente es máxima y disminuye en el área central, al sur de punta Camarinal, sobre 1,75Kn hasta $1 \mathrm{Kn}$. (34)

En el área central la corriente de marea se sitúa en la dirección del eje, pero cerca de tierra sigue la dirección de la costa. 
ESTUDIO DEL POTENCIAL DE APROVECHAMIENTO ENERGÉTICO DEL OCÉANO EN LA COSTA ANDALUZA.

Autora: Mạ Pilar Blanco Fernández

\subsubsection{GRADIENTE $\underline{\text { SALINO }}$}

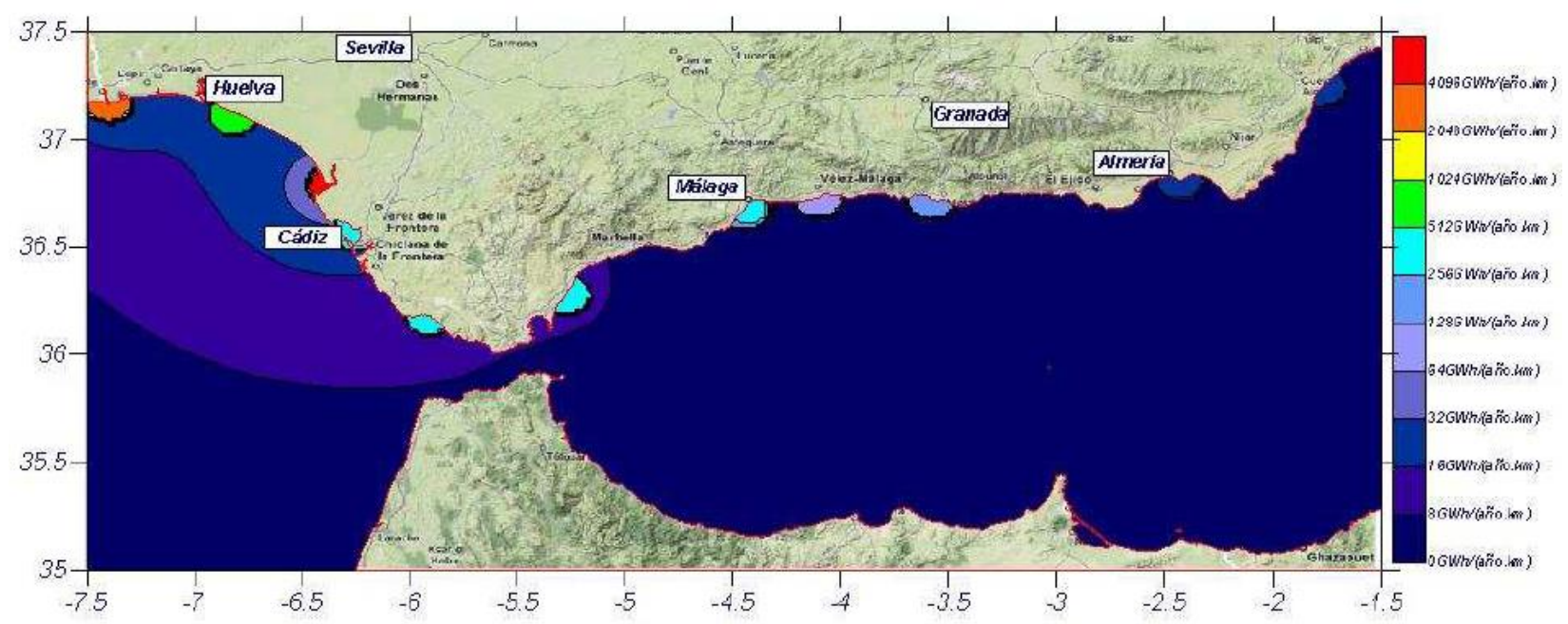

Figura 91: Potencial del gradiente salino en la costa Andaluza (31)

El potencial del gradiente salino es de media de 895 MW en el Océano Atlántico y 101 MW en el Mar Mediterráneo.

Este vector energético es poco explotable con un alto impacto económico y ambiental.

Por las condiciones climáticas de la Comunidad el gradiente salino varía mucho durante el año y el caudal es pequeño.

Por estas razones no se considerará esta energía en el capítulo 2.5

\subsubsection{GRADIENTE TÉRMICO}

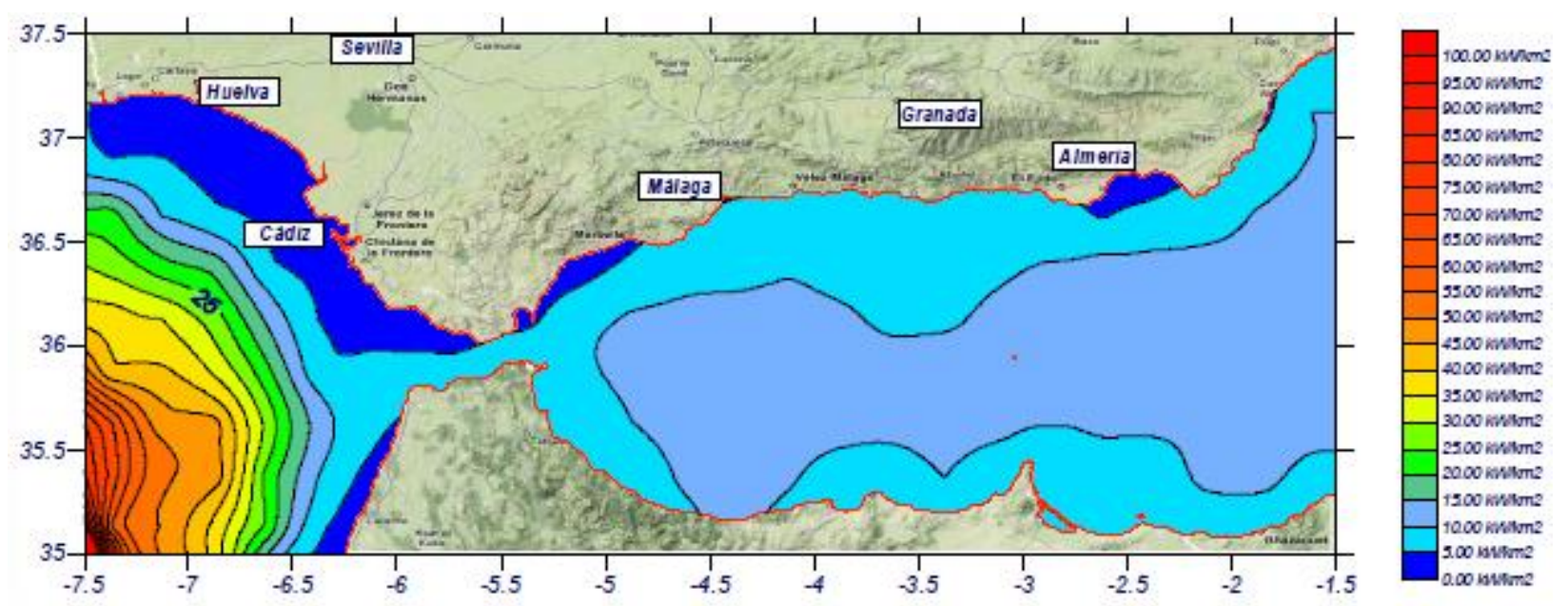

Figura 92: Densidad térmica de la costa Andaluza (31) 


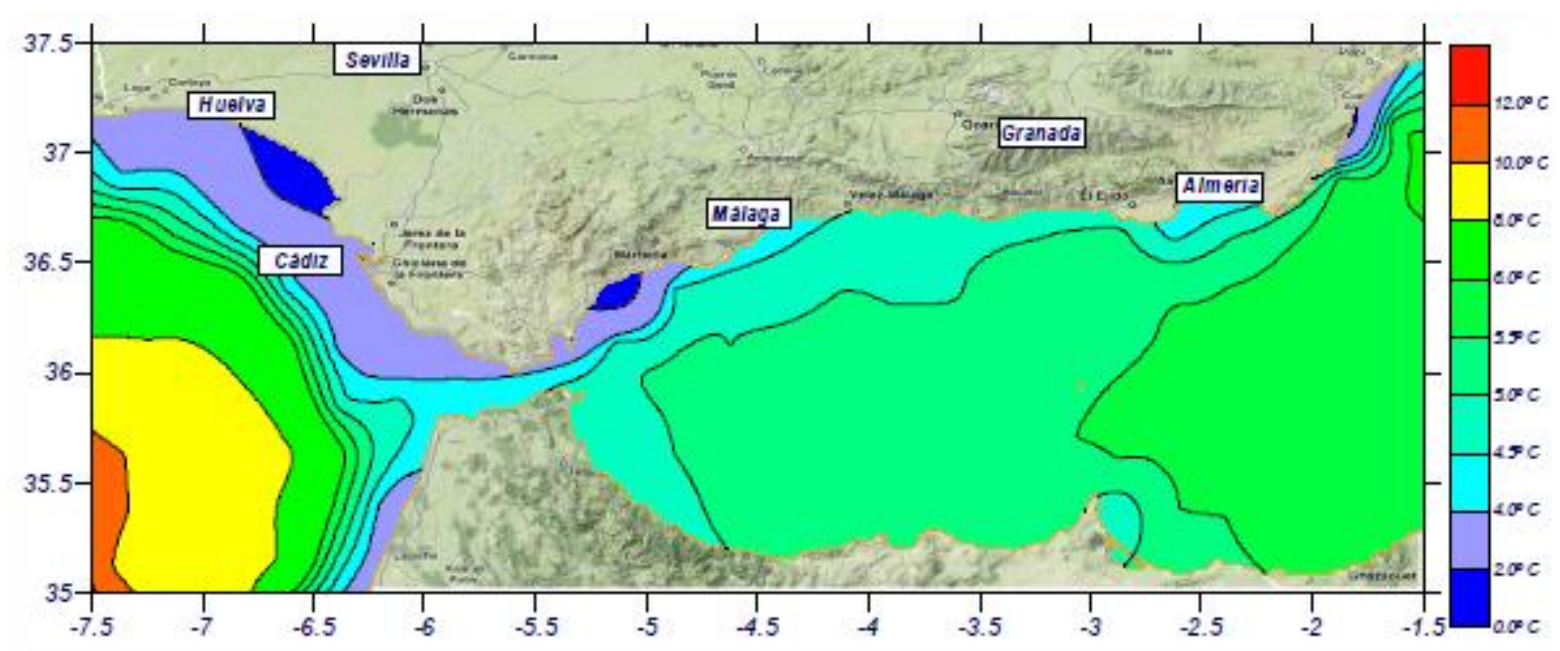

Figura 93: Diferencias de temperatura en la costa Andaluza (31)

La máxima densidad energética está en torno a los $40 \mathrm{KW} / \mathrm{Km}^{2}$, representando una potencia de 350MW a 100 años.

En la Figura 93 se observa que el salto térmico es inferior a $10^{\circ} \mathrm{C}$, mientras que es necesario un salto térmico de $20^{\circ} \mathrm{C}$ para que las tecnologías que aprovechan esta energía sean aplicables. Por esta razón, no estudiaré dispositivos que aprovechen el salto térmico en el capítulo 2.5

\subsubsection{ZONAS DE EXCLUSIÓN}

Las zonas de exclusión son aquellas áreas que se deben excluir del estudio por sus potenciales efectos ambientales negativos o conflictividad con otros usos del medio marino. Para su definición se han utilizado los siguientes grupos temáticos:

1. Para la protección de la biodiversidad (con los correspondientes permisos pueden ser utilizadas):

a. Lugares que actualmente componen la Red Natura 2000 (Zonas de Especial Protección para las Aves y Lugares de Importancia Comunitaria)

b. Áreas marinas susceptibles de ser declaradas en el futuro Parque Nacional, según estudio realizado al efecto por el Organismo Autónomo Parques Nacionales.

c. Hábitat prioritarios o de interés comunitario u otros hábitat marinos con gran valor ambiental y fragilidad frente a estas instalaciones (en general coinciden con hábitat de gran valor para la conservación de los recursos pesqueros) 
d. Banda de protección y amortiguación de 6 millas desde la línea de costa en torno a los humedales de importancia internacional Ramsar (www.ramsar.org) para la conservación de las principales rutas migratorias a lo largo del litoral, Salinas de Cabo de Gata, Punta Entinas-Sabinar y Albufera de Adra en el Mediterráneo; Marismas del Odiel, Doñana y Bahía de Cádiz en el Atlántico.

e. Enclaves de excepcional importancia para la migración de las aves y otros grupos biológicos: paso del Estrecho (esta zona sólo sería de exclusión para los aerogeneradores marinos)

2. Para la protección de las especies, hábitat y actividad pesqueros:

a. Áreas de instalación de las almadrabas reguladas por el MAPA, según cartografía aportada por la Secretaría General de Pesca Marítima.

3. Para la prevención de riesgos derivados de eventuales accidentes con el tráfico marítimo (de acuerdo con la disposición adicional segunda del RD 1028/2007):

a. Dispositivos de separación del tráfico y zonas aledañas, comunicados por la Dirección General de Marina Mercante

4. Para la protección de los bienes materiales:

a. Todos los yacimientos conocidos por la Dirección General de Costas de arenas explotables (claves para la regeneración de playas)

5. Zonas de uso militar (con los correspondientes permisos pueden ser utilizadas) La Junta de Andalucía muestra especial interés por la vulnerabilidad del patrimonio histórico y las afecciones sobre el paisaje que podrían producirse frente a la instalación de parques marinos. (35)

La Consejería de Agricultura y Pesca considera necesario asegurar el tránsito de las especies altamente migratorias a través del Estrecho de Gibraltar. Insiste en la necesidad de poner en marcha proyectos de pequeña envergadura para la evaluación real de las repercusiones que puedan ocasionar este tipo de infraestructuras a la actividad pesquera en particular y a los recursos en general.

La Consejería de Medio Ambiente estima que deben contemplarse como zonas de exclusión los espacios naturales protegidos ya sea a través de figuras de carácter autonómico, estatal o internacional. Asimismo, establece que a dichas áreas deberían añadirse los espacios 
designados como Important Bird Area (IBA) por la Sociedad Española de Ornitología, dada la importancia que dichos espacios tienen para la ornitofauna. De igual forma, propone la consideración como zonas de exclusión de los hábitat comprendidos en el Real Decreto 1997/1995, de 7 de diciembre y sus posteriores modificaciones, en concreto, 1110- Bancos de arena cubiertos permanentemente por agua marina poco profunda; 1120- Praderas de Posidonia Oceánica; 1140- Llanos fangosos o arenosos que no están cubiertos de agua cuando hay marea baja. Señala la vital importancia del Estrecho de Gibraltar como conexión entre el Mediterráneo y el Atlántico para innumerables especies.

La Dirección General de Bienes Culturales de la Consejería de cultura considera necesario que se tengan en consideración las normas vigentes sobre patrimonio histórico y los planes y Programas aplicables en la Comunidad Autónoma. Determina que deberían contemplarse como zonas de exclusión las zonas y servidumbres arqueológicas ya delimitadas y cartografiadas. Sin embargo, también plantea que por motivos de conservación de estos bienes no sean dadas a conocer las coordenadas de localización de los bienes de interés cultural sumergidos, lo que resulta incompatible con incluirlos en la representación gráfica que se haga pública de zonas de exclusión. Igualmente, considera que deben establecerse las medidas correctoras y demás actuaciones que eviten cualquier pérdida o deterioro del patrimonio histórico para las nuevas localizaciones en cumplimiento de lo previsto en la normativa autonómica sobre Patrimonio de Andalucía (orientación de calificaciones del suelo hacia áreas de menor riesgo, realización de catas o estudios previos, incorporación de informes arqueológicos, entre otros)

La Consejería de Obras Públicas y Transportes insiste en que los futuros parques marinos deberían cumplir las determinaciones establecidas en los Planes de Ordenación del Territorio de ámbito subregional en Andalucía y las futuras modificaciones o revisiones de estos Planes 


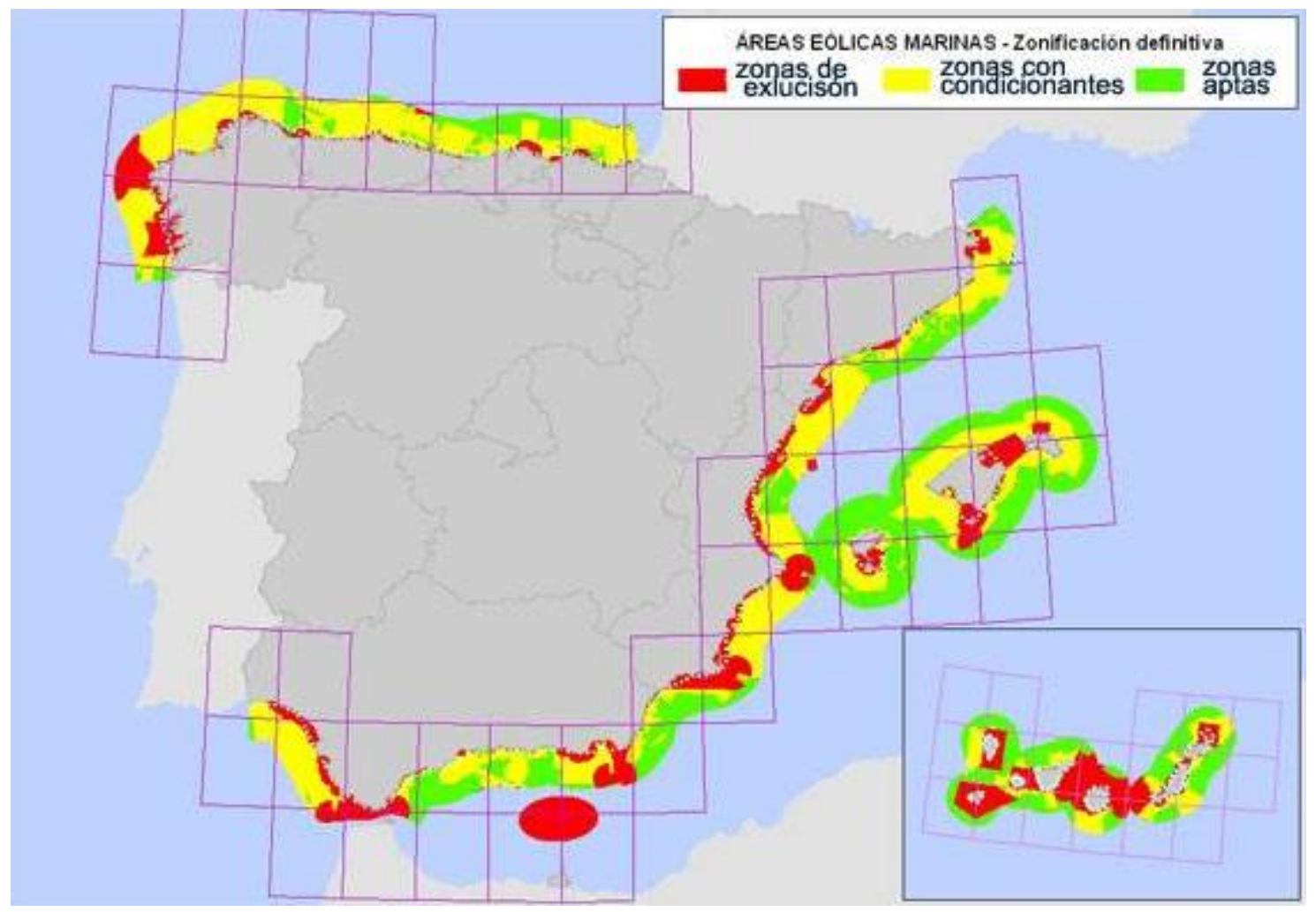

Figura 94: Mapa eólico marino de España (36)

En la Figura 94 se representan las zonas donde se pueden instalar parques eólicos marinos cerca de la costa. Estas mismas zonas se pueden utilizar para instalar otros dispositivos de energías renovables marinas.

Por sus características especiales solo estudiaré en detalle la zona del Estrecho.

\subsubsection{RUTAS DE NAVEGACIÓN.}

En el Estrecho de Gibraltar existe un tráfico de unos 82.000 buques anuales, de los cuales 12.000 son movimientos entre África y Europa.

Este tráfico está delimitado por dos canales definidos por las siguientes coordenadas:

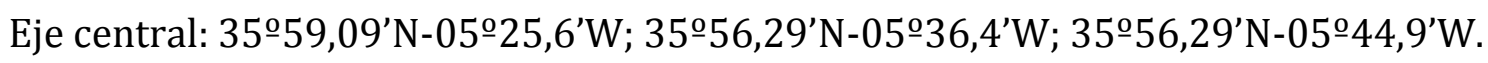

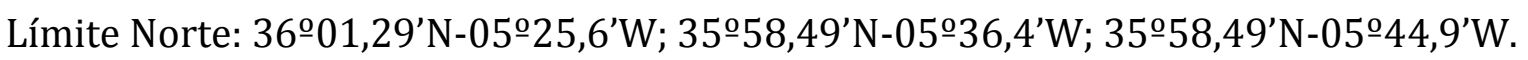

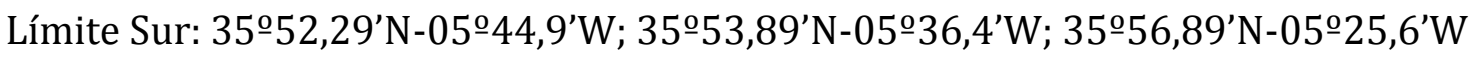
Las zonas situadas entre los límites exteriores del dispositivo y las costas se consideran zonas de navegación costera. 


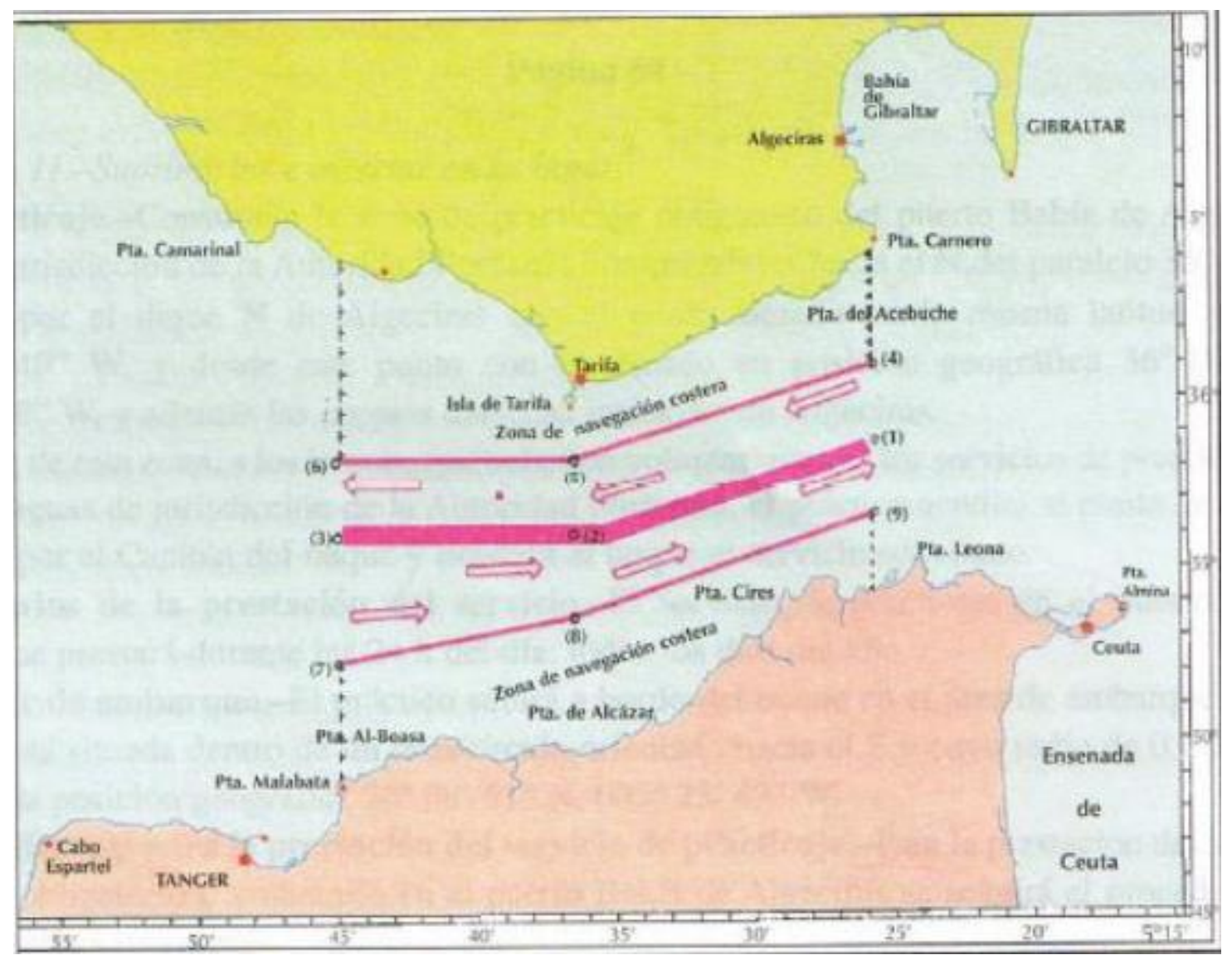

Figura 95: Canales de navegación zona Estrecho

Dentro de la navegación hay que añadir a los submarinos que, aunque no se puede especificar, suelen utilizar la parte más profunda y central del Estrecho.

\subsubsection{ZONA MILITAR.}

En la zona del Estrecho las zonas militares se presentan en la Figura 96, las zonas en rojo indican baterías de costa de radio 50Km (Punta Paloma y Monte Camarinal). La parte negra indica las zonas terrestres y en azul el campo de tiro. 


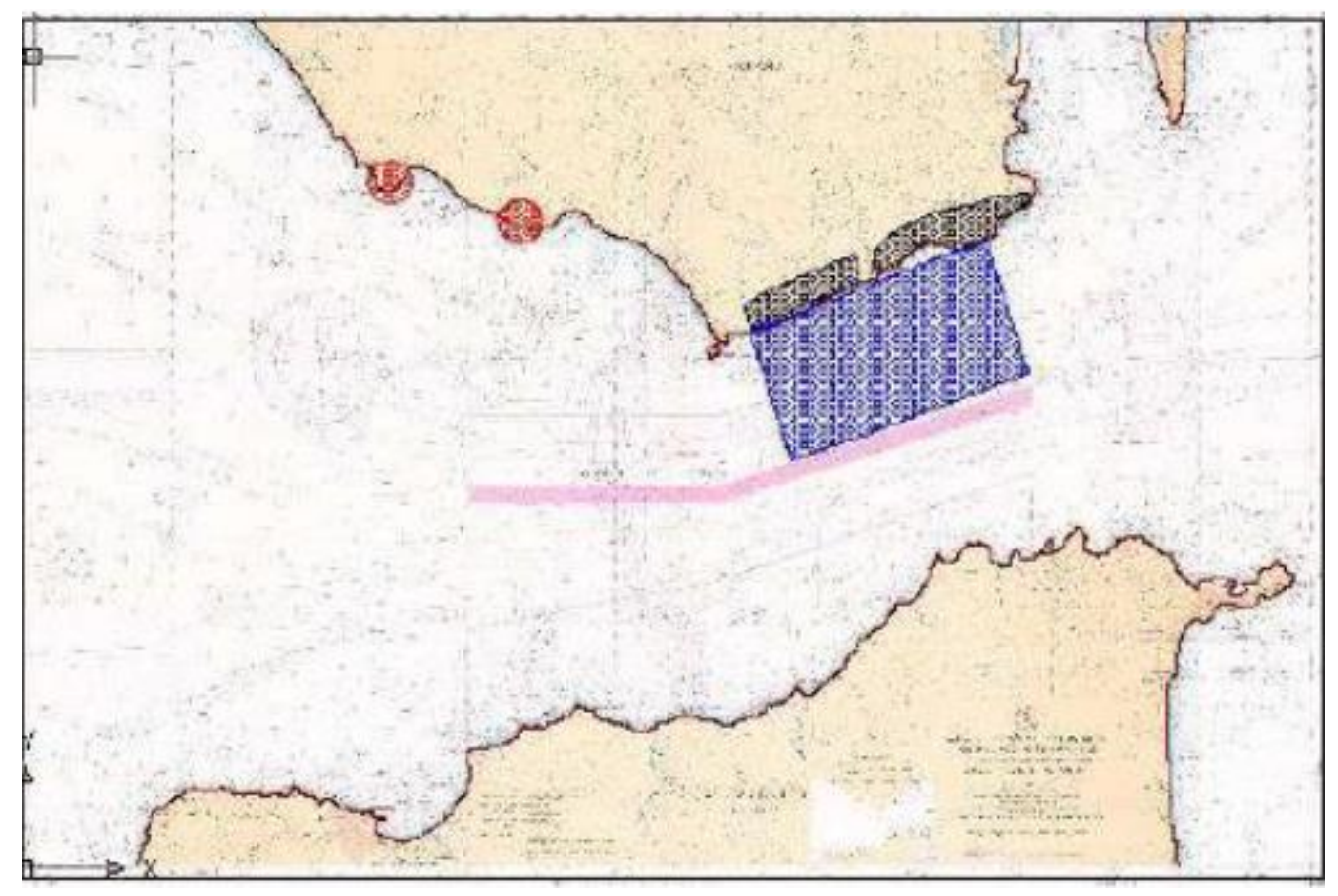

Figura 96: Zona militar, zona Estrecho

\subsection{ADECUACIÓN DE DISPOSITIVOS A LAS CARACTERÍSTICAS DE LA COSTA ANDALUZA.}

Como se puede observar de la Figura 94 todas las zonas de interés energético en el Estrecho han sido excluidas y las zonas cercanas a la costa de las otras zonas en estudio presentan condicionantes por lo que, en general, serán aptas las tecnologías de gran profundidad y aquellas que aprovechen instalaciones portuarias.

Por su gran potencial eólico, la costa andaluza presenta grandes posibilidades en este sector, sin embargo debido a su poca plataforma continental y a que la mayoría de la zona costera se considera zona de exclusión, se deben utilizar dispositivos eólicos flotantes. Esta tecnología está actualmente en estado de prototipo.

Por ser un dispositivo flotante debe estar correctamente balizado para no interferir en la navegación.

Las tres zonas en estudio pueden aprovechar esta energía, aunque la más energética es la zona occidental.

En cuanto a la energía de las olas, la zona más energética es la zona Occidental que podría generar electricidad de calidad que se vertiera a la red Estatal, sin embargo en la zona 
ESTUDIO DEL POTENCIAL DE APROVECHAMIENTO ENERGÉTICO DEL OCÉANO EN LA COSTA ANDALUZA.

Autora: Ma Pilar Blanco Fernández

Oriental sería apropiado utilizar dispositivos que abastecieran instalaciones haciéndolas autónomas. El esquema de una instalación podría ser el que aparece en la Figura 97

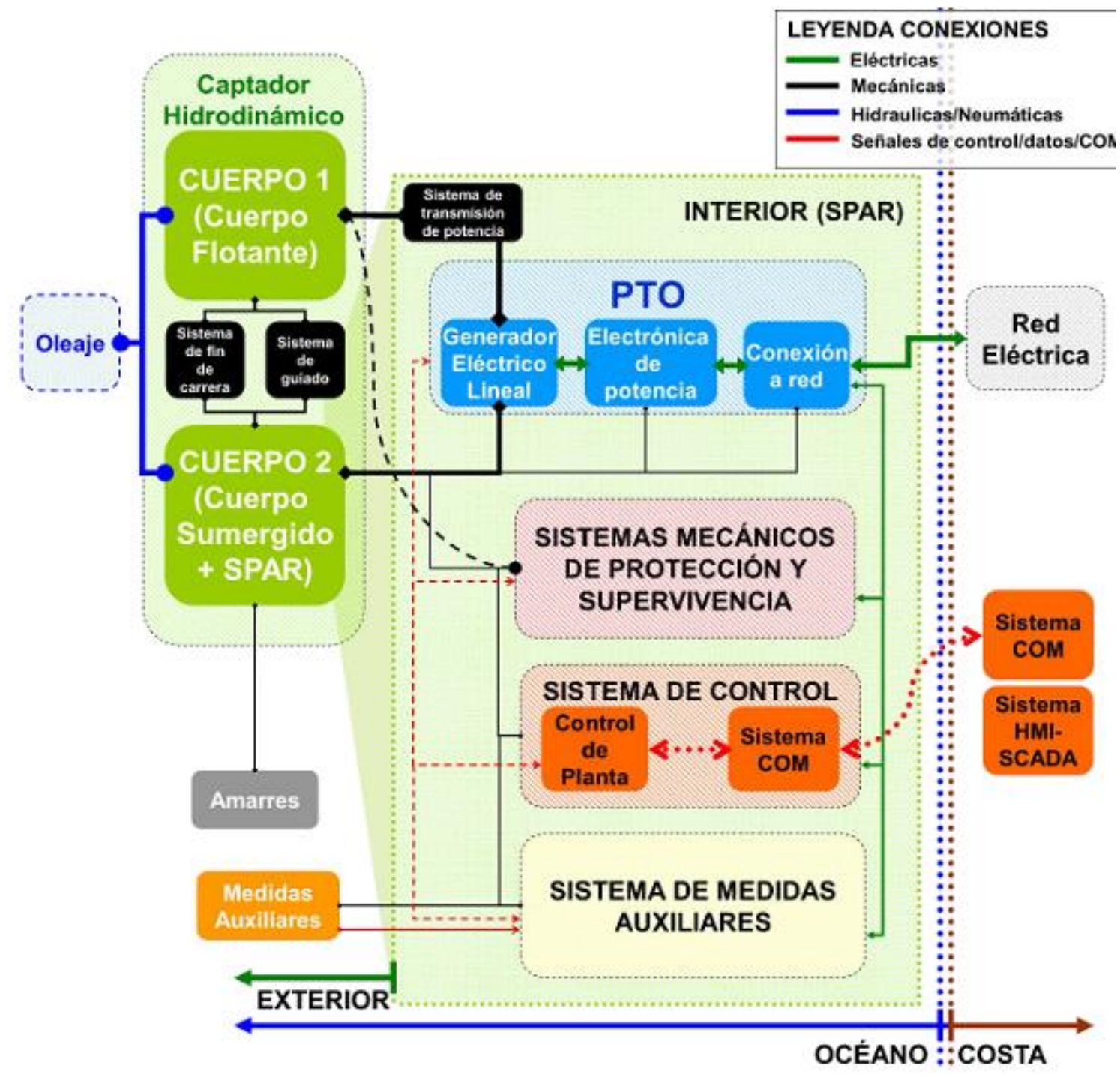

Figura 97: Esquema genérico de los dispositivos y elementos que conforman un sistema de aprovechamiento de la energía de las olas (37)

En lo referente a las mareas, como se ha expuesto anteriormente, las mayores diferencias están en la parte atlántica, siendo esta zona la única que aprovecharía esta fuente de energía en dispositivos asociados a instalaciones portuarias o rompeolas, naturales o artificiales.

De esta manera, en la zona Occidental se pueden utilizar instalaciones similares a la de Pico o Mutriku y en la zona Occidental y Oriental dispositivos tipo Energetech, Tapchan o SSG. En la zona del Estrecho apenas hay diferencia de mareas, excepto a la altura de Cádiz incluida 
en la zona Occidental, por lo que habría que estudiar específicamente la energía undimotriz de cada punto de la costa para establecer la oportunidad de este tipo de dispositivos. Por ser la mayor parte de las zonas en estudio zonas de exclusión o con fondo abrupto, no son rentables los dispositivos próximos a la costa pilotados o apoyados por lo que habrá que irse a soluciones flotantes tipo Butterfly, Figura 98, con muy poco calado que pueden fondearse cerca de las playas.

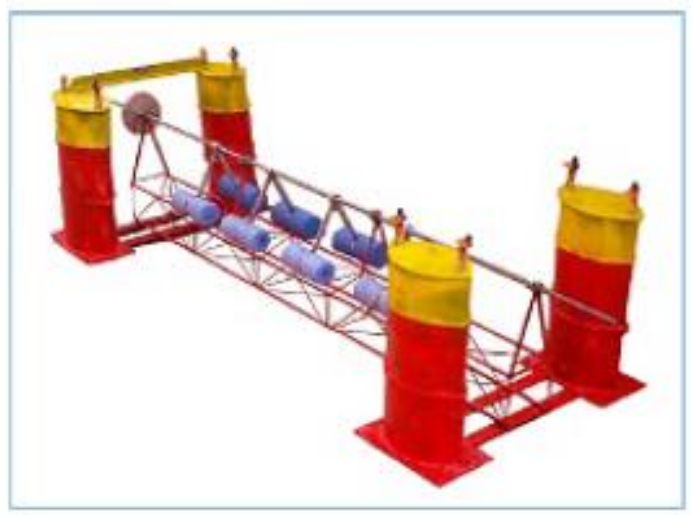

Figura 98: Infografía dispositivo Butterfly (38)

Las características propias del Estrecho hacen que esta zona sea una de las 10 regiones del mundo más aptas para el aprovechamiento de las corrientes de las mareas. En este caso habría que utilizar dispositivos flotantes como el proyecto Magallanes o similares. En el caso de dispositivos off-shore de aprovechamiento de la energía undimotriz, en la zona Occidental se pueden instalar dispositivos tipo Cilindro de Bristol y PowerBuoy, ya que el perfil del fondo marino es suave y permite instalaciones fijas al fondo a no demasiada distancia de la costa.

Tanto en la zona Occidental como la Oriental permiten instalaciones del tipo Pato de Salter, Clam, Pelamis, AquaBuoy, WaveBob y Wavedragon. En estas instalaciones el tipo de fondeo será el adecuado a fondo arenoso o fango, ya que, excepto en las zonas de exclusión que el fondo es rocoso, en el resto del área en estudio el suelo es de este tipo.

\subsection{OPORTUNIDAD DE LA COMBINACIÓN DE TECNOLOGÍAS.}

Además de para la generación de electricidad, los dispositivos WEC se pueden utilizar combinados con otras tecnologías para otros usos, por ejemplo:

a. Producción de hidrógeno por electrólisis, desarrollado en el apartado 2.6.1 
b. Bombeo de fluidos, la energía mecánica producida por estos dispositivos se puede utilizar para accionar bombas que impulsen agua u otros fluidos hidráulicos a presión, mejor que mediante la electricidad.

c. Desalinización de agua de mar a través de ósmosis inversa, producción de agua potable a través de compresores de vapor o Producción combinada de electricidad y agua potable, desarrollado en el apartado 2.6.2

d. Refrigeración y aire acondicionado, los dispositivos WEC se pueden utilizar para el bombeo y compresión del fluido de trabajo en una planta de refrigeración o aire acondicionado de instalaciones portuarias u offshore.

e. Ayudas a la navegación y recopilación de datos meteorológicos, desde 1965 Japón está utilizando boyas con sistemas OWC para la señalización de las rutas de navegación. Este mismo sistema se puede utilizar en boyas de obtención de datos meteorológicos.

f. Protección de la línea de la costa, los dispositivos onshore se pueden construir en rompeolas o en los puertos, tanto existentes como en nueva construcción, esto influiría positivamente en la opinión pública y en la rentabilidad de explotación de las actividades portuarias.

g. Purificación/oxigenación del agua, determinados dispositivos se pueden utilizar también para oxigenación del agua de mar. Esta re-oxigenación puede proteger o reestablecer los ecosistemas acuáticos del fondo marino en los que la contaminación haya producido áreas de empobrecimiento de oxígeno.

h. Acuicultura, los dispositivos pueden actuar como zonas de refugio artificiales de especies marinas aumentando la concentración de las mismas en esas zonas. Actualmente la demanda anual de pescado supera las cantidades sostenibles en millones de toneladas lo que favorece las piscifactorías y la acuicultura. La capacidad de producir electricidad y zonas de refugio aumentará considerablemente el valor de cualquier proyecto. Desarrollado en el apartado2.6.3 


\subsubsection{OBTENCIÓN DE HIDRÓGENO}

\subsubsection{INTRODUCCIÓN}

Una pila de combustible puede definirse como un dispositivo electroquímico que transforma, directamente y de forma continuada, la energía proveniente de la oxidación del hidrógeno en energía eléctrica. Su principio de funcionamiento es inverso al de una electrólisis:

$$
\text { Hidrógeno }+ \text { Oxígeno } \Leftrightarrow \text { Electricidad }+ \text { Agua }
$$

El hidrógeno se puede obtener de diversas maneras y lo ideal es que la energía necesaria para obtenerlo proceda de una fuente renovable, consiguiendo, de esta manera, un combustible completamente limpio.

Con estas premisas se estudia la viabilidad de una instalación offshore de obtención de hidrógeno del mar, obteniendo la energía eléctrica necesaria a partir de la energía del océano.

Mediante hidrólisis no se necesitan grandes cantidades de agua para obtener cantidades considerables de hidrógeno, aproximadamente dos litros de agua producen una cantidad de hidrógeno con la potencia energética de un litro de gasolina. Además existe una fuente inagotable de materia prima en el agua de los océanos (39).

El proceso electrolítico consiste en lo siguiente. Se disuelve una sustancia en un determinado disolvente, con el fin de que los iones que constituyen dicha sustancia estén presentes en la disolución. Posteriormente se aplica una corriente eléctrica a un par de electrodos conductores colocados en la disolución. El electrodo cargado negativamente, cátodo, atrae a los iones positivos o cationes y el electrodo cargado positivamente, ánodo, atrae a los negativos o aniones. La energía necesaria para separar a los iones e incrementar su concentración en los electrodos proviene de una fuente eléctrica que mantiene la diferencia de potencial entre ellos.

En los electrodos, los electrones son absorbidos o emitidos por los iones, formando concentraciones de los elementos compuestos deseados. Así en la electrólisis del agua se forma hidrógeno en el cátodo y oxígeno en el ánodo. 


\subsubsection{DISEÑO DE INSTALACIONES}

Los principales generadores de hidrógeno son Alcalinos, utilizan una disolución de $\mathrm{KOH}$, (unipolares o bipolares) o de membrana polimérica sólida, el electrolito es una membrana sólida conductora (PEM).

Como se ve en la Tabla 8 hay varios tipos de generadores de hidrógeno pero la mayoría están en fase de investigación.

Tabla 8: Tipos de Pilas de Combustible (40)

\begin{tabular}{|c|c|c|c|c|}
\hline Tecnología & $\begin{array}{l}\text { T operación } \\
\left({ }^{\circ} \mathrm{C}\right)\end{array}$ & Combustible & Rendimiento & Potencia \\
\hline Alcalina (AFC) & $80-100$ & $\mathrm{H}_{2}$ & 60 & 5-150 KW \\
\hline Polímeros (PEM) & $70-80$ & $\begin{array}{l}\mathrm{H}_{2} \text { puro o de reformado de } \\
\text { compuestos hidrogenados }\end{array}$ & $40-50$ & $5-250 \mathrm{KW}$ \\
\hline $\begin{array}{l}\text { Metanol Directo } \\
\text { (DMFC) }\end{array}$ & $50-100$ & Metanol diluido & $30-40$ & $0.01-0.2$ \\
\hline $\begin{array}{l}\text { Ácido Fosfórico } \\
\text { (PAFC) }\end{array}$ & $200-220$ & $\begin{array}{l}\mathrm{H}_{2} \text { de reformado de } \mathrm{GN} \text { o } \\
\text { metanol }\end{array}$ & $40-50$ & $50 \mathrm{KW}-2 \mathrm{MW}$ \\
\hline Carbonatos (MCFC) & $600-650$ & \multirow{2}{*}{$\begin{array}{l}\text { H2 y CO del reformado } \\
\text { interno de gas natural o } \\
\text { gasificación del carbón }\end{array}$} & $45-60$ & $100 \mathrm{KW}-2 \mathrm{MW}$ \\
\hline Óxido sólidos (SOFC) & $800-1000$ & & $50-65$ & $100-250 \mathrm{KW}$ \\
\hline
\end{tabular}

En general un generador de hidrógeno está compuesto por varias celdas electrolíticas, fabricadas de forma modular para facilitar el montaje y desmontaje. Su descripción aparece en la Figura 99

Cada celda cuenta con las siguientes partes:

- Diafragmas para micro-filtración de gases. Deben cumplir con tres exigencias principales, permeables a iones de $\mathrm{H}_{3} \mathrm{O}^{+}$y $\mathrm{OH}^{-}$, impermeables para $\mathrm{H}_{2} \mathrm{y} \mathrm{O}_{2}$ y resistentes contra el electrolito en condiciones de temperatura y presiones elevadas. El diafragma es el que condiciona la pureza de los gases producidos, el rendimiento total del generador de hidrógeno y facilita el sellado mecánico de las celdas.

- Medio electrolítico, solución de $\mathrm{KOH}$ 


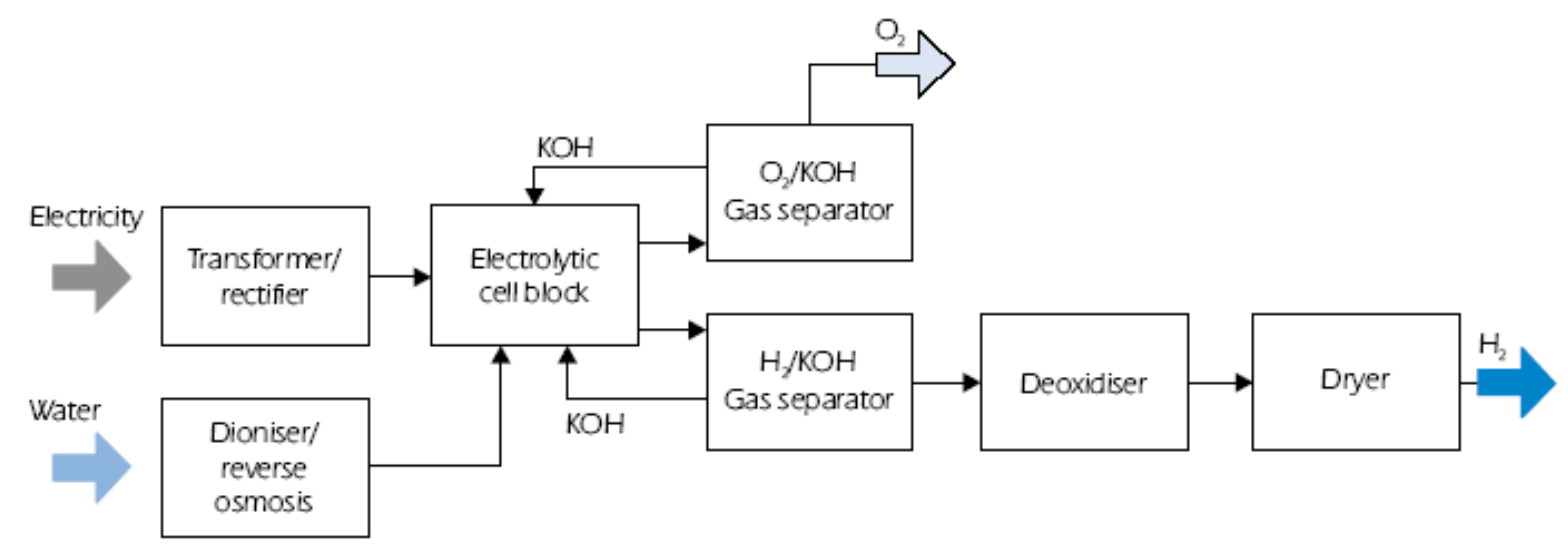

Figura 99: Esquema de un electrolizador alcalino (41)

Los requisitos típicos de una planta de hidrólisis incluyen electricidad, para la electrólisis, agua de refrigeración para la unidad de generación de hidrógeno, presurización de los gases e inertización y el almacenamiento del Hidrógeno (42) según se representa en la Figura 100

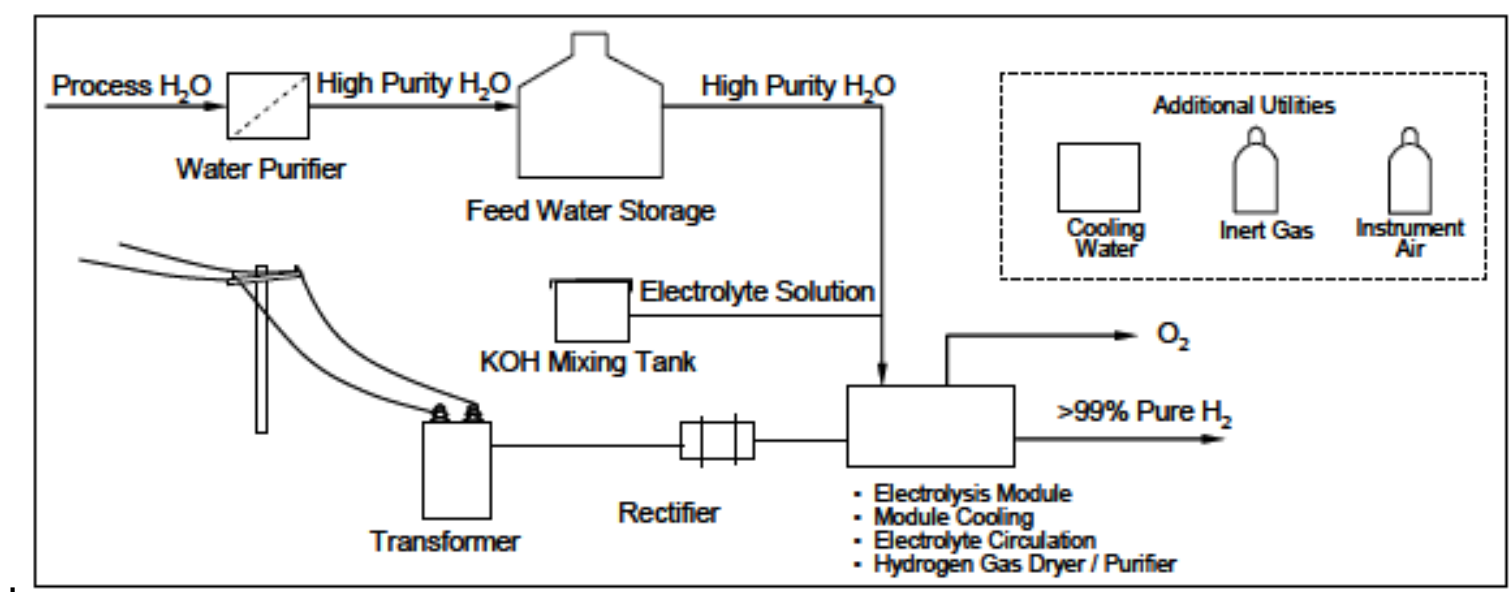

Figura 100: Electrolysis process flow diagrams (42)

\subsubsection{ALMACENAMIENTO Y TRANSPORTE DEL HIDRÓGENO.}

Debido a su baja densidad, el hidrógeno es un gas difícil de almacenar. Sin embargo existe una gran variedad de posibilidades para su almacenamiento de forma que puede seleccionarse la técnica más adecuada para cada aplicación.

En la Tabla 9 se pueden ver las características del hidrógeno según los distintos tipos de almacenamiento (41). 
Tabla 9: Características de los métodos de almacenamiento de hidrógeno

\begin{tabular}{|c|c|c|c|}
\hline Tecnología & $\begin{array}{c}\text { Volumen } \\
(\mathrm{l})\end{array}$ & Masa (kg) & $\begin{array}{c}\text { Densidad } \\
\left(\% \mathrm{H}_{2} \text { en peso) }\right.\end{array}$ \\
\hline 35MPa, $\mathrm{H}_{2}$ comprimido & 145 & 45 & 6.7 \\
\hline $70 \mathrm{MPa}, \mathrm{H}_{2}$ comprimido & 100 & 50 & 6.0 \\
\hline Criogénico, $\mathrm{H}_{2}$ líquido & 90 & 40 & 1.4 \\
\hline Hidruros metálicos, $\mathrm{H}_{2}$ & 55 & 215 & 7.5 \\
\hline sólido & & & \\
\hline
\end{tabular}

\section{ALMACENAMIENTO DE HIDRÓGENO GASEOSO}

La forma más convencional de almacenamiento de hidrógeno es en botellas de acero a presión o tanques ligeros (a 35MPa) o botellas de alta presión (70MPa) para reducir el volumen que ocupan.

Una alternativa al almacenamiento de hidrógeno gaseoso, para aplicaciones de automoción, lo ofrecen las microesferas de vidrio. El proceso de carga del hidrógeno se realiza aprovechando la permeabilidad del hidrógeno a alta presión (35-70MPa) y temperaturas de $300^{\circ} \mathrm{C}$ en los huecos de las microesferas en un envase resistente a la presión. Una vez realizada la carga, el sistema se enfría hasta temperatura ambiente de forma que el gas queda retenido en las microesferas. Posteriormente, para su uso, es necesario calentar la microesfera a $200-300^{\circ} \mathrm{C}$ para liberar el hidrógeno de forma controlada y alimentar el motor o la pila de combustible.

Los principales problemas que presenta esta técnica son la baja densidad volumétrica, las altas presiones de llenado y la alta temperatura de liberación del hidrógeno. Sin embargo ofrecen la ventaja de ser inherentemente seguras ya que durante el transporte está a baja presión y permite tanques no esféricos o cilíndricos. Se ha demostrado una densidad de almacenamiento de $5.4 \%$ en peso (43).

\section{ALMACENAMIENTO DE HIDRÓGENO LÍQUIDO}

El hidrógeno puede almacenarse en forma líquida a temperaturas criogénicas $\left(-253^{\circ} \mathrm{C}\right)$. La principal ventaja de este sistema es su alta densidad energética por unidad de volumen incluso a relativamente bajas presiones. Su principal desventaja es que existen pérdidas por 
evaporación en los periodos en los que no se utiliza si los contenedores no están altamente aislados.

Otro sistema de almacenamiento líquido es utilizar disoluciones de borohidruros. En este caso, el hidrógeno se libera a partir de una reacción de hidrólisis catalítica:

$$
\mathrm{NaBH}_{4}(\mathrm{l})+2 \mathrm{H}_{2} \mathrm{O}(\mathrm{l})->4 \mathrm{H}_{2}(\mathrm{~g})+\mathrm{NaBO}_{2}(\mathrm{~s})
$$

La densidad de almacenamiento teórica es de $10.9 \%$ en peso (43).

ALMACENAMIENTO DE HIDRÓGENO SÓLIDO

El almacenamiento sólido es potencialmente seguro y eficiente tanto para aplicaciones de transporte como estacionarias. Se consideran cuatro grupos de materiales adecuados para este tipo de almacenamiento (43) (44):

Materiales basados en el carbono (nanotubos y nanofibras de grafito)

Los nanotubos de carbono (CNT's) están constituidos por redes hexagonales de carbono curvadas y cerradas, formando tubos de carbono nanométricos con una serie de propiedades excelentes. Son ligeros, huecos y porosos con alta resistencia mecánica.

Este sistema puede permitir almacenar densidades dobles que las de tanques de hidrógeno líquido. Sin embargo este almacenamiento es posible sólo a temperaturas inferiores a 196드 y cuando se deja a temperatura ambiente evapora la mayor parte.

Hidruros recargables

El hidrógeno tiene la propiedad de reaccionar con diferentes metales de transición formando hidruros. Las reacciones son reversibles en condiciones adecuadas de presión y temperatura por lo que una determinada masa metálica puede ser cargada y descargada un número prácticamente ilimitado de veces y se puede utilizar como depósito de almacenamiento sólido de hidrógeno. Casi todos los hidruros operan a presiones moderadas, no hay pérdidas y permiten la limpieza del hidrógeno. Este se libera cuando se aplica calor a los materiales y mediante la reducción de la presión.

Este tipo de almacenamiento es seguro y manejable y permite almacenar más H2 por unidad de volumen que con el hidrógeno líquido. Sin embargo el peso del sistema es elevado como consecuencia de los bajos niveles de retención de $\mathrm{H} 2$ ( $<2.5 \%$ en peso)

Hidruros químicos (reactivos con $\mathrm{H}_{2} \mathrm{O}$ )

Pueden generar hidrógeno mediante reacciones de hidrólisis

Hidruros químicos (térmicos) 
El $\mathrm{NH}_{4} \mathrm{BH}_{4}$ puede ser descompuesto térmicamente en 4 pasos con obtención de hidrógeno TRANSPORTE DE HIDRÓGENO GASEOSO

El hidrógeno gas suele ir comprimido en depósitos entre 20-70MPa. Los depósitos convencionales de gas comprimido, a 20-35MPa son de acero austenítico y para presiones superiores se están desarrollando nuevos materiales compuestos de fibra de carbono y polímeros o bien de aluminio reforzado con fibra de carbono. Estos depósitos se pueden transportar en camiones, ferrocarril o barco.

Igualmente está establecida comercialmente la tecnología de transporte de hidrógeno por tubería, Alemania tiene un gaseoducto de $210 \mathrm{~km}$ operando desde 1939, transporta 8900 $\mathrm{kg} / \mathrm{h}$ de hidrógeno a través de una tubería de $0.25 \mathrm{~m}$ de diámetro con una presión de $2 \mathrm{MPa}$ (45). Para este gas, las tuberías deben tener mayor diámetro que las actuales de gas natural o una mayor presión para suministrar la misma cantidad de energía. A igualdad de capacidad energética de la línea de transporte, el coste total de una línea para hidrógeno es del orden de seis veces el de gas natural (43).

TRANSPORTE DE HIDRÓGENO LÍQUIDO

En el proceso de licuación se consume una gran cantidad de energía primaria, sin embargo, como se observa en Figura 101, presentan una importante economía de escala por lo que a partir de un determinado volumen de producción puede tomarse la opción de licuar. 


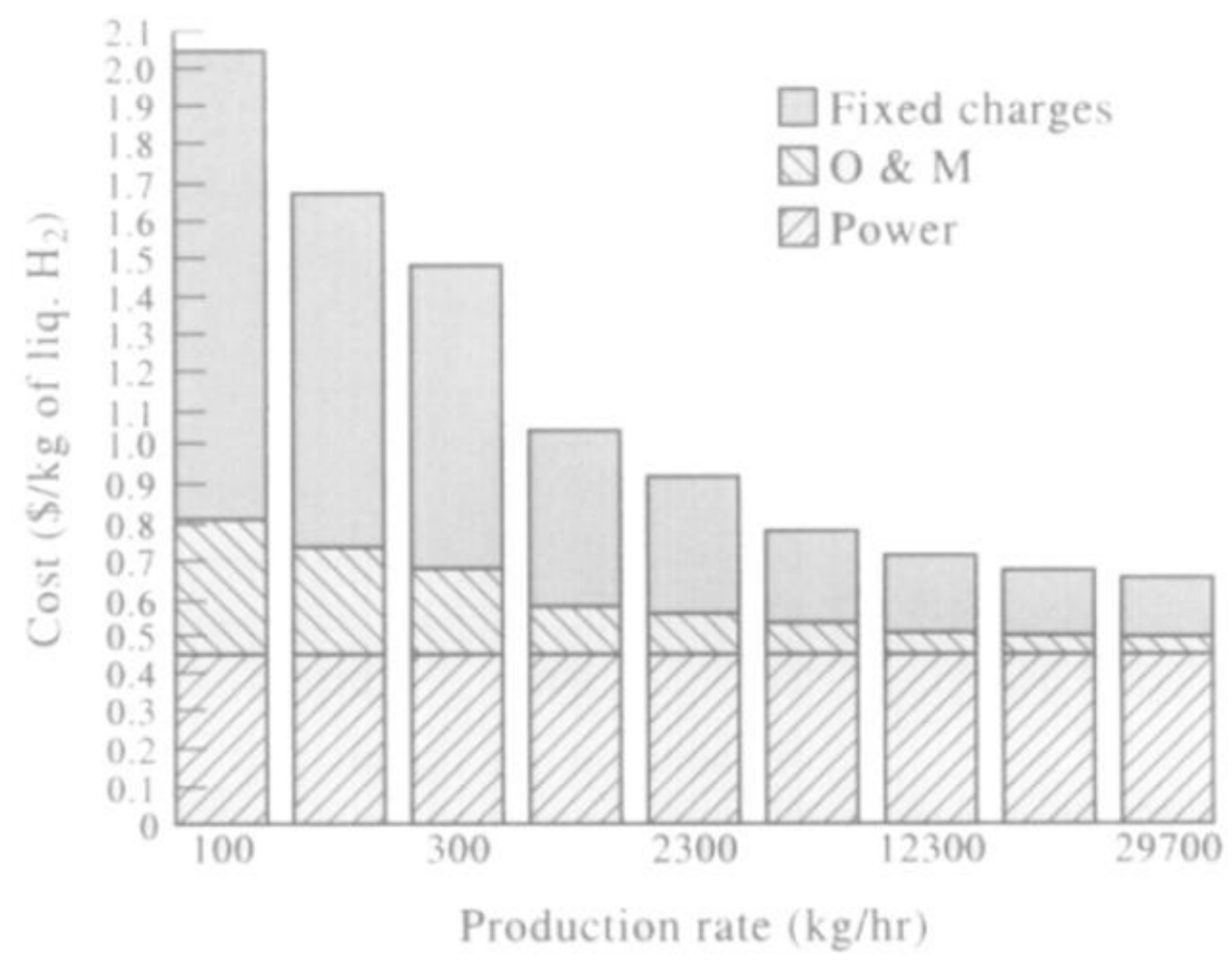

Figura 101: Coste de energía, operación y mantenimiento y gastos fijos del capital invertido en un licuefactor optimizado de hidrógeno a gran escala (46)

Para el transporte por camión o por barco, a largas distancias, es necesario tener en consideración que las pérdidas por evaporación pueden alcanzar unas cantidades entre el 0.2 y $0.4 \%$ del hidrógeno líquido por día. En el caso del transporte por mar se requerirían barcos rápidos para limitar el impacto de estas pérdidas o que el producto pueda recuperarse y utilizarse para la propulsión del barco.

Otra manera de transportar el hidrógeno líquido es utilizando tuberías especiales, aisladas mediante aislamiento poroso, aislamiento por vacío o no aisladas. (47) (45)

\subsubsection{POSIBILIDAD DE INSTALACIONES OFFSHORE}

Uno de los condicionantes para la viabilidad de una instalación de generación de hidrógeno en alta mar es que el dispositivo de energía eléctrica genere suficiente potencia in situ para la explotación de la unidad offshore.

El consumo de una unidad offshore media aparece en la Tabla 10 
Tabla 10: Consumo eléctrico medio de una plataforma offshore

\begin{tabular}{|c|c|c|}
\hline \multirow{2}{*}{ Service } & Normal Operation & Emergency \\
\cline { 2 - 3 } & $\mathrm{kW}$ & $\mathrm{kW}$ \\
\hline BALLAST & 145,00 & 0,00 \\
\hline ACCOMMODATION & 84,40 & 20,00 \\
\hline AIR & 28,00 & 0,00 \\
\hline COOLING & 254,00 & 0,00 \\
\hline MISCELLANEOUS & 39,60 & 0,00 \\
\hline SERVICES & 383,60 & 0,00 \\
\hline VENTILATION-A/C & 105,00 & 0,00 \\
\hline
\end{tabular}

En este balance no se ha tenido en cuenta el consumo eléctrico de los equipos propios necesarios para la generación y acumulación de hidrógeno.

Según los datos de NREL (42) las plantas de hidrólisis consumen menos de 50KWh/Kg de hidrógeno generado, con una eficiencia del 67\%. Si incrementáramos la presión y/o la temperatura, obtendríamos mejores valores de eficiencia, pero para este trabajo utilizaré el indicado.

Si consideramos que la producción diaria de una central de producción de hidrógeno teórica sería de $50000 \mathrm{Kg} /$ día (42), utilizaríamos 104 MW de electricidad.

Por lo tanto, para que la instalación off shore sea autónoma, necesitaremos un dispositivo, o conjunto de ellos, que suministre al menos 105.21 MW.

\subsubsection{CONCLUSIÓN}

Uno de los principales factores que influyen en la generación del hidrógeno es el coste de la electricidad utilizada en su generación, prácticamente el 80\% del total como se observa en el gráfico de la Figura 102.

Disminuir el costo de la electricidad mediante la utilización de energías renovables permitiría la utilización de forma competitiva del hidrógeno como combustible para la automoción. 
Tener plantas de producción y suministro de hidrógeno en alta mar facilitaría el desarrollo de las pilas de combustible como propulsión de buques y UUV abaratando los costes del transporte por mar y reduciendo los riesgos de contaminación por derrames de combustible así como las emisiones de $\mathrm{CO}_{2}$ a la atmósfera.

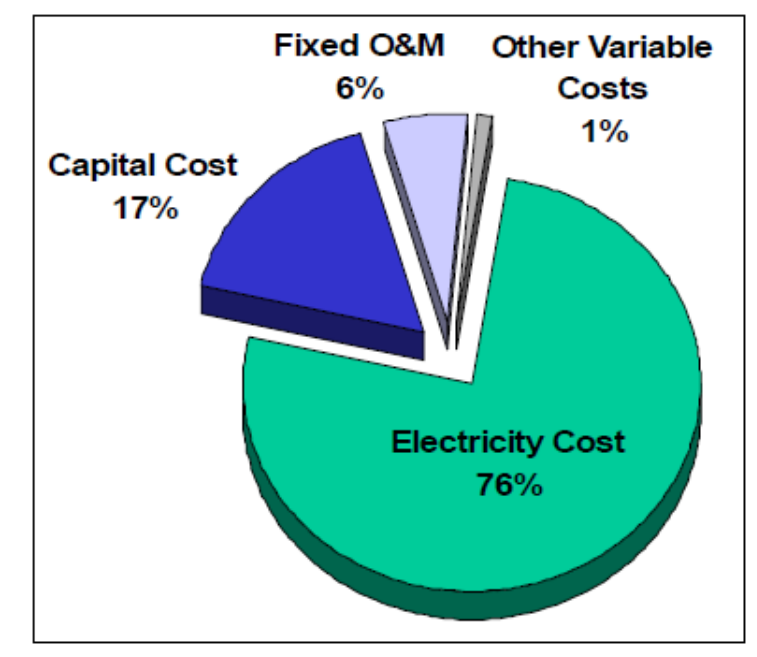

Figura 102: Reparto de costes de producción de Hidrógeno

Por otro lado, estas instalaciones servirían de palanca para la investigación de artefactos flotantes de aprovechamiento de la energía del océano, favoreciendo el desarrollo y la diversificación de la industria naval en las zonas donde se implanten.

\subsubsection{DESALINIZACIÓN DEL AGUA DE MAR}

\subsubsection{INTRODUCCIÓN}

La desalinización está creciendo tan rápido que es más que seguro que jugará un papel fundamental en el abastecimiento de agua en los próximos años. Este crecimiento se da con mayor fuerza en los países con una baja disponibilidad de acceso al recurso y tenderá a acentuarse en los próximos años.

A nivel mundial, se puede afirmar que alrededor de sesenta millones de ciudadanos beben actualmente agua desalinizada. Ahora bien, si se tiene en cuenta que el crecimiento esperado de la población podría llegar a 9000 millones de habitantes en el año 2030 y que gran parte se establecerá en la franja costera, se necesitará una producción de agua desalinizada de 140-160 millones de $\mathrm{m}^{3}$ diarios para hacer frente al incremento de la demanda. (48) 
La capacidad mundial de las plantas desalinizadoras, incluidas las de origen renovable, se espera que aumente a un ratio anual superior al 9\% entre el 2010 y el 2016. Este mercado crecerá tanto en los países emergentes como en los desarrollados, desarrollándose también en áreas rurales y de difícil acceso, como las islas, donde la red eléctrica, procedente de combustibles fósiles, es muy cara. Alrededor del 54\% del crecimiento global se espera que suceda en Oriente Medio y Norte de África, donde 21 millones $\mathrm{m}^{3} / \mathrm{d}$ de agua desalinizada en el 2007 pasarán a ser 110 millones de $\mathrm{m}^{3} / \mathrm{d}$ en el 2030, del cual el 70\% será en Arabia Saudí, los Emiratos Árabes, Argelia y Libia.

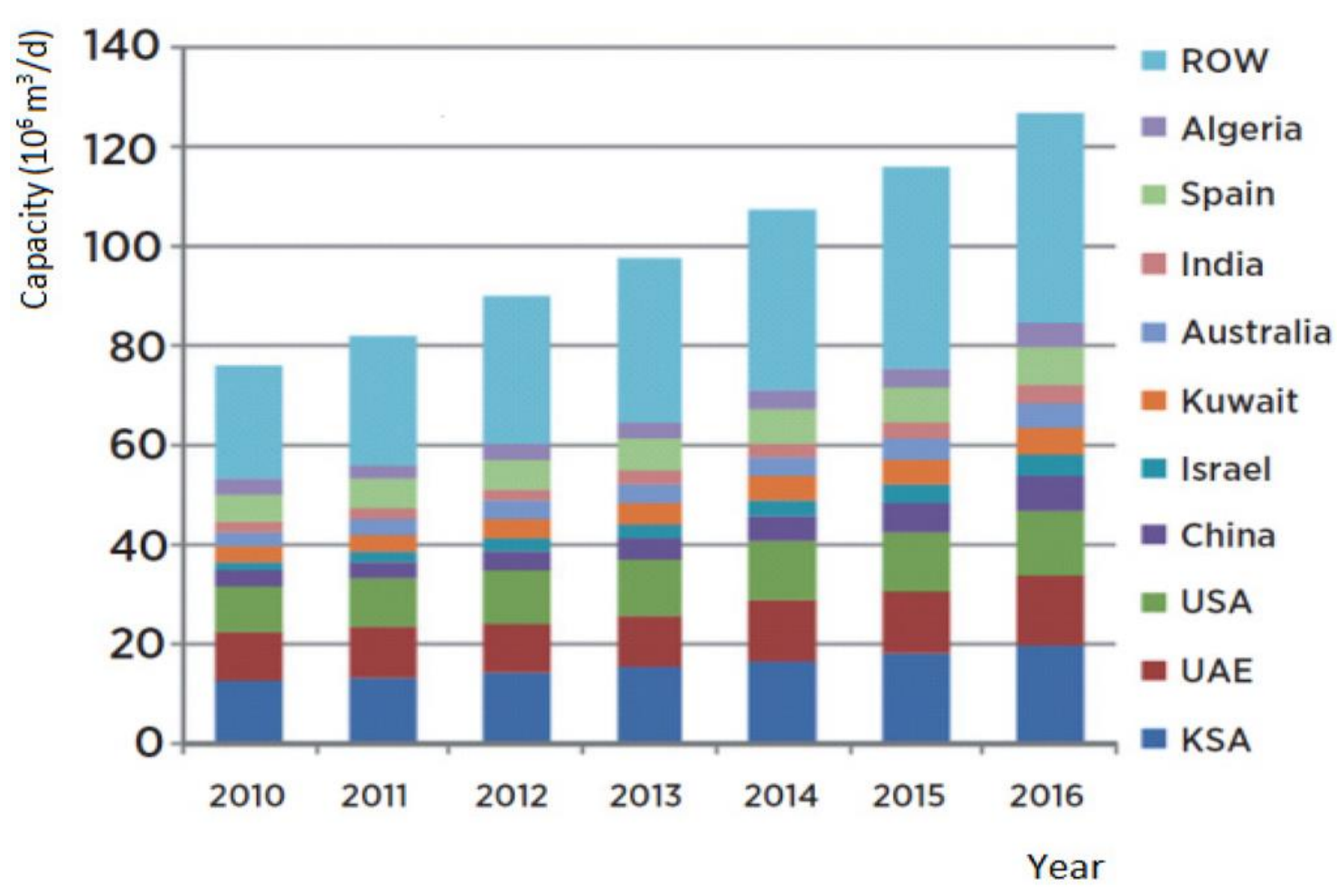

Figura 103: Capacidad instalada de desalinización, 2010-2016 (49)

Por lo tanto, siendo el agua de mar un recurso inagotable no sujeto a incertidumbres climatológicas, la desalinización se convierte en una opción perfectamente viable para el suministro de agua potable y de regadío. Si además reducimos los costes de producción, ligados fundamentalmente al consumo energético, mediante energías renovables obtenidas in situ y combinadas con la desalinizadora habríamos dado solución a los problemas derivados del déficit de recursos hídricos existentes en las zonas costeras sin aumentar la huella de $\mathrm{CO}_{2}$ 


\subsubsection{DISEÑO DE INSTALACIONES.}

Los procesos más fiables que son explotados comercialmente se pueden dividir en dos categorías:

- Térmicos (destilación)

○ Evaporación súbita multi-etapa (MSF por sus siglas en inglés). Cada etapa consiste en varias cámaras de evaporación consecutivas que están a presión decreciente. (representa el 70\% de la capacidad de producción de agua desalinizada mundial)

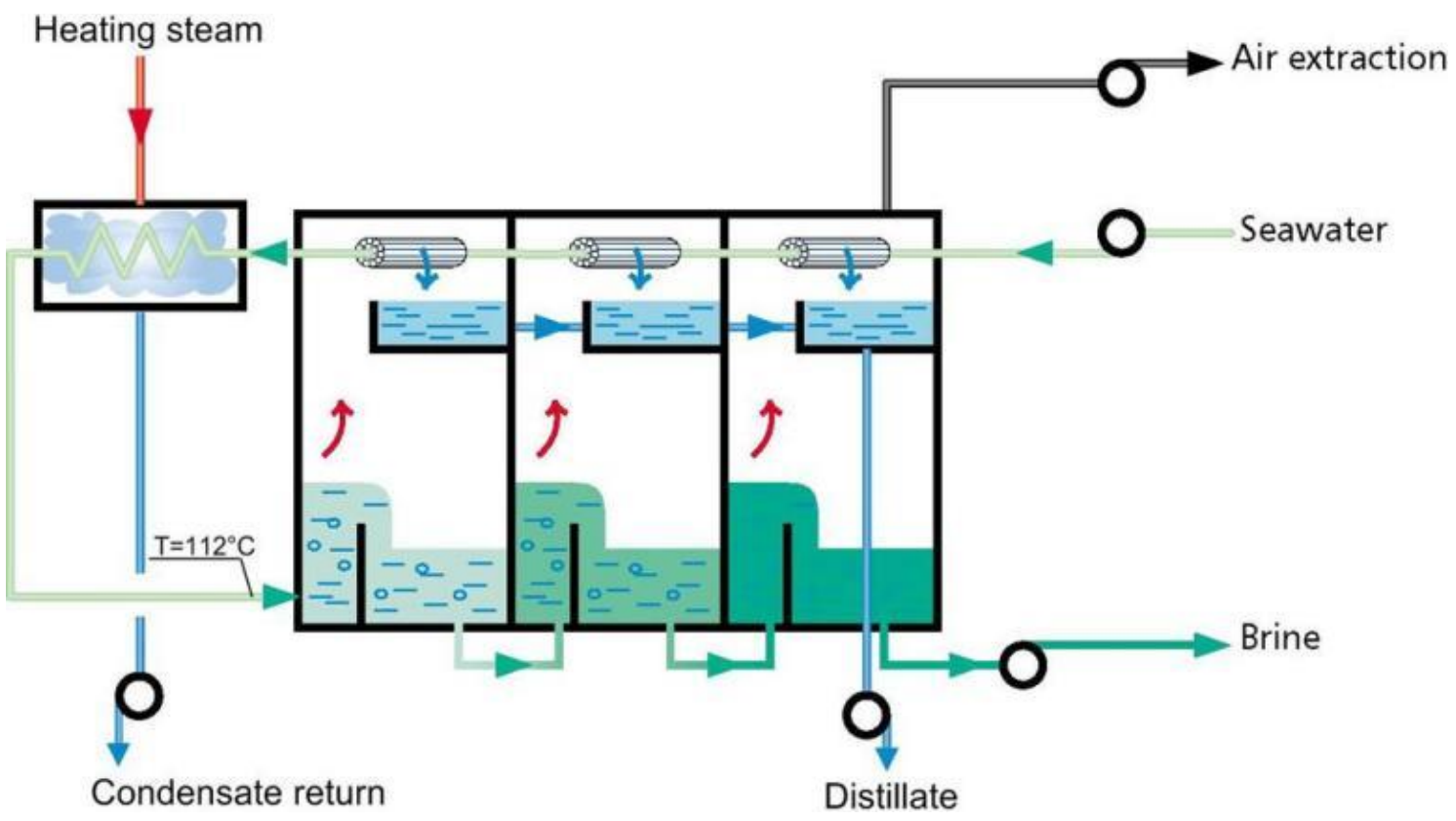

Figura 104: Esquema de operación MSF

○ Evaporación efecto múltiple (MED por sus siglas en inglés) Consiste en varias celdas consecutivas (o efectos) que mantienen niveles de presión y temperatura decrecientes. Cada celda consiste en un serpentín horizontal en el que en la parte más alta se rocía con agua de mar que cae entre los tubos debido a la gravedad. 


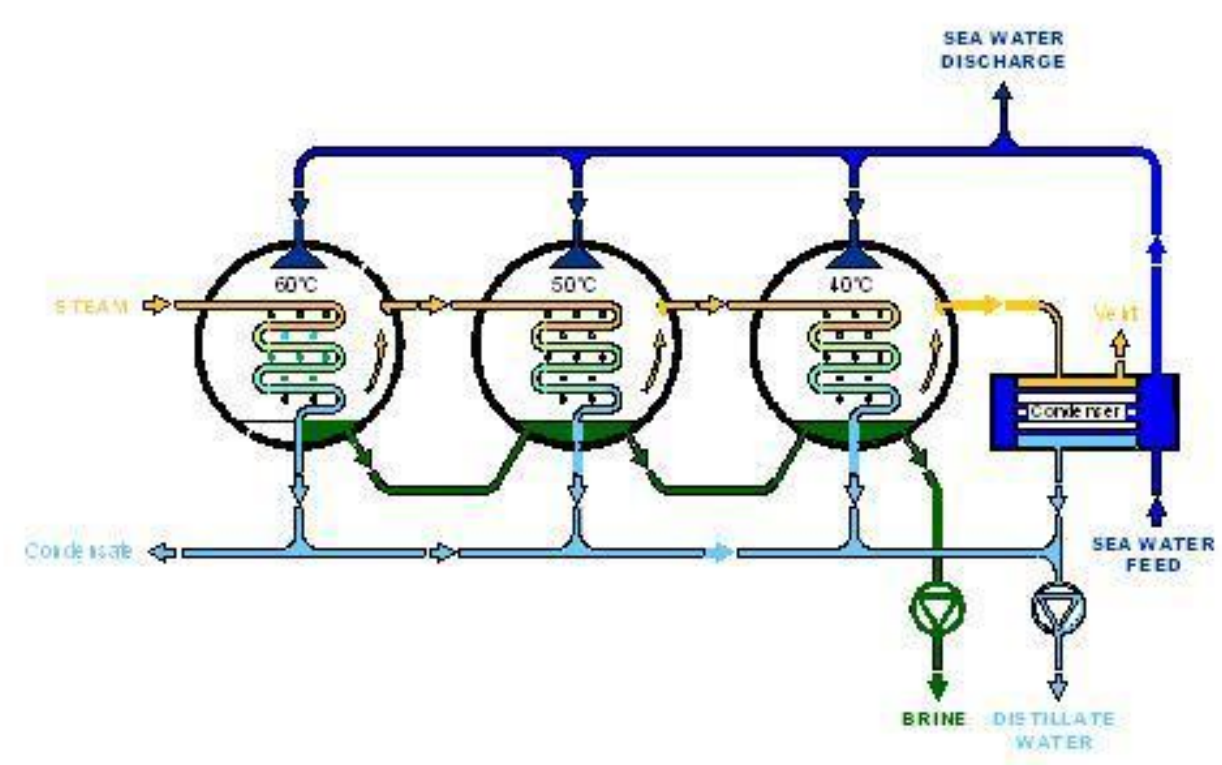

Figura 105: Esquema de operación MED

○ Compresores térmicos (TVC por sus siglas en inglés) El agua de mar se calienta al final del condensador hasta $45^{\circ} \mathrm{C}$ aproximadamente. Al pasar por los tubos se evapora una parte que se hace pasar por filtros y se condensa. Suelen ir asociados a los procesos MED para aumentar su eficiencia.

○ Compresores de vapor mecánicos (MVC por sus siglas en inglés), utiliza el principio de la bomba de calor por lo que es el método más eficiente termodinámicamente. 


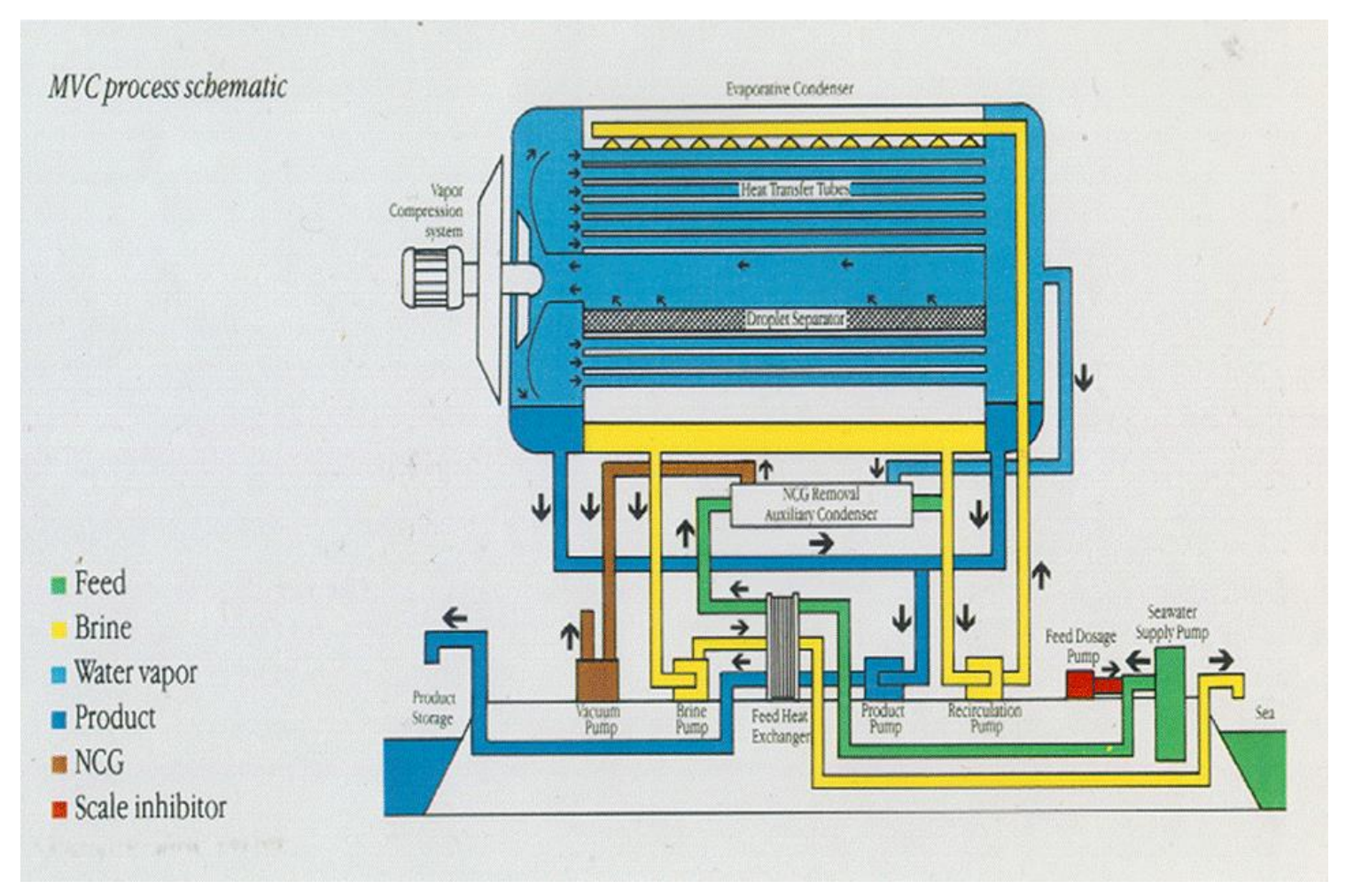

Figura 106: Esquema de operación MVC (50)

- Con membrana:

○ Ósmosis inversa (RO por sus siglas en inglés) Se utiliza tanto para desalinizar aguas salobres como agua de mar. Consiste en presurizar una solución salina sobre una membrana semipermeable en una magnitud suficiente para facilitar el paso del agua pura. (representa más del 80\% de la producción de agua desalinizada en España)

○ Electrodiálisis (ED), este proceso se utiliza principalmente para desalinizar aguas salobres. Se basan en el transporte de iones a través de membranas selectivas bajo la influencia de un campo eléctrico.

Como el proceso más utilizado en España es el de ósmosis inversa será el que considere en adelante para este capítulo.

Una instalación de ósmosis inversa consta fundamentalmente de las siguientes etapas:

1. Toma de agua de mar

2. Pretratamiento

3. Sistema de alta presión y recuperación de energía

4. Ósmosis inversa 
5. Post tratamiento de agua desalada

6. Vertido de salmuera

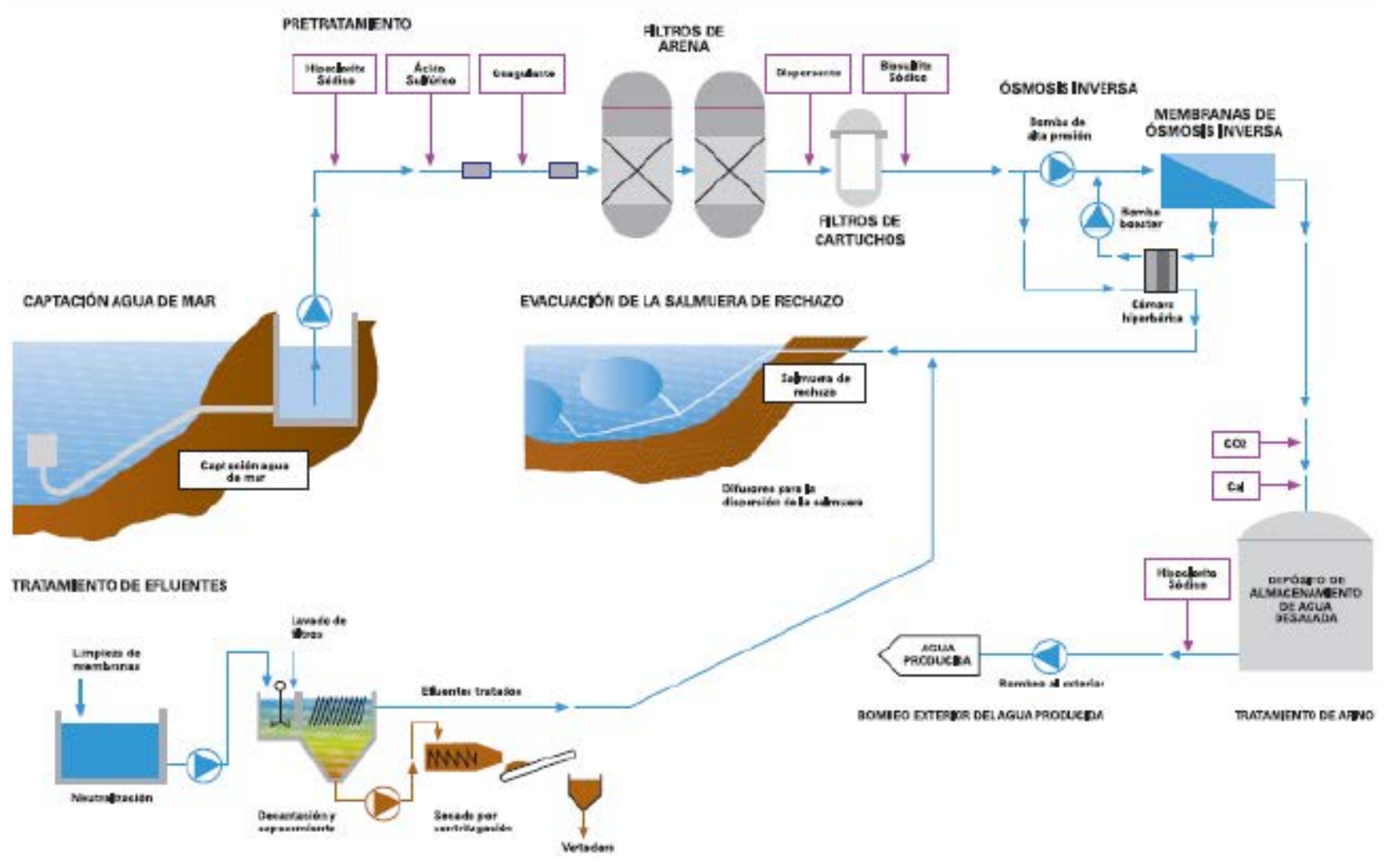

Figura 107: Esquema de planta desalinizadora por RO (48)

Con los diseños y tecnologías actuales se pueden esperar factores de recuperación del orden del 50\%, lo que significa que la concentración de sales en el rechazo es de 70-80g/l. El vertido de las salmueras, si bien muy concentrado, representa un pequeño caudal relativo, por lo que no cabe esperar serias amenazas para el medio marino, aunque debe ser controlado para evitar daños en determinadas especies vegetales y, sobre todo, para estudiar la reacción de las posidonias oceánicas.

El impacto de dicho vertido dependerá tanto de las características del sistema receptor como de las condiciones hidrogeológicas en la zona de descarga (oleaje, corrientes y mareas, batimetría, profundidad de descarga, etc.) Por lo que habrá que dar solución a este vertido, por ejemplo aprovechándolo para la obtención de sal para el consumo humano o industrial. 


\subsubsection{ALMACENAMIENTO Y TRANSPORTE.}

Debido a la gran superficie que necesita una planta desalinizadora sólo se pueden instalar en tierra por lo que el almacenamiento y transporte será el de cualquier planta desaladora convencional.

\subsubsection{POSIBILIDAD DE INSTALACIONES OFFSHORE/ONSHORE}

Los dispositivos WEC más adecuados serán aquellos que se sitúen en la costa o a poca distancia de la misma, suministrando la electricidad mediante un cable submarino o reemplazando el suministro eléctrico por una bomba de agua que produzca agua a altas presiones para usarla directamente en la planta desalinizadora.

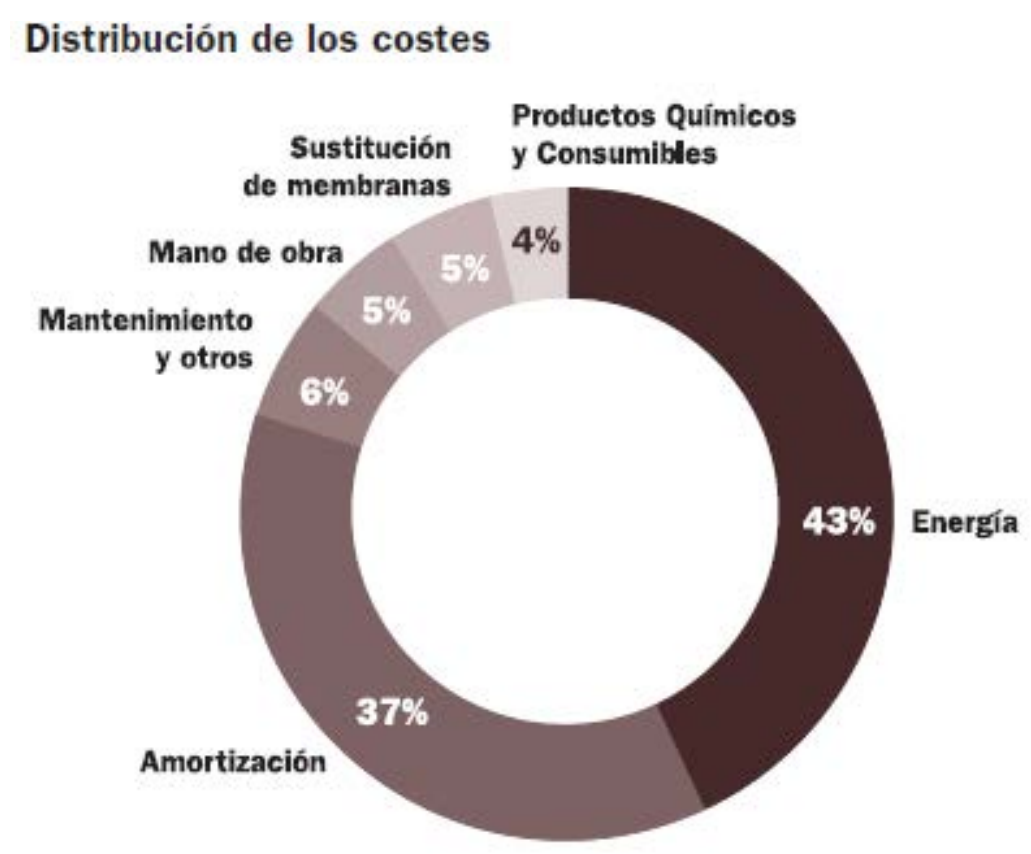

Figura 108: Distribución de los costes de desalinización ${ }^{3}$ (48)

Si consideramos una planta como la de Carboneras que genera $125.000 \mathrm{~m}^{3} /$ día con un consumo de $3 \mathrm{KWh} / \mathrm{m}^{3}$ para desalinizar agua de mar y $1.5 \mathrm{KWh} / \mathrm{m}^{3}$ para desalinizar aguas salobres, necesitamos un dispositivo, o campo de ellos, que suministren más de 200000 kWh al día. (51)

Buscando en la Tabla 6 vemos que los más energéticos no son los cercanos a la costa, por lo que, si queremos utilizar energía undimotriz para alimentar la planta desalinizadora,

\footnotetext{
${ }^{3}$ Si no se tiene en cuenta la amortización, entonces la energía representará prácticamente las tres cuartas partes del coste total del agua.
} 
necesitaríamos un campo de dispositivos WEC Offshore y después enviar mediante un cable submarino la electricidad generada a tierra.

Esta opción puede encarecer mucho toda la instalación, por lo que sólo sería interesante en aquellos lugares en los que hacer llegar energía de la red eléctrica sea mucho más caro y con fondos profundos en la cercanía de la costa.

Otra opción que se está investigando actualmente es utilizar un dispositivo "pato de salter" para obtener directamente agua desalinizada. El funcionamiento de este sistema se basa en que las variaciones de presión que se producen en el pato generan vapor de agua que puede ser separado, condensado y trasladado después a la costa mediante tubería submarina a una distancia entre uno y cinco $\mathrm{Km}$.

El mecanismo concreto consiste dividir el pato en dos compartimentos, uno relleno de agua a $100^{\circ} \mathrm{C}$ que sirve de lastre y el otro se llena de agua de mar; la sección intermedia contiene un tercer compartimento que actúa como intercambiador de calor y colector de vapor. Cuando el pato reposa sobre el mar, el compartimento de agua marina se llena y el agua se calienta; en el momento en que recibe el golpe de ola, el pato oscila con lo que la presión en el lado que contiene agua marina disminuye produciendo vapor que es recogido en el colector; al pasar la ola, el pato vuelve a caer llenándose de nuevo. El agua caliente se va enfriando poco a poco, pero se ha calculado que solo haría falta volver a calentarla una vez al mes gracias al aislamiento del dispositivo.

\subsubsection{CONCLUSIÓN.}

El aumento de la población mundial, el incremento de las áreas urbanas y el cambio climático han reducido severamente el suministro de agua potable. Además la extracción de agua potable para las áreas metropolitanas se está haciendo cada vez más difícil, si no imposible. Sin ninguna duda, el futuro se basa en la aplicación de tecnologías "NEWater" tales como la desalación o la reutilización de agua procedente de aguas residuales tratadas. La desalinización, especialmente en las zonas costeras, es el método más rentable para la sostenibilidad de suministro de agua a largo plazo en comparación con otras opciones. La desalinización del mar y agua salobre para el abastecimiento de agua potable y riego en las regiones costeras áridas y semi-áridas del mundo parece ser una tecnología muy prometedora. De hecho, la desalinización es ya una alternativa competitiva con respecto a otras opciones, porque el agua producida es de bajo costo en la mayoría de los casos, los 
requerimientos de energía se han reducido de manera significativa $\mathrm{y}$, por último pero no menos importante, es amigable con el medio ambiente, sobre todo cuando el proceso es alimentado por fuentes de energía renovables. También hay que señalar que la combinación entre la desalinización y las fuentes de energía renovables en los sistemas de desalinización que funcionan de forma independiente y autónoma, es una solución única para el agua en las zonas costeras, relativamente aisladas con posibilidades débiles y limitadas de conexión a las redes de suministro de energía locales

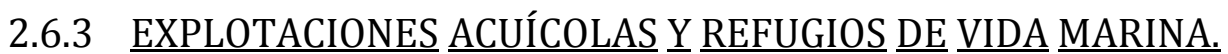

\subsubsection{INTRODUCCIÓN.}

La acuicultura se define como la acción de criar peces, moluscos, crustáceos y vegetación acuática en ambientes físicos controlados, con el fin de reemplazar y mejorar las condiciones que estos organismos encuentran en ambientes normales.

La acuicultura tiene una historia de 4000 años, pero ha sido desde hace 50 cuando se ha convertido en una actividad socioeconómica relevante. Existen referencias de prácticas de cultivo de carpa en la antigua China, Egipto, Babilonia, Grecia, Roma y otras culturas euroasiáticas y americanas.

Las referencias más antiguas se dan en la antigua China. En el año 1400 A.C. ya existían leyes de protección frente a los ladrones de pescado. El primer tratado sobre el cultivo de carpa data del $475 \mathrm{AC}$, atribuido al chino Fan-Li.

Entre griegos y romanos existen numerosas referencias, Aristóteles y Plinio el Viejo escribieron sobre el cultivo de ostras, Plinio en concreto atribuye al general romano Lucinius Murena el invento del estanque de cultivo y cita las grandes ganancias de su explotación comercial en el siglo I.

En la cultura occidental actual, la acuicultura no recobró fuerza hasta la Edad Media, en monasterios y abadías, aprovechando estanques alimentados por cauces fluviales, en los que el cultivo consistía en el engorde de carpas y truchas.

En el año 1758 se produjo un importante descubrimiento, la fecundación artificial de huevos de salmones y truchas por Stephen Ludvig Jacobi, un investigador austriaco, aunque su investigación no salió del laboratorio y quedó en el olvido. 
En1842, dos pescadores franceses, Remy y Gahin, obtuvieron puestas viables, totalmente al margen del hallazgo de Jacobi. Lograron alevines de trucha que desarrollaron en estanque con éxito. El descubrimiento llevó a la Academia de Ciencias de París a profundizar en el hallazgo y con ello la creación del Instituto Huninge, el primer centro de investigación en acuicultura.

\subsubsection{DISEÑO DE INSTALACIONES}

La acuicultura es una actividad que abarca muy variadas prácticas y una amplia gama de especies, sistemas y técnicas de producción. El éxito de la acuicultura moderna se basa en el control sobre la reproducción de las especies, en el mejor conocimiento de su biología, en las innovaciones tecnológicas y en el desarrollo de alimentos específicos.

Existen diferentes tipos de cultivos según la intensidad y tecnificación del cultivo.

- Acuicultura extensiva. Son sistemas de cultivo de baja intensidad y tecnología, en los que se aprovechan condiciones naturales favorables. Los más conocidos son los de organismos filtradores marinos, como ostras, almejas y mejillones, y de macroalgas marinas, que se realizan directamente sobre fondos arenosos de áreas intermareales o sobre estructuras apoyadas en el fondo, como estacas y mesas de cultivo, o flotantes como bateas y líneas. En ellos se procede a la siembra y el proceso de alimentación y engorde es natural.

- Acuicultura semi-intensiva. Sistemas de cultivo más controlados y de mayor rendimiento, en los que el grado de tecnología en intervención es mucho mayor a los extensivos. Los cultivos de peces en jaulas flotantes directamente en el mar o en lagos son sistemas semi-intensivos. El agua es la del medio, sin ningún sistema de bombeo, pero se aportan alimentos y se realiza un mínimo control del cultivo. También son sistemas semi-intensivos los cultivos en estanques y canales en circuito abierto o semiabierto, aprovechando aguas corrientes, algo muy frecuente en truchicultura.

- Los cultivos intensivos se realizan normalmente en instalaciones separadas del medio natural, en tanques o piscinas aisladas con sistemas técnicos de captación y recirculación de agua y con un control total del medio y de los individuos. Son mucho más caros que los procesos menos tecnificados. En estos el aumento del rendimiento o la necesidad de un mayor control son determinantes. 
Tipos de establecimientos acuícolas en España (52):

- Jaulas (viveros en el mar), estos establecimientos consisten en aros de plástico rígido que dan soporte y flotación a bolsas de red en el interior de las cuales se estabulan y crían peces.

- Bateas y long-lines (en el mar), se trata de estructuras flotantes para el cultivo de moluscos bivalvos. Las bateas constan de una plataforma de la que penden las cuerdas de cultivo y los long-lines son estructuras no rígidas que constan de una línea madre dispuesta en la superficie del mar de la que cuelgan a su vez las cuerdas de cultivo. Los long-lines suelen presentar mejores resultados en aguas abiertas (utilizadas en Andalucía), mientras que las bateas operan mejor en aguas más resguardadas (como es el caso de las Rías Gallegas).

- Tanques de agua salada (viveros en tierra firme), se trata de establecimientos construidos en obra sobre tierra firme en la costa y que obtienen su agua mediante bombeo desde captaciones en el mar o pozos.

- Tanques de agua dulce (viveros en tierra firme), consisten en establecimientos construidos en obra sobre los márgenes de los ríos o de sus fuentes, que aprovechan la circulación natural del agua.

- Esteros (en playa o zona intermareal), son establecimientos de acuicultura en los que el cultivo se realiza con una mínima intervención física sobre el medio. Es el caso de la producción de almejas y ostras. Se realiza en zonas de playa o áreas intermareales en las que los animales son depositados directamente sobre el sustrato o en mallas sobre mesas. Es también el tipo de granjas localizadas en estanque excavados en la tierra en antiguas zonas salineras o marismas, siendo un ejemplo de ello los esteros para la producción de peces. 
ESTUDIO DEL POTENCIAL DE APROVECHAMIENTO ENERGÉTICO DEL OCÉANO EN LA COSTA ANDALUZA.

Autora: Mạ Pilar Blanco Fernández

\section{La acuicultura extensiva en agua dulce}

Los estanques se mantienen de manera que se

favorezca el desamrollo de la fauna aduatica con

un rendimiento superior al del ecosisterna natural.

La densidad es baja y la almentación de los peces

es natura. Algunos productores aportan un comple

merito almenticlo. Btos estanques desermpefian

un papel mportante y postivo en el palsaje,

la gestión del agua y la biodiversidad.

Ejemplos - Carpa, en policultura con otras

especles (coregono, lucloperca, ludia, bagre, etc.

La acuicultura de especies marinas en las instalaciones en tierra

La crla de peces marinos (sobre todo de los peces planos) puede tamblen desarrollarse en cuencas artifidales en tlerra, pero almentactas por agua de mar. La croulackón del agua proporciona un entorno cerrado y controlado que es necesario para una producción dotima en los criaderos y las incubadoras de las especles marinas. Ejemples - Rodaballo, lenguado común, lenguado de Senegal, lubina, dorada

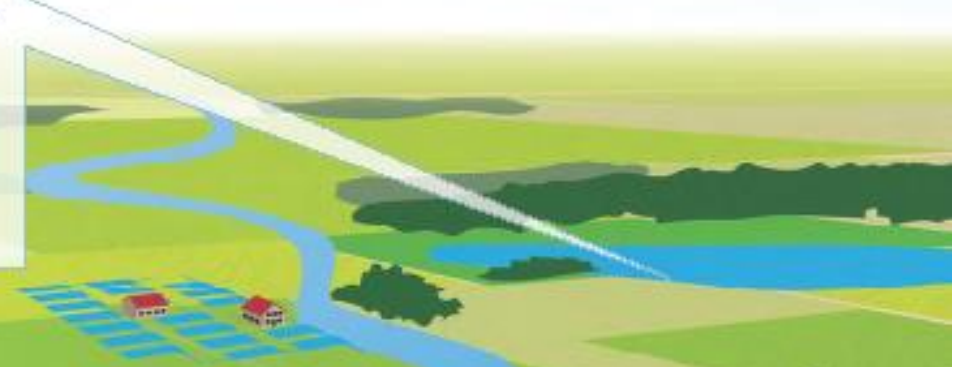

\section{La aculcultura extensiva}

\section{en agua salobre}

Los animales (a menudo arrastrados por las corrientes marinas) se mantienen en lagunas acondkionadas a tal efecto (ejemplo: vallicultura en Italla, estero en España). La introducción de alevnes de ncutadora y la aportación corrolementarla de allmentos refuerza el carácter semtextenswo de este cladero. Este tipo de aculcultura desempenta un papel mportante en la conservación del patrimonio natural costero. Elemplos - Lubha, anguta, lenguado, lenguado de Senegal, dorada, lisa, esturión, camarones $y$ markscos. 
ESTUDIO DEL POTENCIAL DE APROVECHAMIENTO ENERGÉTICO DEL OCÉANO EN LA COSTA ANDALUZA.

Autora: Mạ Pilar Blanco Fernández

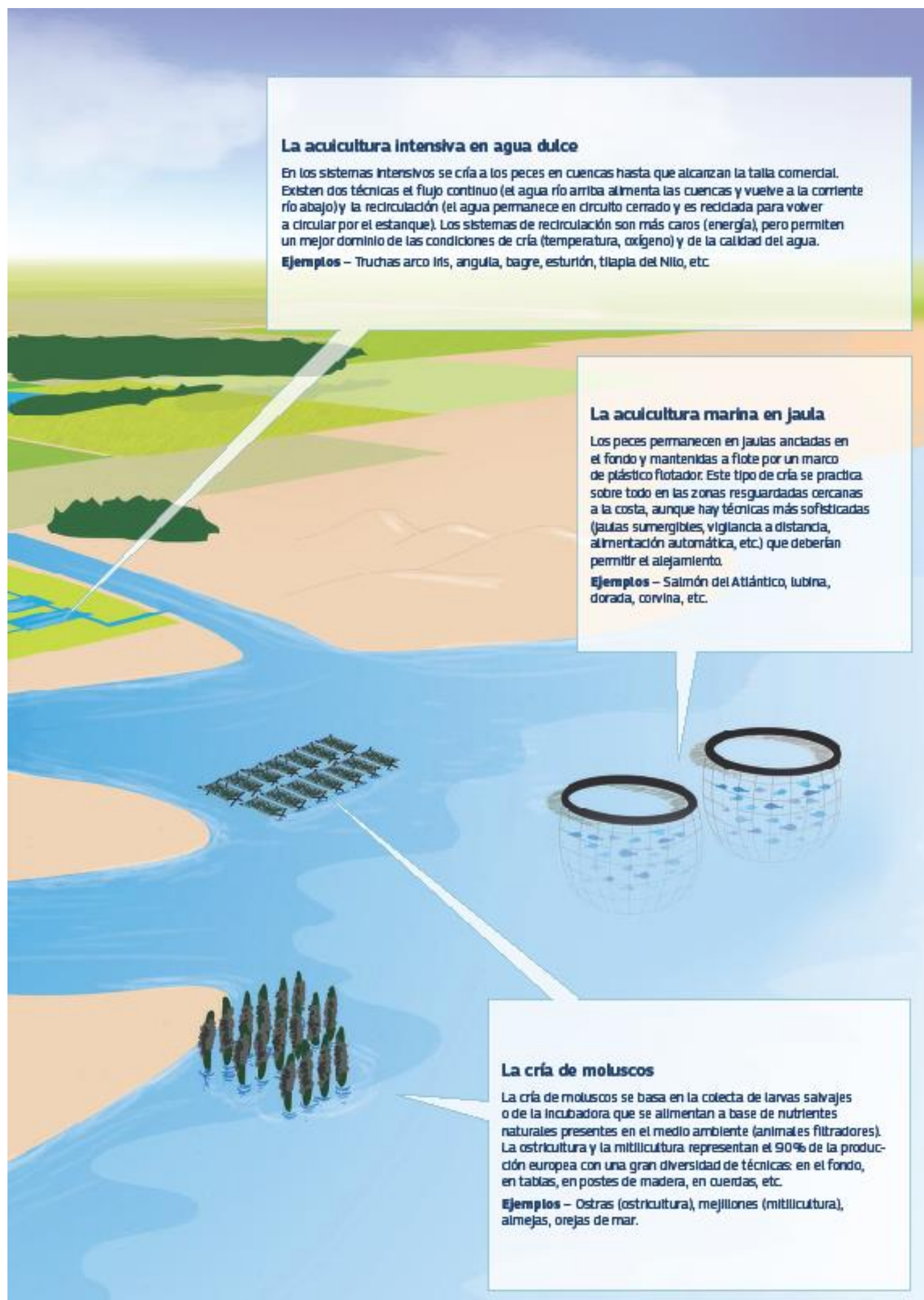




\subsubsection{POSIBILIDAD DE INSTALACIONES OFFSHORE/ONSHORE.}

En el 2012 se presentó en el Parque Científico de Barcelona el proyecto H2OCEAN. Se trataba de un proyecto cofinanciado por la Unión Europea y desarrollado por la empresa española AWS Truepower junto con un consorcio internacional de 17 entidades para crear una plataforma oceánica capaz de generar hidrógeno en alta mar gracias a la energía mareomotriz y eólica, además de poseer una planta purificadora de agua, piscifactorías y puntos de recarga de hidrógeno para barcos. (53)

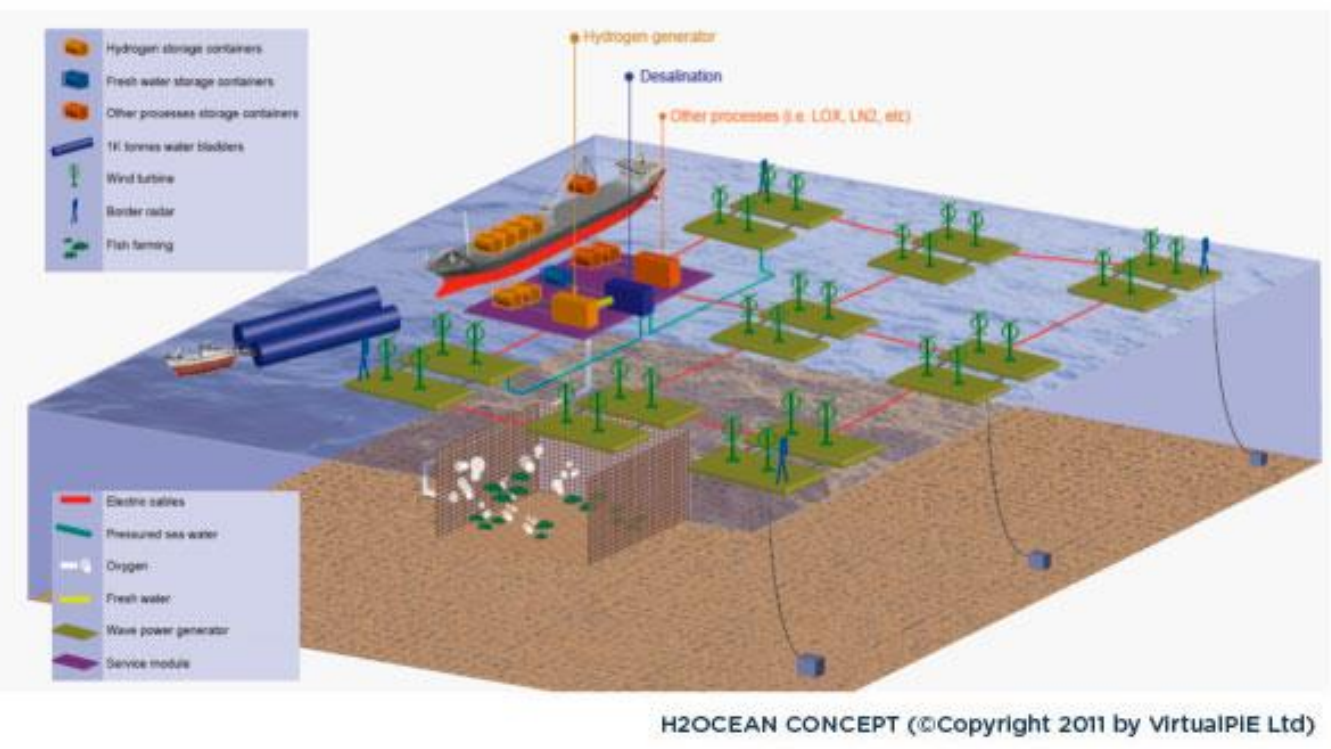

Figura 109: Esquema de plataforma H2Ocean (54)

El sistema que genera la electricidad es mediante varios cuerpos flotantes como se ve en la Figura 110

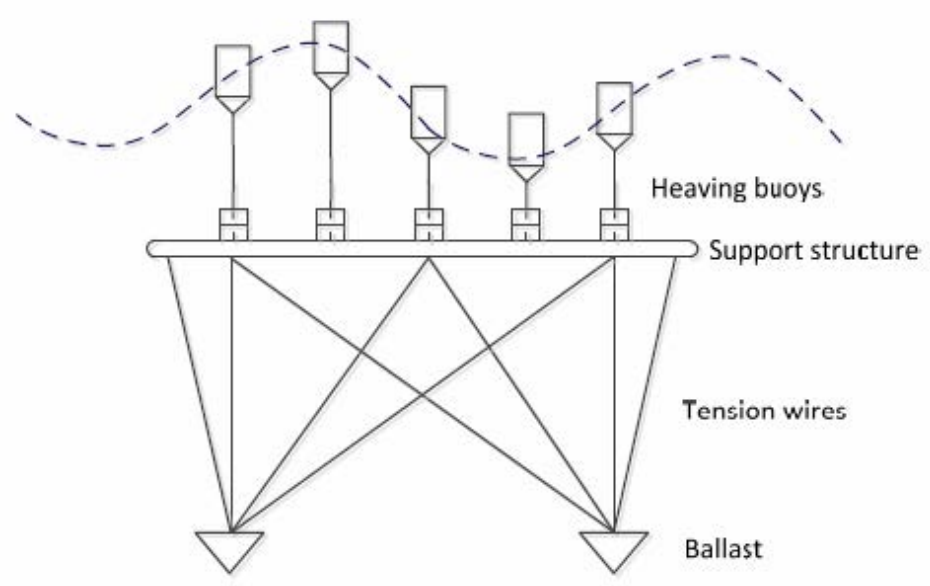

Figura 110: Esquema del dispositivo WEC de la plataforma H2Ocean (53) 


\subsubsection{CONCLUSIÓN}

La acuicultura ha crecido de manera exponencial en los últimos 50 años partiendo de una producción de menos de 1 millón de toneladas en 1950 a 51.7 millones de toneladas en 2006 (FAO 2008).

La pesca mundial se estancará en los próximos 30 años según datos de la FAO y la demanda anual de pescado supera las cantidades sostenibles en millones de toneladas lo que favorece las piscifactorías y la acuicultura que han aumentado la producción un 7\% anual desde el 2000.

En Europa, la acuicultura representa aproximadamente el 20\% de la producción de pescado y da empleo directo a unas 85.000 personas. Produce alrededor de 1.2 millones de toneladas y 4 billones de $€$. España es el cuarto país en producción en la Europa de los 28 aportando el 10,70\% del valor en $€$ y el 18,68\% del volumen generado.

En España en el 2012 la acuicultura supuso 19,892 horas equivalentes mientras que el procesado de los productos fueron 18,324 horas y la pesca 33.129 horas $^{4}$. Las principales especies capturadas fueron las que aparecen en la Tabla 11.

Tabla 11: Principales especies capturadas por la flota española (55),

\section{ES}

\begin{tabular}{|l|r|r|}
\hline Skipjack tuna & 128027 & $14.2 \%$ \\
\hline Sharks & 92452 & $10.2 \%$ \\
\hline Hake & 88801 & $9.8 \%$ \\
\hline Yellowfin tuna & 85794 & $9.5 \%$ \\
\hline Sardine & 49024 & $5.4 \%$ \\
\hline Mackerel & 47010 & $5.2 \%$ \\
\hline
\end{tabular}

Las principales especies producidas fueron las que aparecen en la Tabla 12

Tabla 12: Especies producidas en España (55)

\begin{tabular}{|l|r|r|r|r|}
\hline ES & value & $\%$ value & volume & $\%$ volume \\
\hline Seabass & 92559 & $21.6 \%$ & 14946 & $6.6 \%$ \\
\hline Mussel & 79962 & $18.6 \%$ & 162012 & $71.6 \%$ \\
\hline Gilt-head seabream & 76924 & $17.9 \%$ & 18897 & $8.4 \%$ \\
\hline Trout & 42156 & $9.8 \%$ & 15799 & $7.0 \%$ \\
\hline
\end{tabular}

\footnotetext{
${ }^{4}$ Datos 2013
} 
Por otro lado las organizaciones y organismos internacionales muestran su preocupación por el cambio climático lanzando políticas "vinculantes”. Así la FAO lanzó el reto de la acuicultura sostenible y el marco de la UE de Aprovechamiento Energético hace referencia a la eficiencia en el consumo de la energía, lo que unido al Plan Estratégico Nacional de la Acuicultura que entre sus acciones estratégicas establece la reducción de la HC así como la eficiencia en el consumo del agua y oxígeno plantean la oportunidad de utilizar energías renovables para los procesos productivos acuícolas, en estos casos las sinergias son claras. En Andalucía hay varios proyectos de acuicultura en aguas profundas que están dando resultados satisfactorios con lo que la implementación de dispositivos que les suministren in situ la energía o los consumibles necesarios para los procesos se plantea en un futuro próximo (56) 


\section{CONCLUSIONES}

Se entiende por externalidades a todos los costes o beneficios que recaen sobre la sociedad y el medio ambiente como consecuencia de una actividad económica y que no están introducidos en la estructura del precio del producto que los ocasiona. La cuantificación es difícil y, sin embargo, son muy importantes para las energías renovables ya que si las aplicamos en el precio del kWh producido por medio de una fuente renovable, ese $\mathrm{kWh}$ puede ser más barato que el producido por un medio tradicional a partir de una fuente no renovable.

En la UE las externalidades, en el 2012, estaban en el rango de 150 a 310 billones de $€$. Los impactos mayores se producen en el cambio climático, prácticamente la mitad del total, el agotamiento de los recursos energéticos, 22\%, y la formación de partículas, 15\% del total (57) En la Figura 111 y Figura 112 se ven los costes de las externalidades por tecnología en la UE de los 28 en el $2012^{5}$.

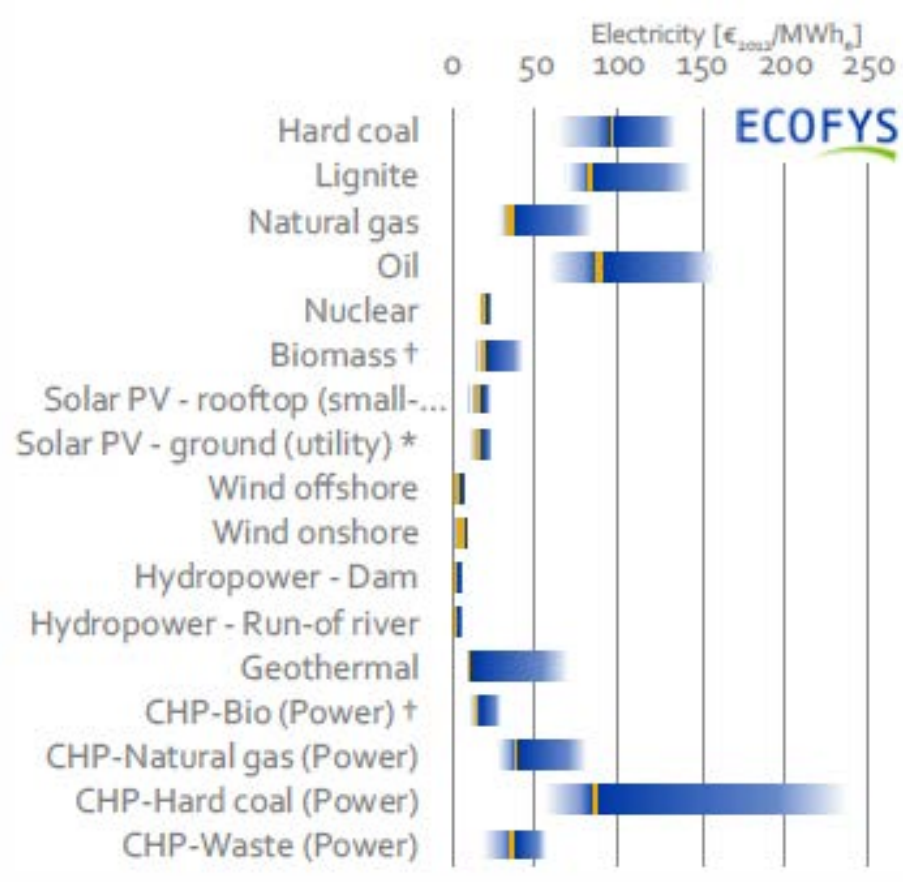

Figura 111: Rango de las externalidades por tecnología para las tecnologías de la electricidad (barras azules), UE28 media ponderada (líneas naranjas) $\left(€_{2012} / \mathrm{MWh}_{\mathrm{e}}\right)(57)$

\footnotetext{
${ }^{5}$ Los valores presentados para Solar son una sobrestimación de la situación actual debido al alto ritmo de desarrollo de esta tecnología, mejorando la eficiencia y reduciendo el impacto aguas arriba. Asume que la Biomasa procede únicamente de los residuos de la agricultura y restos de madera, es decir, no incluye biomasa procedente de cultivos dedicados
} 


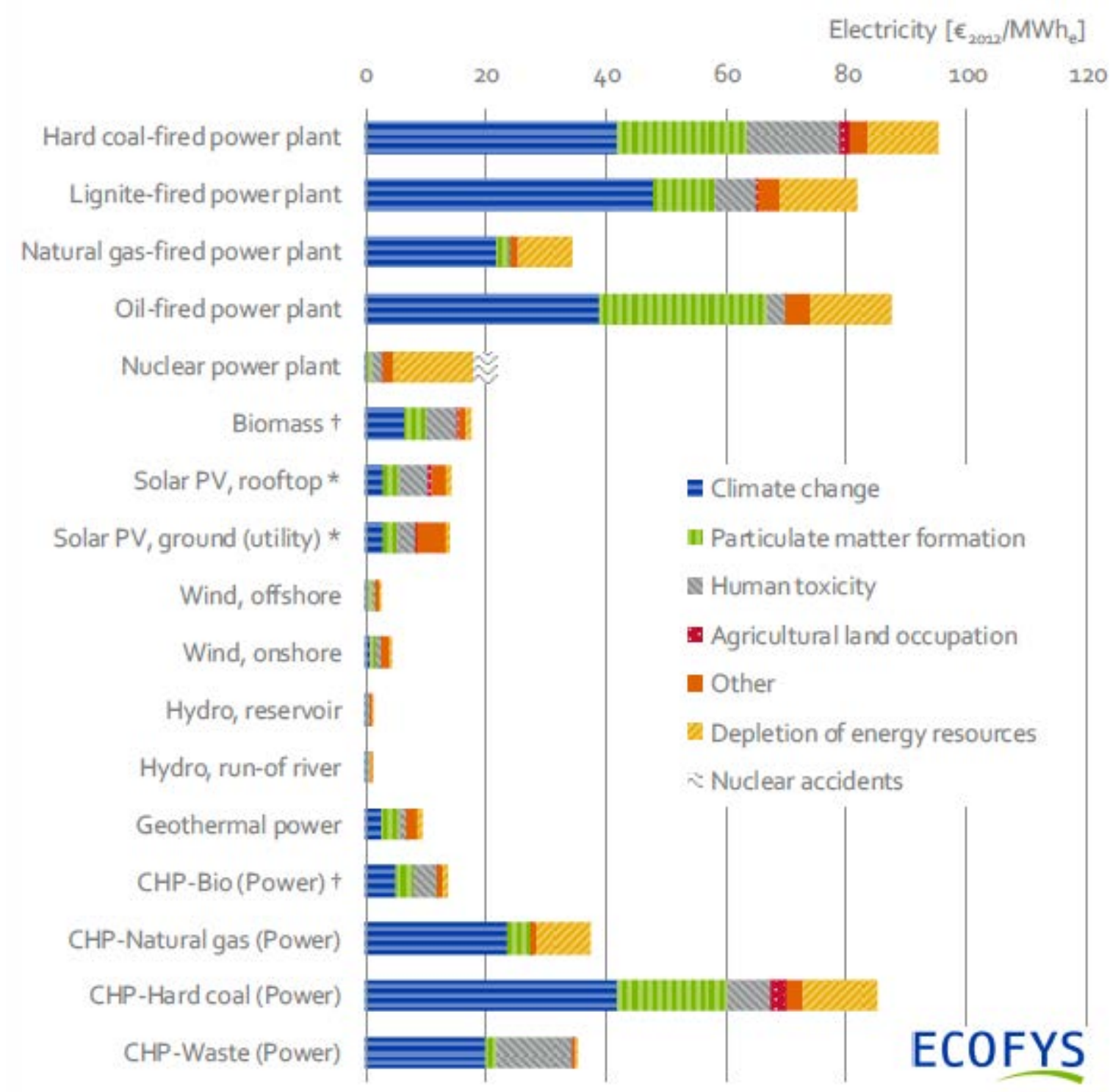

Figura 112: Rango de las externalidades por tecnología para las tecnologías de la electricidad, UE28 media ponderada $\left(€_{2012} / \mathrm{MWh}_{\mathrm{e}}\right)(57)$

Si observamos los datos por países de la UE28, España es el sexto país en el coste de las externalidades (57) si además tenemos en cuenta las subvenciones que se aplican a las distintas tecnologías de obtención de electricidad, Figura 114, un cambio hacia las energías renovables en la obtención de electricidad puede aportar una solución atractiva para España y en particular para Andalucía que con un 51\% de su energía procedente del carbón y el gas, Figura 113 la potencia total es de 15.760,8 MW en 2015, ha aumentado en la última década cinco veces la potencia instalada mediante fuentes renovables, principalmente solar fotovoltaica (58), en la Tabla 13 se ve la potencia instalada por tecnología renovable. 


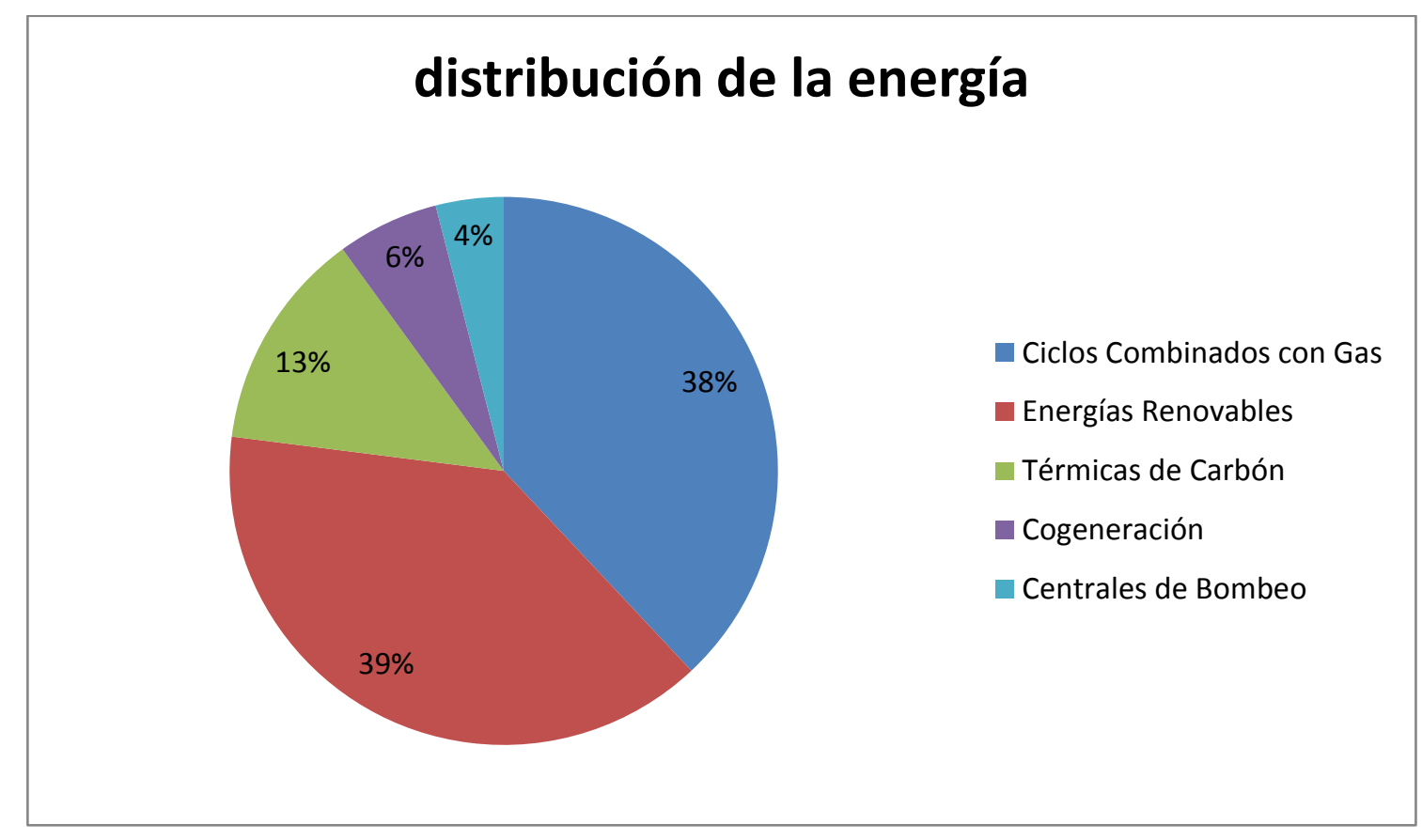

Figura 113: Distribución de la energía en Andalucía según la tecnología energética (datos de 2015)

Tabla 13: Datos generales potencia eléctrica renovable en Andalucía (MW) (datos al 31/03/2017) (58)

\begin{tabular}{|c|c|}
\hline TECNOLOGÍA $^{6}$ & ANDALUCÍA \\
\hline Biogás Generación Eléctrica & 30,75 \\
\hline Biomasa Generación Eléctrica & 257,48 \\
\hline Eólica & $3.324,31$ \\
\hline Fotovoltaica & 889,05 \\
\hline Hidroeléctrica & 620,68 \\
\hline Termosolar & 997,40 \\
\hline Otras tecnologías renovables & 4,50 \\
\hline Total & $6.124,17$ \\
\hline
\end{tabular}

${ }^{6}$ Los datos referentes a Biogás, Eólica, Fotovoltaica e Hidroeléctrica incluyen la potencia conectada a la red más la aislada. 


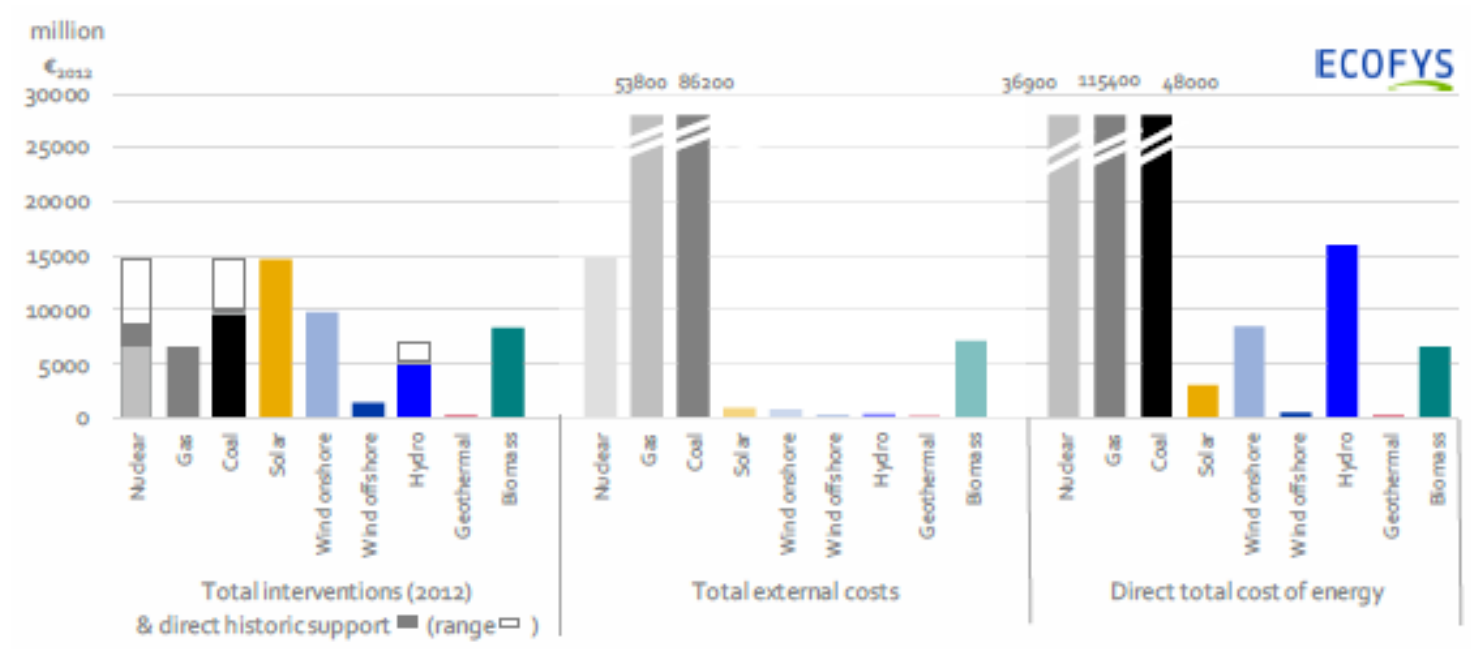

Figura 114: Subvenciones, externalidades y costes de la energía por tecnología 2012 (M€ 2012) (57)

Aunque los costes teóricos de una planta de olas se encontrarían entre 3,9 y 6,7 M€ $€_{2010} / \mathrm{MW}$ mientras que en la de corrientes se situarían entre 4,9 y 5,6 $\mathrm{M}_{2010} / \mathrm{MW}$ el futuro se presenta optimista debido a las políticas medioambientales que está implementando la UE, la financiación de los países, no sólo directamente en proyectos de I+D si no apoyando las contribuciones públicas y privadas, y las curvas de aprendizaje. En estos valores hay que tener en cuenta que el coste de operación se encontraría entre 30 y $52 \mathrm{M} €_{2010} / \mathrm{MW} / \mathrm{año}$, dentro de los costes de operación el 75\% aproximadamente está asociado a los costes de mantenimiento y reparaciones. En cuanto a las horas de funcionamiento podría oscilar entre 2.200 y 3.100 horas anuales. (59) (60) 


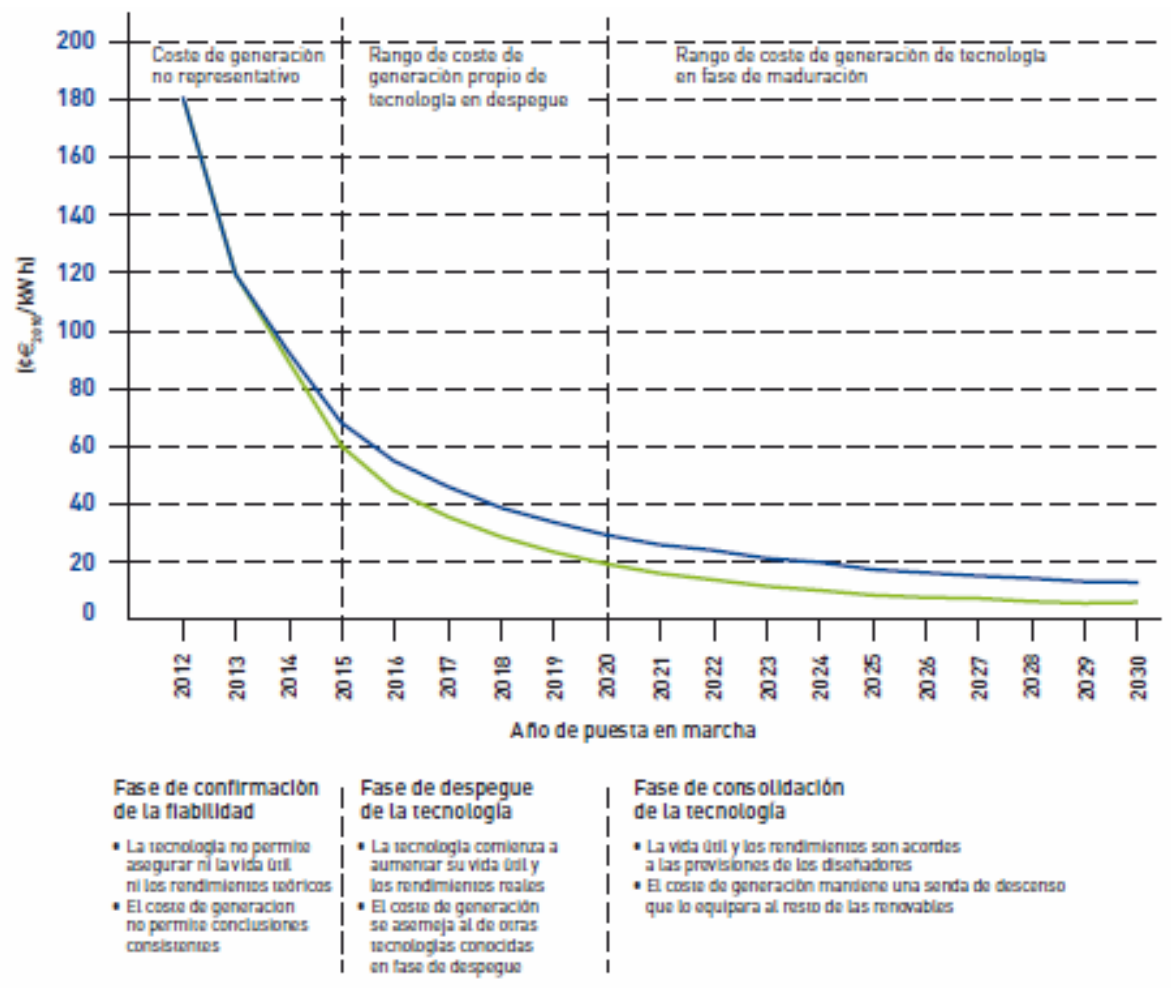

Figura 115: Evolución del coste de generación para plantas de olas (2020-2030) (59)

Si además tenemos en cuenta que en Andalucía la población tenderá a aumentar ligeramente y observando la tendencia de los últimos años en los que las provincias que más han aumentado la población son las costeras (61) las soluciones aportadas en los capítulos 2.6.1,2.6.2 y 2.6.3 favorecerán el suministro energético y de agua potable en esas zonas disminuyendo de esta manera los costes de inversión debidos a largas líneas eléctricas y las infraestructuras asociadas a la generación eléctrica por tecnologías convencionales. 


\section{GLOSARIO}

Batimetría: Ciencia que mide las profundidades marinas para determinar la topografía del fondo marino.

ED: $\quad$ Electrodiálisis

Fetch: Distancia en la que el viento sopla sin cambios significativos de dirección y sin encontrar obstáculos. A mayor fetch, mayor desarrollo de las olas.

FP: $\quad$ Floating point

Isobata: Líneas de igual profundidad.

Mar de fondo: Estado del mar cuando está agitado en zonas costeras en calma, debido a corrientes submarinas o a la actividad geológica del fondo marino

MED: $\quad$ Multiple effect distillation, Evaporación efecto múltiple

MSF: $\quad$ Multi-stage flash distillation, Evaporación súbita multi-etapa

MVC: $\quad$ Mechanical vapor compression, Compresor mecánico de vapor.

OTD: $\quad$ Overtopping device

OWC: $\quad$ Oscilating Watter Column

PTO: $\quad$ Power Take Off.

RO: $\quad$ Reverse osmosis, Ósmosis inversa

TEC: $\quad$ Tidal Energy Converter.

TVC: $\quad$ Thermal vapor compression, Compresor de vapor térmico.

WAB: $\quad$ Wave activated bodies

WEC: Wave Energy Converter. 


\section{LISTA DE FIGURAS Y TABLAS}

\subsection{LISTA DE FIGURAS}

Figura 1: Esquema de funcionamiento de una planta de potencia osmótica (Starkraft) .......... 7

Figura 2: Esquema de funcionamiento tecnología PRO

Figura 4: Circulación atmosférica general teniendo en cuenta el efecto de la fuerza de Coriolis (2)

Figura 6: Componentes de un aerogenerador de eje horizontal (2)

Figura 8: Estructura interna de la Tierra y repartición de flujos caloríficos según la estabilidad geológica de la zona (3)

Figura 10: Distribución del potencial geotérmico en España (4)

Figura 11: Yacimiento geotérmico de alta temperatura

Figura 12: Yacimiento geotérmico de baja temperatura

Figura 13: Esquema de funcionamiento de una planta de vapor seco (6) 20

Figura 15: Esquema de funcionamiento de una planta de ciclo binario (6)

Figura 17: Central hidroeléctrica de agua fluyente (2)...................................................................25

Figura 18: Central hidroeléctrica con embalse (2). 25

Figura 19: Representación esquemática de los tipos de olas que existen en la superficie del océano y de la energía en ellas contenida

Figura 21: Distribución de energía del oleaje en aguas profundas en $\mathrm{kW} / \mathrm{m}$ a nivel Europeo (9)

Figura 23: Principales corrientes marinas (10) . .33

Figura 24: Rotor axial y de flujo cruzado (8) . .36

Figura 25: Esquemas de estructuras soporte (8). 36

Figura 26: Origen de las mareas (2) 37

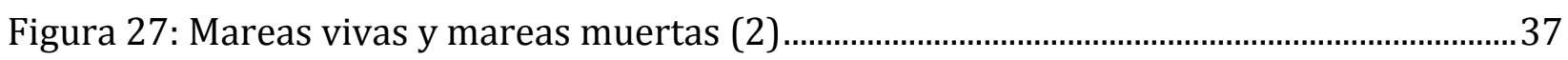

Figura 29: Mapa mundial de amplitud de mareas (11) ......................................................................39

Figura 30: Esquema de una central mareomotriz de ciclo elemental de efecto simple (2) ...41

Figura 32: Esquema de central mareomotriz de ciclo múltiple (2) ............................................. 43

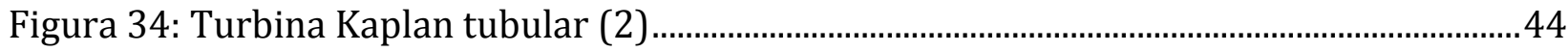

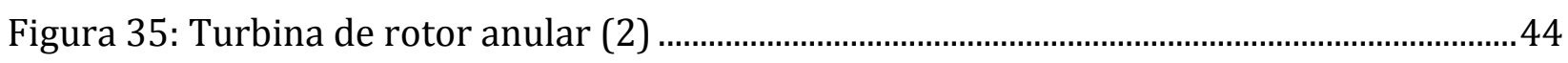


Figura 36: Distribución genérica de la temperatura en mar abierto (2) .....................................45

Figura 38: Disposición esquemática de una central C.E.T.O. de 100MW (8)..............................47

Figura 40: Esquema conceptual de un sistema captador solar térmico de baja temperatura

Figura 41: Esquema conceptual de un sistema captador solar térmico de media temperatura (2)

Figura 42: Esquema conceptual de un sistema captador solar térmico de alta temperatura (2)

Figura 43: Esquema conceptual de una instalación solar fotovoltaica (2) ................................52

Figura 44: Actuación de las olas sobre un WEC (14) ...................................................................59

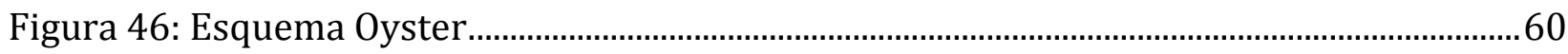

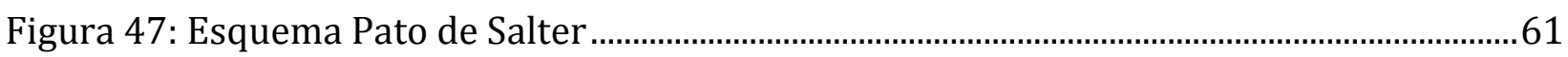

Figura 48: Esquema dispositivo Pelamis.................................................................................... 62

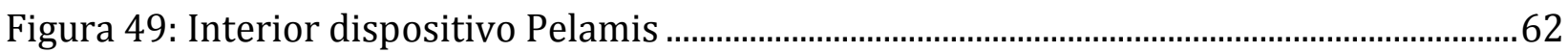

Figura 50: Esquema de dispositivo balsa de Cockerell ..................................................................63

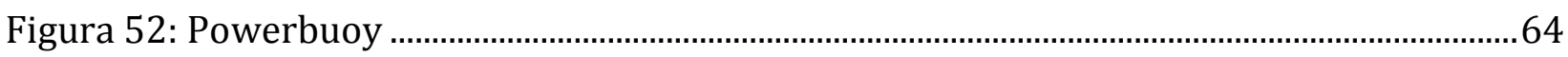

Figura 53: Esquema de dispositivo Powerbuoy …….......................................................................64

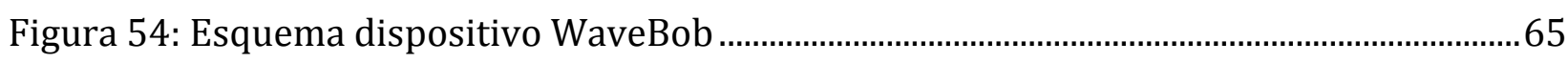

Figura 55: Esquema de funcionamiento dispositivo AWS ..............................................................66

Figura 57: Infografía Wavestar en posición de protección frente a tormentas .........................67

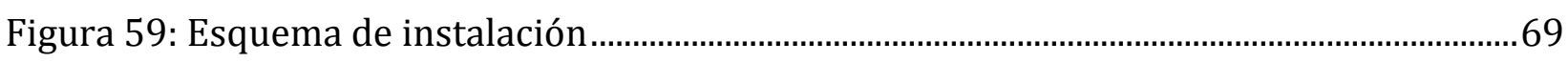

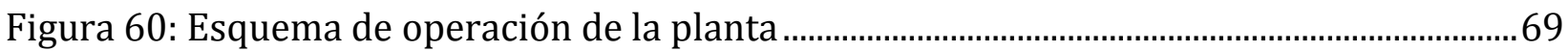

Figura 61: Infografía del captador de Energetech .......................................................................... 70

Figura 62: Esquema de operación dispositivo Mighty Whale ......................................................... 70

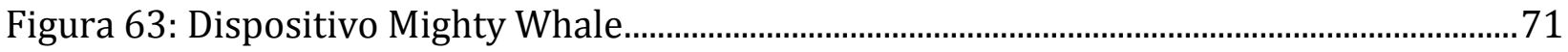

Figura 64: Instalación de la central Mutriku.................................................................................... 71

Figura 65: Esquema de la cámara de cada OWC Nereida..................................................................72

Figura 67: Esquema de funcionamiento dispositivo CLAM ........................................................... 73

Figura 69: Esquema de dispositivo TAPCHAN (Boyle, 1996) ......................................................... 74

Figura 70: Planta y sección de un dispositivo WD, modelo de 1998 con rampa de curvatura

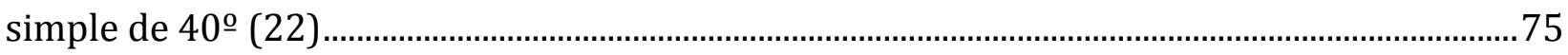


Figura 72: Perfil de la estructura de contención de un lago de marea .........................................77

Figura 73: Plano del futuro lago de marea de Swansea Bay (Gales)...............................................78

Figura 74: Elementos principales de una turbina convencional bidireccional .......................... 79

Figura 76: Corte horizontal dispositivo turbina BEC.......................................................................80

Figura 77: Corte vertical dispositivo turbina BEC ......................................................................... 81

Figura 78: Dibujo de turbina Kobold (26) ……............................................................................. 82

Figura 80: Dibujo de dispositivo TEC de cuatro rotores de Tidal Stream Partners (27).........83

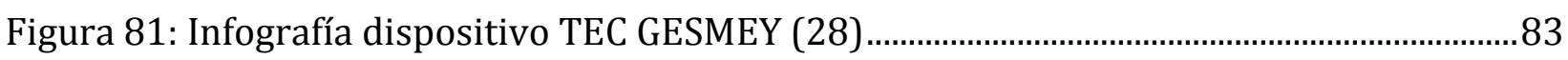

Figura 82: Dibujo de un futuro campo de generadores TEC de dos rotores (29) .....................84

Figura 84: Diseño de dispositivo Stingray ..................................................................................... 85

Figura 85: Flujo de energía asociado al oleaje en Andalucía ..........................................................86

Figura 86: Potencial de corrientes marinas en Andalucía ...............................................................87

Figura 87: Batimetría (datos de IHM y de NGDC) ........................................................................... 88

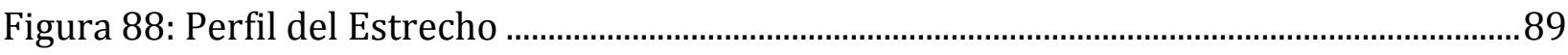

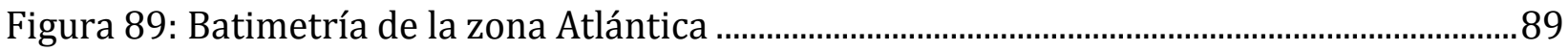

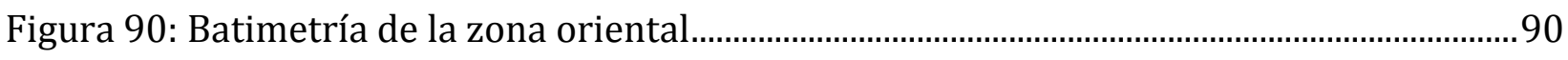

Figura 92: Densidad térmica de la costa Andaluza (31)..............................................................94

Figura 93: Diferencias de temperatura en la costa Andaluza (31)...............................................95

Figura 94: Mapa eólico marino de España (36)................................................................................ 98

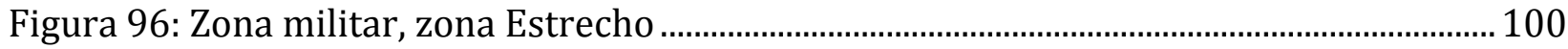

Figura 98: Infografía dispositivo Butterfly (38) ........................................................................... 102

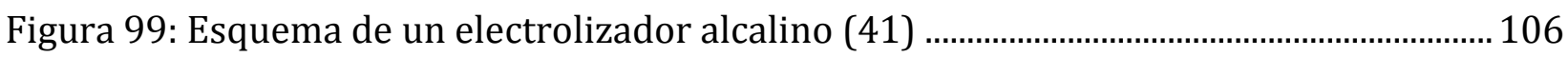

Figura 100: Electrolysis process flow diagrams (42) ……............................................................. 106

Figura 101: Coste de energía, operación y mantenimiento y gastos fijos del capital invertido en un licuefactor optimizado de hidrógeno a gran escala (46) .................................................. 110

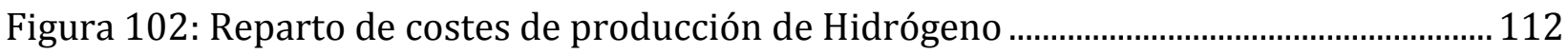

Figura 103: Capacidad instalada de desalinización, 2010-2016 (49)....................................... 113

Figura 104: Esquema de operación MSF ……............................................................................ 114

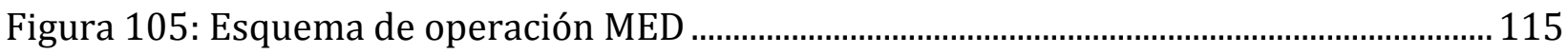

Figura 106: Esquema de operación MVC (50)............................................................................. 116 
Figura 107: Esquema de planta desalinizadora por RO (48) ……............................................ 117

Figura 108: Distribución de los costes de desalinización (48) .................................................. 118

Figura 109: Esquema de plataforma H20cean (54).................................................................. 125

Figura 111: Rango de las externalidades por tecnología para las tecnologías de la electricidad (barras azules), UE28 media ponderada (líneas naranjas) ( $€_{2012} / \mathrm{MWh}_{\mathrm{e}}$ ) (57)

Figura 112: Rango de las externalidades por tecnología para las tecnologías de la electricidad, UE28 media ponderada $\left(€_{2012} / \mathrm{MWh}_{\mathrm{e}}\right)(57)$

Figura 113: Distribución de la energía en Andalucía según la tecnología energética (datos de 2015)

Figura 114: Subvenciones, externalidades y costes de la energía por tecnología 2012

$\left(\mathrm{M} €_{2012}\right)(57)$.

Figura 115: Evolución del coste de generación para plantas de olas (2020-2030) (59)...... 132 


\subsection{LISTA DE TABLAS}

Tabla 1: Principales usos de la energía geotérmica en función de la temperatura .19

Tabla 2: Capacidad máxima de generación neta de centrales de energía marina para producir electricidad.

Tabla 3: Capacidad máxima conectada de generación neta de centrales de energía marina para producir electricidad 26

Tabla 4: Energía de las olas dependiendo del modelo seleccionado (9)....................................53

Tabla 5: Efectos en el medio ambiente de dispositivos WEC ........................................................55

Tabla 6: Principales características de los dispositivos WEC.........................................................55

Tabla 7: Resumen Potenciales Brutos Marinos en Andalucía ...........................................................86

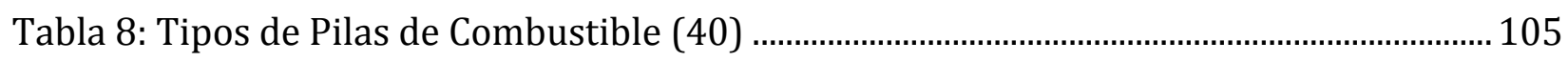

Tabla 9: Características de los métodos de almacenamiento de hidrógeno............................. 107

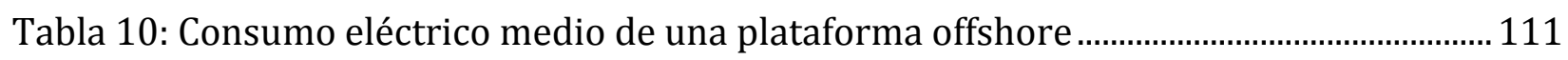

Tabla 11: Principales especies capturadas por la flota española (55),..................................... 126

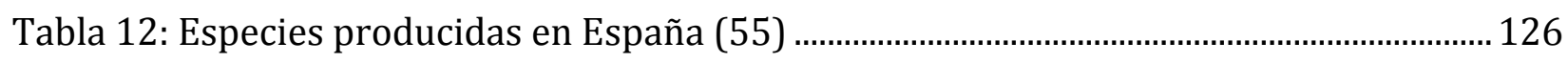

Tabla 13: Datos generales potencia eléctrica renovable en Andalucía (MW) (datos al 31/03/2017) (58) 


\section{BIBLIOGRAFÍA}

1. Cal Hevia, Alexandre. Energía Azul.

2. Calero Pérez, Roque, Carta González, José Antonio y Padrón Hernández, José

Manuel. Energía. Las Palmas : Ayuntamiento de las Palmas, 2000.

3. igme. Instituto Geominero de España. [En línea] [Citado el: 15 de 01 de 2017.]

http://www.igme.es/Geotermia/La\%20energ\%EDa\%20geot\%E9rmica.htm.

4. —. Insituto Geominero de España. [En línea] [Citado el: 06 de 02 de 2017.]

http://www.igme.es/Geotermia/potencial\%20geot\%E9rmic.htm.

5. Llopis Trillo, Guillermo y Rodrigo Angulo, Vicente. Guía de la Energía Geotérmica. Madrid : Fundación de la Energía de la Comunidad de Madrid. www.fenercom.com.

6. Promoeener-A. www.promoener-a.com. [En línea] 16 de 05 de 2016. http://promoeener-a.com/wp-content/uploads/2011/12/Tecnologias-deaprovechamiento-de-recursos-geotermicos.pdf.

7. IRENA (2016). Renewable Energy Statistics 2016. The International Renewable Energy Agency. Aby Dhabi : IRENA, 2016. www.irena.org/Publications. ISBN 978-92-95111-91-2.

8. Fernández Díez, Pedro. Biblioteca sobre Ingeniería Energética. [En línea] [Citado el: 04 de 03 de 2015.] http://es.pfernandezdiez.es/.

9. Cavia del Olmo, Berta. Explotación del Potencial de Energía del Oleaje en Función del Rango de Trabajo de Prototipos Captadores (Tesina). Barcelona, Cataluña : upcommons.upc.edu, 2009.

10. NASA Ocean Motion. [Online] 03 17, 2017. http://oceanmotion.org/global-surfacecurrents.htm.

11. NASA Scientific Visualization Studio. [Online] 03 17, 2017.

https://svs.gsfc.nasa.gov//stories/topex/tides.html.

12. Harvesting the waves. The emergence of waves as a useful source of energy. Thorpe, Tom. Agosto de 2002, ingenia online, págs. 21-26.

http://www.ingenia.org.uk/Ingenia/Articles/179\#top.

13. Department of Business, Economic Development and Tourism. Feasibility of Developing Wave Power as a Renewable Energy Resource for Hawaii. Honolulu : s.n., 2002.

14. Energías de las olas: Situación y Futuro. Ibañez Ereño, Pedro. A Coruña : Tecnalia, 2008. Xornada sobre Enerxia que Ven do Mar. 
15. Aquamarnie Power. www.aquamarinepower.com. [En línea] www.aquamarinepower.com.

16. The European Marine Energy Centre Ltd. EMEC ORKNEY. [En línea] [Citado el: 27 de 04 de 2016.] www.emec.org.uk.

17. AquaBuOY in Portugal. AquaEnergy Group Ltd. Weinstein, Alla. www.finavera.com.

18. Ocean Power Technologies. OPT. [En línea] [Citado el: 30 de 01 de 2017.] http://www.oceanpowertechnologies.com/.

19. Wavebob. [En línea] [Citado el: 25 de 09 de 2015.] www.wavebob.com.

20. Wavestar. wavestarenergy.com. [En línea] [Citado el: 06 de 10 de 2016.] http://wavestarenergy.com/.

21. The SSG Wave Energy Converter: Performance, Status and Recent Developments.

Vicinanza, D., y otros, y otros. 5, s.l. : MDPI, 2012, Energies, págs. 193-226. ISSN 19961073.

22. Strategy for fegulating the crest free board of a floating wave energy converter. Hald, T. $\mathbf{y}$ Friis-Madsen, E. 04 de 20 de 2001, Marec 20001, págs. 1-9.

23. Tidal Energy Ltd. Tidal Energy. [En línea] [Citado el: 17 de 01 de 2017.] http://www.tidalenergyltd.com/.

24. Blue Energy. [En línea] [Citado el: 17 de 01 de 2017.] http://www.bluenergy.com/vertical-axis-turbine/vaht/.

25. The Kobold marine turbine: from the testing model to the full scale prototype. Calcagno, Guido y Moroso, Alberto. Londres : s.n., 2007. Tidal Energy Summit.

26. SEAPOWER SCRL. www.seapowerscrl.com. [En línea] [Citado el: 23 de 11 de 2016.] www.seapowerscrl.com.

27. The Engineering Business Ltd. Stingray Tidal Stream Energy Device-Phase 3. s.l. : DTI, 2005. T/06/00230/00/REP.

28. Carnero, Alfonso. Catedra-Soermar-UPM. www.catedra-soermar-upm.com. [En línea] [Citado el: 10 de 03 de 2017.] http://www.catedra-soermar-upm.com/wpcontent/uploads/2015/06/GESMEY_rev01.pdf.

29. Directorate-General for Research. SEAFLOW Pilot projecto for the exploitation of marine currents. Brussels : European Commission, 2005. EUR 21616. 
30. LUNAR ENERGY.www.lunarenergy.co.uk. [En línea] 2012. [Citado el: 12 de 03 de 2017.] www.lunarenergy.co.uk.

31. EnerOcean S.L. Estudio sobre el potencial bruto de energías marinas en el litoral Andaluz (Fase I). Sevilla : Agencia Andaluza de la Energía, 2009.

www.agenciaandaluzadelaenergia.es.

32. - Estudio sobre el potencial marino, 2ª Fase. Sevilla : Agencia Andaluza de la Energía, 2009. AAE2009-0266.

33. Análisis de las direcciones de los vientos en Andalucía. Viedma Muñoz, Manuel. 1, 1998, Nimbus, págs. 153-168.

34. Juanes González, Juan Manuel. El potencial energético útil, de las corrientes marinas en el estrecho de Gibraltar (Tesis Doctoral). Madrid : UPM, 2007. http://oa.upm.es/1076/.

35. Junta de Andalucía. Proyecto de Decreto por el que se declaran determinadas Zonas Especiales de Conservación con habitats marinos del litoral andaluz. 1992.

36. MITYC. Estudio Estratégico Ambiental del Litoral Español para la Instalación de Parques Eólicos Marinos. 2009.

37. Blanco Aguado, Marcos. Desarrollo de un Procedimiento Basado en Algoritmos de Optimización para el Dimensionado de Absorbedores Puntuales Aplicados a la Conversión de Energía Undimotriz (Tesis Doctoral). Madrid : UPM, 2015.

38. Experiencias en el Mediterráneo para obtención de energía eléctrica de las olas del mar. Novás Cortés, Andrea. Madrid : s.n., 2016. JERME2016.

39. SERC. Schatz Energy Research Center. Humbolt State University. [En línea] SERC. [Citado el: 15 de 03 de 2016.] http://www.schatzlab.org/spanish/h2fuel.html.

40. El hidrógeno como vector energético y las Pilas de Combustible. González García-Conde, Antonio. [ed.] INTA. Madrid : INTA, 2013. XI CICLO DE CONFERENCIAS AUITA, ETSIA, EIAE.

41. Conde, Estefanía y Reyes, Eduardo. Producción y Almacenaje de Hidrógeno. 2006.

42. Joe Genovese, Knut Harg, Mark Paster y John Turner. Current (2009) State-of-the-Art Hydrogen Production Cost Estimate Using Water Electrolysis. Golden, Colorado : National Renewable Energy Laboratory, 2009. NREL/BK-6A1-46676.

43. González García-Conde, Antonio. Producción, almacenamiento y distribución de hidrógeno. 
44. Hirscher, Michael. Asociación Española del hidrógeno. www.aeh2.org. [En línea] 14 de Marzo de 2014. [Citado el: 14 de diciembre de 2014.] http://ehec.info/images/plenaries/10Hirscher.pdf.

45. Fernández-Bolaños, Clara. Distribución del Hidrógeno. Energética del Hidrógeno. Contexto, Estado Actual y Perspectivas de Futuro. Sevilla : E.T.S.I., 2005, 3.3.

46. An Economic Analysis of Three Hydrogen Liquefaction Systems. Syed, M.T., y otros, y otros. s.l. : Elsiever Science, 1998. S0360-3199(97)00101-8.

47. Energía Sostenible. [En línea] [Citado el: 20 de 03 de 2017.] http://www.energiasostenible.net/almacenamiento_y_transporte_de_hidrog.htm.

48. La desalinización en España. Cuadernos sectoriales. 2007.

49. Desalination Technologies: Hellenic Eperience. Zotalis, Konstantinos, y otros, y otros. 5, 2014, Water, Vol. 6, págs. 1134-1150. doi:10.3390/w6051134.

50. The Mechanical Vapor Compression: 38 Years of Experience. Lokiec, Fredi y Ophir, Abraham. Gran Canaria : s.n., 2007. IDA WC/MP07-084.

51. Impacto ambiental de la desalación. Martínez de la Vallina, Juan J.

52. APROMAR. La acuicultura en España 2016. Asociación Empresarial de Productores de Cultivos Marinos en España. 2016. www.apromar.es.

53. Serna Cantero, Álvaro. Offshore Hydrogen Production using Wave Energy (Tesis de Master). Valladolid : Universidad de Valladolid, 2013.

54. H2OCEAN. www.h2ocean-project.eu. [En línea] [Citado el: 13 de 02 de 2017.] www.h2ocean-project.eu.

55. European Union. Facts and Figures on the Common Fisheries Policy 2016. Belgium : European Union, 2016. ISSN 1977-3609.

56. Zurita Manrubia, Francisco, y otros, y otros. La acuicultura marina en Andalucía. s.l. : Junta de Andalucía, 2014.

57. Alberici, S., y otros, y otros. Subsidies and Costs of EU Energy. Final Report. s.l. : ECOFIS, 2014. DESNL14583.

58. Agencia Andaluza de la Energía. Informe de Infraestructuras energéticas, Andalucía. s.l. : Junta de Andalucía, 2017.

https://www.agenciaandaluzadelaenergia.es/sites/default/files/documentos/informe_and aluz_miea_0.pdf. 
59. The Boston Consulting Group. Evolución Tecnológica y Prospectiva de Costes de las Energías Renovables. Estudio Técnico PER 2011-2020. Madrid : IDAE, 2011.

60. Ocean Energy Systems. An International Vision for Ocean Energy 2017. s.l. : OES, 2017.

61. www.juntadeandalucia.es.

https://www.juntadeandalucia.es/institutodeestadisticaycartografia/estadisticaygeografica. [En línea] [Citado el: 30 de 05 de 2017.]

https://www.juntadeandalucia.es/institutodeestadisticaycartografia/estadisticaygeografic a/1_PoblacionAndaluza.pdf.

62. Fernández, P. Biblioteca Sobre Ingeniería Energética. www.pfernandezdiez.es. [Online] [Cited: 03 20, 2017.]

http://files.pfernandezdiez.es/EnergiasAlternativas/mar/PDFs/02Corrientes.pdf.

\section{OTRAS FUENTES CONSULTADAS}

CENTRO NACIONAL DE ENERGÍAS RENOVABLES (CENER) (www.cener.com)

AGENCIA ANDALUZA DE LA ENERGÍA. Andalucía Renovable, 2011.

INSTITUTO PARA LA DIVERSIFICACIÓN Y AHORRO DE LA ENERGÍA. Plan de Energías Renovables 2011-2020, 2011.

GRUPO INTERGUBERNAMENTAL DE EXPERTOS SOBRE EL CAMBIO CLIMÁTICO (IPCC). Fuentes de Energía Renovables y Mitigación del Cambio Climático, 2011. 
ESTUDIO DEL POTENCIAL DE APROVECHAMIENTO ENERGÉTICO DEL OCÉANO EN LA COSTA ANDALUZA.

Autora: Mạ Pilar Blanco Fernández

7. ANEXO: LA COSTA ANDALUZA 
ESTUDIO DEL POTENCIAL DE APROVECHAMIENTO ENERGÉTICO DEL OCÉANO EN LA COSTA ANDALUZA. Autora: Ma Pilar Blanco Fernández

ZONA: ESTRECHO DE GIBRALTAR

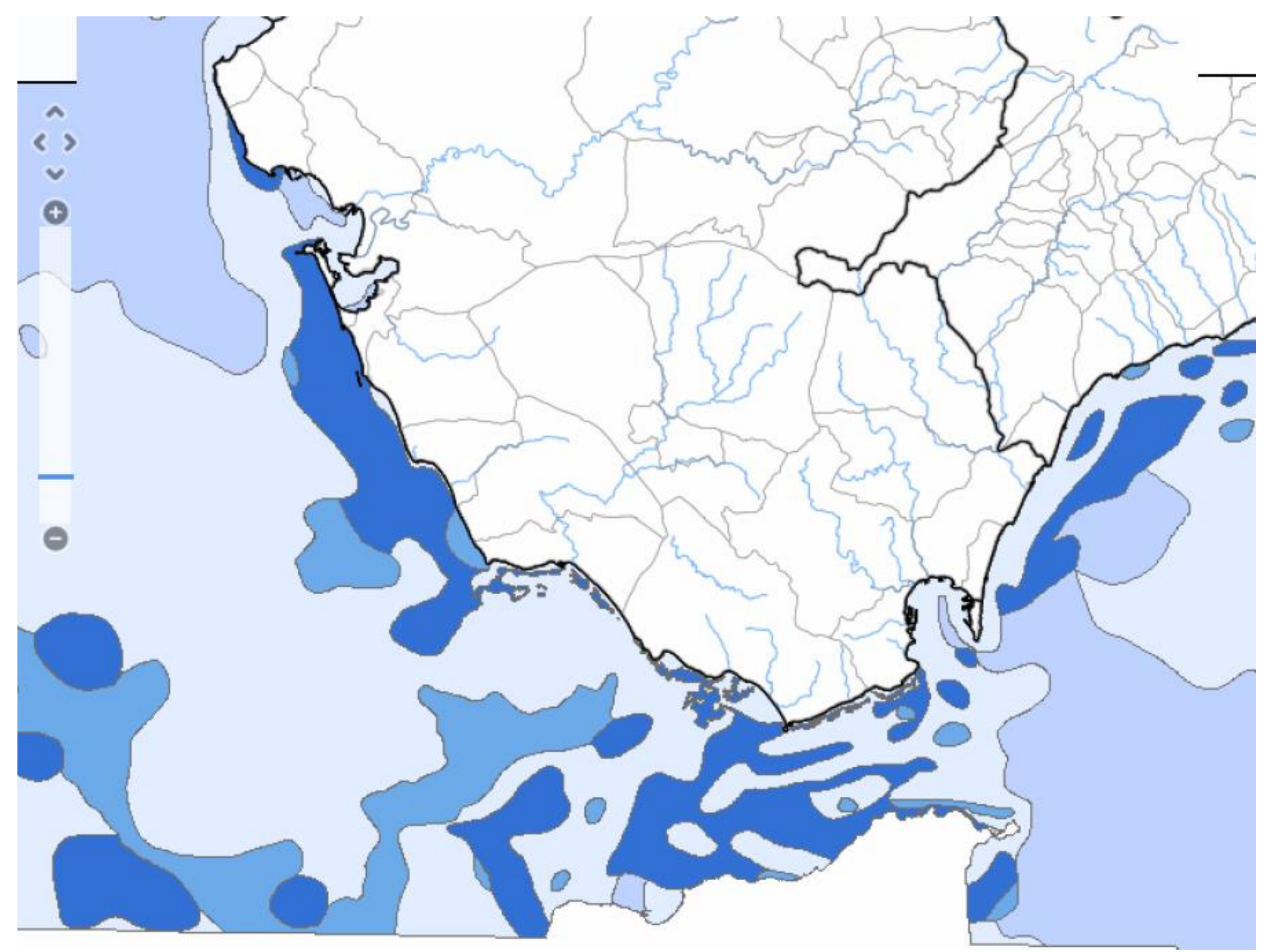


ESTUDIO DEL POTENCIAL DE APROVECHAMIENTO ENERGÉTICO DEL OCÉANO EN LA COSTA ANDALUZA. Autora: $M$

ZONA: OCCIDENTAL

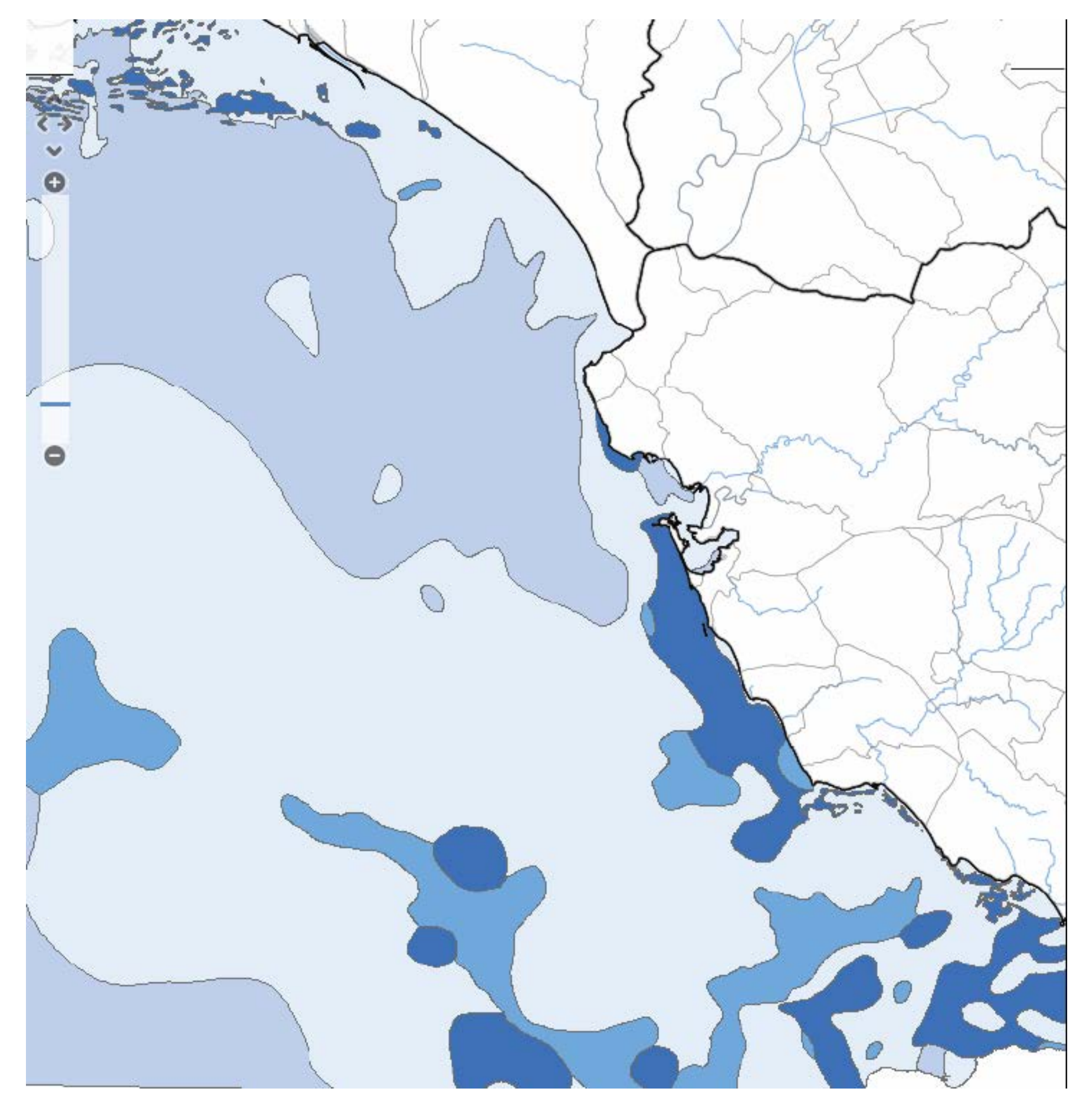


ESTUDIO DEL POTENCIAL DE APROVECHAMIENTO ENERGÉTICO DEL OCÉANO EN LA COSTA ANDALUZA.

ZONA: ORIENTAL

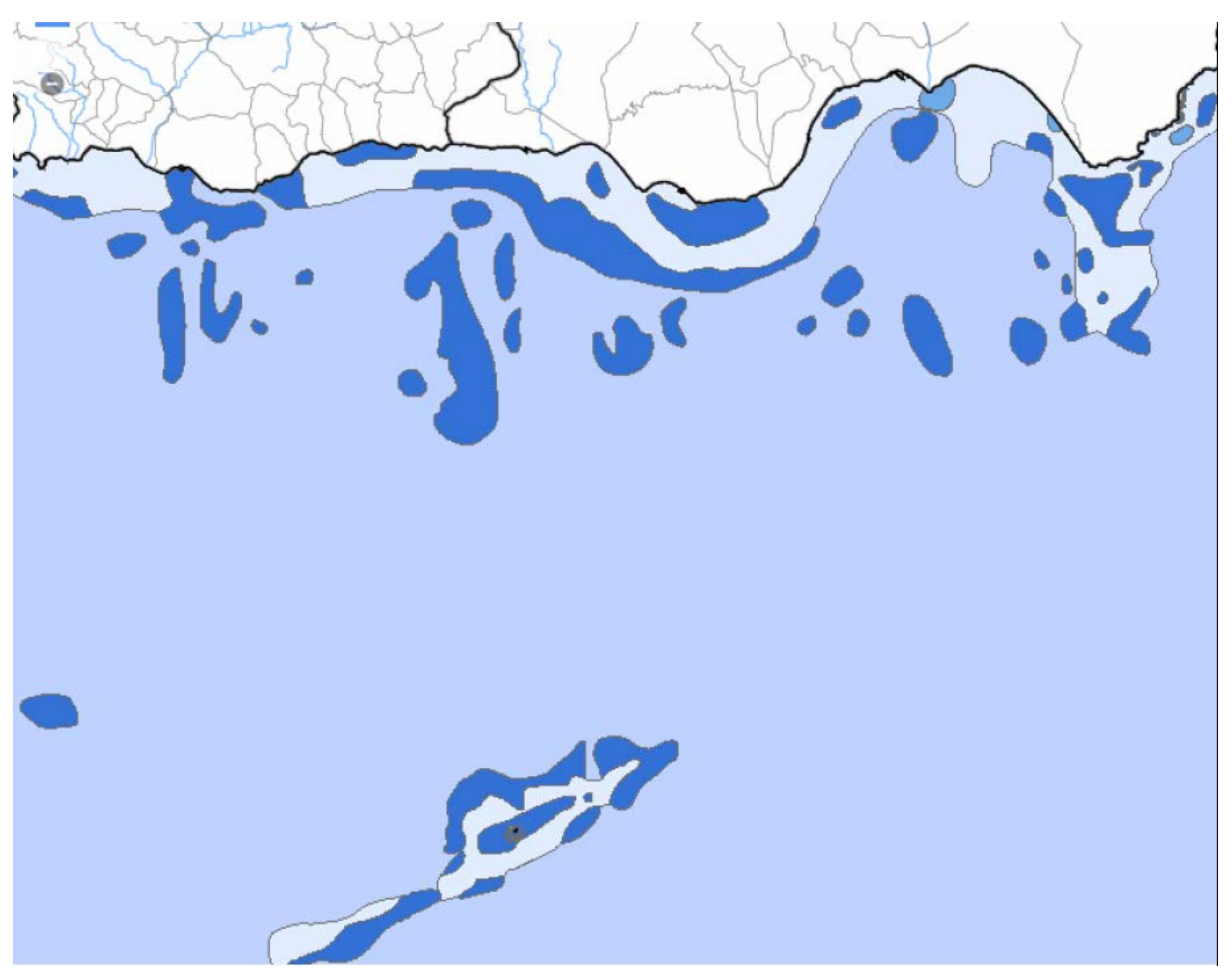


ESTUDIO DEL POTENCIAL DE APROVECHAMIENTO ENERGÉTICO DEL OCÉANO EN LA COSTA ANDALUZA.

Autora: Ma Pilar Blanco Fernández

\section{ANEXO: MAPA EÓLICO DE LA COSTA ANDALUZA.}


ESTUDIO DEL POTENCIAL DE APROVECHAMIENTO ENERGÉTICO DEL OCÉANO EN LA COSTA ANDALUZA.

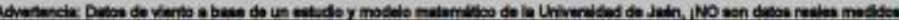

Datos solicitados: Año=2004, Altura $=80$, Coordenadas UTM $(\mathrm{x}, \mathrm{y})=(265.201,3.988 .999)$ Datos más cercanos: Municipio=TARIFA, Zona=TARIFA, Provincia=CÁDIZ

Resultados: Vm=9,41 [m/s], Dirección: NNE, Energía=8.062 [W/m2], Coordenadas $\operatorname{UTM}(x, y)=(266.153,3.992 .780)$

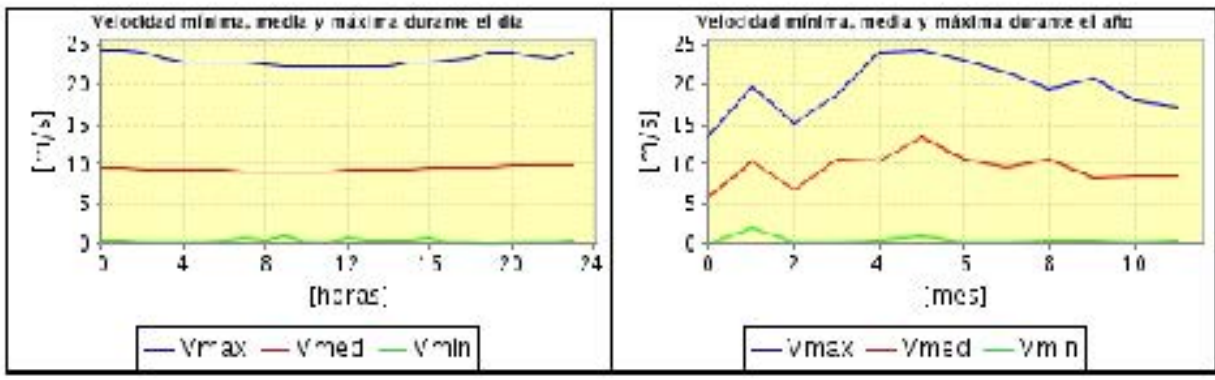

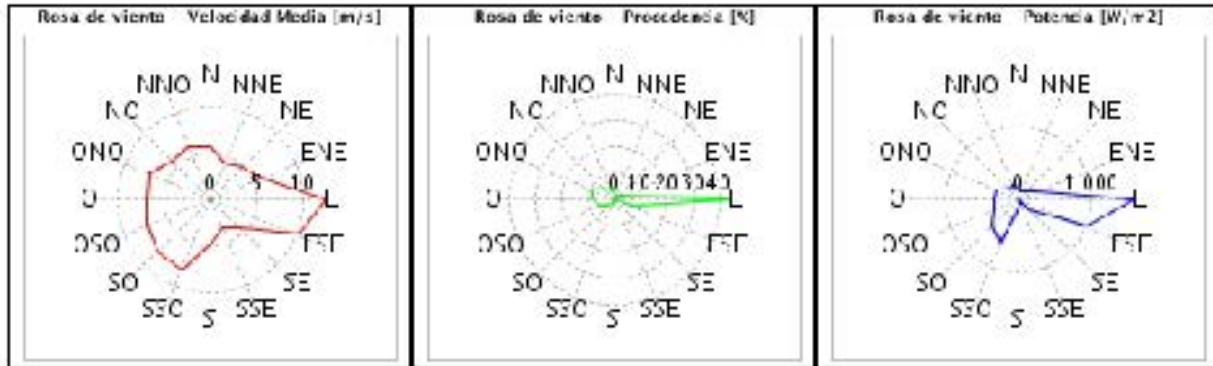

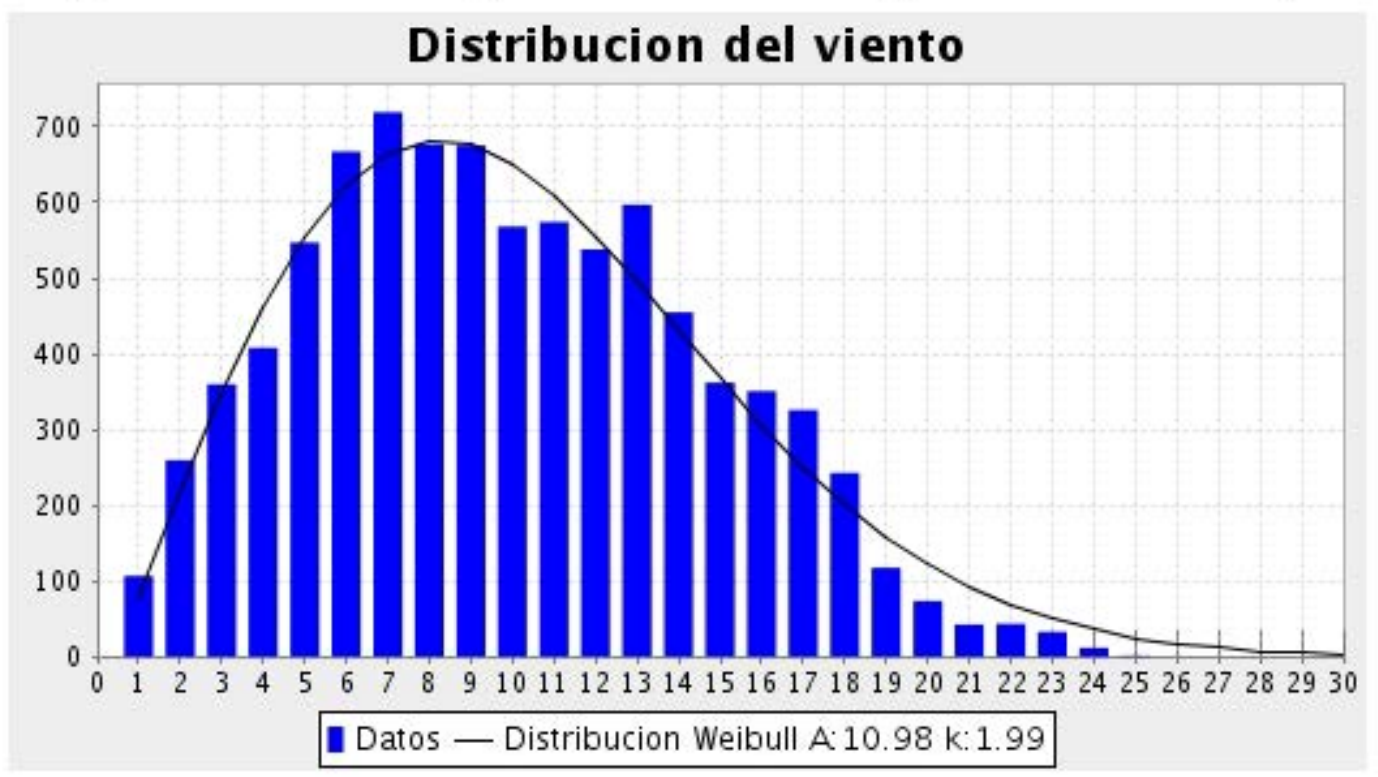


ESTUDIO DEL POTENCIAL DE APROVECHAMIENTO ENERGÉTICO DEL OCÉANO EN LA COSTA ANDALUZA.

Datos solicitados: Año=2003, Altura $=10$, Coordenadas UTM( $\mathrm{x}, \mathrm{y})=(\mathbf{5 9 8 . 5 8 5}, \mathbf{4 . 0 9 5 . 7 0 1 )}$ Datos más cercanos: Municipio=CARBONERAS, Zona=CARBONERAS, Provincia=ALMERIA

Resultados: Vm=5,99 [m/s], Dirección: $N$, Energia =2.128 [W/m2], Coordenadas $U T M(x, y)=(590.993,4.094 .185)$

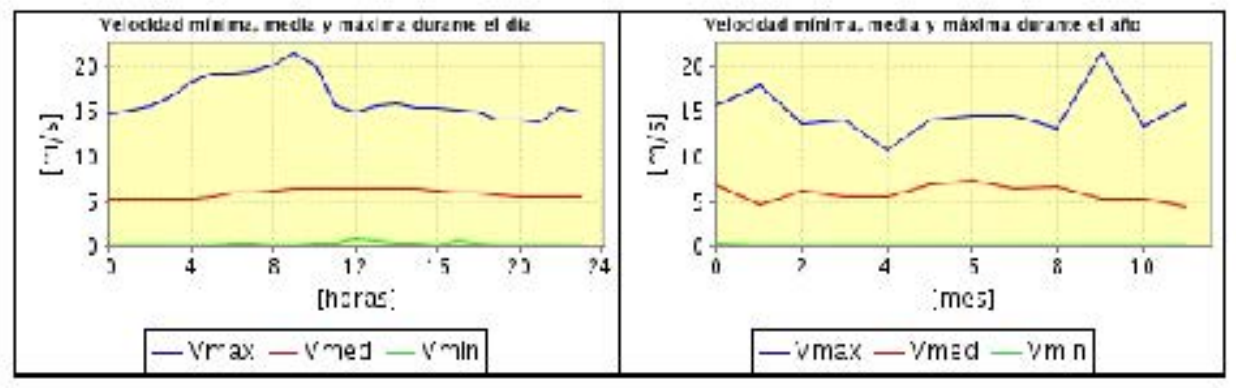

\begin{tabular}{|c|c|c|}
\hline 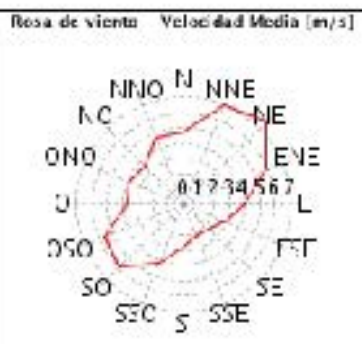 & 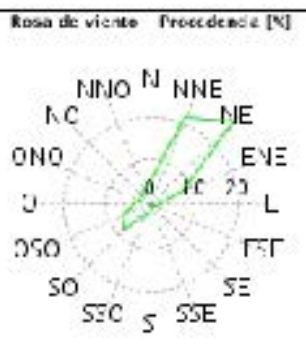 & Rosa de richia Patened [W; \\
\hline
\end{tabular}

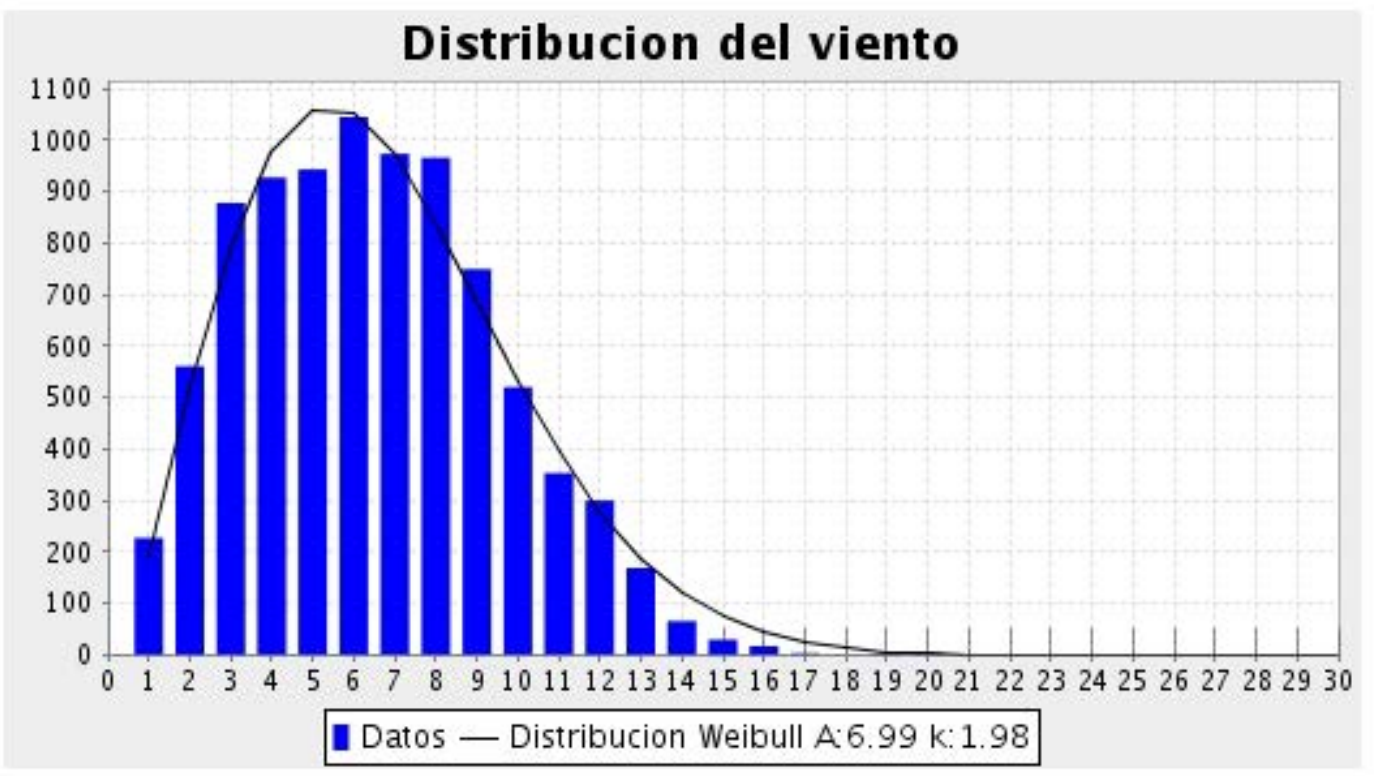


ESTUDIO DEL POTENCIAL DE APROVECHAMIENTO ENERGÉTICO DEL OCÉANO EN LA COSTA ANDALUZA.

Datos solicitados: Año=2003, Altura $=10$, Coordenadas UTM(x,y) $=(148.040,4.122 .677)$ Datos más cercanos: Municipio=PUNTA UMBRIA, Zona=PUNTA UMBRIA, Provincia=HUELVA

Resultados: Vm=5,56 [m/s], Dirección: $S$, Energía=1.733 [W/m2], Coordenadas $U T M(x, y)=(144.559,4.117 .003)$
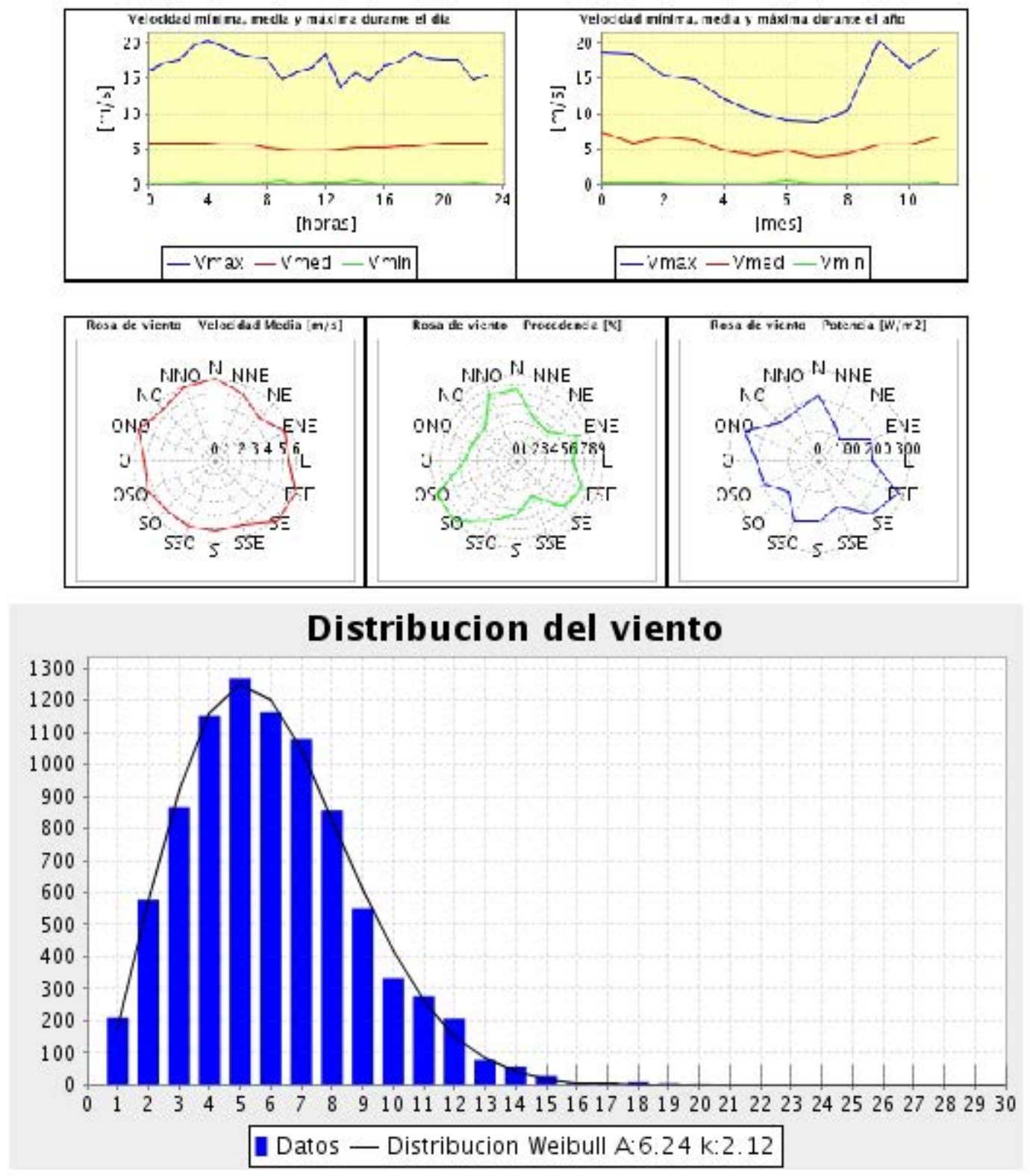
ESTUDIO DEL POTENCIAL DE APROVECHAMIENTO ENERGÉTICO DEL OCÉANO EN LA COSTA ANDALUZA.

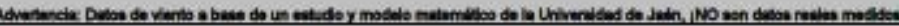

Datos solicitados: Año=2004, Altura $=80$, Coordenadas UTM(x,y) $=(199.447,4.058 .697)$ Datos más cercanos: Municipio=ROTA, Zona=ROTA, Provincia=CÁDIZ

Resultados: Vm=7,46 [m/s], Dirección: NNE, Energía=4.061 [W/m2], Coordenadas $\operatorname{UTM}(x, y)=(205.445,4.054 .861)$

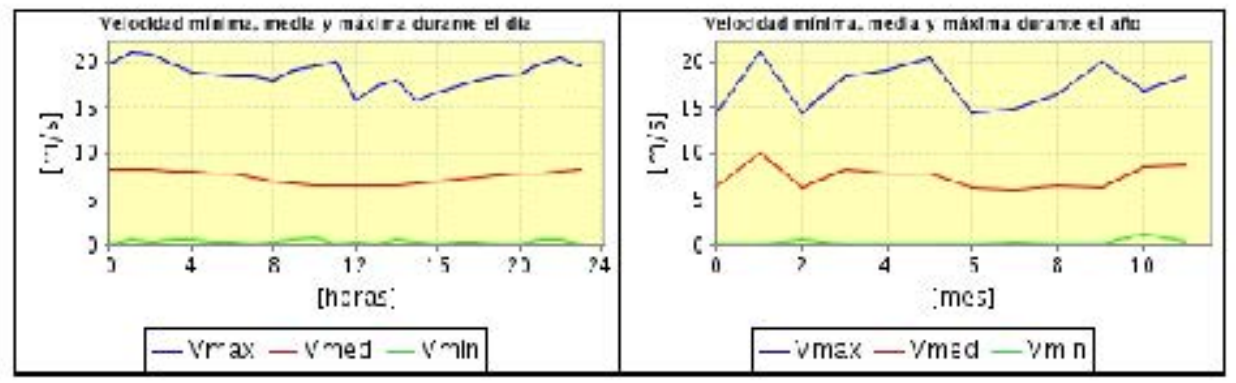

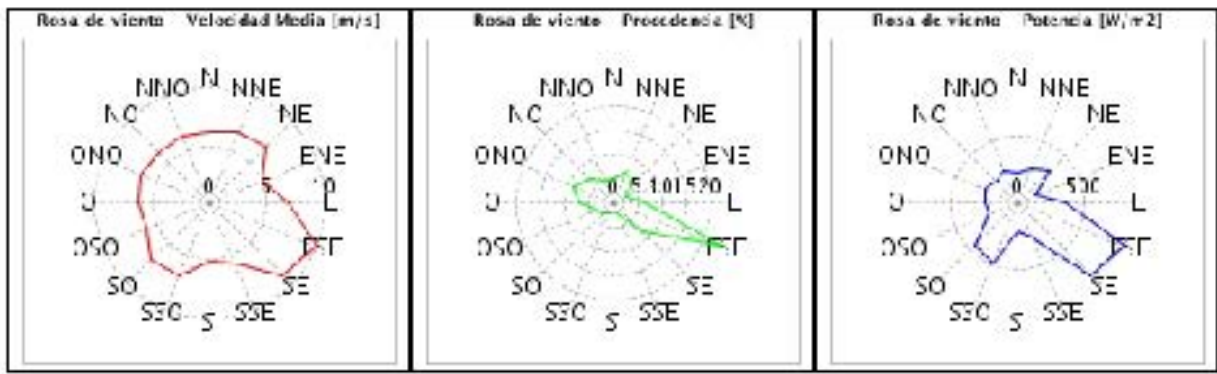

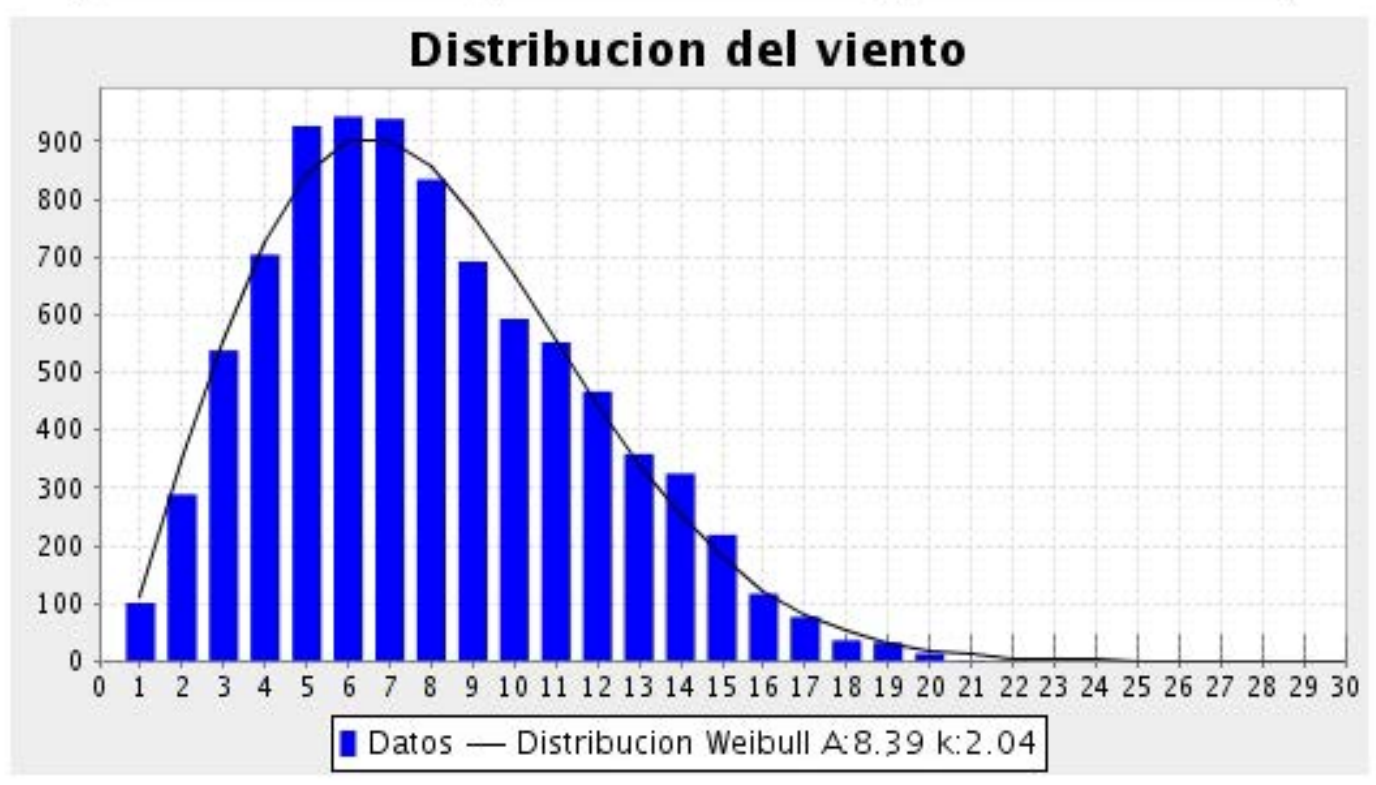




\section{MAPA EÓLICO DE ANDALUCÍA}
MAPA EÓ L I C O
D E
A N D A L U C Í A

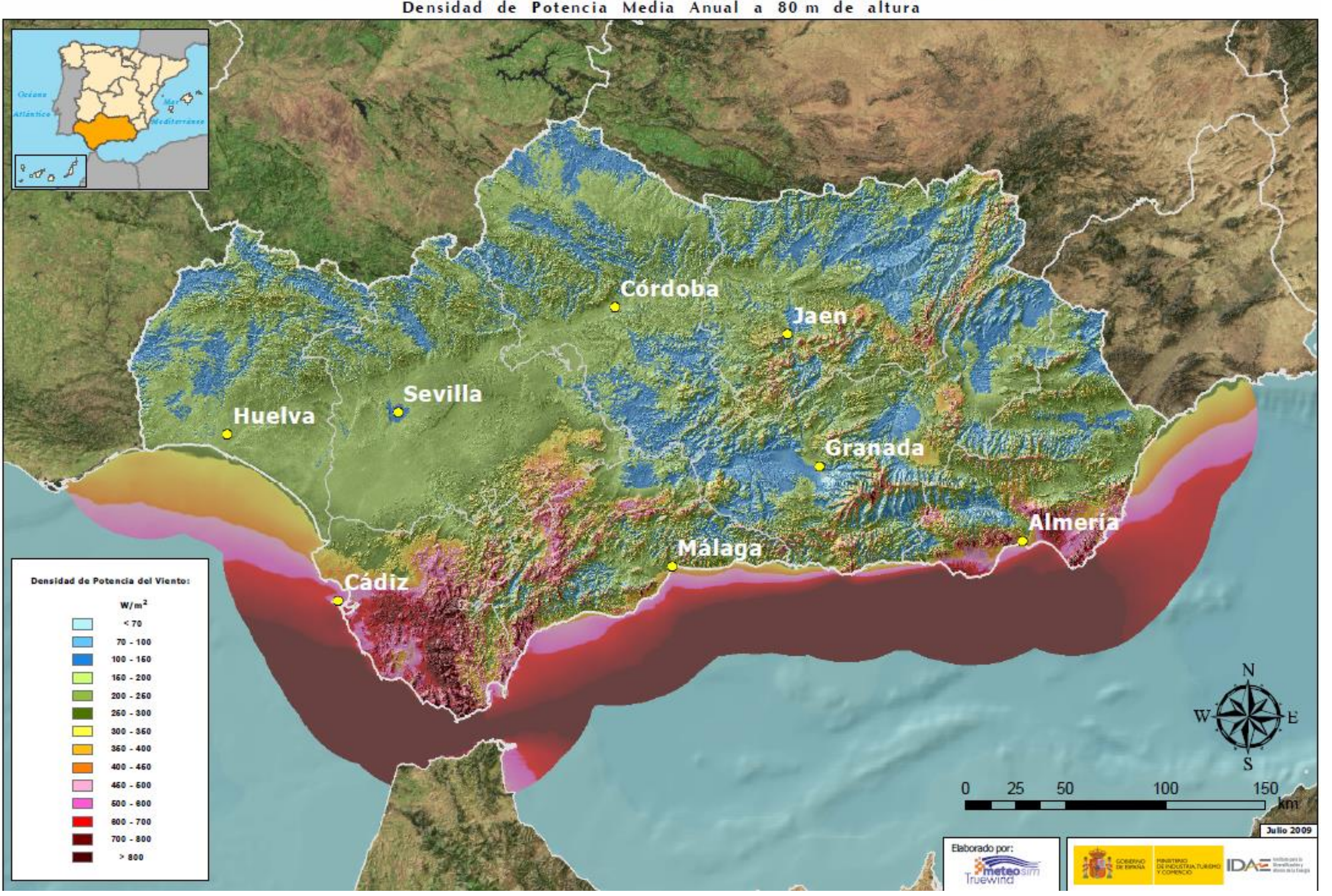


MAPA EÓLICO DE ANDALUCÍA Velocidad Media Estacional a $80 \mathrm{~m}$ de altura
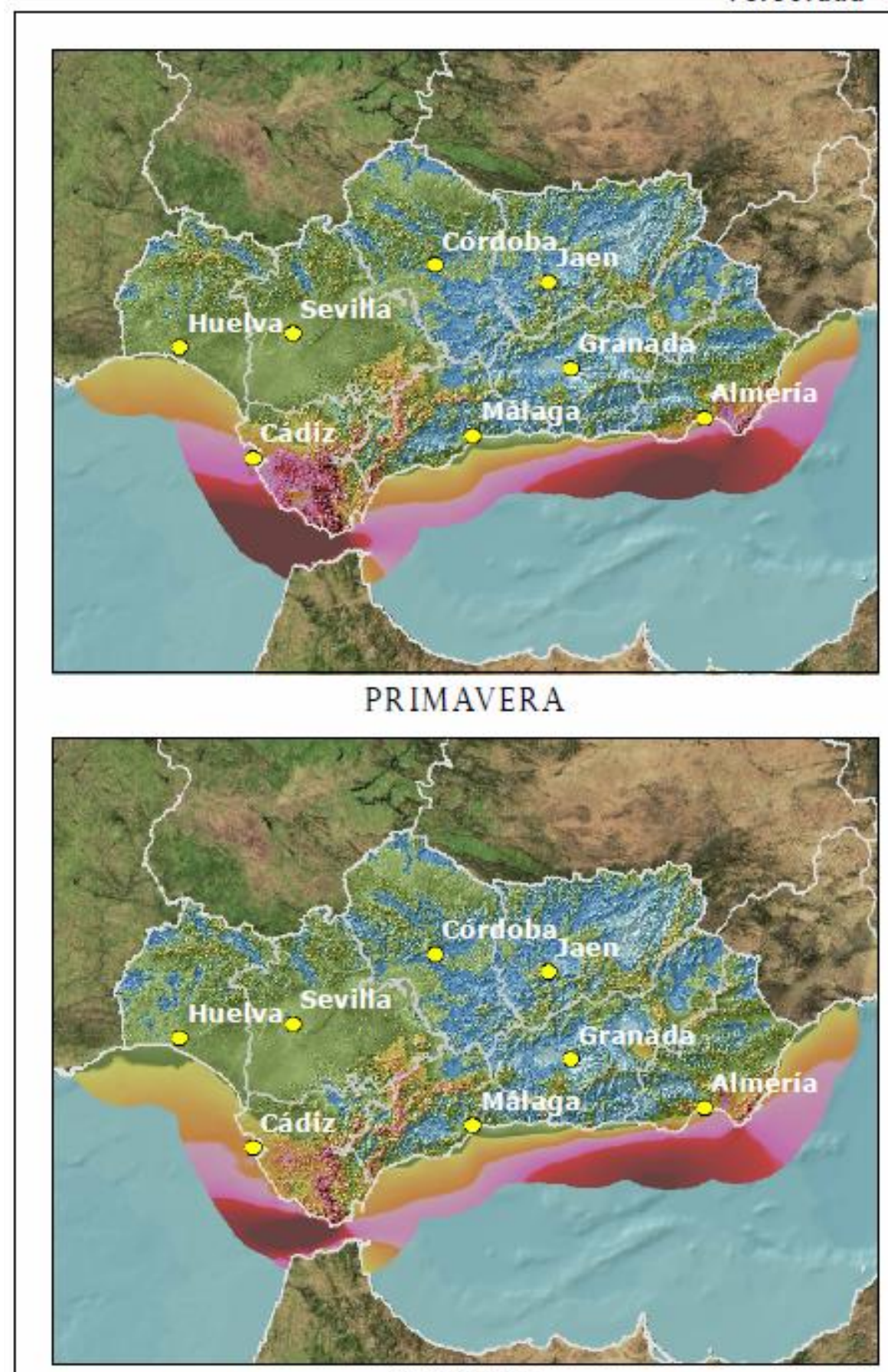

OTOÑO
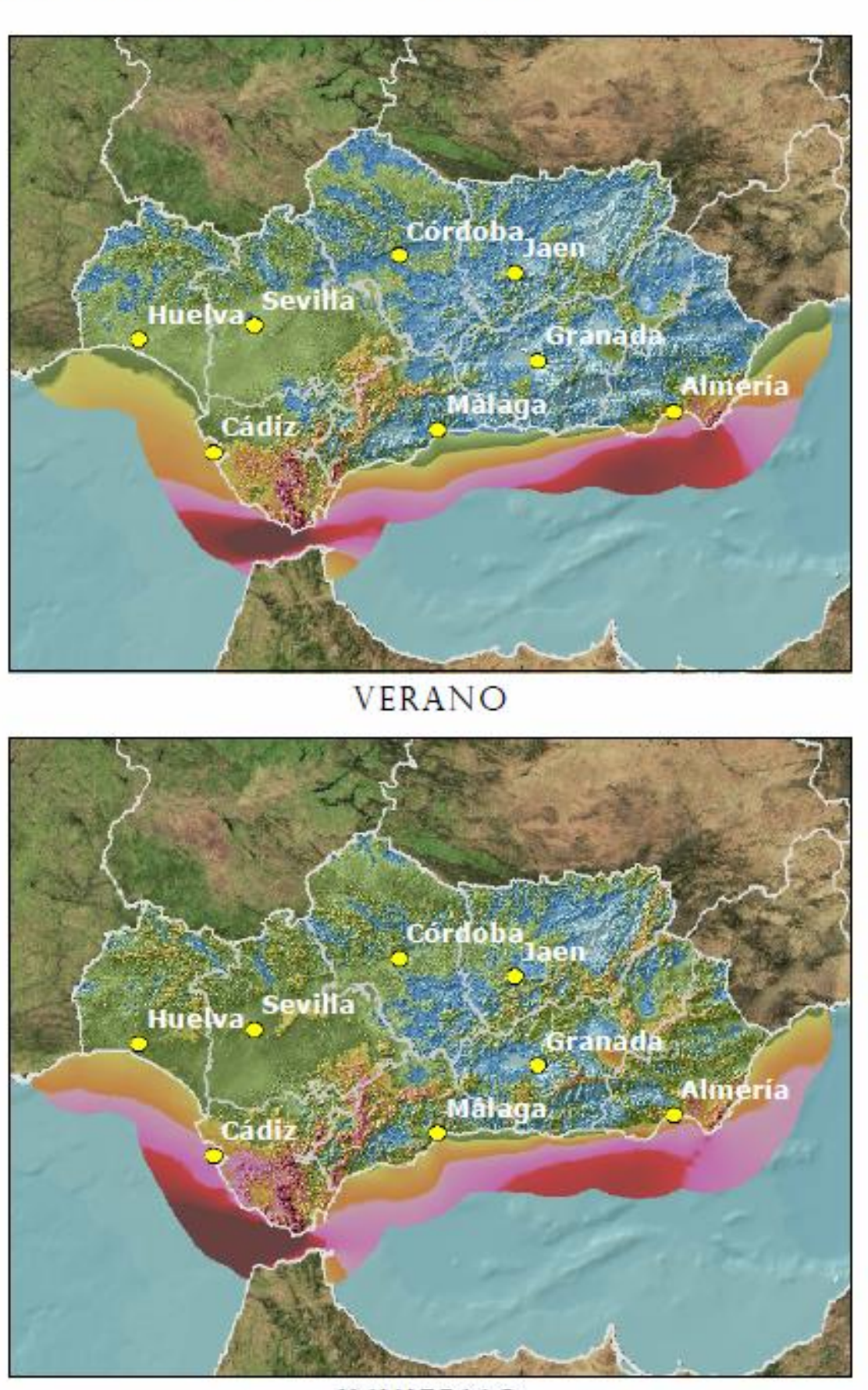

INVIERNO

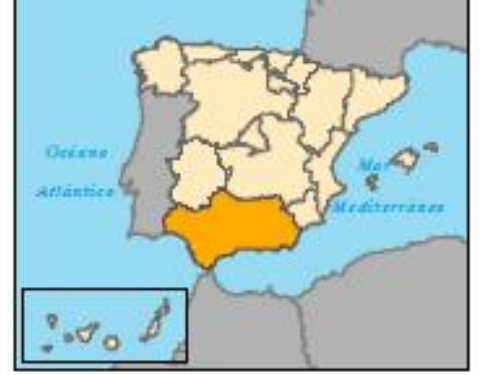

velocidad del Viento:

$\square \quad \begin{gathered}\mathrm{m} / \mathrm{s} \\ <4\end{gathered}$

$\square$

- 46.6 .0

6.6-8.0

. $8.0 \cdot 8.6$

$\square$ 7.0.7.6

7.6-8.0

$\square$ 8.0.8.

$8.6 \cdot 8.0$

(.0.-8.6

Ex $\times 10$

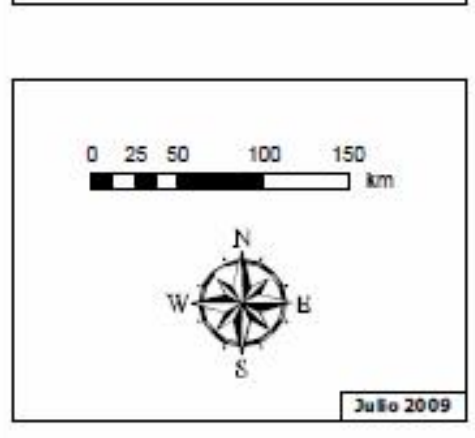

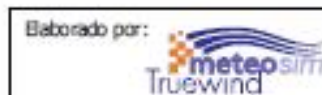

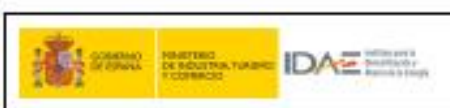


M A PA EOLICO DE A N A L U C A Velocidad Media Anual a $80 \mathrm{~m}$ de altura

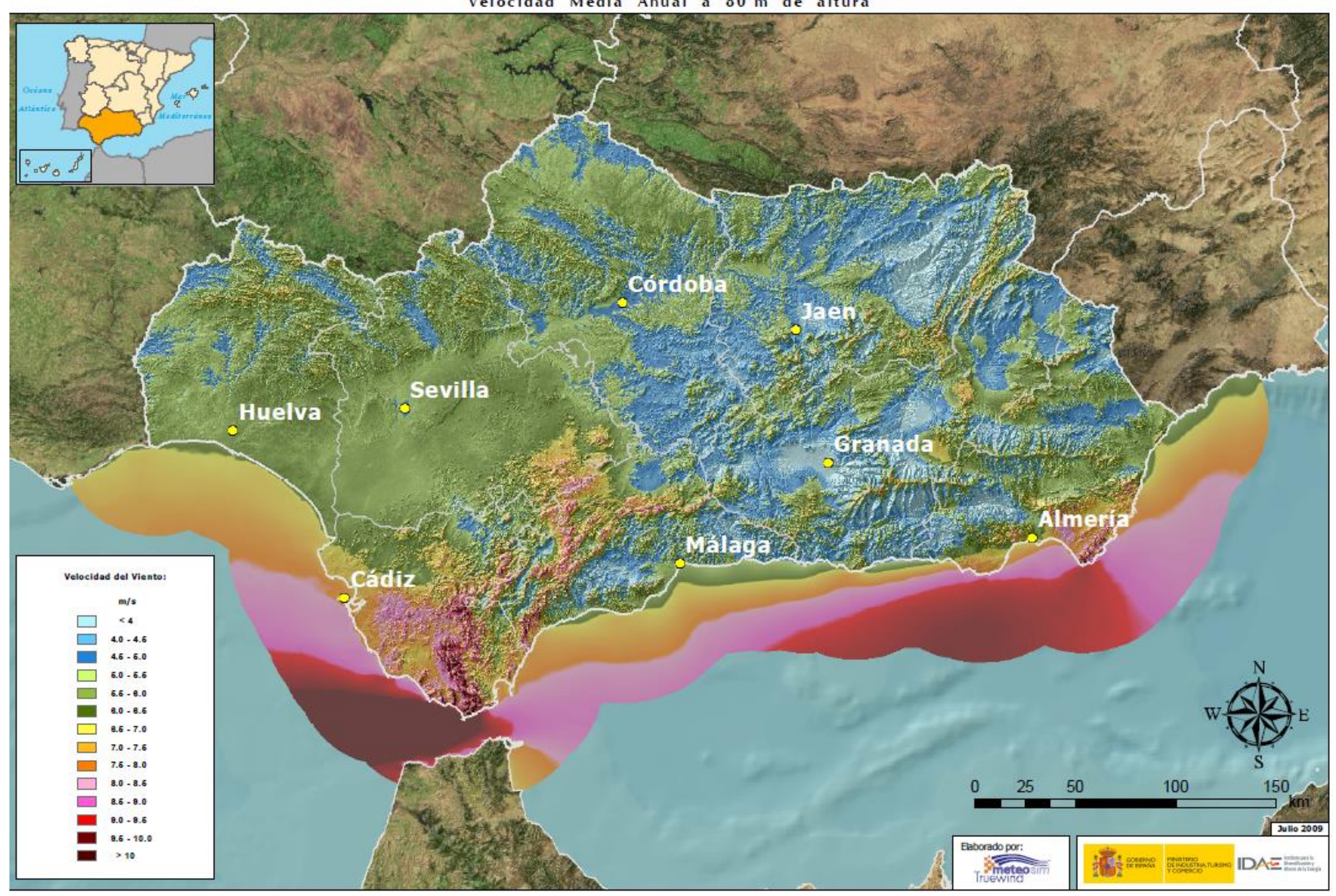


ESTUDIO DEL POTENCIAL DE APROVECHAMIENTO ENERGÉTICO DEL OCÉANO EN LA COSTA ANDALUZA.

Autora: Ma Pilar Blanco Fernández

\section{ANEXO: MAPA DE CORRIENTES MARINAS EN LA COSTA ANDALUZA.}

URL de acceso al servicio de la Junta de Andalucía

http://www.juntadeandalucia.es/medioambiente/site/rediam/menuitem.04dc44281e5d53cf8ca78ca731 525ea0/?vgnextoid=1ead18c1be837310VgnVCM1000001325e50aRCRD\&vgnextchannel=b0ee726c4d6 af310VgnVCM1000001325e50aRCRD\&vgnextfmt=rediam\&/r=lang_es\#apartadobdad18c1be837310Vgn VCM1000001325e50a

URL de acceso al servicio de Puertos del Estado.

http://www.puertos.es/es-es/oceanografia/Paginas/portus.aspx 